Chapman University

Chapman University Digital Commons

\title{
Relationships Among Mentoring Support and Student Success in a Chinese First-Year Experience Program
}

Tianxiang Liu

Chapman University, tialiu@chapman.edu

Follow this and additional works at: https://digitalcommons.chapman.edu/education_dissertations

Part of the Educational Leadership Commons

\section{Recommended Citation}

Liu, T. (2021). Relationships among mentoring support and student success in a Chinese first-year experience program [Doctoral dissertation, Chapman University]. Chapman University Digital Commons. https://doi.org/10.36837/chapman.000329

This Dissertation is brought to you for free and open access by the Dissertations and Theses at Chapman University Digital Commons. It has been accepted for inclusion in Education (PhD) Dissertations by an authorized administrator of Chapman University Digital Commons. For more information, please contact laughtin@chapman.edu. 


\title{
Relationships Among Mentoring Support and Student Success in a Chinese First-Year Experience Program
}

\author{
A Dissertation by \\ Tianxiang Liu \\ Chapman University \\ Orange, CA \\ Attallah College of Educational Studies \\ Submitted in partial fulfillment of the requirements for the degree of \\ Doctor of Philosophy in Education
}

December 2021

Committee in charge:

Whitney McIntyre Miller, Ph.D., Co-Chair

Ryan Allen, Ph.D., Co-Chair

John Brady, Ph.D. 
The dissertation of Tianxiang Liu is approved.

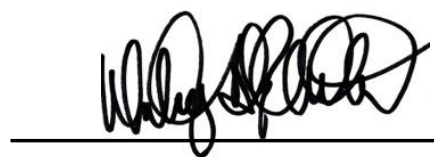

Whitney McIntyre Miller, Ph.D., Co-Chair

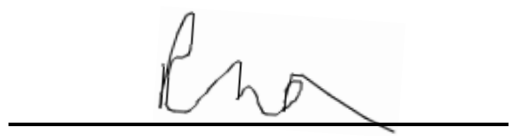

Ryan Allen, Ph.D. Co-Chair
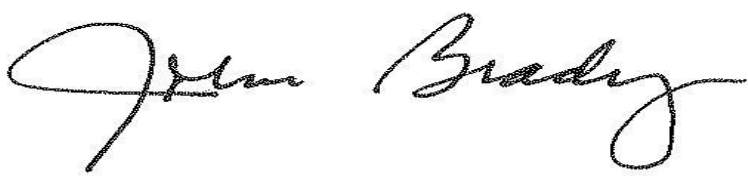

John Brady, Ph.D.

August 2021 


\section{Relationships Among Mentoring Support and Student Success in a Chinese First-Year Experience Program}

Copyright (C) 2021

by Tianxiang Liu 


\section{ACKNOWLEDGEMENTS}

I have always been curious about the unknown world, and I have always maintained a positive and optimistic attitude towards the uncertain future. I was lucky enough to enter the adventure of studying for my $\mathrm{PhD}$ at Chapman University through a highly competitive selection. Having worked in a private college for nearly 15 years, I have been looking forward to pursuing a $\mathrm{PhD}$. With the guidance and help of many people, I accomplished this dream at an unexpected time.

Looking back on this difficult journey, I am grateful and will always bear in mind the professors, leaders, colleagues, and classmates who had been paying attention to and helping me learn and grow along the way.

First, I would like to thank my dissertation committee for their inspiration and guidance. I am very grateful to my dear Dr. McIntyre Miller, cochair of my dissertation committee, for helping me open the door to academic research and giving me careful guidance. Dr. Ryan Allen, cochair of my dissertation committee, who gave me comprehensive, and patient help both academically and in life. Dr. John Brady, you have always given me timely and relevant guidance at the most critical moments of my research. When my wife was ill, Dr. Dawn Hunter took great care of us. Dr. Griffiths, it is you who introduced me to the field of quantitative research and taught me the most basic research methods. In this process, I gradually adapted to the way of study and research of doctoral programs, and my study plan was promoted smoothly. Dr. Lindsey Dippold gave me the most coaching help in dissertation writing, and her enthusiastic support helped me get through the winter and see the light at the end of the tunnel. Another very important help came from the peer support of SNU-Chapman program, which provided warmth in the snow for me in this doctoral program. Overall, support from all sides has been turned into 
my inner spiritual strength; this courage and persistence are the key elements that enabled me to complete my doctoral dissertation.

Finally, I would like to express my gratitude to my wife, who has sacrificed her health to support our family and give me all the support. And thanks to my understanding daughter, who always looked forward to more time with her father. 


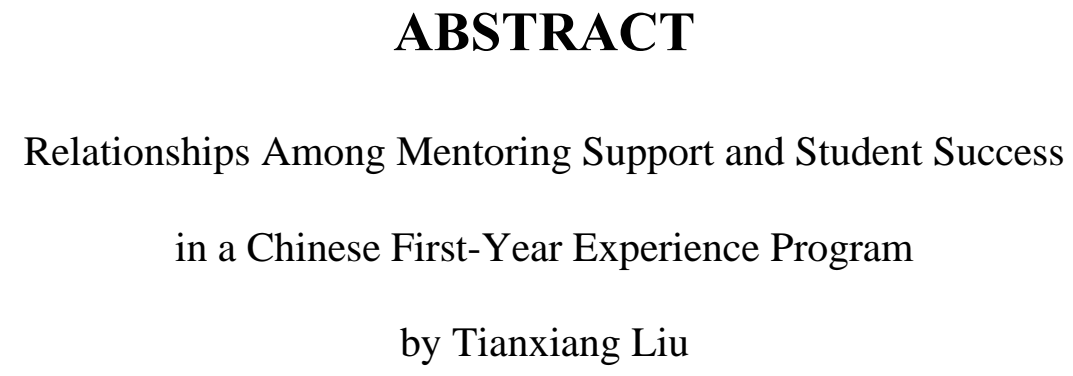

China's higher education reform led to the rise of private universities leading to a surge in the number of private universities, which have lacked funds and resources compared to their public peers. While private universities have allowed for expanded access to higher education, quite a few students have not been well prepared for study at this level. Therefore, private colleges in China need to provide more resources for students to help them succeed. Western countries, with more robust histories of private higher education, adopted the strategy of peer mentoring to solve the problem of first-year students' retention, which guided significance to solve the dilemma in Chinese private universities.

Because of their short history, there have been few quantitative studies on peer mentoring in private colleges in China. To fill this gap, 1,153 undergraduate students from a private college in China were recruited for this quantitative research study on peer mentoring. Through factor analysis, the College Student Mentoring Scale (CSMS) was validated in a private college in Mainland China. Furthermore, the correlation between mentoring support and college integration and academic success was examined for all first-year students, female students, first-generation students, and different major groups. The results showed only Psychological and Emotional Support (PES) and Academic Knowledge subject Support (AKS) were validated in CSMS of four constructs. 
Pearson correlations were used, and significant positive correlations between mentoring support and student integration were found for all first-year students, female students, firstgeneration students, and different major groups. Spearman correlations were used, and significant positive correlations between mentoring support and academic success were found for female students, business major group students. Significant positive correlations between AKS and academic success were also found for first-generation students.

This study has some limitations in the generality of results, such as cross-sectional survey and self-reported data. But it does provide an important validation tool for the CSMS in Mandarin and within a Chinese setting for the first time. In future studies, it is recommended that CSMS can be used in different public and private institutions in Mainland China. 


\section{TABLE OF CONTENTS}

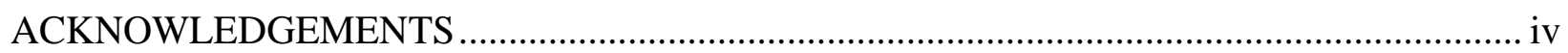

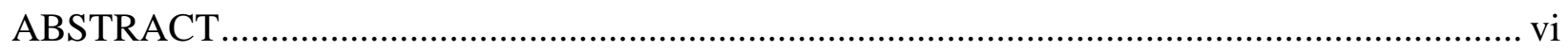

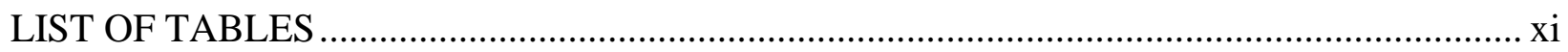

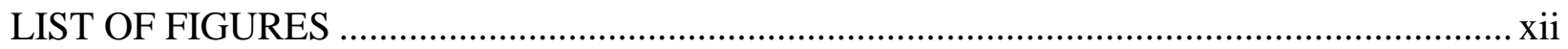

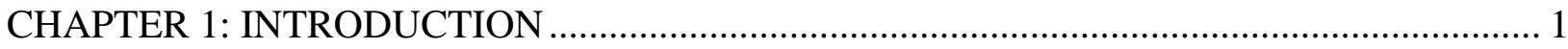

Statement of the Problem............................................................................................ 4

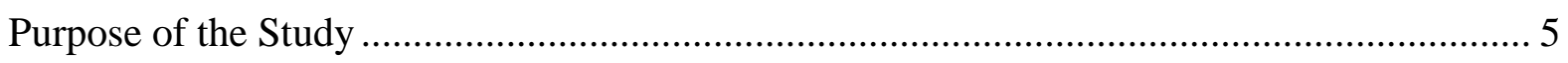

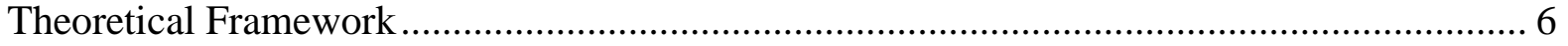

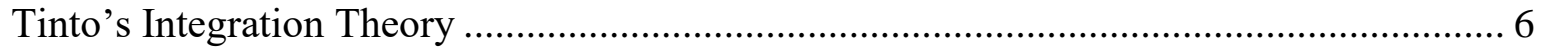

Astin's Involvement Theory ................................................................................. 7

Crisp et al.'s Mentoring Framework ...................................................................... 7

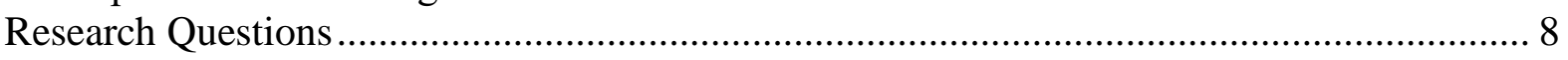

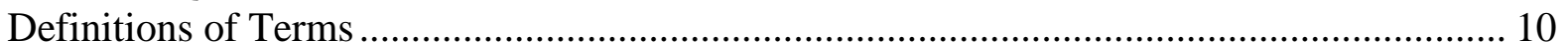

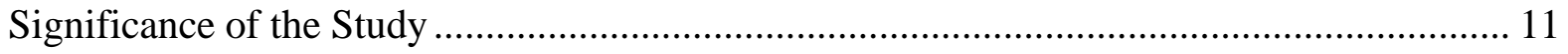

CHAPTER 2: REVIEW OF LITERATURE .................................................................. 13

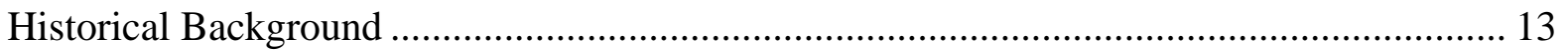

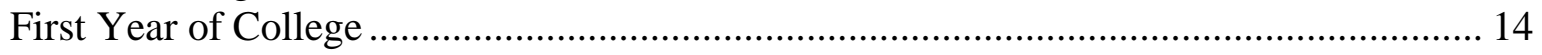

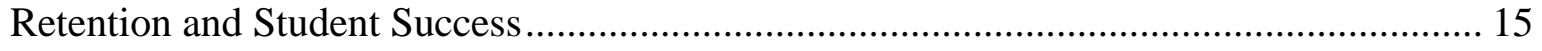

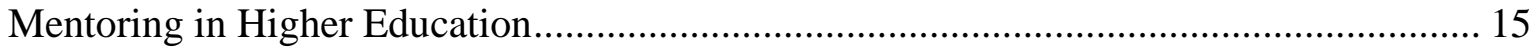

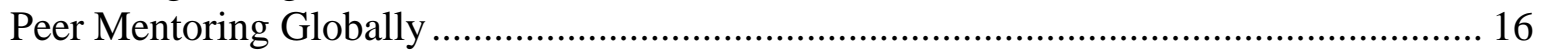

A Review of Student Success Theories .......................................................................... 18

Theories of Student Success ................................................................................... 19

Student Success for First-Year Students ....................................................................... 24

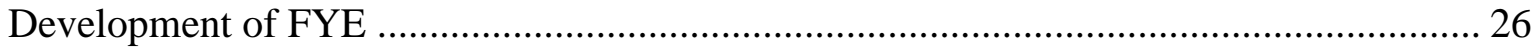

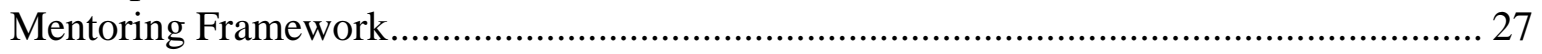

Assessment of Measurement ......................................................................................... 30

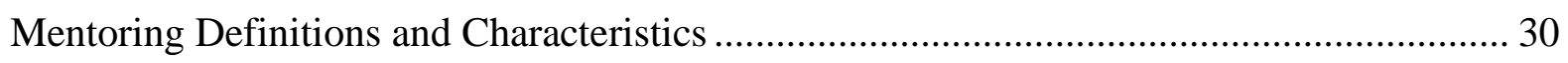

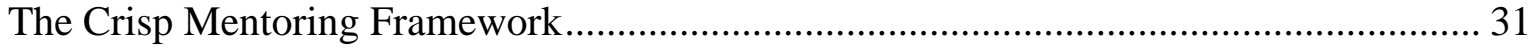

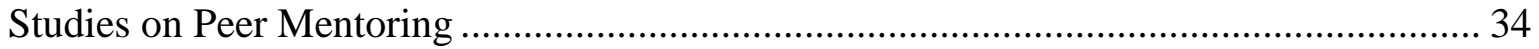

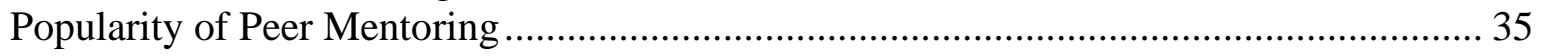

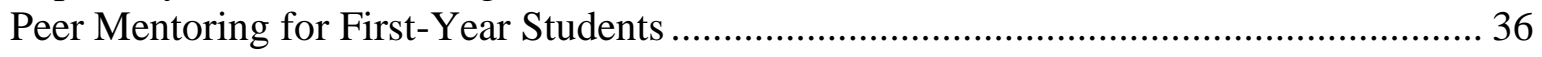

Relevant Empirical Studies in Western Countries....................................................... 37

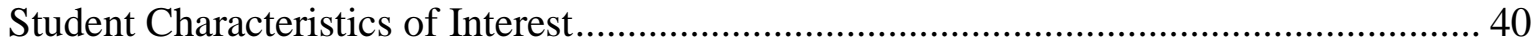

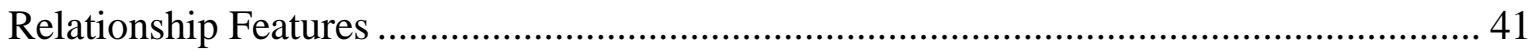

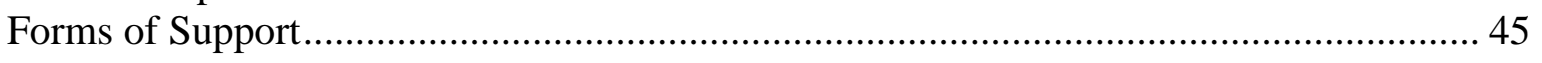

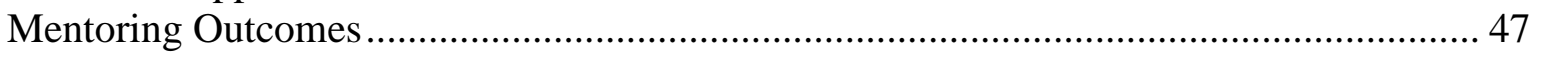

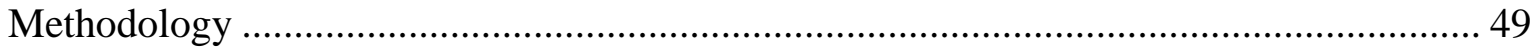

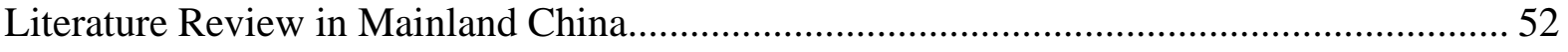

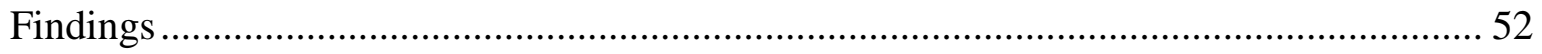




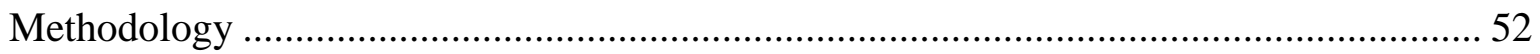

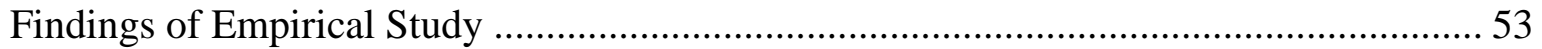

Findings of Theoretical Study ................................................................................... 55

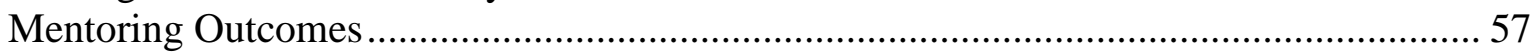

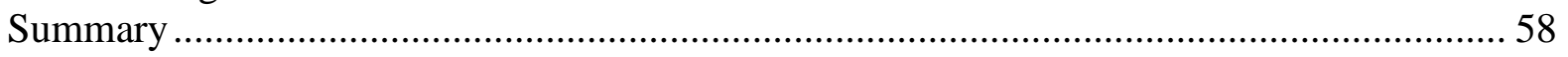

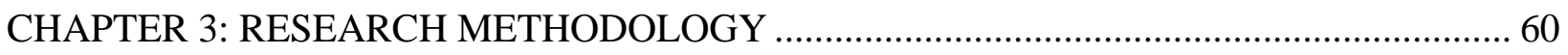

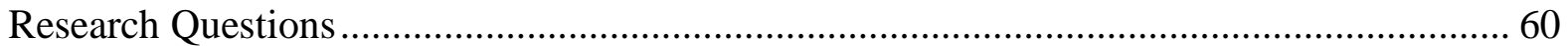

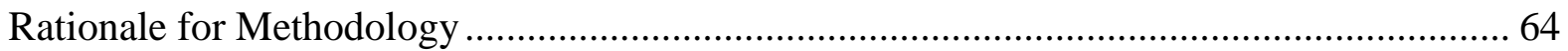

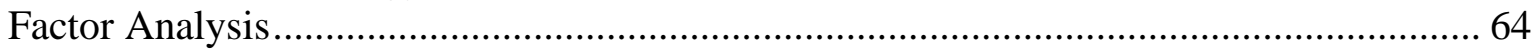

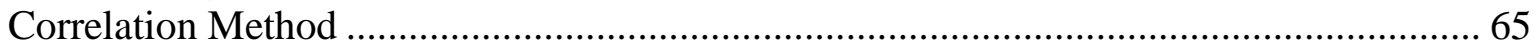

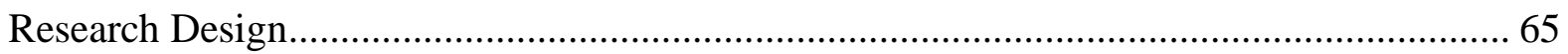

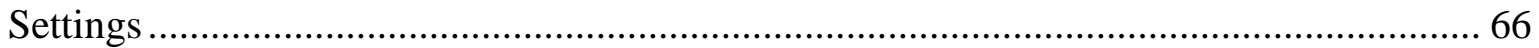

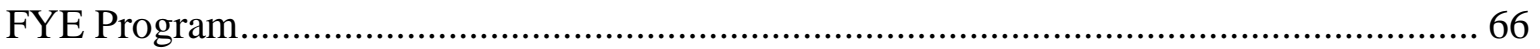

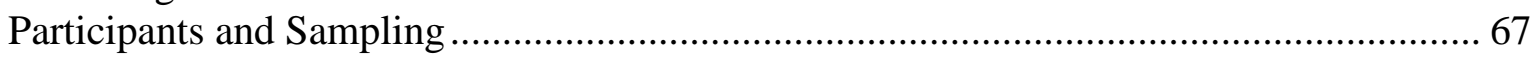

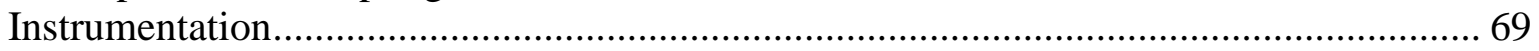

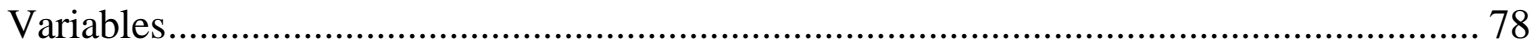

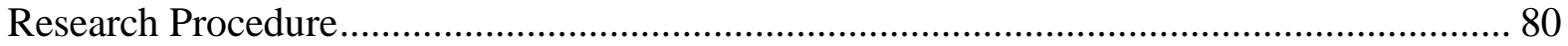

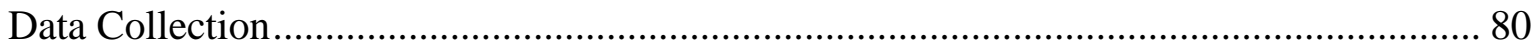

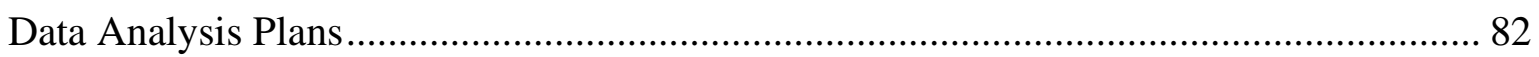

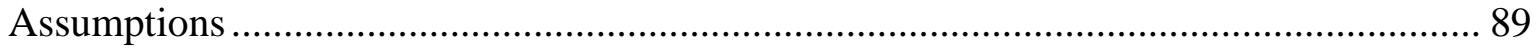

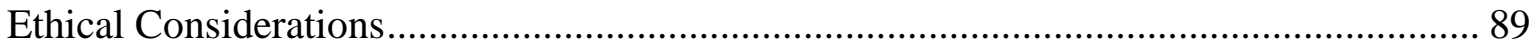

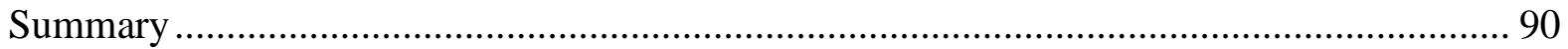

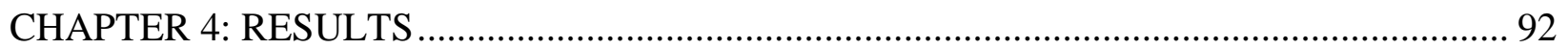

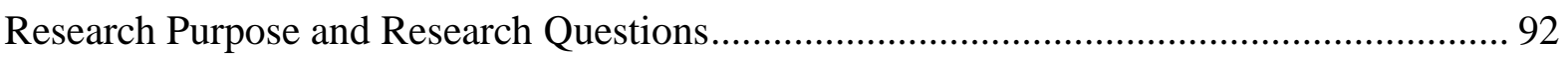

Preliminary Analyses ..................................................................................................... 93

Demographic Variables ................................................................................................ 93

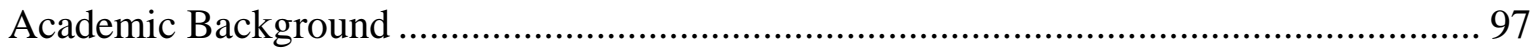

Description of CSMS 25 Items ………………………........................................... 98

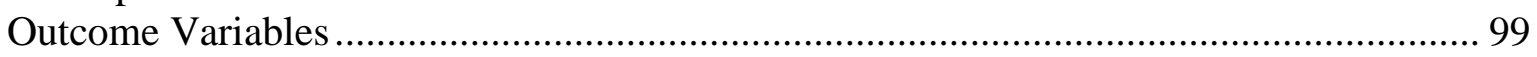

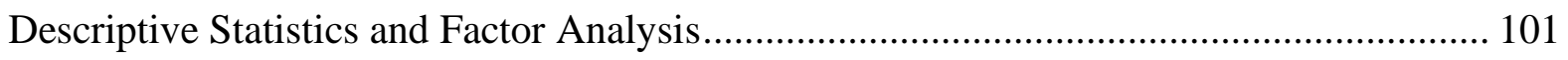

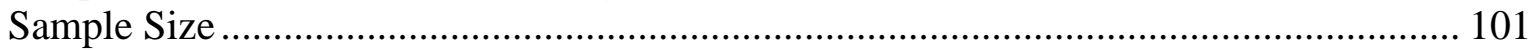

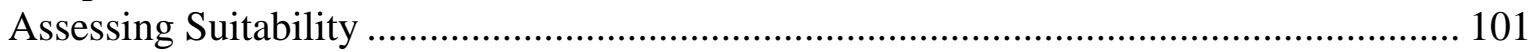

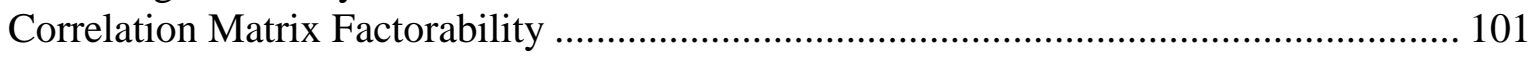

Linearity and Outliers............................................................................................ 102

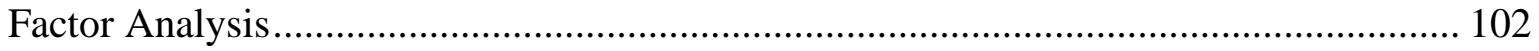

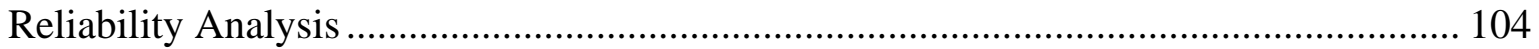

Descriptive Statistics and Correlation Analysis................................................................... 106

Description of Variables............................................................................................. 107

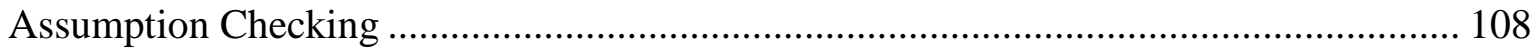

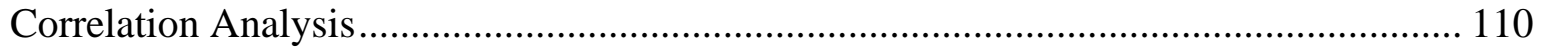

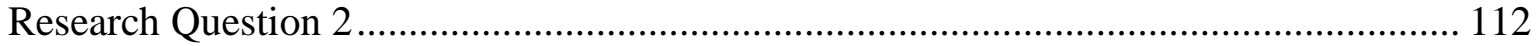

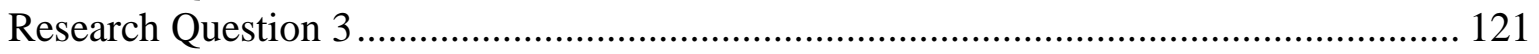

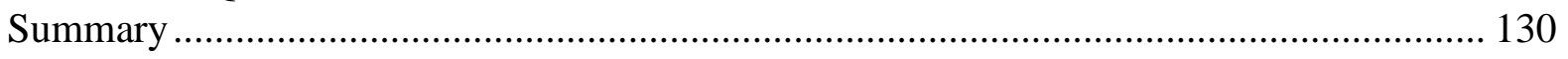

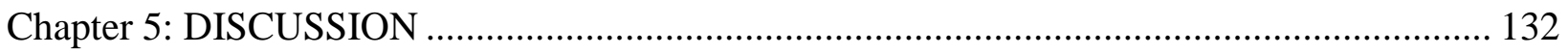




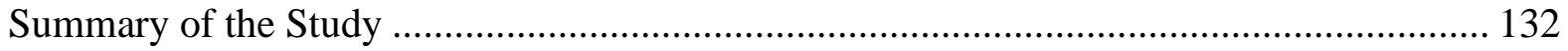

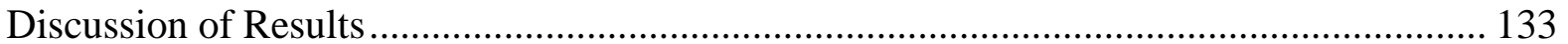

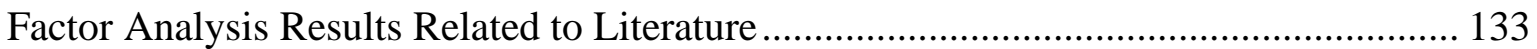

Results of Correlation Analyses Associated With Literature............................................ 135

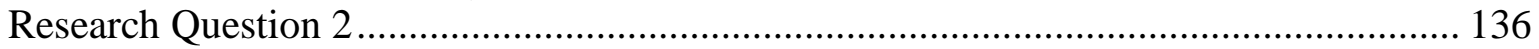

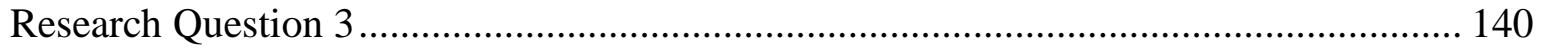

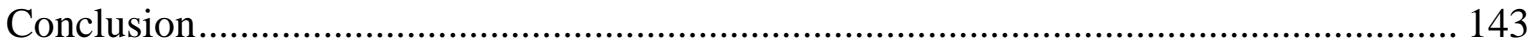

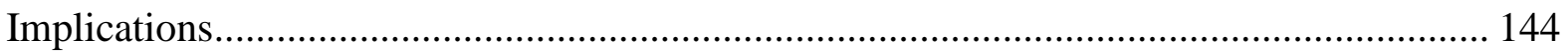

Implications for Counselors and Administrators ……………………….................... 145

Implications for First-Year Students and Peer Mentors .................................................. 147

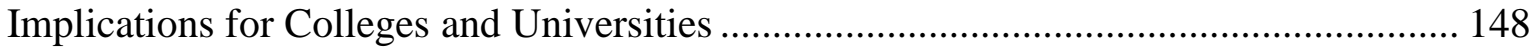

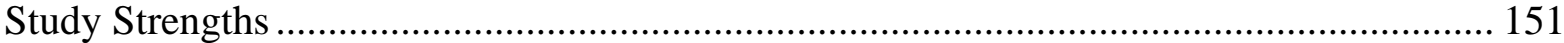

Study Limitations and Future Directions ..................................................................... 152

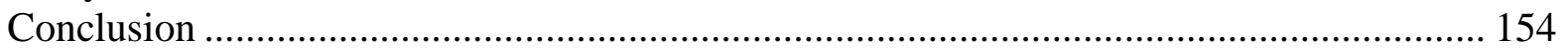

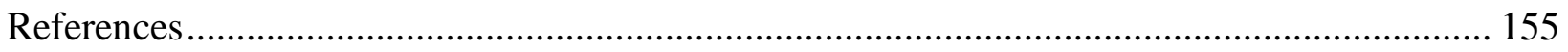

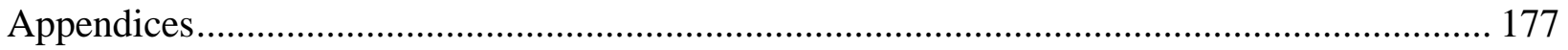




\section{LIST OF TABLES}

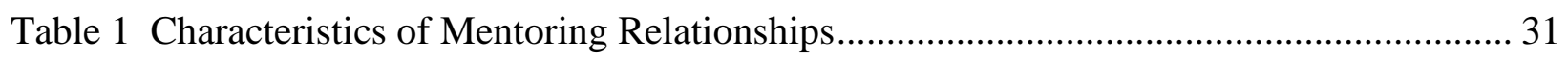

Table 2 Relationship Features in Western Countries................................................................. 42

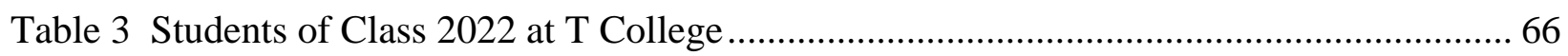

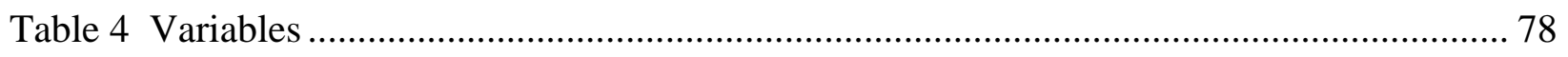

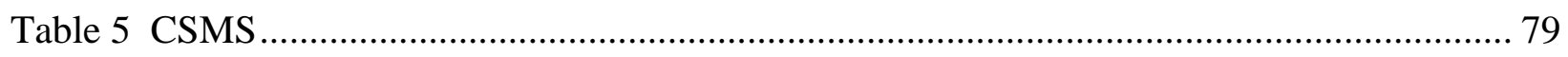

Table 6 Research Questions and Analysis Methods ................................................................. 93

Table 7 Demographic Characteristics of Participants................................................................ 94

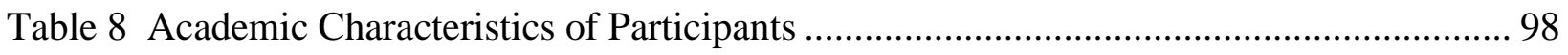

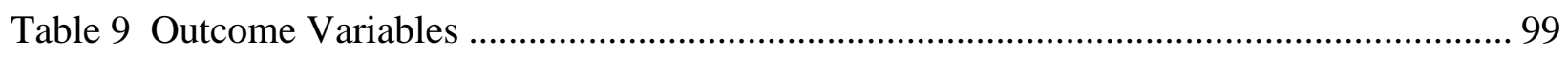

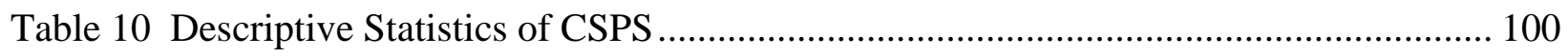

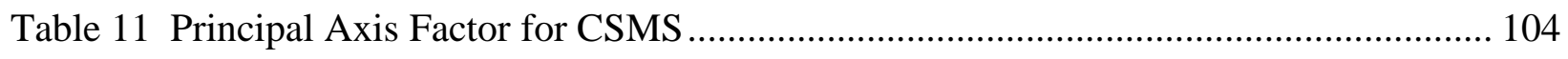

Table 12 Standardized Factor Loading for Final Scale …………………………................. 106

Table 13 Descriptive Statistics of the Primary Final Variables.................................................. 108

Table 14 Correlations Among CSMS Variables for Different Groups....................................... 111

Table 15 Research Question 1 Results: Factor Analyses Associated With Literature ............... 134

Table 16 Results of Research Question 2 and Research Question 3: Correlation Results

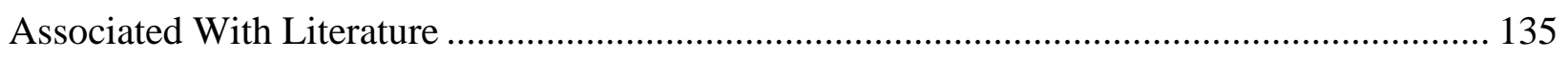




\section{LIST OF FIGURES}

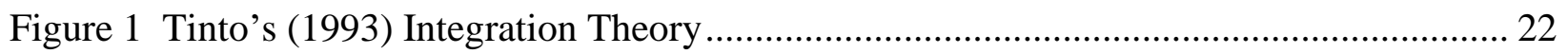

Figure 2 Academic Success Model for First-Year Students in China .................................... 26

Figure 3 Mentoring Undergraduate Students.............................................................. 34 


\section{CHAPTER 1: INTRODUCTION}

The reform of higher education in China at the end of the 20th century led to the rise of private universities in the nation. According to the China Education Information Center (Ministry of Education of the People's Republic of China, 2020), the number of private colleges and universities in China has increased by over 750 in the past two decades, and private colleges and universities have 7,088,280 students on campus. In the last few decades, the Chinese government has invested almost exclusively into its public universities rather than into private universities, though there has been growing attention on the former in recent years (Allen, 2021). Under China's unified national college entrance examination system, the scores of students admitted to private universities are generally lower than those of traditional public universities, and quite a few of them are not ready to study in universities (Davey et al., 2007). Therefore, Chinese private universities and colleges need to provide more resources for students to help them achieve student success.

In the age of economic globalization, undergraduate students face various difficulties and challenges in their first year in sectors across the world, and student retention problems have a certain universality in higher education (Akinla et al., 2018). Meanwhile, the popularization of higher education and the diversity of student sources made many students under difficulties in adapting in the first year in Western countries (Clark \& Andrews, 2009). The strategy of peer mentoring was adopted to solve the retention problem of first-year students in Western countries, which is of significance to solve the dilemma faced by first-year students in Chinese private colleges and universities (Clark \& Andrews, 2009; Crisp et al., 2017). The popularization and diversification of higher education contribute to student retention problems, and peer mentoring can be one of the strategies to solve this problem. However, research on this topic and area in 
China has been scant, meaning the Western theory and sets of literature will be used as a foundation for this research.

The students' experience in the first year of college is important for student success; therefore, universities have a responsibility to provide comprehensive support (Tinto, 1987). Academic success and institutional integration were two important indicators of student success in the first year (Cuseo, 2007) and, therefore, important for supporting resources. There have been similar adaption problems for first-year students in U.S. higher education since the 1970s, and U.S. higher education has many programs for dealing with such problems. First-year experience (FYE) programs were born from the 1960s to 1970s, which mainly served the increasing demand of first-year students for enrollment expansion of higher education in the United States (Saunders \& Romm, 2008). Peer mentoring was proven to be one of the most effective of these strategies in FYE programs (Budge, 2006; McInnis et al., 2000). Peer mentoring activities can be found in different educational contexts in the United States, United Kingdom, Australia, Canada, and South Africa (Lunsford et al., 2017). Peer mentoring is an important support resource for first-year students that coexists with student-student relationships, faculty-student relationships, and staff-student relationships (Crisp \& Cruz, 2009; Gershenfeld, 2014; Jacobi, 1991).

Mentoring programs proved to be an effective strategy to solve such problems and achieve student success. Peer mentoring can help first-year students establish a connection with university learning and the campus and develop a sense of belonging in the United States (Drake, 2011). Budge's (2006) literature review maintained that peer mentoring was a formal, nontraditional genre that became an important part of college life. Formal mentoring involves more structure in the mentoring process and relationships, and the mentee is often assigned to a 
specific mentor; mentors usually receive training and are consciously matched with mentees through organizational systems (Budge, 2006). Informal mentoring is a spontaneous relationship between two or more individuals in which one provides support, advice, and guidance to the other (Eby \& Lockwood, 2005; Hernandez et al., 2017). Peer mentoring in higher education is usually seen as a more formal relationship within a specific campus context, in which experienced students give guidance, support, and specific advice to less experienced students (Akinla et al., 2018; Crisp et al., 2017; Yomtov et al., 2017). Compared with informal mentoring, peer mentoring research focused on formal mentoring programs for first-year students on college campuses (Erickson et al., 2009). In higher education, traditional mentoring refers to the encouragement and guidance for students by a knowledgeable and experienced faculty (Budge, 2006). In contrast to traditional mentoring relationships, peer mentoring has been a less costly, more effective, and more popular strategy to help students succeed in higher education (Gershenfeld, 2014; Jacobi, 1991). The specific operational forms of peer mentoring programs are distinguished according to the characteristics of each institutional project in terms of their duration, function, and source of FYE program (Rieske \& Benjamin, 2015). The goal of peer mentoring in higher education is often constructed in FYE programs for student retention and student success (Tinto, 1999).

Since underprepared first-year students need more resources and guidance from universities (Zhang, 2011), and few empirical studies have been conducted on this aspect of higher education in China. Given that much of the foundational research in this area originates from the U.S. higher education, it is important to localize the contexts of FYE programs to Mainland China. Mentoring is an effective strategy to reduce student drop-out rates and became a popular topic in higher education in the United States; with the help of mentoring, college 
students can better cope with challenges (Schrader \& Brown, 2008). Both the government and universities have invested much money to establish FYE programs to improve student retention in Western countries (Hunter, 2006). Furthermore, compared with faculty and staff's support, the peer mentors' support for first-year students is one of the most representative (Keeling, 2004). As research showed peer mentors from advanced grade levels could have a more emotional resonance with first-year students, peer mentoring became a popular topic in higher education and achieved better effects (Lunsford et al., 2017). But existing studies have mainly focused on the promotion of academic success, retention, and integration for first-year students by peer mentoring in Western countries (Gershenfeld, 2014). Some studies have shown peer mentoring has a significant impact on students' college success (Crisp \& Cruz, 2009; Jacobi, 1991).

There is a gap in research for mentoring first-year college students in Mainland China. Compared with the rich research literature in Western countries, there are few relevant empirical studies in Mainland China (Cao, 2014). By reviewing the literature of peer mentoring in Western cultural countries and China and using Nora and Crisp’s (2007) framework, I conducted a postprogram survey study at a private, medium-sized college in China. Given my position as a director of student affairs at a medium-sized, Chinese private college, the adaptability of firstyear students in China's private colleges and universities aligns well with professional goals and interests.

\section{Statement of the Problem}

In recent years, there has been a rapid expansion of private higher education in China; many students entering these universities have problems adjusting to first-year studies and life after entering private universities (Cao, 2014). FYE programs have emerged to help students transition, including peer mentoring in the first year, but there are few empirical studies on these 
programs in China. In comparison, U.S. higher education has mature theoretical and practical research studies on this issue. Therefore, from a global perspective, there is a gap in the research. This study serves to narrow that gap by conducting an empirical study that applies peer mentoring theory from the United States to the students' adjustment in the first year of private higher education in China.

China had 7,088,280 students in private universities, more than $23 \%$ of the total number of college students across the country (Ministry of Education of the People's Republic of China, 2020). Many private colleges have begun the implementation of peer mentoring programs. Due to the lack of reliable and valid scales measuring in China, there have been few high-quality empirical studies on peer mentoring for first-year students in China. According to the results of the study of Western literature, it is critical to carry out the empirical research of peer mentoring to promote college student success using valid scales, especially in terms of academic success, measured by GPA and integration in student engagement (Crisp \& Cruz, 2009).

Research on peer mentoring in FYE programs can provide decision-making reference for colleges and universities to continuously improve the FYE program, minimize the first-year students' drop-out rate, and improve students' graduation rates (Gershenfeld, 2014). This research is significant because it can potentially help various groups of college students in private colleges and universities to better achieve college success.

\section{Purpose of the Study}

The purpose of this survey study is to examine Tinto's (1993) integration theory, Astin's (1984) involvement theory, and Crisp et al.'s (2017) mentoring framework to predict students' student integration and academic success for all first-year students, female students, firstgeneration students, and different major groups in a Chinese FYE program at T College. First, 
Crisp's (2009) College Student Mentoring Scale (CSMS) was validated in a Mainland China context. The independent variables were the total scores of CSMS and the scores of two constructs of CSMS: psychological and emotional support (PES) and new academic subject knowledge support (NAKS; Crisp, 2009). The dependent variables are defined as College Student Perception Scale (CSPS) and cumulative grade point average (GPA; Yomtov et al., 2017). I investigated the relationships among students' CSMS scores (i.e., total scores, PES scores, and NAKS scores) and integration scores as measured by CSPS. I investigated the relationships among students' CSMS scores (i.e., total scores, PES scores, and NAKS scores) and cumulative GPA for all first-year students, female students, first-generation students, and different major groups in a Chinese FYE program at T College.

\section{Theoretical Framework}

My research has been guided by the framework of Tinto's (1993) integration theory with the variable of student integration measured by CSPS and Astin's (1984) involvement theory with the variable of academic success measured by GPA; meanwhile, Crisp et al.'s (2017) mentoring framework was used to measure the variable of students' perception of mentoring support with CSMS. Tinto's (1993) integration model with the variable of CSPS and Crisp et al.'s (2017) mentoring framework with the variable CSMS both used the form of self-reported scales to test students' perceptions on student success and peer mentoring.

\section{Tinto's Integration Theory}

Tinto’s (1993) theory on student integration identified first-year college students engaging with peer mentors can promote academic integration and social integration, achieve personal intention consistent with the college's commitment, eventually achieve retention and persistence. He emphasized that among the many reasons for the retention crisis of college 
students, the inability of students to integrate into college life academically and socially in the first year is an extremely important aspect. At the same time, colleges and universities need to take a series of effective strategies.

\section{Astin's Involvement Theory}

Astin's (1984) involvement theory refers to the psychological energy students put into the academic experience in class. From this perspective, the amount of student learning and personal development associated with any educational program is proportional to the quality and quantity of student participation in the program. I investigate the relationship between the variable of mentoring support with CSMS and academic success with accumulative GPA.

\section{Crisp et al.'s Mentoring Framework}

Crisp et al.'s (2017) mentoring framework is based on Nora and Crisp's (2007) mentoring theory with CSMS. Nora and Crisp's (2007) mentoring framework formed four dimensions: (a) psychological and emotional support, (b) goal setting and career paths, (c) academic subject knowledge support, and (d) the role model. After a period of development, Crisp et al.'s (2017) took the mentoring framework one step further; their new framework includes five parts: (a) educational context, (b) student characteristics, (c) relationship features, (d) forms of support, (e) mentoring outcomes. Based on Crisp et al.'s (2017) theoretical framework, I validated Crisp's (2009) CSMS scales in a Chinese FYE program. Then, I used Crisp's (2009) CSMS to measure students' perception of mentoring support in Mainland China. 


\section{Research Questions}

Three research questions guided my investigation in this study.

Research Question 1: Can the CSMS, based on the four-factor model, be used as a valid indicator to measure the first-year students' perceptions of peer mentoring in a Chinese FYE program?

Hypothesis 1a: The CSMS, based on the four-factor model, can be used as a valid indicator to measure the first-year students' perceptions of peer mentoring in a Chinese FYE program.

Research Question 2: How are first-year students' perceptions of peer mentoring on the CSMS correlated to integration, as measured by CSPS in a Chinese FYE program in the four different student groups?

Research Question 2a: Are all first-year students' perceptions of peer mentoring on CSMS scores correlated to integration, as measured by CSPS in a Chinese FYE program? Hypothesis 2a: There is a positive correlation between all first-year students' CSMS scores and integration scores, as measured by CSPS in a Chinese FYE program.

Research Question 2b: Are female first-year students' perceptions of peer mentoring on CSMS scores correlated to integration, as measured by CSPS in a Chinese FYE program?

Hypothesis 2b: There is a positive correlation between female first-year students' CSMS scores and integration scores, as measured by CSPS in a Chinese FYE program.

Research Question 2c: Are first-generation, first-year students' perceptions of peer mentoring on CSMS scores correlated to integration as measured by CSPS in a Chinese FYE program? 
Hypothesis 2c: There is a positive correlation between first-generation first-year students' CSMS scores and integration scores, as measured by CSPS in a Chinese FYE program.

Research Question 2d: Are first-year students' perceptions of peer mentoring on CSMS scores correlated with cumulative GPA in a Chinese FYE program, and do these potential correlations vary by major groups?

Hypothesis 2d: There is a positive correlation between some major groups of students' perceptions of CSMS scores and student integration scores, as measured by CSPS, in a Chinese FYE program.

Research Question 3: How are the first-year students' perceptions of peer mentoring on CSMS related to cumulative GPA in a Chinese FYE program in the four major groups?

Research Question 3a: Are all first-year students' perceptions of peer mentoring on CSMS scores correlated to cumulative GPA in a Chinese FYE program?

Hypothesis 3a: There is a positive correlation between all first-year students' perception of peer mentoring on CSMS scores and cumulative GPA in a Chinese FYE program.

Research Question 3b: Are female first-year students' perceptions of peer mentoring on CSMS scores correlated to cumulative GPA in a Chinese FYE program?

Hypothesis 3b: There is a positive correlation between female first-year students' perception of peer mentoring on CSMS scores and cumulative GPA in a Chinese FYE program.

Research Question 3c: Are first-generation first-year students' perceptions of peer mentoring on CSMS scores correlated with cumulative GPA in a Chinese FYE program?

Hypothesis 3c: There is a positive correlation between first-generation first-year students' perception of peer mentoring on CSMS scores and cumulative GPA in a Chinese FYE program. 
Research Question 3d: Are first-year students' perceptions of peer mentoring on CSMS scores correlated with cumulative GPA in a Chinese FYE program, and do these potential correlations vary by major groups?

Hypothesis 3d: There is a positive correlation between some major groups of students' perceptions of peer mentoring on CSMS scores and cumulative GPA in a Chinese FYE program.

\section{Definitions of Terms}

The following terms are concepts involved in this study and have specific a connotation in this research. Operational have also been included. Detailed descriptions of operationalized concepts are discussed in Chapter 3.

- First-generation students: The first-year students recruited into the higher education whose father or mother did not receive a bachelor's degree (Nadelson et al., 2013).

- First-year experience (FYE) program: Programs set up by institutions to help first-year students achieve a successful transition in the first year of university and improve students' retention rates and institutional integration (DeAngelo, 2014). FYE programs usually include four parts: campus orientation, academic advising, first-year seminars courses, and learning community in the United States; peer mentoring was used in campus orientation, first-year seminars, and learning communities (Hunter, 2006).

- Peer mentoring: At the undergraduate level, peer mentoring referred to the matching of more experienced students with less experienced peers to provide psychological, emotional, academic, and professional guidance and assistance, which could be one-toone or in a group with no hierarchy; the target of this relationship was mostly for retention. When compared with traditional mentoring, peer mentoring is a widely popular form in contemporary undergraduate retention programs (Crisp, 2009; Kram, 1985; 
Lunsford et al., 2017). CSMS was validated in Mainland China, and the validated CSMS had two constructs: psychological and emotional support (PES) and new academic subject knowledge support (NAKS; Crisp, 2009).

- Student integration: According to Wolf-Wendel et al. (2009), "Integration as a state of being is based on a perception of the student fit with the campus, and by extension, a perception of interaction that reflects the values and norms of the institution and its culture" (p. 416). Student integration is mainly embodied in student sense of belonging, well-being, and satisfaction in the first year. Student integration-including academic integration and social integration — is the most important prerequisite for realizing student retention in college (Tinto, 1993).

- Student retention: This concept is viewed from the institutional level. Students reenroll each semester continuously until graduation; it is one of the most important indicators of student success in college (Manyanga et al., 2017). Academics gradually added FYE to the retention program for student success (Bean, 2005; McInnis, 2001).

- Student success: Student success has rich connotations in higher education and includes the following five aspects: student retention, educational attainment, academic achievement, student advancement, and holistic development (Cuseo, 2007). There are three domains of first-year student success in college: academic achievement (i.e., GPA), critical thinking, and social-emotional adjustment (van der Zanden et al., 2019).

\section{Significance of the Study}

Students' first-year transition is critical to their success in college. Mentoring is an important support strategy to help students transition into college. Peer mentoring is the latest high-impact practice, is an effective approach for supporting undergraduate students and is part 
of the global first-year student support system for university education (Crisp et al., 2017). Most research on mentoring has been done in Australia, the United Kingdom, the United States, and Canada. Mainland China has become a new growth area for peer mentoring programs, compared with Western countries.

There are few rigorous empirical studies on peer mentoring programs in China, so it is particularly important to use the CSMS (Crisp, 2009) to carry out empirical research in Mainland China. The CSMS was a survey designed to measure students' perceptions of the mentoring support at university. The implementation of this study provided peer mentoring policy recommendations for private universities and can help improve peer mentoring programs in China. This research can also help future first-year students better achieve first-year transitions in China. This study can provide a good foundation for empirical research on peer mentoring in Mainland China and promote in-depth academic research in this field. With the further development of empirical research on peer mentoring in FYE programs, the governments in China may invest more resources to help students through the difficult transition period in the first year. 


\section{CHAPTER 2: REVIEW OF LITERATURE}

The purpose of this review was to provide a background for my research through the contextual literature based on the relationship between students' perceived peer mentoring support and student success in a Chinese first-year experience (FYE) program, especially on student groups including all first-year students, female student, first-generation students, and four major groups students. To prepare for this study, I synthesized the literature of peer mentoring research in Western countries and in Mainland China. I also drew on supporting theories and conceptual frameworks of peer mentoring in Western countries to support the research in Mainland China, as well as the research on the outcome, methodology, and effectiveness of peer mentoring. The literature review is presented in this chapter.

First, I reviewed student success theories for mentoring in higher education and analyzed the development of the FYE movement. Second, I summarized the development of the concept of mentoring to find the consensus of mentoring in higher education, focusing on Crisp et al.'s (2017) integrated conceptual model of mentoring undergraduate students. Third, I presented empirical research on peer mentoring and college student success in Western countries, which included: (a) educational context, (b) interest of student characteristic, (c) relationship feature, (d) forms of support, (e) mentoring outcomes, and (f) methodology. Finally, this review explored the handful of literature on peer mentoring in Mainland China.

\section{Historical Background}

In the context of massification and diversification in higher education, improving retention and student success have become critical issues discussed both in theory and practice throughout the world. Through the initial exploration of peer mentoring in practice in Mainland China, it is clear that empirical studies of peer mentoring lagged far behind the development of 
practical programs. Western countries conducted in-depth studies on retention and student success. This chapter discusses the relevant theories, methodologies, and empirical research of Western countries into Mainland China.

\section{First Year of College}

Tinto is a well-known scholar in the field of sociology and education. Since the 1970s, his theory of student departure and later theory of student integration have been widely recognized by the academic community (Manyanga et al., 2017). Tinto (1987) argued that (a) all retention strategies should be student centered, (b) students' demand for retention in the first year should be addressed systematically by the university, and (c) institutions should use all institutional resources to ensure students' success in their first year. Therefore, there was a need for high-quality first-year programs organized by universities for student success, and they became an important part of student retention programs (Manyanga et al., 2017). In contrast to the inadequate faculty mentoring, peer mentoring became an alternative strategy chosen by many colleges and universities to solve difficulties under the condition of a large number of undergraduates and limited resources to help students achieve success in college (Akinla et al., 2018; Lunsford et al., 2017).

In college, students' first-year experiences were closely related to student retention; a good first-year experience could help students achieve integration, and the ultimate purpose of the program was to achieve college success (van der Zanden et al., 2019). The first year of college — especially the first semester — was a critical time for college students to integrate into the campus and to be successful throughout their college years (Tinto \& Wallace, 1986). In terms of the implementation of retention policy, Tinto (1993) suggested universities (a) provide sufficient resources to faculty and staff, (b) be committed to a long-term development goal, and 
(c) make the first effort to retain students. Institutional actions should be coordinated in a collaborative manner to ensure a systematic, campus-wide approach to student retention.

\section{Retention and Student Success}

Lang (2001) observed that higher education retention and attrition issues caused serious concern globally over the past few decades. Clark and Andrews (2009) emphasized the massification of higher education, the diversity of student sources, and the shortage of funds in universities caused worries about whether higher education was worth the money.

Student success has included many aspects, but integration, retention, and academic progress are the three most important aspects for first-year students in higher education (Fox et al., 2010; Kuh, 2001; Yomtov et al., 2017). To deal with the retention crisis, mentoring has been a critical strategy to achieve student success in the United States (Jacobi, 1991; Manyanga et al., 2017). Therefore, mentoring in higher education was particularly prevalent in Western countries (Chester et al., 2013; Collings et al., 2014; Crisp et al., 2017). With the globalization and popularization of higher education, China and the United States have faced similar situations in student retention and success.

\section{Mentoring in Higher Education}

Mentoring in higher education has become a common practice in Western countries such as the United States, the United Kingdom, and Australia as a way to promote students' college success (Crisp et al., 2017; Lunsford et al., 2017). Under the conditions of gradually diversified students and limited funds of colleges and universities, peer mentoring was adopted by many colleges and universities in practice and regarded as an economic intervention strategy to solve the student retention crisis and help students achieve college success (Budge, 2006). 
Jacobi (1991) and Crisp and Cruz (2009) claimed research on mentoring lagged far behind its practical development in higher education. In particular, the effectiveness of peer mentoring, as a form of mentoring adopted by more and more universities, is in urgent need of further research in terms of literature review (Crisp et al., 2017; Gershenfeld, 2014). Compared with the traditional hierarchy mentoring structure, peer mentoring mostly provided psychological and task-based support as an equal status (Terrion \& Leonard, 2007).

Peer mentoring has been institutionalized in practice in FYE programs at many colleges and universities and has been a priority for many first-year students to achieve college success (Young \& Keup, 2016). However, a consistent concept of mentoring was not formed in higher education (Crisp \& Cruz, 2009; Jacobi, 1991). The traditional mentoring model in higher education meant faculty or staff advised students for academic, developmental purposes. For the effectiveness of peer mentoring for undergraduates, the consensus in the mentoring research field has not been fully formed.

\section{Peer Mentoring Globally}

As a newly growing field in higher education to solve the retention crisis, peer mentoring started in the United States and the United Kingdom and spread worldwide (Budge, 2006; Crisp et al., 2017; Lunsford et al., 2017). In Western countries, the theoretical research and practical exploration of peer mentoring have been abundant in English literature; without the context of English-speaking, the literature on peer mentoring is lacking (Lunsford et al., 2017). Due to the globalization of education, mentoring for first-year college students has been adopted in Mainland China, but relevant research on it is rarely seen in English literature. 


\section{Peer Mentoring in Western Countries}

Peer mentoring was improved based on the traditional mentoring model in Western countries; originally, it was the guidance of an experienced senior person to the young, which has been transformed into a relationship between young people of similar age and similar experience at college (Terrion \& Leonard, 2007). Kram and Isabella (1985) argued peer mentoring had two main functions: a task-related or career-related function and psychological function. Peer mentors should have the following characteristics: (a) leadership and willingness to take the time, (b) helping students of gender and race, (c) having university and mentoring experiences, and (d) having good academic achievements (Terrion \& Leonard, 2007). Careerrelated peer mentoring characteristics included program of study (i.e., subject-specific knowledge) and self-enhancement motivation. Psychosocial functions included communication skills, supportiveness, trustworthiness, interdependent attitude to mentoring, empathy, personality match with mentee, enthusiasm, and flexibility (Terrion \& Leonard, 2007). In terms of the basic characteristics of peer mentoring, there are some variations between the U.K. tradition and the U.S. tradition (Collings et al., 2014; Crisp \& Cruz, 2009; Lunsford et al., 2017); but from the perspective of peer mentoring outcomes, studies of peer mentoring are still broadly consistent in comparing Anglo-Western countries such as the United States, the United Kingdom, Australia, and New Zealand (Lunsford et al., 2017).

\section{Peer Mentoring in Mainland China}

With the globalization and popularization of higher education, China and Western countries face similar student retention and success situations. China's higher education has entered the ranks of mass education, and more first-year students enter the university campus; because some first-year students lack the necessary understanding of university life, their 
adaptive ability is weak; the incompatible with the academic requirements makes some college students feel anxious (Zhang, 2011). Therefore, the peer mentoring programs were introduced to allow peer mentors to participate in extended orientation education, help first-year students to set new goals, and adapt to college life as soon as possible (Shi, 2008). Compared with the vigorous development of peer mentoring in practice in higher education, empirical research on peer mentoring is lagging using rigorous research methods (Cao, 2014). I will further discuss literature on peer mentoring in Mainland China later in this chapter.

\section{A Review of Student Success Theories}

In higher education, theories for retention and student success were broader than mentoring theories. Manyanga et al. (2017) reviewed student retention theories in higher education over the past 80 years from the historical development process. There were eight theoretical models of student retention in higher education: (a) student mortality model (McNeely, 1937), (b) student attrition model (Bean, 1980, 1983), (c) student integration model (Tinto, 1987, 1993), (d) theory of involvement (Astin, 1968, 1985), (e) social and personal beliefs model (Pascarella, 1980), (f) dropout syndrome model (Bean, 1985), and (g) college dropout model (Tinto, 1975). Manyanga et al. found the student integration model (Tinto, 1975, 1993), student attrition model (Bean, 1980, 1990), and theory of involvement (Astin, 1985) were widely used in research for student success.

First, Jacobi (1991) addressed important theoretical frameworks for studying mentoring undergraduate students based on retention and student success theories. Then, Jacobi summarized four important theoretical models: (a) involvement in learning from Astin (1977), (b) academic and social integration from Tinto (1975), (c) social support from House (1981) and Cobb (1976), and (d) developmental support from Chickering (1969) and Perry (1970). Jacobi 
(1991) found Astin paid more attention to students' specific behaviors, and Tinto focused on students' subjective feelings. Astin's theory focused on students' psychological feelings and concrete results, and Tinto's theory was more concerned with integration in new environments.

Researchers of first-year college student success focused on three areas: academic achievement, social-emotional adjustment, and critical thinking (van der Zanden et al., 2019). For my research, I focused on the first two domains of student success and conceptualized my outcome variable using Tinto's integration theory. Meanwhile, I conceptualized my outcome variable (GPA) using Astin's involvement theory.

\section{Theories of Student Success}

How to help students stay in college and graduate without lowering academic standards is a problem that every university has to face; therefore, student retention became a nationwide concern in higher education in the United States since the last century (Manyanga et al., 2017). As mentioned, the popularization of higher education and the diversification of students' sources make the retention problem of college students more and more complex (Clark \& Andrews, 2009). In outcomes-based frameworks for mentoring, retention theory attracted the most attention of researchers and has far-reaching influence in practice (Crisp et al., 2017). As Jacobi (1991) interpreted, Astin paid more attention to students' specific behaviors, while Tinto focused on students' subjective feelings.

\section{Integration Theory}

Tinto’s $(1975,1993)$ integration theory was fundamental for students who integrated into institutions and explained students' retention. Tinto claimed that universities were responsible for cultivating students' commitment to institutional commitment and providing full guidance and help to first-year students; successful social and academic integration rebuilt higher 
education. Tinto (1975) argued that a good fit was a key factor in students' intentions and the institution's goal. If the student's intentions and goals match the commitment of the institution, which means retention and graduation will be achieved. Tinto (1993) found students alone could not solve academic difficulties to achieve education and career goals and could not truly integrate into the academic and social life of the university. Student attrition was a failure of themselves and the university, and the important task of higher education leaders was to form a retention policy. School leaders should define the goals and commitments of the students they enrolled in, and students should identify their own goals and commitments (Tinto, 1993).

Effective retention had three principles: the program (a) was committed to serving the students and putting the students' welfare first; (b) focused first and foremost on the education of all students, not just some of them; and (c) aimed to create a supportive atmosphere of social and academic inclusion that made all students felt competent. Tinto's (1993) integration included six stages: preentry attributes, goals commitments, institutional experiences, integration, goals commitments, and outcomes; among them, the most important middle three stages include goals and commitments of colleges and universities, institutional experiences, and integration (i.e., academic and social) as shown in Figure 1.

First, many factors affect students' study and life in college before they enter college, such as different demographic characteristics, including gender, first-generation family, onechild family, etc. For instance, in the case of China, academic ability includes different Gaokao (i.e., Chinese national college entrance examination) scores and students' goals and expectations for college. A second factor involves intention. After students enter the university, their personal intentions may be consistent with the goals and commitments provided by the university. Peer mentors help students socially and academically in the first year of college to integrate into 
college experiences as soon as possible. If first-year students have a better experience of academic and social integration, it is easier for them to align their personal commitment with the institutional commitment. Accordingly, students will eventually choose persistence or retention instead of dropping out (Tinto, 1993).

In institutional experiences, there were formal and informal experiences, with formal focusing on classrooms and the latter on participation in peers' interaction. Tinto (2012) advocated universities and colleges took the classroom seriously to enhance student success; participation—in and out of the classroom—was particularly important for student development. Tinto claimed that universities should consider systematically offering comprehensive assistance to first-year students, rather than choose add-ons, which meant institutions provided only one piece of help for the first year, rather than providing comprehensive and effective help (Tinto, 1999). The FYE program was a full range of help and guidance for first-year students, and the key lay in the comprehensive integration of peers and mentoring. 


\section{Figure 1}

Tinto's (1993) Integration Theory in China

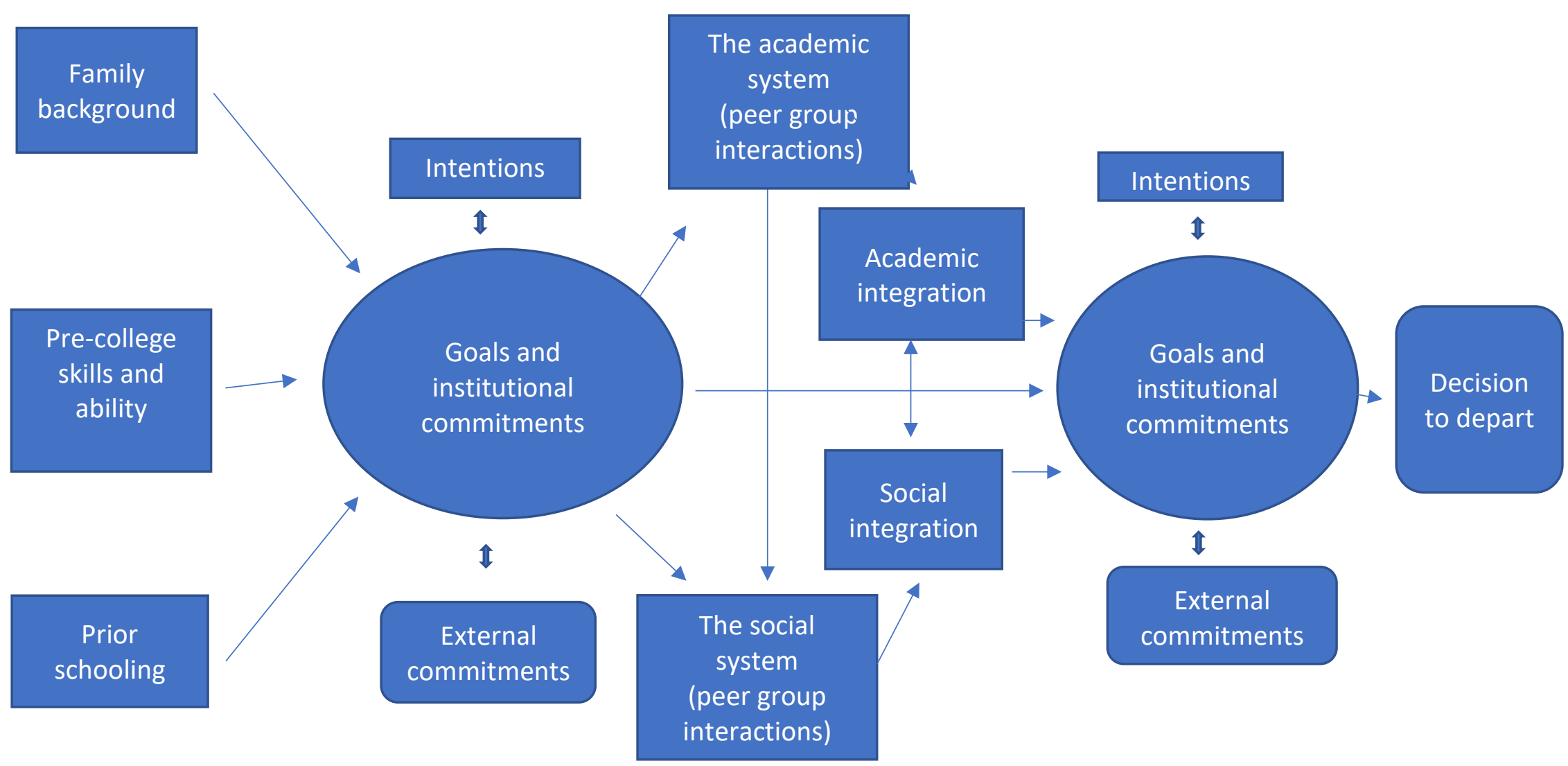

Note. Modified from Leaving College: Rethinking the Causes and Cures of Student Attrition (2nd ed), by V. Tinto, The University of Chicago Press, p. 114. Copyright 1987, 1993 by The University of Chicago Press. Reprinted with permission. 


\section{Involvement Theory}

Astin (1968, 1987) studied how students' behavior and attitudes change as they develop and excel at university. Students' personality, behavior, values, beliefs, and students' development potential are influenced by educational programs, faculty, student peer groups, students' college experience, and university culture. Astin (1993) invented the input, environment, and outcomes (IEO) model, with the main purpose of evaluating classroom settings and activities to promote learning. Astin $(1985,1993)$ also put forward five basic principles of students and development: psychological and physical investment; continuous investment; quantitative and qualitative investment; learning outcomes were related to the quality and quantity of participation; effectiveness of educational policies in motivating students.

It was necessary to clarify the connections and differences between these concepts: involvement, engagement, and integration, which added unique and important things to the understanding of student development and success (Wolf-Wendel et al., 2009). Astin (1984) defined involvement as the physical and psychological energy that students put into their academic experience; this involvement could be academic and social; the more involved a student was, the more successful students were in college. A high cumulative GPA can be regarded as one of the indicators of academic success at a fundamental level. The time and energy that students engaged in their studies and other activities, and the experiences and outcomes that these activities brought, constituted their success; the institutions allocated administrative and other resources and organized learning opportunities and services to encourage students to participate in and to benefit from these activities (Kuh, 2001).

Integration was interpreted as the extent to which students shared the attitudes and beliefs of their peers and teachers and the extent to which students complied with the institution's 
structural rules and requirements and reflected the institution's cultural identity (Tinto, 1993). With the overlap of these three concepts, involvement reflected the individual's psychological and physical levels (Wolf-Wendel et al., 2009). Stage and Hossler (2000) described integration as a prerequisite for participation and engagement: students got comfort and a sense of belonging to the university, and they wanted to be involved.

Kuh $(2001,2003,2009)$ put forward the concept of student engagement, which referred to the time and effort that students put into the activities related to the expected results of the university, and how the university institutions guided students to engage in these activities. Kuh's engagement theory is based on Tinto's (1993) integration theory; Kuh (2007) argued integration was an outcome as students were academically or socially engaged at universities. Tinto's (1993) understanding of the relationship between the three concepts was clearer; he described involvement and engagement as an act and integration as a state or perception of fit. First-year students needed to integrate into the campus environment and gradually realize the importance of student engagement (Kuh, 2007; Tinto, 1999). Therefore, both student involvement and integration were seen as an indicator of a student's success. Mentoring was a high-impact strategy to realize student involvement and integration, which related to student success (Harper \& Quaye, 2015; Jacobi, 1991). In conclusion, academic success and institutional integration can be used as two significant indicators of student success for first-year students.

\section{Student Success for First-Year Students}

In Western countries, universities and colleges tried to build the support necessary to improve retention, academic achievement, and integration experiences in higher education, which were critical components of student success (Lunsford et al., 2017). Students learned differently from different situations, such as student engagement, retention, and holistic 
development (Cuseo, 2007; Kuh, 2007; Tinto, 1999). Mentoring was an extraordinary strategy to employ student engagement related to student success (Harper \& Quaye, 2015; Jacobi, 1991). Student success was a high-frequency term in higher education discourse and usually has referred to developing the outcomes students hope to obtain. Student success included the following five aspects: (a) student retention, (b) educational attainment, (c) academic achievement, (d) student advancement, and (e) holistic development (Cuseo, 2007).

Gardner (2013) modified Tinto’s (1975) integration theory and Astin’s (1993) involvement theory to promote the academic integration of first-year students. Meanwhile, Gardner combined integration theories with involvement theory in FYE courses for student success at a community college in the United States.

For this research, I modified Tinto's (1993) integration theory and Astin's (1993) involvement theory to examine peer mentoring for first-year student success in Mainland China (see Figure 2). I examined student success, including integration and academic performance in FYE courses with peer mentoring. As for the measurement of student success for first-year students, Yomtov et al. (2017) and Moschetti et al. (2018) chose CSPS to examine the integration for first-year student experience. 


\section{Figure 2}

\section{Academic Success Model for First-Year Students in China}
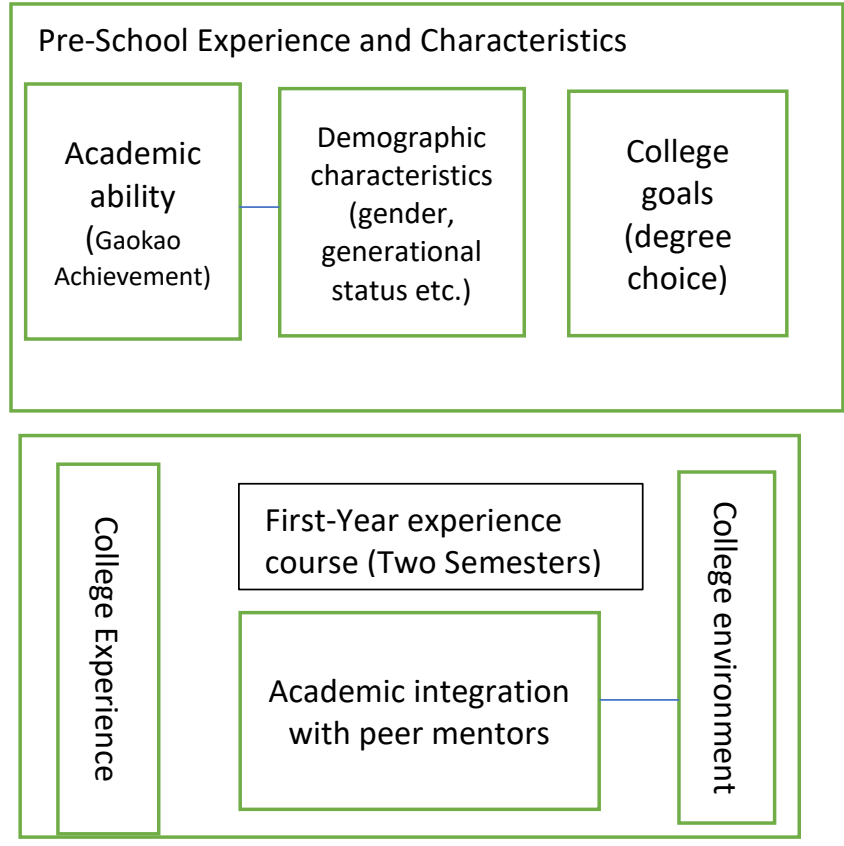

Student outcomes

(academic performance e.g., GPA, retention)

Note. "Predicting community college student success" by A. F. Gardner, 2013, ProQuest LLC, Ed.D. Dissertation, p. 61 (https://libres.uncg.edu/ir/wcu/f/Gardner2013.pdf). Copyright (2021) by Western Carolina University. Reprinted with permission.

\section{Development of FYE}

Based on Tinto's integration theory (1993) and Astin's (1993) involvement theory, U.S. colleges and universities adopted a series of policies to comprehensively and systematically help first-year students (Astin, 1997; Dey \& Astin, 1989). To help first-year students achieve overall success, the FYE program was dedicated to providing systematic assistance to first-year students and sprung up across the United States. FYE programs were an umbrella concept to bridge all 
kinds of resources to support students in the first year of college (Keeling, 2004). The FYE program, including first-year seminar, is a program at many colleges and universities in the United States that has aimed to assist students in the first year's transition by integrating all resources, including faculty, administrators, staff, and peers, for social and academic integration (Saunders \& Romm, 2008). First-year seminar contains extended orientation seminar, academic (uniform content) seminar, academic (variable content) seminar, preprofessional or disciplinelinked seminar, basic study skills seminar, and hybrid seminar.

College students have faced many difficulties in the first year; there has been an urgency to increase retention rates and make a smooth transition, leading to academic attention for retention research in Western countries (Bullen et al., 2010). White et al. (1995) claimed the FYE program should provide students chances to communicate socially with peers and faculty and proposed that students interact with academic advisors, staff, peers, and other faculty. Different kinds of mentor roles existed across higher education institutions, and institutions have had unique programs to help first-year students make a smooth transition (Rieske \& Benjamin, 2015). The FYE program integrated various institutional resources, including peer mentoring in course-based FYE programs to support first-year students in the United States (Young \& Keup, 2016); peer mentors were of the same age as the first-year students and had similar experiences, making it easier to listen to the mentees and provide academic and social support for mentees (Terrion \& Leonard, 2007).

\section{Mentoring Framework}

The development of mentoring can be traced back to the 1970s in the United States (Jacobi, 1991). With the deepening of social needs and empirical research, mentoring research also entered a period of rapid growth; however, scholarly research on mentoring has the 
development of practical programs (Crisp \& Cruz, 2009; Jacobi, 1991). Jacobi (1991) found that it was urgent to form a basic consensus on the conception, role, and theoretical framework of mentoring in the middle and late 20th century. For example, Crisp and Cruz (2009) found over 50 concepts of mentoring in their literature review, but there was a lack of consistent conception and theoretical framework for mentoring research at that time. In the subsequent development of theoretical research, newer theoretical studies appeared and tried to solve the problem of the lack of consistent mentoring conception. In the subsequent development of theoretical research, newer theoretical studies appeared and tried to solve the problem of the lack of consistent mentoring conception.

Mentoring was developed in higher education, business management, and psychology in the 20th century as an effective intervention strategy (Jacobi, 1991). Traditionally, mentoring involved a large status gap between mentors and mentees, such as the relationship between university professors and students in higher education (Budge, 2006). In higher education in Western countries such as the United States and the United Kingdom, mentoring became an important program strongly supported by the government and given priority to development by institutions with great resources (Collings et al., 2014; Crisp et al., 2017). Studies on mentoring in Western countries demonstrated that its main values were reducing the dropout rate of students in colleges and universities and improving retention rates (Budge, 2006; Crisp \& Cruz, 2009).

In the mentoring research of higher education, a consistent concept and a consistent theoretical framework were lacking. Crisp et al. (2017) reviewed the mentoring literature between 2008 and 2015 and divided undergraduate mentoring theory into three basic categories: typology-related frameworks, process-based frameworks, and outcomes-based frameworks. 
Typology-related frameworks developed from studies in the field of business and organizational management. Based on the professional and psychosocial functions of Kram's (1988) mentoring relationship, Crisp and Colleagues (Crisp, 2009; Crisp \& Cruz, 2009; Nora \& Crisp, 2007) had an extension of four-dimension functions: psychological and emotional support, degree and career support, academic subject knowledge support, and existence of a role model, which provided a framework that focuses on the forms of help students receive through mentoring relationships. As for the mentoring process, factors motivating participation between mentor and mentee or identifying how the nature of the interaction was governed needed to be clarified. Some theories aim to capture the stages or stages of relationship development (Hunt \& Michael, 1983; Kram, 1988; Zachary, 2002). Outcomes-based frameworks are an important part and suitable for my research.

Crisp's (2009) conceptual framework was based on Tinto's (1993) theory, and they had the same foundation of the student's perception, which was an essential element for both theories. The framework of Crisp included four dimensions: psychological and emotional support, setting goals and career paths, academic subject knowledge support, and role modeling (Crisp \& Cruz, 2009). Crisp (2009) contributed the addition of the academic support dimension to make a significant theoretical breakthrough in the development of the theoretical framework for mentoring college students.

Mentoring activities have aimed to help students overcome difficulties and achieve holistic development and success in higher education (Crisp, 2009; Jacobi, 1991). Therefore, peer mentoring also provided important resources to facilitate students' academic and social integration. First-year students realized active involvement and integrated into the campus, which formed a good foundation for achieving academic success (Astin, 1984; Tinto, 1993). I 
agree with Crisp's (2010) assumption, “students' perceptions of their mentoring experiences during college would directly influence the degree to which students become socially and academically integrated, which would, in turn, mediate students' commitment to both the institution and to attaining a college degree" (p. 47).

\section{Assessment of Measurement}

Among the numerous mentoring scales, not many are suitable scales for ordinary undergraduates, and those with high reliability and validity are rare. Chen et al. (2016) reviewed 22 measurement scales in the field of mentoring since 1990, of which 11 were in higher education. I analyzed each of those 11 scales and found only four scales for undergraduate students. Among them, only four mentoring scales were suitable for measuring college students. Among the four mentoring college student scales, Crisp's (2009) and Crisp and Cruz's (2010) scales had the highest reliability and validity, which aimed at measuring college students' mentorship and were suitable for measuring peer mentoring of first-year students. From these scales, I chose Crisp's (2009) scale as my final scale to measure peer mentoring in a Chinese FYE program.

\section{Mentoring Definitions and Characteristics}

There was a gradual deepening process for mentoring definitions by researchers. Kram (1985) provided some basic descriptions of mentoring, in which an experienced person was committed to providing developmental support and help to those with less experience from the perspective of career progress. Later, Jacobi (1991) concluded that mentoring had three functions: emotional and psychological support, career guidance, and role modeling. After a review of empirical studies, Crisp and Cruz (2009) summed up four common understandings of mentoring: (a) most studies focus on the growth and development of the students being 
mentored; (b) three types of support exist, including professional, career, and emotional aspects; (c) personal and reciprocal relationships were important; and (d) mentors hold more experience and accomplishments than their mentees. Finally, Crisp et al. (2017) summarized the most basic features of mentoring in five aspects: (a) relationship features, (b) form of relationship, relationship structure, (c) relationship structure, (d) program types, and (e) forms of support. In this study, the following classification of mentoring characteristics was adopted, as shown in Table 1.

\section{Table 1}

Characteristics of Mentoring Relationships

\begin{tabular}{ll}
\hline Characteristic & \multicolumn{1}{c}{ Description/examples } \\
\hline Relationship features & Intent, purpose, intensity, duration \\
Form of relationship & Faculty, staff, graduate students, peers \\
Relationship structure & $\begin{array}{l}\text { One on one, group } \\
\text { Program types }\end{array}$ \\
$\begin{array}{c}\text { Orientation and retention, mentoring programs designed to support targeted } \\
\text { populations, undergraduate research and honors programs } \\
\text { Psychological and emotional support, degree support, career support, } \\
\text { Form of support }\end{array}$ & \begin{tabular}{l} 
academic subject knowledge support \\
\hline
\end{tabular}
\end{tabular}

\section{The Crisp Mentoring Framework}

Crisp and Cruz (2009) completed a critical literature review about mentoring college students. They proposed an operational conceptual framework for mentoring relationships among college students and provided a broad theoretical perspective from the viewpoints of business, psychology, and educational literature. This operational conceptual model was validated in a study of students from Hispanic serving institutions (Crisp \& Cruz, 2010) and community colleges (Crisp, 2009). At the same time, the CSMS (Crisp, 2009) is also widely used in practice. Crisp and Cruz found more than 50 definitions of mentoring; some perceived 
mentoring as an activity and others as a concept or process. Crisp and Cruz paid attention to the function of mentoring. Compared to the contribution from Jacobi (1991), Crisp and Cruz's (2009) conceptual framework added a new dimension of academic achievement for mentoring college students, which is suitable for studying the relationship between college student mentoring and academic success. Crisp and Cruz argued mentoring experiences included a wide range of forms of support, including help with professional and career development, role modeling, and psychological support. Subsequently, they reframed the concept of mentoring, conceptualized the mentoring relationships, and formed a specific conceptual framework.

I chose Crisp et al.'s (2017) latest mentoring framework, including the five basic aspects of educational context, student characteristics, relationship features, forms of support, and impact on students' outcomes, to form a dynamic model. The details of this model were shown in Crisp et al.’s (2017) conceptual framework, based on Crisp's (2009) framework, including four dimensions: (a) psychological and emotional support, (b) setting goals and career paths, (c) academic subject knowledge support, and (d) role modeling. In the conceptual mentoring model I used, a prominent feature was that educational context influenced the types of support provided by mentoring. At the same time, the characteristics of the mentored students also affected the type of mentoring support (Crisp et al., 2017). As the infrastructure and dosage were common and unique elements of mentoring programs (Karcher et al., 2006), the relationship feature of intent, purpose, intensity, and duration should be discussed in detail.

Compared with instrumental mentoring, developmental mentoring relationships promoted student growth by providing emotional and academic development creative activities (Karcher et al., 2006). In Crisp et al.'s (2017) conceptual model (see Figure 3), relationship features and support forms were combined to the category of developmental relationship that was transformed 
into a platform to receive support and help. Although the research focus was on the availability of mentoring to students, this framework emphasized the differentiation of mentoring relationships from one another by the forms of support provided in the context of relationships and relationship characteristics; furthermore, relational functions and characteristics ultimately contributed to student mentoring outcomes (Crisp et al., 2017).

The conceptual model assumed different types and forms of support intersected and had different effects for undergraduates (Crisp et al., 2017). The effects and outcomes of mentoring support were assumed to be conditionally dependent on characteristics of the mentoring relationship. This model assumed that mentoring relationships had a direct, positive impact on a variety of student outcomes, such as academic achievement (e.g., GPA), and also had an indirect influence through their relationships to intermediate outcomes, which were defined as the experience of involvement and integration, and so on (Crisp et al., 2017). 


\section{Figure 3}

\section{Mentoring Undergraduate Students}

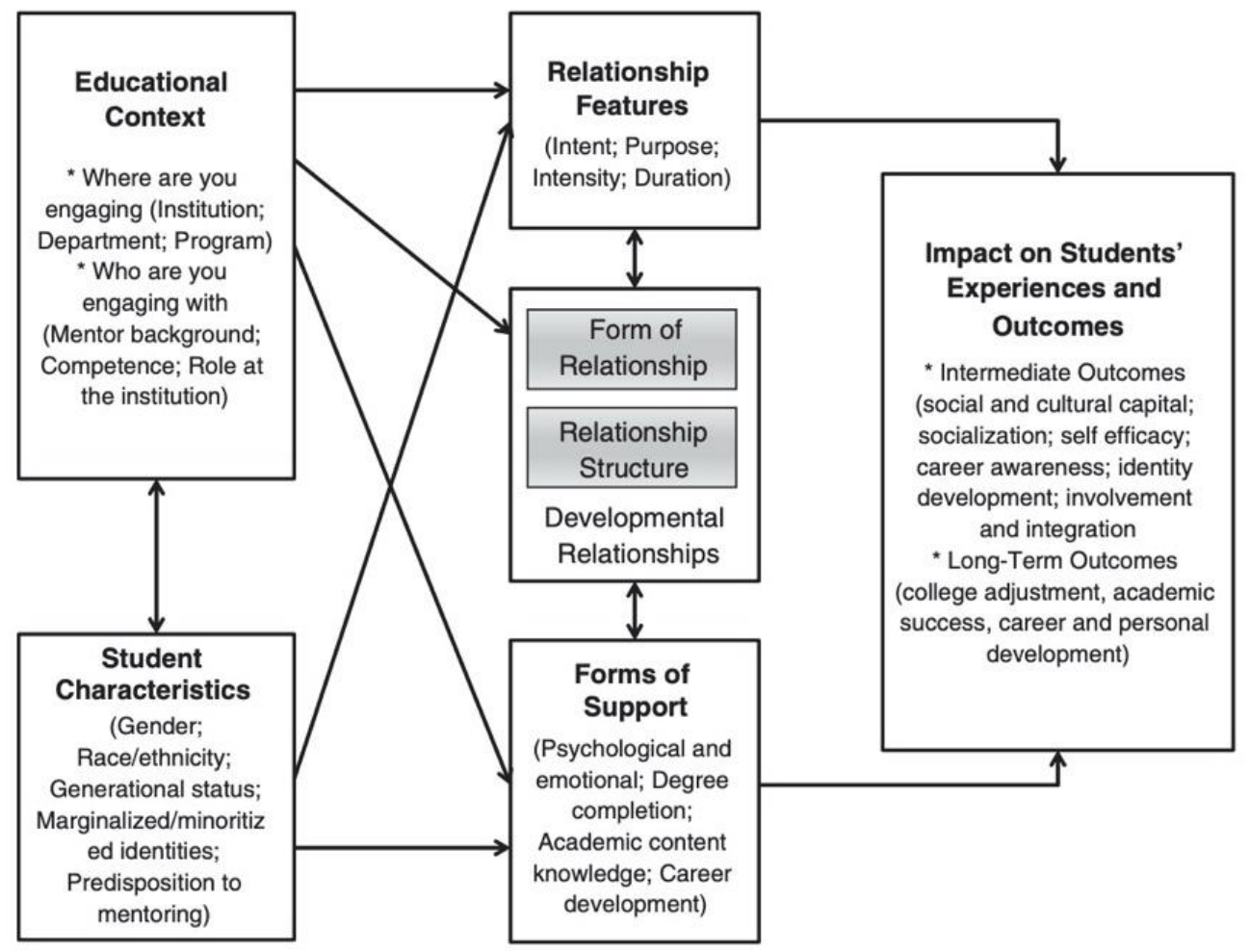

Note. From "Mentoring Undergraduate Students," by G. Crisp, V. L. Baker, K. A. Griffin, L. G. Lunsford, and M. J. Pifer, 2017, ASHE Higher Education Report, 43, p. 81. (https://doi.org/10.1002/aehe.20117). Copyright (2021) by John Wiley Sons. Reprinted with permission.

\section{Studies on Peer Mentoring}

Peer mentoring occurring between persons of similar age is nontraditional mentoring, which was seen as a strategy and helped struggling students adapt to campus and improve their success in college (Budge, 2006; Kram, 1983; Terrion \& Leonard, 2007). Peer mentoring refers to the guidance and help given to first-year students by senior students of similar ages and experiences, usually in similar majors at university (Crisp et al., 2017). Traditionally in higher 
education, mentoring was mainly applied to graduate education; when the attrition rate of students increased, universities began to adopt mentoring to improve students' academic success to cope with the challenge (Budge, 2006; Jacobi, 1991). Peer mentoring was closely related to the FYE program for incoming undergraduates.

\section{Popularity of Peer Mentoring}

Gershenfeld (2014) pointed out peer mentoring became popular among colleges and universities; it was significant to research peer mentoring to improve student success and examine the effectiveness of peer mentoring. Astin (1993) found peers were the most powerful source of influence, affecting almost every aspect of development, including cognitive, emotional, psychological, and behavioral aspects. Peer mentoring was popular because it was considered a strategy to help struggling students adapt to campus and improve their success in college (Kram, 1983; Terrion \& Leonard, 2007; Yomtov et al., 2017). However, the growing attraction of choosing college students as peer mentors seemed to ignore the importance of age differences between mentors and students (Vaidya et al., 2002).

Peer interaction is critical for the social integration of college students; when first-year students feel a clear connection with other students with similar interests and aspirations, they develop a sense of belonging and are more likely to stay in college in their first year (Tinto, 1975, 1987). Peer mentoring activities in the first year of college gave students a sense of comfort and connection; in this process, the learning enthusiasm of first-year students was likely to be fully stimulated, which made it easier for students to retain in higher education (Kuh et al., 2006).

In short, peer mentoring is one of the most important resources for students' holistic growth and success in the first year of college. For colleges and universities, peer mentoring is 
the resource with the lowest cost and easier to recruit in large quantities for student success. In terms of educational context, faculty or staff as mentors had more advantages than peers in a general sense (Crisp et al., 2017); however, with peer mentoring for first-year students in transition, the mentor's peer status may have an advantage over other members at college.

\section{Peer Mentoring for First-Year Students}

Crisp et al. (2017) contextualized four types of undergraduate mentoring programs, of which the orientation and retention programs and peer mentoring programs were distinctive. The goals of these orientation and retention programs to overcome the adjustment difficulties in the first year of university and achieve a smooth transition to college life; peer mentoring was used to achieve an academic or professional goal. Peer mentoring for first-year students is where the two programs overlap; that is, peer mentoring has been used to complete students' orientation and help retain students (Crisp et al., 2017).

Some peer mentoring programs were open to all first-year students, while others were open only to first-generation, low-income, or minority students (Hurtado et al., 2008). At the same time, peer mentoring has also been recommended by the National Collegiate Honors Council (n.d.) of the United States as an independent mechanism to help first-year students. Formally, some peer mentoring was one-on-one for first-year students, and some were group mentoring; some were in the FYE classroom, and another was in the living-learning community. After the analysis, I decided to use the mentoring undergraduate students' framework (Crisp et al., 2017). As students, as a key, were helpful to the success of first-year students, I further examined whether peer mentoring was effective in the success of first-year students and did a systematic review. 


\section{Relevant Empirical Studies in Western Countries}

Literature on peer mentoring for first-year college students in both Western and Chinese cultures were included in the review. In Western culture, the research on peer mentoring firstyear students was mature and abundant. Although there were differences in the languages used in different national contexts, research on peer mentoring in the United Kingdom, Australia, and Canada is consistent with research focused on the United States (Lunsford et al., 2017). However, the study of peer mentoring is still relativity recent in China, and it is necessary to carry out empirical research with rigorous research methods in the country. This literature review focused on the exploration of peer mentoring on undergraduate students' success in Mainland China compared with the literature in Western countries.

I used the research achievements of peer mentoring in Western countries to guide the literature review in the Chinese context because mentoring became a national strategy for solving the retention crisis in the United States, United Kingdom, and Australia, and peer mentoring has been widely used in higher education. Mentoring originated in the United Kingdom and in the United States and was prevalent in institutions in Western countries. In addition, this study applied the mature mentoring research in Western countries to Mainland China, so the Chinese literature from Mainland China was also studied.

Empirical papers from 2008 to 2019 demonstrate a consensus in mentoring research in Western countries. Peer mentoring based on a comprehensive educational context (e.g., FYE programs) became a trend. In methodology, researchers increasingly used these correlation research designs. In terms of group selection, different characteristic groups were considered by the mentoring program, such as gender, first-generation status, and students in FYE programs. Crisp and Cruz's (2009) conceptual framework was a favorite theoretical framework. The review 
found that the mentoring research on first-year students mainly focused on the functions of psychological and emotional support (PES) and academic and knowledge support (AKS). In terms of mentoring outcomes, a student success development trend with retention, academic success, and integration as the main components was formed.

Studies mainly come from three Western countries: United States, United Kingdom, and Australia, each accounting for nearly a third; only one article was from Canada. For example, in the United States, the researchers focused more on academic success and group mentoring in FYE programs. In contrast, in the United Kingdom, researchers paid more attention to students' overall integration and well-being.

In the literature of Western countries, the studies of Dennehy and Dasgupta (2017) and Yomtov et al. (2017) used quantitative data, and the effectiveness level was very high according to Gershenfeld's (2014) effectiveness standard. Dennehy and Dasgupta (2017) chose rigorously tested interventions using random sampling and found female peer mentors early in college increased women's positive academic experience. Yomtov et al. (2017) used a quasiexperimental design to confirm peer mentors improved first-year experiences of university students. Colvin and Ashman (2010) used data triangulation method to validate qualitative data and give the results a higher validity. The effectiveness of peer mentoring is a hot topic in higher education, and evidence-based mentoring research is critical. As mentioned by Gershenfeld (2014), such themes were rarely covered in literature reviews, especially the effectiveness of peer mentoring for first-year college students. I think this gap is in literature reviews for mentoring first-year students in Western countries.

As two high-quality reviews by Jacobi (1991) and Crisp and Cruz (2009) before 2007, this study included 20 empirical papers on the topic of peer mentoring and student success in the 
field of higher education, of which two were dissertation papers and the others were all peerreviewed studies since 2008. As mentioned earlier, Crisp et al. (2017) provided an understanding way of mentoring undergraduate students. This paper reviewed the literature from five perspectives of Crisp et al.'s (2017) mentoring model categories: (a) educational context, (b) student characteristics, (c) relationship features, (d) forms of support, and (e) mentoring outcomes.

In terms of institutional context, 12 studies in this review focused on peer mentoring in the context of specific disciplines: two studies of education majors, five studies of science, technology, engineering, and math (STEM) majors, and five studies of business majors (Chester et al., 2013; Dos Reis \& Yu, 2018; Heirdsfield et al., 2008). Collings et al. (2014, 2015) researched peer mentoring at the institutional level, and participation was mandatory for all firstyear students. Sparks (2017) and Yomtov et al. (2017) focused their research on mentoring at the institutional level for students with high risks of attrition, such as minority students, firstgeneration college students, and so on. Five articles focused on peer mentoring in the specific environment of the FYE classroom (Budny et al., 2010; Colvin \& Ashman, 2010; Moschetti et al., 2018; Robinson, 2018; Yomtov et al., 2017).

Peer mentors in 20 studies involved in Western countries with student peers in the 2nd, 3rd, or 4th years of undergraduate study. In contrast, Henry et al.'s (2011) study chose graduate students as peer mentors in a course-embedded mentoring program. The educational context is a fundamental factor for studying peer mentoring programs. Therefore, in terms of peer mentors' context for first-year students, it was considered mainstream to recruit undergraduates of the same age and similar majors to serve as peer mentors. 


\section{Student Characteristics of Interest}

According to Tinto's (1993) integration theory, the different demographic characteristics and the different backgrounds for first-year students before entering the university have an impact on students' university integration. Characteristics of the mentored student groups I was interested in fell into four categories: seven (33\%) studies from orientation and retention programs are covered by all first-year students; three (14\%) studies are from special groups (e.g., STEM) mentoring programs; four (19\%) studies from female, first-generation, and other underrepresented groups mentoring programs; seven (33\%) studies from other disciplinespecified group mentoring programs. The other discipline-specified group included kinds of majors similar to STEM majors with difficulties learning.

In the second half of the 20th century, mentoring research in higher education often focused on gender factors (Budge, 2006). I considered female groups because the traditional ones focused on male students in research. Traditional mentoring has paid more attention to male students, and there is insufficient practice and research on underrepresented groups, such as female students in higher education (Jacobi, 1991). Campbell and Campbell (1997) found no obvious difference in correlation between faculty mentoring and GPA in gender groups. Dennehy and Dasgupta (2017) found positive outcomes in peer mentoring for women in engineering in their first year of college. Another qualitative study on peer mentoring for engineering students found positive effects (Lim et al., 2017).

Robinson (2018) and Sparks (2017) regarded peer mentoring experienced by firstgeneration students as an indicator of success at college in empirical studies. Moschetti et al. (2018) pointed out that peer mentoring was important social capital for Latinx college students at 
a Hispanic serving institution, as first-generation college students need additional attention. Therefore, research on peer mentoring for first-generation students is also valuable.

There has been a great demand for peer mentoring in higher education because some majors were difficult to learn. For education majors, O'Brien et al. (2012) focused on the relationship between peer mentoring and satisfactory academic experience. Heirdsfield et al. (2008) found peer mentoring promoted positive social and academic outcomes in longitudinal perspectives. Peer mentoring enhanced business majors' academic performances widely for firstyear students (Dos Reis \& Yu, 2018; Fox et al., 2010; Gunn et al., 2017). In addition, peer mentoring can help first-year students of psychology, midwifery, and pharmacy successfully transition in the first year of university (Chester et al., 2013; Etzel et al., 2018; Hogan et al., 2017). Students in STEM majors often need special help as they struggle academically and achieved college success (Budny et al., 2010; Dennehy \& Dasgupta, 2017; Lim et al., 2017).

In the United Kingdom, all the first-year students were involved in peer mentoring programs (Phillips et al., 2004). In this context, the mentoring program is accessible to every first-year student for a successful transition (Collings et al., 2014, 2015). In 20 studies of peer mentoring in Western countries, four types of interest populations were found.

\section{Relationship Features}

Since Crisp et al.'s (2017) mentoring framework is the foundation in my study, program types, including orientation programs, retention programs, and undergraduate research programs, were chosen. Because Tinto's (1993) integration attached great importance to the learning and living experience of students in the first year of college, the duration of peer mentoring programs for first-year students are typically between 6 weeks and a year. Gershenfeld (2014) claimed the research on mentoring always lacked one dimension, namely the description of the key 
operational characteristics of peer mentoring programs. Due to peer mentoring programs' different intentions and purposes, there were differences in intensity and duration; researchers often overlooked such characteristics (Crisp et al., 2017). Among selected mentoring program elements, I found three important aspects: ratio, frequency or duration, and mandatory or voluntary (Crisp et al., 2017; Gershenfeld, 2014; see Table 2). Combined with previous participants and functions, I used these three aspects to analyze the operational characteristics of the program in a subsequent review. Peer mentoring took place once a week in line with the course. The orientation program lasted about 8 weeks, and the FYE program lasted about a semester (14-16 weeks).

Table 2

Relationship Features in Western Countries

\begin{tabular}{|c|c|c|c|c|c|}
\hline Author (year) & Program type & Ratio & $\begin{array}{l}\text { Frequency } \\
\text { /duration }\end{array}$ & $\begin{array}{l}\text { Mandatory } \\
\text { /voluntary }\end{array}$ & Country \\
\hline $\begin{array}{l}\text { Heirdsfield et al. } \\
\text { (2008) }\end{array}$ & $\begin{array}{c}\text { Orientation } \\
\text { program }\end{array}$ & $1: 5$ & 6 weeks & Mandatory & Australia \\
\hline $\begin{array}{l}\text { Budny et al. } \\
\text { (2010) }\end{array}$ & $\begin{array}{c}\text { Orientation } \\
\text { program (course) }\end{array}$ & $\begin{array}{l}\text { group } \\
1: 10-15\end{array}$ & 8 weeks & Mandatory & U.S. \\
\hline $\begin{array}{l}\text { Colvin \& Ashman } \\
\text { (2010) }\end{array}$ & $\begin{array}{l}\text { Retention program } \\
\text { (course) }\end{array}$ & $\begin{array}{l}\text { group } \\
1: 37\end{array}$ & $\begin{array}{c}1 \text { semester (14 } \\
\text { weeks) }\end{array}$ & Voluntary & U.S. \\
\hline Fox et al. (2010) & $\begin{array}{l}\text { Undergraduate } \\
\text { research program }\end{array}$ & $\begin{array}{l}\text { group } \\
2: 6\end{array}$ & 8 weeks & Voluntary & U.K. \\
\hline $\begin{array}{l}\text { Henry et al., } \\
\text { (2011) }\end{array}$ & $\begin{array}{l}\text { Retention program } \\
\text { (course) }\end{array}$ & $\begin{array}{l}\text { group } \\
1: 19\end{array}$ & $\begin{array}{c}1 \text { semester (14 } \\
\text { weeks) }\end{array}$ & Voluntary & U.S. \\
\hline $\begin{array}{l}\text { O'Brien et al. } \\
\text { (2012) }\end{array}$ & $\begin{array}{c}\text { Orientation } \\
\text { program }\end{array}$ & $\begin{array}{l}\text { group } \\
1: 5-6\end{array}$ & 6 weeks & Voluntary & Australia \\
\hline $\begin{array}{l}\text { Chester et al. } \\
\text { (2013) }\end{array}$ & $\begin{array}{l}\text { Undergraduate } \\
\text { research program } \\
\text { (course) }\end{array}$ & $\begin{array}{l}\text { group } \\
1: 5-8\end{array}$ & 6 weeks & Voluntary & Australia \\
\hline $\begin{array}{l}\text { Collings et al. } \\
\text { (2014) }\end{array}$ & Retention program & $1: 1$ & $\begin{array}{c}10 \text { weeks (an } \\
\text { hour per week) }\end{array}$ & Mandatory & U.K. \\
\hline $\begin{array}{l}\text { Collings et al. } \\
\text { (2015) }\end{array}$ & Retention program & $1: 1$ & $\begin{array}{l}10 \text { weeks (an } \\
\text { hour per week) }\end{array}$ & Mandatory & U.K. \\
\hline $\begin{array}{l}\text { Cornelius et al. } \\
\text { (2016) }\end{array}$ & $\begin{array}{l}\text { Undergraduate } \\
\text { research program }\end{array}$ & $\begin{array}{l}\text { group } \\
1: 5\end{array}$ & 12 weeks & Voluntary & Australia \\
\hline
\end{tabular}




\begin{tabular}{|c|c|c|c|c|c|}
\hline Author (year) & Program type & Ratio & $\begin{array}{l}\text { Frequency } \\
\text { /duration }\end{array}$ & $\begin{array}{l}\text { Mandatory } \\
\text { /voluntary }\end{array}$ & Country \\
\hline $\begin{array}{l}\text { Dennehy \& } \\
\text { Dasgupta (2017) }\end{array}$ & $\begin{array}{l}\text { Underrepresented } \\
\text { population program }\end{array}$ & $1: 1$ & 1 year & Mandatory & U.S. \\
\hline Gunn et al. (2017) & $\begin{array}{l}\text { Retention program } \\
\text { (course) }\end{array}$ & $\begin{array}{l}\text { group } \\
1: 8-10\end{array}$ & $\begin{array}{c}1 \text { semester (14 } \\
\text { weeks) }\end{array}$ & Mandatory & Canada \\
\hline $\begin{array}{l}\text { Hogan et al. } \\
\text { (2017) }\end{array}$ & $\begin{array}{c}\text { Undergraduate } \\
\text { research program }\end{array}$ & $1: 3$ & I & Voluntary & Australia \\
\hline Lim et al. (2017) & $\begin{array}{l}\text { Undergraduate } \\
\text { research program }\end{array}$ & $\begin{array}{l}\text { group } \\
2: 2\end{array}$ & I & Voluntary & U.S. \\
\hline Sparks (2017) & $\begin{array}{l}\text { Underrepresented } \\
\text { population program } \\
\text { (course) }\end{array}$ & I & $\begin{array}{c}1 \text { semester (14 } \\
\text { weeks) }\end{array}$ & Voluntary & U.S. \\
\hline $\begin{array}{l}\text { Yomtov et al. } \\
\text { (2017) }\end{array}$ & $\begin{array}{l}\text { Retention program } \\
\text { (course) }\end{array}$ & $\begin{array}{c}\text { group } \\
2: 20-25\end{array}$ & $\begin{array}{c}1 \text { semester (14 } \\
\text { weeks) }\end{array}$ & Voluntary & U.S. \\
\hline $\begin{array}{l}\text { Dos Reis \& Yu } \\
\quad(2018)\end{array}$ & $\begin{array}{l}\text { Undergraduate } \\
\text { research program } \\
\text { (course) }\end{array}$ & $1: 3$ & $\begin{array}{c}1 \text { semester (14 } \\
\text { weeks) }\end{array}$ & Voluntary & $\begin{array}{l}\text { South } \\
\text { Africa }\end{array}$ \\
\hline Etzel et al. (2018) & $\begin{array}{l}\text { Undergraduate } \\
\text { research program }\end{array}$ & $\begin{array}{l}\text { group } \\
1: 3-4\end{array}$ & 6 months & Voluntary & U.S. \\
\hline $\begin{array}{l}\text { Moschetti et al. } \\
\text { (2018) }\end{array}$ & $\begin{array}{l}\text { Underrepresented } \\
\text { population program } \\
\text { (course) }\end{array}$ & $\begin{array}{c}\text { group } \\
2: 20-25\end{array}$ & $\begin{array}{c}1 \text { semester (14 } \\
\text { weeks) }\end{array}$ & Voluntary & U.S. \\
\hline Robinson (2018) & $\begin{array}{l}\text { Retention program } \\
\text { (course) }\end{array}$ & $\begin{array}{l}\text { group } \\
1: 25-30\end{array}$ & $\begin{array}{c}1 \text { semester (14 } \\
\text { weeks) }\end{array}$ & Voluntary & U.S. \\
\hline
\end{tabular}

In the literature of Western countries, I reviewed a total of 20 empirical articles on peer mentoring, 10 of which belonged to orientation and retention programs, accounting for $50 \%$ of the total literature of Western countries; and six of the studies were course-based peer mentoring programs (Budny et al., 2010; Collings et al., 2014, 2015; Colvin \& Ashman, 2010; Henry et al., 2011; O'Brien et al., 2012). There were three underrepresented population programs, two of which were course-based peer mentoring (Moschetti et al., 2018; Sparks, 2017).

There were seven underrepresented population programs, five of which were coursebased peer mentoring (Moschetti et al., 2018; Sparks, 2017). In general, 70\% of the Western literature I reviewed adopted group mentoring; in addition, 10 studies used course-based group mentoring, which accounted for $50 \%$ of the studies from Western countries I reviewed. 
Researchers often questioned the effectiveness of peer mentoring, and under the guidance of faculty or staff, the reliability of course-based peer mentoring improved greatly. Mentoring could enhance the ability to learn experience and wisdom from others; group mentoring, which drew greater wisdom from more people, should be a higher priority (Huizing, 2012). Near-peer mentoring meant the program had first-year students as the primary mentees, and mentors must be near-peer (i.e., 2nd-year students) but not limited to them (Akinla et al., 2018). Near-peer mentoring was of great significance to the retention of college students; $90 \%$ of the studies in my Western countries' literature were near-peer mentoring in higher education.

In the orientation and retention peer mentoring program, the situation of relationship features was different from those of the United States and the United Kingdom. In the United States, most peer mentoring programs were built into the orientation course or FYE course with 1:10-15 ratio (Budny et al., 2010; Colvin \& Ashman, 2010; Heirdsfield et al., 2008; Henry et al., 2011; Moschetti et al., 2018; Yomtov et al., 2017).

Among the 20 studies in Western countries, only three studies selected participants to collect data from mentors and mentees (Fox et al., 2010; Gunn et al., 2017; Lim et al., 2017). The remaining 16 studies collected data from the mentees. Colvin and Ashman (2010) and Gunn et al. (2017) chose to analyze the benefits and challenges in peer mentoring from the perspectives of mentors and mentees. Lim et al. (2017) discussed peer mentoring (un)shared experiences in engineering majors in a qualitative study.

In the course-based FYE programs, peer mentoring was 3-4 months with about 12-14 opportunities to meet in class (Colvin \& Ashman, 2010; Moschetti et al., 2018; Yomtov et al., 2017). On the other hand, peer mentoring in the orientation programs usually lasted 4-6 weeks (Budny et al., 2010; O'Brien et al., 2012). Mentoring in specific disciplines was maintained once 
a week, and the mentoring relationship generally lasted from 1 semester to 1 year (Chester et al., 2013; Dos Reis \& Yu, 2018; Etzel et al., 2018; Gunn et al., 2017).

The ratio between mentor and mentee was also one of the indicators of close contact. In most first-year student programs in the United States, peer mentoring was curricular and guided in the classroom; generally speaking, the ratio of mentor-to-mentee has been about 1:15-20 on average (Budny et al., 2010; Colvin \& Ashman, 2010; Moschetti et al., 2018; Yomtov et al., 2017). In the tradition of peer mentoring in the United Kingdom, the proportion of mentors and mentees in the two studies was basically 1:1 (Collings et al., 2014, 2015). In Australia and South Africa, under the influence of the British tradition, the proportion of mentors and mentees is around 1:3 (Dos Reis \& Yu, 2018; Hogan et al., 2017). In general, the proportion of traditional peer mentoring and mentees in the United Kingdom was mostly low, and the proportion of traditional peer mentoring and mentees in the United States was mostly high.

Whether first-year students' participation in peer mentoring programs was voluntary or mandatory depended largely on the country of the program and the specific institutional context. In two studies in the United Kingdom and one in Australia, participation was mandatory for the entire school or first-year students in a major (Chester et al., 2013; Collings et al., 2014, 2015). However, in U.S. colleges and universities, most programs were voluntary, except for some STEM peer mentoring programs (Budny et al., 2010; Dennehy \& Dasgupta, 2017).

\section{Forms of Support}

As the mentoring framework of Crisp et al. (2017) was based on four functions: psychological and emotional support, academic subject knowledge support, degree and career support, and the existence of a role model, I analyzed the literature according to the functions of mentoring in this section. Four basic functions from Crisp et al.'s (2017) mentoring framework 
constituted the premise and basis for analyzing the form of support. The scope of the literature selected in this review was the empirical research on peer mentoring of first-year college students in Western countries. The main purpose of the section is to study the retention crisis in the first year of college and to consider effective strategies for students' transition.

The forms of support were an important link between the educational context, student characters, and mentoring outcomes in Crisp et al.'s (2017) mentoring framework. The mentoring functions of FYE and the first-year transition programs were focused on psychological and emotional support and academic subject knowledge support. In terms of the function of mentoring programs, most studies support that mentoring had psychological and emotional support functions (Chester et al., 2013; Collings et al., 2014; Colvin \& Ashman, 2010; Dennehy \& Dasgupta, 2017; Etzel et al., 2018; Gunn et al., 2017; Hogan et al., 2017; Lim et al., 2017; Moschetti et al., 2018; O’Brien et al., 2012).

Collings et al. (2014, 2015) adopted a controlled comparative evaluation and a longitudinal study to reveal the function of psychological and emotional support for peer mentoring. Yomtov et al. (2017) and Moschetti et al. (2018) confirmed course-based FYE programs could help students realize smooth transitions in college from a psychological and emotional support perspective. O'Brien et al. (2012) found peer mentoring for first-year students in a tiered group program in education majors had the functions of psychological and emotional support, academic subject knowledge support, and role models.

Six peer mentoring studies focused on academic subject knowledge support function (Chester et al., 2013; Dos Reis \& Yu, 2018; Etzel et al., 2018; Fox et al., 2010; Henry et al., 2011; Sparks, 2017). Dos Reis and Yu (2018) and Fox et al. (2010) directly focused on the positive impact of peer mentoring on academic success. Chester et al. (2013), Sparks (2017), and 
Budny et al. (2010) provided academic subject knowledge support for first-year students while promoting FYE programs based on psychological and emotional support functions.

Finally, the mentoring function of degree and career support was only mentioned in two studies for first-year students in this review (Etzel et al., 2018; Hogan et al., 2017). The mentoring function of the existence of a role model was found in three studies (Colvin \& Ashman, 2010; Dennehy \& Dasgupta, 2017; Gunn et al., 2017). Each mentoring program simultaneously generated multiple forms of support, which was closely related to mentoring outcomes (Crisp et al., 2017). Therefore, the associativity of its mentoring function could be found in the following mentoring outcomes.

\section{Mentoring Outcomes}

According to Tinto's (1993) theory, the engaged college experience contributed to firstyear students' institutional integration, and student integration could be one of the indicators of student success at college. Based on Crisp et al.’s (2017) mentoring framework, different educational contexts and support forms of functions in different peer mentoring programs produced different outcomes accordingly. Guided by Crisp et al.'s (2017) mentoring theory, mentoring became a development and retention strategy for undergraduates, student integration is one of the intermediate outcomes that influence student success; academic success (i.e., GPA) is the long-term outcomes of mentoring that influence students' success. Studies showed that mentoring efforts were positively correlated with various developmental and academic outcomes (Crisp et al., 2017). The goal of peer mentoring was to promote the growth of first-year students and provide assistance for their development in higher education (Crisp \& Cruz, 2009).

In this review, I categorized mentoring outcomes found mainly in two aspects using Crisp et al.'s (2017) framework: (a) retention and integration and (b) academic achievement and 
integration. First, eight empirical studies examined the positive effects of peer mentoring on first-year student experience through quantitative data, and positive experience at university was an important predictor of student success in the first year (Chester et al., 2013; Collings et al., 2014, 2015; Heirdsfield et al., 2008; Lim et al., 2017; Robinson, 2018; Yomtov et al., 2017). Collings et al. $(2014,2015)$ found peer mentoring was an effective strategy to attain student well-being, integration, and retention in the first year by program evaluation and longitudinal study.

Retention and integration for first-year students on campuses were essential aspects of student success in their first year. Moschetti et al. (2018) and Hogan et al. (2017) found that peer mentoring had a significant benefit on developmental adaption and academic integration in the first year. Moschetti et al. (2018) and Yomtov et al. (2017) studied peer mentoring in the FYE program to promote first-year students' academic integration and social integration.

Some positive experiences were an important predictor of academic and social integration in quantitative research (Collings et al., 2014, 2015; O'Brien et al., 2012; Robinson, 2018; Yomtov et al., 2017). For underrepresented student groups’ programs, Dennehy and Dasgupta (2017) found a positive relationship between peer mentoring support and academic achievements for female mentees. Moschetti et al. (2018) contended peer mentoring had a positive impact on first-generation students' integration as social capital.

In qualitative studies, Henry et al. (2011) found the outcome of psychological and emotional support and academic knowledge was very prominent, but challenges were also mentioned (Colvin \& Ashman, 2010; Heirdsfield et al., 2008). Heirdsfield et al. (2008) found peer mentoring produced positive outcomes (i.e., sense of belonging and smooth transition), only in the context of the university education system and under the conditions of administrative 
support. Colvin and Ashman (2010) argued the communication distance between peer mentors and students was difficult to grasp; there are two extreme cases where peer mentors might not be accepted by mentees or mentees might be too dependent on mentors. When peer mentors were overinvolved, FYE instructors and students might resist peer mentors.

Subsequently, among the 20 pieces of Western literature in English, results of five showed peer mentoring activities were positively correlated with academic achievement (Budny et al., 2010; Chester et al., 2013; Cornelius et al., 2016; Dos Reis \& Yu, 2018; Fox et al., 2010). Academic achievement was a traditional and fundamental indicator of student success. Nearly $30 \%$ of the studies focused on academic success directly. Some studies were on the relationship between peer mentoring and GPA (Budny et al., 2010; Dennehy \& Dasgupta, 2017) or academic performance (Dos Reis \& Yu, 2018; Fox et al., 2010). Other literature revealed the relationship between peer mentoring and academic support (Chester et al., 2013; Etzel et al., 2018; Moschetti et al., 2018). In colleges and universities, academic success represented by GPA has been the basic goal pursued by peer mentoring (Budny et al., 2010; Dennehy \& Dasgupta, 2017). In fact, for the experience of first-year students, academic integration on campus and social integration supported each other, and students' social integration also indirectly supported academic integration. I used institutional integration and GPA as dependent variables in the dissertation research.

\section{Methodology}

Theoretical framework is an important premise and basis for scale selection. Crisp et al.'s (2017) mentoring framework is related to Crisp's (2009) mentoring scale. In the 20 studies that I reviewed, Crisp's (2009) mentoring scale was chosen for three studies (Gunn et al., 2017; Robinson, 2018; Sparks, 2017). 
Among the 20 studies in Western countries, there were five features in their research methods. First, this review included nine correlation research studies that measured the relationship between peer mentoring and student success. Three studies examined the effectiveness of peer mentoring. Three studies focused on evaluating peer mentoring programs, also using correlation studies; three of the studies used longitudinal studies, and five of the studies used primarily qualitative data. Qualitative data were collected from six studies (Colvin \& Ashman, 2010; Cornelius et al., 2016; Heirdsfield et al., 2008; Henry et al., 2011; Hogan et al., 2017; Lim et al., 2017). Heirdsfield et al. (2008) collected qualitative and quantitative data for 3 consecutive years to analyze the positive impact of peer mentoring on first-year students. Colvin and Ashman (2010) used data triangulation from observations, reflection journals, and interviews to explore peer mentoring roles and benefits. They found peer mentors were connecting links, peer leaders, learning coaches, student advocates, and trusted friends. Cornelius et al. (2016) discussed the importance of the matching process for positive transition with peer mentors. Hogan et al. (2017) collected qualitative and quantitative data from mentees and mentors to understand mentoring for first-year midwifery students. Henry et al. (2011) to examined Nora and Crisp's (2007) mentoring framework of four constructs and found a new construct: the mentee's predisposition. Overall, the six qualitative analysis studies lay a solid foundation for the effectiveness of peer mentoring for first-year students in Western countries. Correlation research methods were widely used in studies of peer mentoring on student success. Robinson (2018) examined the relationship between first-year students' perceptions of being mentored and their success with a correlation study. Sparks (2017) investigated whether perceptions of peer mentoring can act as predictors for student success. Regarding other research methods, both first-year students' and juniors' mentors were studied with a semi-experimental 
method, and both were controlled (Fox et al., 2010). The sample size of this study was too small, which seriously affected validity. Yomtov et al. (2017) employed a quasi-experimental design to investigate the first-year experiences from peer mentoring programs in the United States. Moschetti et al. (2018) studied peer mentoring for first-year Hispanic students over a 3-year period. The sample sizes of these two studies were large enough to make the methods more valid.

Collings et al. (2014) evaluated peer mentoring levels of student well-being, integration, and retention in the United Kingdom. Moschetti et al. (2018) and O'Brien et al. (2012) evaluated peer mentoring for first-year transition, retention, and academic success in Australia. Moschetti et al. (2018) evaluated peer mentoring as social capital in the United States. In all three evaluations, peer mentoring programs had a positive effect on student success. Collings et al. (2015) chose a longitudinal method to evaluate a peer mentoring scheme in the first semester and examined first-year students' satisfaction, integration, and well-being.

Meanwhile, self-reported methods have been widely used in peer mentoring studies, which are suitable for investigating new student experiences (Chester et al., 2013; Moschetti et al., 2018; Yomtov et al., 2017). Etzel et al. (2018) found a postprogram survey was also a useful survey method because the assessments could be more objective after completing the program. Researchers tended to use self-report to test perceived peer mentoring for first-year students to understand the impact of peer mentoring on college students' success. Regarding selection of a mentoring scale, CSMS and Crisp's (2009) mentoring framework were the preferred choice of researchers (Gunn et al., 2017; Robinson, 2018; Sparks, 2017). Student success of integration was examined by the College Student Perception Scale (CSPS) for first-year students (Moschetti et al., 2018; Yomtov et al., 2017). 


\section{Literature Review in Mainland China}

As peer mentoring programs in Western countries were introduced into China in the past 20 years, the research on peer mentoring in the whole academic community in Mainland China is relatively delayed. Cao (2014) reviewed all articles about peer mentoring and peer mentoring programs in higher education from 2000-2013 and divided them into three broad categories: student affairs, mentoring, and others. Cao (2014) categorized peer education into four groups: peer mentoring, peer tutoring, peer-assisted learning, and supplemental instrumentation. There were 37 relevant articles for college student issues. Based on Cao's (2014) review, I searched the China National Knowledge Infrastructure database for peer mentoring and first-year students. There were 11 articles on peer mentoring college students found from 2000 to September 2019.

\section{Findings}

The findings of the literature review on peer mentoring in Chinese higher education are mainly divided into five aspects: (a) methodology, (b) findings of empirical study, (c) findings of theoretical study, and (d) mentoring outcomes.

\section{Methodology}

Seven articles specifically described peer mentoring for student success in Mainland China. Among them, only one article was a descriptive introduction to peer mentoring programs using quantitative and qualitative data. There was a general lack of high-quality empirical research on peer mentoring. The seven pieces of Chinese literature I reviewed were empirical articles. As mature mentoring scales such as Crisp's (2009) mentoring scale have not been introduced into mainland China, Yue and Li (2016) used self-made questionnaires, and the other six studies described peer mentoring programs for first-year students with no empirical data; the other six were simply descriptive and there was no analysis. Yue and Li surveyed 200 students 
from 15 subcolleges in three private universities in the Guangdong province in China; meanwhile, they also collected qualitative data on the interviews. However, there were only survey results and no description of validity and reliability in Yue and Li's study. Therefore, it is urgent to use a maturity scale with high reliability and validity to measure the mentoring programs for first-year students in Mainland China.

\section{Findings of Empirical Study}

From this review, it can be found Crisp et al.'s (2017) mentoring theory and Tinto's (1993) integration theory have not been applied in empirical research in Mainland China. In the seven empirical articles, only Yue and Li (2016) used a scale in research, and the other descriptions were all too general (i.e., Li, 2018; Liu, 2013; Liu et al., 2019; Ma \& Ma, 2016; Tao, 2011; Xie, 2018). Yue and Li used a self-made questionnaire on the status quo of peer education in private colleges to collect quantitative data from three private colleges in Guangdong Province. According to their survey, the selection and training mechanisms of peer education were not mature. Among Chinese peer mentoring literature reviewed, most were too general while mentoring was only one component of the intervention; some other articles were simply descriptive and there was no analysis. Few high-quality empirical studies exist on peer mentoring in higher education in Mainland China.

Yue and Li (2016) did not use a theoretical framework in their research. The purpose was to investigate students' perceptions of peer mentors, mentors' training, program implementation, and existing problems through questionnaires. The peer mentoring involved in this study was hybrid, involving enrollment, orientation, FYE, living-learning, and community services. Yue and $\mathrm{Li} \mathrm{(2016)} \mathrm{found} \mathrm{peer} \mathrm{education} \mathrm{has} \mathrm{not} \mathrm{been} \mathrm{widely} \mathrm{recognized} \mathrm{and} \mathrm{promoted} \mathrm{in} \mathrm{private}$ colleges and universities in Mainland China. Universities' administrators and faculty did not 
have a deep understanding of peer education, and they know little about the evolution, development, and education model of peer education in Mainland China.

\section{Student Characteristics of Interest}

Yue and Li (2016) investigated 200 students to collect quantitative and qualitative data in three private universities in the Guangdong province in China; among the participants, $23.6 \%$ were first-year students, $28.7 \%$ were 2 nd-year students, $27.6 \%$ were 3 rd-year students, and $20.1 \%$ were 4 th-year students. They found respondents had insufficient cognition of peer education (i.e., $85.4 \%$ of participants thought peer education was a better form, but $68.2 \%$ of respondents were not clear about the specific connotation of peer mentoring). In the interview, the researchers learned that the students understanding of peer education important limited to psychological counseling, and drew the conclusion that the peer education idea and education method was not as an important means of students' affairs administration in colleges and universities moral education system, which means not to peer education as a way of normal student affairs administration (Yue \& Li, 2016).

\section{Relationship Features}

As Crisp et al.’s (2017) mentoring theory has not been introduced into Mainland China, the four classifications of mentoring programs have not been applied. The only study including quantitative data was Yue and Li's (2016) study on education undergraduates in a private university. The survey results showed that the actual situation of peer education in related private colleges is not ideal; most of the peer education activities are carried out spontaneously by students, and few peer mentoring activities are organized through the college system (Yue \& Li, 2016). According to Yue and Li's (2016) survey data, $85.4 \%$ of the interviewees think peer education is a better model of education, but $68.2 \%$ of the students are "not very familiar" with 
the specific connotation and education methods of peer education. In the interview, students' understanding of peer education was mainly limited to psychological counseling, and they thought peer education is peer psychological counseling. Other functions of peer education are unclear.

The survey showed the recruitment program was not perfect, and most recruited peer mentors were taken by student cadres; training mechanism of peer education was not sound enough and participants showed they were not fully competent as peer mentors in certain situations (Yue \& Li, 2016). The following data can explain the shortcomings of peer mentoring in this survey of this program; $72.3 \%$ of the students surveyed thought the main bodies of peer education were the student members of the Communist Party of China, student cadres, and people with excellent performance, and had not heard of special recruitment programs on peer mentoring. Peer mentor training is usually carried out by ordinary administrative personnel, and there is a lack of professional and high-level leadership training programs (Yue \& Li, 2016).

The survey results showed that $84.9 \%$ of the students were willing to turn to peer groups for help when they are in trouble, but $67.8 \%$ of them say that the college only occasionally carries out some peer counseling related to mental health, and most of them reported that they rarely had the opportunity to contact peer mentors; $61 \%$ of participants thought peer education mainly focused on indoctrination and theoretical preaching, and lacks affective engagement of specific project activities (Yue \& Li, 2016).

\section{Findings of Theoretical Study}

As mentioned earlier, Tinto's (1993) integration theory and Crisp et al.'s (2017) mentoring theory are popular in Western countries, but rarely introduced in Mainland China. There were four theoretical articles on peer mentoring in Mainland China (Qian, 2011; Shi, 
2008; Zhang, 2011; Zhang \& Duan, 2014). Shi (2008) acknowledged China's higher education was in a transition from elite education to mass education, and China has entered the primary stage of mass higher education. To ensure the quality of education did not decline and the number of undergraduate students increased rapidly, the peer mentoring system became an economical way to solve this dilemma, practiced by many colleges and universities (Shi, 2008). Zhang (2011) demonstrated the ideas of peer mentoring were from Western countries in Mainland China; the school should establish a student-centered orientation program to serve the development and transition of first-year students.

Zhang and Duan (2014) emphasized the theoretical basis of peer mentoring was the philosophy of intersubjectivity. Qian (2011) held that the transition of China's higher education, from elitism to popularization, led to the transformation of talent training, so it was urgent to establish a multilevel, undergraduate mentoring system to include peer mentoring. Academic advisors and ideological mentors also guided students in the same large system. In sum, theoretical research on peer mentoring in Mainland China is still in its infancy. Mentoring theory and framework, which were mature in Western countries, were not fully disseminated. However, peer mentoring research in Mainland China also has its own characteristics; ideological and political education has been integrated into peer mentoring programs.

The method of using peer mentors for first-year college students from Western countries was introduced into Mainland China in 2009 (Wang, 2010; Zhang, 2011). Shi (2008) introduced the concept of peer mentoring for undergraduates from the perspective of psychology in China. Zhang and Duan (2014) introduced the urgency of using peer mentoring from the perspective of practical problems in higher education in China. 


\section{Mentoring Outcomes}

Tinto's (1993) integration theory is the research basis of Crisp et al.'s (2017) mentoring theory in Western countries. According to Crisp et al.'s (2017) mentoring, mentoring outcomes can be divided into two categories: long-term outcomes and intermediate outcomes. In my study, student integration in the first year is an intermediate outcome indicator, and accumulative GPA is a long-term outcome indicator.

In Mainland China, one important task of student affairs management is to carry out ideological and political education; peer mentoring of first-year students has also been under its influence (Li, 2018). In Mainland China, peer mentors are positioned to help college students solve practical difficulties while completing the task of ideological and political education with the help of counselors (Qian, 2011). Therefore, from the existing limited literature, I found the main outcome of peer mentoring focused on institutional adaptions of student leadership. Compared with the research in western countries, there is little research on the relationship between peer mentoring and students' academic success in the first year of college.

Peer mentors need to develop leadership in dealing with conflict. Hua (2019) regarded peer mentors as second leaders who needed to act as leaders and subordinates simultaneously and played a profound and extensive role in the program. Mentors' leadership will be enhanced precisely because of this state of multirole contradiction. Peer mentors act the role of a leader of students and as subordinates, accept guidance from the faculty. They handle two roles and switch between mentoring, which requires high social skills, empathy, and self-regulation abilities and maintaining the relationships between faculty and students. Finally, peer mentors become a bridge between faculty and mentored students; mentors need to constantly improve their self- 
confidence, explore their strengths, examine their shortcomings, and improve those shortcomings at any time (Hua, 2019).

\section{Summary}

In the context of higher education popularization and retention crises, peer mentoring in FYE programs is an alternative student success strategy both in theory and in practice. The main theoretical bases of mentoring chosen in this study were Tinto's (1993) integration theory and Astin's (1984) involvement theory. Crisp's (2009) mentoring framework, updated by Crisp et al. (2017) was widely used for student success in higher education in Western countries (Crisp, n.d.;

Gunn et al., 2017; Henry et al., 2011; Robinson, 2018; Sparks, 2017), and it is urgent to introduce Crisp's (2009) and Crisp et al.'s (2017) mentoring framework to Mainland China to fill in the research gap. The mentoring framework I finally chose was Crisp et al.'s (2017) conceptual model, which contained five basic elements: educational context, student characteristics, relationship features, forms of support, and mentoring outcomes. Then, I used Crisp et al.'s five-factor conceptual model to synthesize peer mentoring literature in Western countries in higher education. This chapter reviewed peer mentoring literature for first-year students in Western countries and Mainland China.

The literature on peer mentoring programs I reviewed included the institutional level, subschool or discipline level, and program level in Western countries in terms of the educational context. In my dissertation research, I chose the institutional level on educational context, which means the peer mentoring program requires all first-year students to attend. In my reviewed literature, student characteristics included gender, generational status, and students' majors. I chose first-year students, female students, first-generation students, and four major groups of students. In terms of forms of support, mentoring for first-year college students was mainly 
focused on PES and academic subject knowledge support. Therefore, as for peer mentoring, students' experience and outcomes related to forms of supports are concentrated in two aspects: students' integration and academic achievement (i.e., GPA). Moreover, through the literature review, I found peer mentoring is effective in higher education in Western countries.

In the literature of Mainland China, empirical studies on peer mentoring first-year students in student success with vigorous methods are exceedingly rare, and only one study with quantitative data was found. Mainland China lacks mentoring scales with reliability and validity. The theoretical research articles on peer mentoring in Mainland China stayed within the introduction of theory from Western countries and there are few mature theoretical research frameworks in research. Outcomes of peer mentoring added a new content of ideological and political identity in Mainland China, which is similar to civic education in Western countries; few studies have been found on the relationship between peer mentoring and academic success for first-year students. In terms of research methods, the literature review used a correlation research design based on different groups as the main choice. Crisp's (2009) CSMS is also the mentoring scholars' general choice for scales and constitutes the basis of my research in Chapters 3 and 5 of this dissertation. 


\section{CHAPTER 3: RESEARCH METHODOLOGY}

This chapter introduces the research methods of this study. The purpose of this study is to: (a) validate Crisp's (2009) College Student Mentoring Scale (CSMS) in Mainland China and (b) examine the relationship between mentoring support, student integration, and accumulative GPA for all first-year students, female students, first-generation students, and different major groups in a Chinese FYE program at T College. Based on the research purposes, I chose a postprogram survey method to conduct quantitative research on peer mentoring of first-year students at a medium-size, private, Chinese college. The College Students Perception Scale (CSPS) is used to examine student integration in the first year.

\section{Research Questions}

Research Question 1: Can the CSMS, based on the four-factor model, be used as a valid indicator to measure the first-year students' perceptions of peer mentoring in a Chinese FYE program?

Research Question 2: How are the first-year students' perceptions of peer mentoring on CSMS correlated to integration as measured by CSPS in a Chinese FYE program for total, gender, generational, majors' groups?

Research Question 2a: Are all first-year students' perceptions of peer mentoring on CSMS scores correlated to integration as measured by CSPS in a Chinese FYE program? Are all first-year students' perceptions of peer mentoring on Psychological and Emotional Support (PES) scores correlated to integration as measured by CSPS in a Chinese FYE program? Are all first-year students' perceptions of peer mentoring on New Academic Subject Knowledge 
Support (NAKS) scores correlated to integration as measured by CSPS in a Chinese FYE program?

Research Question 2b: Are female first-year students' perceptions of peer mentoring on CSMS scores correlated to integration as measured by CSPS in a Chinese FYE program? Are female first-year students' perceptions of peer mentoring on PES scores correlated to integration as measured by CSPS in a Chinese FYE program? Are female first-year students' perceptions of peer mentoring on NAKS scores correlated to integration as measured by CSPS in a Chinese FYE program?

Research Question 2c: Are first-generation first-year students' perceptions of peer mentoring on CSMS scores correlated to integration as measured by CSPS in a Chinese FYE program? Are first-generation first-year students' perceptions of peer mentoring on PES scores correlated to integration as measured by CSPS in a Chinese FYE program? Are first-generation first-year students' perceptions of peer mentoring on NAKS scores correlated to integration as measured by CSPS in a Chinese FYE program?

Research Question 2d: Are first-year students' perceptions of peer mentoring on CSMS scores correlated with integration as measured by CSPS in a Chinese FYE program, and do these potential correlations vary by major groups? Are first-year students' perceptions of peer mentoring on PES scores correlated with integration as measured by CSPS in a Chinese FYE program, and do these potential correlations vary by major groups? Are first-year students' perceptions of peer mentoring on NAKS scores correlated with integration as measured by CSPS in a Chinese FYE program, and do these potential correlations vary by major groups? 
Research Question 3: How are the first-year students' perceptions of peer mentoring on CSMS related to cumulative GPA in a Chinese FYE program for total, gender, generational, majors' groups?

Research Question 3a: Are all first-year students' perceptions of peer mentoring on CSMS scores correlated to cumulative GPA in a Chinese FYE program? Are all first-year students' perceptions of peer mentoring on PES scores correlated to cumulative GPA in a Chinese FYE program? Are all first-year students' perceptions of peer mentoring on NAKS scores correlated to cumulative GPA in a Chinese FYE program?

Research Question 3b: Are female first-year students' perceptions of peer mentoring on CSMS scores correlated to cumulative GPA in a Chinese FYE program? Are female first-year students' perceptions of peer mentoring on PES scores correlated to cumulative GPA in a Chinese FYE program? Are female first-year students' perceptions of peer mentoring on NAKS scores correlated to cumulative GPA in a Chinese FYE program?

Research Question 3c: Are first-generation first-year students' perceptions of peer mentoring on CSMS scores correlated with cumulative GPA in a Chinese FYE program? Are first-generation first-year students' perceptions of peer mentoring on PES scores correlated with cumulative GPA in a Chinese FYE program? Are first-generation first-year students' perceptions of peer mentoring on NAKS scores correlated with cumulative GPA in a Chinese FYE program?

Research Question 3d: Are first-year students' perceptions of peer mentoring on CSMS scores correlated with cumulative GPA in a Chinese FYE program, and do these potential correlations vary by major groups? Are first-year students' perceptions of peer mentoring on PES scores correlated with cumulative GPA in a Chinese FYE program, and do these potential correlations vary by major groups? Are first-year students' perceptions of peer mentoring on 
NAKS scores correlated with cumulative GPA in a Chinese FYE program, and do these potential correlations vary by major groups?

According to the literature from Western countries, first-year students' perceptions of peer mentoring were correlated to positive outcomes in higher education (Budge, 2006; Gershenfeld, 2014; Jacobi, 1991). As an effective retention strategy, peer mentoring is often used to help students likely to encounter retention difficulties in college (Crisp et al., 2017). The results attempted to address the relationship between peer mentoring perceived by first-year students and student success. The student success for first-year students focused on student integration and cumulative GPA (van der Zanden et al., 2019). First-year students, female students, first-generation students, and students in different major groups are the populations I was interested in for peer mentoring research. However, mentoring scales with reliability and validity for evaluating peer mentoring were lacking in Mainland China (Cao, 2014).

CSMS has been used to measure the perceptions of college student mentoring experience for student success in Western countries (Crisp, 2009). When a scale is translated into a different language, it is necessary to test for reliability and validity before use in the new country (Beaton et al., 2000). This research used principal component analysis (PCA) to examine the validity of CSMS translated for Mainland China. After illustrating sufficient validity, correlational survey research design was used to explore relationships between the variables of interest.

This methodological chapter has four main parts. First, the rationale for methodology is discussed. Second, the research purpose and research questions are presented. Next, the research design is interpreted, including factor analysis methods, correlation methods, setting, participants and sampling, and instrumentation. Then, research procedures are presented, including data 
collection and data analysis. Finally, the assumptions of this method and ethical considerations are discussed.

\section{Rationale for Methodology}

Survey research has two main methods: cross-sectional and longitudinal (Leavy, 2017); I choose cross-sectional survey research. I conducted a postprogram study in a cross-sectional time, which meant the data were collected at one point in time (Creswell \& Creswell, 2018). This nonexperimental research used a correlational approach with an explanatory design. The quantitative approach allows for a broader study that involves more subjects at the same time to have greater objectivity and accuracy of results (Leavy, 2017).

Quantitative methodologists have used deductive logic to identify and describe social patterns calculated from numerical and statistical measurements (Salehi \& Golafshani, 2010; Williams, 2007). Therefore, this study was deductive and used a self-reported survey. The selfreported instrument is suitable for measuring quantitative analysis via an online survey (Dillman et al., 2014). I conducted an online self-reported survey to examine relevant hypotheses and answer specific research questions in this study. After data collection, I used IBM Statistical Product and Service Solutions (SPSS) 25 to analyze the data. Reliability and validity are important indicators to evaluate a scale (DeVellis, 2016); thus, I used factor analysis to carry out validity analysis for the dataset.

\section{Factor Analysis}

Principal component analysis (PCA) belongs to the family of factor analysis; in general, factor analysis is suitable for constructing a new theoretical framework, and principal component analysis is suitable for summarizing the material of experience (Pallant, 2016). Therefore, PCA was able to validate a scale in a new educational context or in a new country. There are three 
steps for factor analysis. First, researchers need to evaluate the suitability of the data for factor analysis; the criterion is that the sample size is at least 300 , and the coefficient of items for the strength of intercorrelations is greater than 0.3 (Pallant, 2016). Second, factor extraction determines the smallest number of factors for setting variables and Kaiser's criterion is that factors with an eigenvalue of 1.0 or more are likely to be further investigated. Third, factor rotation is a method of rendering after the number of factors are determined (Pallant, 2016). There are two basic methods of factor rotation: orthogonal and oblique. Orthogonal rotation methods are for uncorrelated factor solutions, and oblique rotation methods are for correlated factor solutions (Pallant, 2016). Following these guidelines, I chose the oblique rotation method because it aligned with my data.

\section{Correlation Method}

The correlation analysis in this research is divided into two stages. The first stage, preliminary analysis, includes examining outliers, examining data distribution, and determining the direction of the relationship between variables. In the next stage, in-depth correlation analysis consists of five aspects: (a) examining the information of all the samples, (b) determining the direction of the relationship between variables, (c) determining the strength of the relationship, (d) calculating the effect size (coefficient of determination), and (e) assessing the significance level.

\section{Research Design}

This study employed a quantitative research design using an original dataset. The data was collected online through the Wenjuanxing website. I used the survey to measure the impact of an already existing intervention in a Chinese FYE program. Four student-participant cohorts (i.e., all first-year students, female first-year students, first-generation first-year students, and 
four major groups) are involved. I used CSMS and CSPS instruments, which were validated at universities in the United States, and had good reliability and validity in the U.S. context.

\section{Settings}

This research was conducted in a medium-sized private college (i.e., T College) in Shanghai, the biggest city in eastern China. There are many private universities and colleges in Shanghai.-T College has had an FYE program for all first-year students for more than 12 years. Students came from more than 25 provinces and were all 4-year undergraduate students, with no international students in the college; local students from Shanghai accounted for $48 \%$ of the total; most first-year students were between the ages of 18 and 20. I used a survey study with an online instrument, which is a method of collecting data quickly and economically. T College has one campus and seven subschools with over 9,446 undergraduates and 31 undergraduate programs shown in Table 3.

\section{Table 3}

Students of Class 2022 at T College

\begin{tabular}{lcc}
\hline Major groups & Submajors & Students \\
\hline Education & 7 & 614 \\
Humanities & 7 & 706 \\
Business & 6 & 473 \\
STEM & 10 & 424 \\
Total & 30 & 2217 \\
\hline
\end{tabular}

Note. Data were provided by the Academic Affairs Office of T College on December 31, 2020.

\section{FYE Program}

Participants were from 66 FYE course sections for the class of 2022, a mandatory FYE program (1-credit course) for first-year students. Peer mentoring in the FYE program at T 
College started in 2008 and has a history of 12 years. The FYE course is a special course designed for first-year students. The peer mentors worked in the FYE course classroom for 1.5 hours a day for 32 weeks ( 2 semesters) a year. The class counselors hosted the first-year seminar and were the course instructors. Each FYE class is discipline specific according to the majors of first-year students, with about 35-40 students in an FYE section. Two peer mentors collectively guide 30-40 first-year students in the classroom. Students spend half their time watching English-learning videos in class, and counselors answer questions about academics and lifestyle during the first year.

Peer mentors also answer questions that the first-year students have regarding the course material. All students at T College who participate in the peer mentoring program had the opportunity to be in the research. The collected demographics of participants focused on gender, age, Hukou, one-child family, first-generational status, major, and GPA. As mentioned, all students participated in the FYE program at T college and students participated in the FYE program collectively according to the enrollment year at $\mathrm{T}$ College.

\section{Participants and Sampling}

My target population included the 9,446 students who took the FYE program in T College; most students were between the ages of 18-22. There were more women than men, accounting for more than $60 \%$ of the total; all T College students have been required to attend the FYE program.

Some of the more cited empirical articles on peer mentoring of first-year students were sampled according to the year of enrollment (Colvin \& Ashman, 2010; Heirdsfield et al., 2008). I sampled participants based on the year of enrollment. The class of 2022 at T College was my target sample population. For students in class of 2022, 2022 is their target graduation year. I 
sampled the students to recall their experiences of the first year. I adopted the method of convenience sampling and selected all students in the class of 2022. The respondents were chosen based on their convenience and availability, and it was completely voluntary for students. The total number of students in the class of 2022 was 2,301 at T college, and the expected participation rate of such questionnaires was around 50\%, according to other similar studies (Colvin \& Ashman, 2010). Convenience sampling was chosen in this study, and the sample was derived from the population. Nonprobability sampling is the selection of participants because they are available, convenient, or represent some characteristic the investigators wanted to study (Dillman et al., 2014); I chose convenience sampling strategy from nonprobability sampling, in which respondents were chosen based on their convenience and availability. The sampling frame in this study was students of the class of 2022 at T College. With the available population of all the current students at T College. I included three inclusion criteria. First, potential participants were students who participated in the FYE program at T College. Second, potential participants were students who filled out a self-reported GPA. Third, potential participants were current college students from the 2 nd year to the 4 th year; therefore, they had a clear experience of peer mentoring. I took a sample from one grade of students at the college.

There were three exclusion criteria for the sample. I did not sample current first-year students because they did not yet obtain their self-reported first-year GPA. Students who graduated were not included because their experiences with peer mentoring may have faded. I did not consider other private college students in Shanghai, because the content and form of peer mentoring varied greatly from university to university. It was only 1 year since the class of 2022 students completed the FYE program. All class of 2022 students were in the FYE at T college. 


\section{Instrumentation}

To realize the purpose of my research and answer the research questions, all data were collected from the survey.

\section{Self-Reported Method}

Self-reported measures are most appropriate when they are directed at the problem of impact and perception, in which case the responses have no reason to fear any negative consequences given by the answer (McCroskey, 1997). Self-report is a kind of test or measurement in survey research that relies on an individual's reporting of their symptoms, behavior, beliefs, or attitudes in psychology; self-reported data is usually collected in pen and paper or electronically, and sometimes through interviews (McCroskey, 1984; Thornberry \& Krohn, 2000). There are many strengths of self-reported measures. The most widely used measure in surveys of attitudes and experiences is the self-reported scale. Paulhus and Vazire (2007) thought even though other survey methods had the same long history, self-reports are still the most favored option. The five strengths of self-reported measures include: easy interpretability, the richness of information, motivation to report, causal force, and sheer practicality. Self-report is communicated in the language of both the assessed and the evaluator, who for example, asks a literate adult to rate some emotions that can reasonably be considered understandable (Paulhus \& Vazire, 2007).

Scales are essential for self-reported methods from strong composite variables. Selfreport survey methods need to be transferred into operational concepts using scales (Jensen \& Karoly, 1992; Kimberlin \& Winterstein, 2008). Measurement instruments are collections of items combined into a composite score and designed to reveal the level of theoretical variables; they are not easily observed by direct means and are often considered as scales (DeVellis, 2016). 
When researchers cannot rely on behavior as an indication of phenomena, it is more useful to assess structure through carefully constructed and validated scales (Dipietro et al., 2008). Composite variables that cannot be directly observed are best evaluated with a scale. Composite variables can find the nature of such a variable with a precision that a single item cannot achieve (DeVellis, 2016). Due to the classical test theory, almost every measurement has an error; a scale with high reliability and validity can minimize error in the measurement, and improving reliability is an essential step (Kimberlin \& Winterstein, 2008). Therefore, in the following discussion, it is important to identify the reliability and validity of the scale used to detect pretranslation and posttranslation in the study.

\section{Construction of CSMS and CSPS in the United States}

I used the CSMS (Crisp, 2009; Crisp \& Cruz, 2010) and the CSPS (Moschetti et al., 2018; Yomtov et al., 2017), which were self-reported scales. Both scales were translated into Chinese with permission from the original designers for the use of this study. The CSMS is a tool used to assess mentoring support for college students. CSMS was validated by Crisp (2009) and secondly validated by Crisp and Cruz (2010). The CSMS has been a widely used instrument for measuring the perception of mentoring support and has been commonly used in student success research (Crisp et al., 2017). CSMS originally consisted of four constructs with 25 survey questions. The CSMS was translated into a Chinese version, and I will discuss the scale in detail

later. The English version of CSMS was validated for cultural adaptability in Hong Kong, China (Kwan, 2014). Crisp's (2009) CSMS used a 5-point Likert scale of 1 (strongly disagree) to 5 (strongly agree).

Crisp and Cruz (2009) reviewed the literature of mentoring college students between 1990 and 2007 to form a foundation for CSMS. The four functional categories of CSMS are 
derived from broad literature reviews. There is an important function of mentoring for psychological and emotional support (Cohen, 1995; Kram, 1988; Levinson et al., 1978; Miller, 2002; Roberts, 2000; Schockett \& Haring-Hidore, 1985); other scholars held that mentoring had a function for degree and career support (Cohen, 1995; Levinson et al., 1978; Roberts, 2000). The function of academic knowledge support for mentoring was also found in the literature (Cohen, 1995; Kram, 1988; Levinson et al., 1978; Miller, 2002; Roberts, 2000; Schockett \& Haring-Hidore, 1985). Cohen (1995) and Kram (1988) confirmed the mentoring function as the existence of a role model. The four dimensions within the literature constituted an important base for the construction of CSMS. Crisp (2009) added a new academic subject knowledge support dimension and made new progress in the development of the mentoring framework for college students.

The CSPS is a one-dimensional scale developed by Plunkett with six items for measuring student integration at university and used to assess student integration for student success (Yomtov et al., 2017). The 6-point Likert scale is used for CSPS $(1=$ strongly disagree, $2=$

disagree, 3 = somewhat disagree, 4 = somewhat agree, $5=$ agree, $6=$ strongly agree $)$. The 6point Likert scale is divided into three levels of positive and negative attitudes to avoid the neutral response and differentiate attitudes in a more detailed way. Therefore, as a measurement tool of outcome variables, it is appropriate for my research of an outcome variable.

\section{Reliability and Validity}

Reliability and validity are essential elements for a good scale (Leavy, 2017). The reliability and validity of CSMS and CSPS involved in this study were originally analyzed in the United States, where they were designed, and they were used after being translated in Mainland China for this study. 
Reliability. Reliability is one of the fundamental problems of social science research, and its importance is undeniable; a reliable tool is one that performs in a consistent and predictable approach (DeVellis, 2016). For the scale to be reliable, its score represents some true state of the assessed variable. Scale reliability is the proportion of variance caused by the true score of the underlying variable. Internal consistency is usually expressed in terms of Cronbach's coefficient alpha (Cronbach \& Meehl, 1955). I used the coefficient alpha to measure the reliability of the translated scale. Internal consistent reliability refers to the homogeneity of items in a scale; the relationship between items and the relationship between items and potential variables are logically related (DeVellis, 2016). A reliable scale consists of several interrelated items and is internally consistent in measurement, and its various items are highly correlated (Santos, 1999). If the items on a scale have a strong relationship with their latent variables, then they also have a strong relationship with each other (DeVellis, 2016).

Crisp (2009) conceptualized and validated CSMS, each of the latent variable's Cronbach coefficient alphas were great than .70 (Crisp, 2009); PES $(\alpha=.912)$, DCS $(\alpha=.903)$, AKS $(\alpha$ $=.883)$, ERM $(\alpha=.845)$. The reliability was considered good in the U.S. educational context. The internal consistencies of CSMS are very high. The CSPS was also reliable in the U.S. context (Yomtov et al., 2017). When I got permission from the developer via email to use the scale, I also got the reliability information for the scale. The reliability for the pretest was .866 and the reliability for the posttest was .848 , which were greater than the .70 cutoff.

Validity. The reliability and validity of the scale in the United States is the basis of my study using the Chinese CSMS in Mainland China. The internal and external validity of CSMS was fully examined in the U.S. context by other scholars. A PCA is employed to conceptualize and validate the multidimensions for mentoring college students; Nora and Crisp (2007) found 
four dimensions of mentoring college students. First, Crisp (2009) randomly sampled 580 students with 7,668 students, and 351 of them completed questionnaires of the self-report instrument; she conceptualized and initially validated the four dimensions of CSMS at a community college in the south-central area of the United States and found Cronbach coefficient alphas of each potential variable sufficient (greater than .70); revised Model 3 were within the appropriate range: $\chi^{2}(249)=639.613, p>.001, \chi^{2} / d f(2.569)$, AGFI (.826), RMSEA (.068), RMR (.032), NFI (.908), CFI (.941), TLI (.929). Confirmatory factor analysis (i.e., multigroup confirmatory factor analysis) was conducted in community college (Crisp, 2010); the final structural model was confirmed: $\chi^{2}(102)=305.597, p>.05$, CFI (.957), TLI (.984), RMSEA (.079), WRMSR (1.180).

Moreover, Crisp and Cruz (2010) performed a confirmatory factor analysis among undergraduate students in a Hispanic-serving institution; they tested invariance among gender, ethnicity, and classification. Validation results of their factor analysis showed that CSMS had good validity. Crisp and Cruz (2010) used CFA secondly to validate CSMS and found the revised Model 3 improved the fit of the model. Although the chi-square was found to be significant, $\chi^{2}(242)=467.279, p<.001$, the Chi-square to degrees of freedom ratio value was less than 2.0, providing evidence of a good fit; confirmatory factor analysis showed the mentoring model is effective and there were significant differences in the structure of factors between White and Hispanic students (Crisp \& Cruz, 2010).

The good validity enables CSMS to become an effective measurement instrument and thus it became widely used in the United States for college students; Crisp highlighted that 15 universities, including The University of Newcastle, The University of Maryland, and 
Pennsylvania State University, had chosen to use the CSMS (Crisp, n.d.). Therefore, the reliability and validity of the CSMS were repeatedly verified in the United States.

\section{Instrument Translation}

To construct a scale with high reliability and validity, the process of cross-cultural adaptation in translation is important for researchers and translators (Beaton et al., 2000). The reliability and validity discussed were only for the original English language versions of the scales. There are five stages in translating and validating process: (a) translation, (b) synthesis, (c) back translation, (d) expert committee review, and (e) pretesting. Beaton et al. (2000) employed this guideline for the process of cross-cultural adaptation of self-report measures, and the scale from Western countries was translated to Japan. Similarly, I translated the U.S. scales of CSMS and CSPS for the Mainland Chinese contexts. Three key factors related to the quality of translation process: qualifications of translators, committee translation methods, and the evaluation process (Harkness et al., 2010).

Preparation. First, I chose an expert committee method and set up the group consisting of four people to be responsible for the scale translations. The expert committee for scale translation included a methodologist, a language professional, and translators (Beaton et al., 2000). Second, in terms of translator resources, the translation committee had a total of four members: two experts proficient in English and student affairs and two doctoral candidates, including myself. All four members were familiar with Chinese and Western cultures and understand English and Chinese. Dr. Gong is a professor of English language translation and also served as vice president of student affairs. Dr. Xu received a doctorate of education from the University of the Pacific, Stockton and is familiar with the methodology of survey research. Dr. $\mathrm{Xu}$ also served as vice president and has a rich research experience of Western higher education 
and China. The evaluation of the process for translating and validating implement in Beaton et al.'s (2000) five stages mentioned earlier.

Translation. I used Crisp's CSMS in Mainland China for the first time. Crisp's CSMS is a self-report instrument and is suitable for the measurement of first-year students' adaptation to a new environment. Crisp has the copyright of CSMS; Plunkett has the copyright of CSPS (Crisp, 2009; Yomtov et al., 2017); before translating the questionnaire, I obtained the consent and authorization of the copyright owner of the scales. The validation of the English version of CSMS was tested in a special area of China, Hong Kong (Kwan, 2014). Kwan (2014) validated the CSMS in Hong Kong as a doctoral dissertation in English; she took the model evaluation approach from the baseline model, two-factor model, four-factor model, and higher-order fourfactor model to employ a confirmatory factor analysis.

Four important principles for self-reported scale translation are: semantic equivalence, idiomatic equivalence, experiential equivalence, and conceptual equivalence (Beaton et al., 2000). I applied these four aspects to my questionnaire translation process. In this translation process, I synthesized 39 items from the English questionnaire to be translated, plus seven new additions of demographic items (i.e., gender, age, Hukou, One-child family, generational status, majors, GPA), 25 items of CSMS, and six items of CSPS. Also, I translated the CSPS that has six items.

This first stage was forward translation by two translators, and I understood the framework and original purpose of the scale and served as Translator 1. Dr. Gong has translation expertise in Chinese and English, so her role was as a naive translator, a language professional, and Translator 2. Procedurally, Translator 1 and Translator 2 worked individually. The 
translators did not change the original structure of the scale and remained faithful to the original meaning and wrote a report for each version $(\mathrm{T} 1 \& \mathrm{~T} 2)$.

Synthesis. In this stage, by comparing the two translations, we found inconsistencies or contradictions to clarify the original meaning of the ambiguous words. Through discussion, these issues were resolved, a basic consensus was reached, and then an agreement was formed on the translated version of T-12 with a report. Compared with the original questionnaire of CSMS, after a discussion, we added a sentence, "When you were in the first year of college?" at the beginning of the 25 questions. According to China's national contexts, we changed the sixth question in CSPS, "You want to spend 4-6 years to graduate from college," to "You want to spend 4 years to graduate from college."

Back Translation. Back Translations (BT1 and BT2) were conducted by Translator 3, another expert (Dr. Xu), and Translator 4 (Tao, doctoral candidate). Dr. Xu and Tao conducted the back-translation of CSMS and CSPS and the instruments were translated back into the English language independently. As Chinese scholars, they are both skilled in the English language, and they are naive about outcome measurements. Dr. Xu created Back Translations 1 (BT1), while Tao created Back Translations 2 (BT2). They wrote a report for each version (BT1 \& BT2).

Expert Committee Review. The composition of this committee is the key to achieving cross-cultural equivalence. We needed to integrate all versions of the questionnaire and to prepare a prefinal version of the questionnaire for pretesting. The committee made key decisions and included complete written documentation of issues and reasons for the decisions (Beaton et al., 2000). The committee was tasked with deciding how to achieve parity between the source 
and target versions in four areas: semantic equivalence, idiomatic equivalence, experiential equivalence, and conceptual equivalence (Beaton et al., 2000).

Two experts — a doctoral student and I—-formed a committee to examine results and conducted a comparative discussion. The expert committee reviewed all reports of the scale. Then, the methodologist (Dr. Xu) commented on the methodological part, and the language professional (Dr. Gong) commented on the language translation section. The expert committee reviewed the overall structure of the translation scale according to the cultural characteristics of the country in use and finally formed a consensus translation scale. Finally, the prefinal version of the Chinese questionnaire was prepared to be delivered to the potential participants.

Pretest. The final stage of the adaptation process is the pretest stage. The field test of the new questionnaire attempted to use a prefinal version in goal-setting subjects. In general, about 20 participants should be tested (Beaton et al., 2000). The cognitive interviewing was conducted; the participants completed the questionnaire and were interviewed to investigate what they thought meant by each questionnaire item and selected responses. The significance and responses of these items were explored; this ensured that the adapted version retained its equivalence in the case of the application (Beaton et al., 2000).

Second, the 19 students who took the pretest were recommended by two senior counselors and none of them belonged to my target sample group in the study. An online pretest was conducted with 19 participants at T College in June 2020. The 19 students were all seniors at T College, and I asked the business school counselors to contact them based on convenience. I uploaded the prefinal version to the Wenjuanxing website and produced an electronic link in June, 2020. The two counselors helped me build a WeChat group of 19 students to discuss the survey. 
I asked students if any items confused them after finishing the Chinese version of the questionnaire in the WeChat group. They were asked about their understanding from three directions (i.e., facts, knowledge, and value) to evaluate if scale contents significantly changed before and after translation. During the process, I found participants reported they understood the basic language and overall meaning of the questionnaire. There were no ambiguities.

Statistics showed the sampling method and the designed field procedures were feasible, effective, and representative in the field, so the questionnaire was revised and finalized based on pretest results (see similar design in World Values Survey, 2010). Finally, I submitted the backtranslation scale to my dissertation committee for review in August 2020.

\section{Variables}

Based on the research question, the main variables of this study were identified based on the examination and use of CSMS and CSPS (Crisp, 2009; Yomtov et al., 2017). The predictor variable was the CSMS and subscales (original version PES/DCS/AKS/ERM), and outcome variables were CSPS and cumulative GPA as two student success indicators shown in Table 4. CSMS and subscales (PES/ NAKS) were validated version in Mainland China. The CSMS and CSPS were self-report instruments, which were used for all first-year students, female students, first-generation students, and four major groups of students.

\section{Table 4}

Variables

\begin{tabular}{ll}
\hline \multicolumn{1}{c}{ Variables } & \multicolumn{1}{c}{ Measurements } \\
\hline $\begin{array}{l}\text { Peer Mentoring Support } \\
\text { (Predictor) }\end{array}$ & CSMS and Final Subscales (PES/ NAKS) \\
$\begin{array}{c}\text { Student Integration } \\
\text { (Outcome) }\end{array}$ & CSPS \\
$\begin{array}{c}\text { Academic Achievement } \\
\text { (Outcome) }\end{array}$ & Cumulative GPA \\
\hline
\end{tabular}


In this study, predictor variables are peer mentoring support measured by CSMS, and

PES and NAKS; outcome variables are student integration measured by CSPS and cumulative

GPA (see Table 4). The details of characteristics of variables in the four subscales of CSMS are shown (see Table 5).

\section{Table 5}

CSMS

\begin{tabular}{|c|c|}
\hline Variable & Characteristic \\
\hline $\begin{array}{l}\text { Psychological } \\
\text { and } \\
\text { Emotional } \\
\text { Support }\end{array}$ & $\begin{array}{l}\text { Listening to students, } \\
\text { providing moral and } \\
\text { emotional support, } \\
\text { identifying problems, } \\
\text { providing encouragement, } \\
\text { and building a support } \\
\text { system for mutual } \\
\text { understanding and } \\
\text { connection }\end{array}$ \\
\hline $\begin{array}{l}\text { Degree and } \\
\text { Career } \\
\text { Support }\end{array}$ & $\begin{array}{l}\text { Assessment of a student's } \\
\text { strengths, weaknesses, and } \\
\text { abilities; considered } \\
\text { opportunities for the } \\
\text { student; helped students } \\
\text { realistically consider the } \\
\text { degree options }\end{array}$ \\
\hline $\begin{array}{l}\text { Subject } \\
\text { Knowledge } \\
\text { Support }\end{array}$ & $\begin{array}{l}\text { Helping acquire the necessary } \\
\text { skills and knowledge to } \\
\text { educate, evaluate, and } \\
\text { challenge students } \\
\text { academically, and to } \\
\text { establish a process of } \\
\text { teaching and learning }\end{array}$ \\
\hline $\begin{array}{l}\text { Existence of a } \\
\text { Role } \\
\text { Model }\end{array}$ & $\begin{array}{l}\text { Providing the students with an } \\
\text { example to motivate them } \\
\text { to overcome the difficulties } \\
\text { of achieving their academic } \\
\text { goals and the personal } \\
\text { experience of success }\end{array}$ \\
\hline
\end{tabular}

Note. From “Conceptualizing and Validating CSMS," by G. Crisp, 2009, Journal of College

Student Development, 50(2), p. 192. (https://doi.org/10.1353/csd.0.0061). In the public domain. 


\section{CSPS}

The CSPS is used to measure the outcome variable of integration experience. Mentors make students feel like part of the college community and engagement. Students have a strong and positive feeling about the university and can turn to at least one person for emotional and academic support. This questionnaire used a 6-point Likert scale $(1=$ strongly disagree, $2=$ disagree, $3=$ somewhat disagree, $4=$ somewhat agree, $5=$ agree, $6=$ strongly agree $)$. Chomeya (2010) used self-reported 6-point Likert scale to examine undergraduates' attitudes and found compared with 5-point Likert scale, it had its own advantages. Nemoto and Beglar (2014) held the outstanding function of 6-point Likert scale was used for the display of outcome and the display of results more accurately.

\section{Research Procedure}

The research process began with the approval of the Institutional Review Board (IRB) at Chapman University. Upon approval, I initiated the formal data collection. The 19 students who participated in the pretest before were not included in my sampling frame. With the permission of T College, the seven subschools' counselors helped me to complete the delivery of the online questionnaire link. All students participated on a volunteer basis, and I stopped the collection when the number of samples I expected was reached.

\section{Data Collection}

At the beginning of the first page of the questionnaire, I provided the electronic version of the informed consent. Participants could only access the specific content of the questionnaire if they agreed to participate. I used a premium version of Wenjuanxing software to administer the survey, which offered more security. 


\section{Site Entry}

I sent a site entry email to the president of T College and the deans of schools in June 2020. Both the vice president for student affairs and the dean of the school wrote back to support my research activities at T College. After the introduction of the school's deans, 15 class-of-2022 counselors agreed to help me forward the information and questionnaire link to students. With the help of the counselors, I sent a recruitment message via WeChat to the class of 2022 after getting IRB approval from Chapman University.

With the support of the president and the dean of the secondary college, 15 counselors agreed to help forward the recruitment information and link of the questionnaire through WeChat. There were about $35-40$ people in each class. Each counselor was responsible for about 3-4 classes. The target sample population size was 1,200.

First, I asked 15 counselors to help send recruitment messages via WeChat to 2,301 students in the class of 2022 at T College. I further emphasized the principle of anonymity and voluntariness in recruitment. Students did not enter any identifying information in the survey. I gave potential participants a week to think about participation and ensured them that they could drop out of the study if they changed their minds. Second, I uploaded the informed consent form and the questionnaire to the Wenjuanxing survey website and formed a network link. Then, I assigned the counselors to send the informed consent form link and the questionnaires to the participants. The electronic version of informed consent was placed before the questionnaire. Participants were only able to complete the subsequent questionnaire if they clicked to consent. At the same time, I also set the option of waiver. During the process of administrating the questionnaire, if participants wanted to stop participating, they could opt out of the study without any effect on them. The students completed the survey through the online link in October 2020. 
Third, the data collection process lasted for 4 weeks in October 2020. In the first week, I sent a comprehensive recruitment message to all potential participants. After a week's consideration, I further entrusted the counselor to send the informed consent form and the questionnaire survey link via WeChat. At the beginning of the 3rd week, I sent a message to remind those who were interested but who did not yet participate. In the 4 th week, I gave the final reminder and thanked the participants (Creswell \& Creswell, 2018). Counselors sent all invitation information via WeChat. Because participants reached the expected target of 1,200 respondents in advance, I finished the questionnaire collection in advance. In addition, to improve the student participation rates, I set up a raffle for my questionnaire on the Wenjuanxing website.

\section{Data Analysis Plans}

The procedures were described in full detail so that the study could be replicated by future researchers (Creswell \& Creswell, 2018). IBM SPSS Statistics 25 for Mac (www.spss.com) was used in the analysis. I downloaded the Excel data from the Wenjuanxing website. The first step was to analyze survey returns. I checked the specific recovery information of the sample, listed the number of students who did not respond, and discussed methods for determining response biases. The second step was to clear the outliers. The third was to conduct a descriptive analysis, which included continuous variables and categorical variables. A preliminary analysis described the data from all continuous variables and categorical variables in the study. I conducted descriptive data analyses for all predictor variables and outcome variables in the study. The continuous variables were descriptive statistics: frequency, minimum, maximum, means, standard deviations, skewness, and kurtosis. The categorical variables mainly examined the frequency. 
Subsequently, I used PCA to validate the reliability and validity of CSMS in Mainland China and to validate the reliability of CSPS. The descriptive analysis showed the mean, standard deviation, and the range of scores of the variables. Then, I conducted an inferential analysis and used the Pearson product-moment correlation and Spearman correlation to analyze the relationship between predictor variables and outcome variables (Leavy, 2017).

In the process, I used correlation to analyze the data. I used Pearson correlation to analyze the correlation between the overall CSMS and students' self-reported integration; the correlations between two constructs (PES, NAKS) and students' integration were discussed; Pearson product-moment correlation was used for all first-year college students, female students, the first-generation students, and four major groups' students. On account of the categorical characteristic of GPA, the nonparametric coefficient of Spearman correlation was used. I used Spearman correlation to analyze the correlation between the overall CSMS and students' cumulative GPA; the correlations between two constructs (PES, NAKS) and students' cumulative GPA. Spearman correlation was used for all first-year college students, female students, first-generation students, and four major groups' students.

All data were recoded to prepare for analysis. The self-reported cumulative GPA was as a predictive variable on a 6 -point scale: $6=3.50-4.00,5=3.00-3.49,4=2.50-2.99,3=2.00-$ $2.49,2=1.50-1.99,1=$ below 1.50 . The analysis showed the mean, standard deviation, and range of scores of the variables. I did data analyses when I collected my data to make sure the assumptions were made for using the Pearson correlation. Because the categorical variable of self-reported cumulative GPA was used as the outcome variable, I used nonparametric statistics, such as Spearman rank correlation. 


\section{Data Cleaning and Descriptive Analysis}

Before the descriptive analysis, I screened the data. I mainly carried out data cleaning from three aspects. First, there was a basic description of the frequency, the mean, the variance of all continuous variables. Then, I took a step closer and checked skewness, kurtosis, and if they were in the normal range. Second, categorical variables' statistical analyses were performed on sample groups to obtain a clear understanding of the population demographics. Measures of central tendency and dispersion (i.e., standard deviations, ranges) were checked. There were outliers in the category variables, such as participants whose ages were not in the normal range, and these data were deleted.

The study analyzed demographic factors such as gender, age, majors, first-generation, birthplace, and one-child family. I looked at demographic variables, using descriptive statistics and correlation analysis to determine relationships.

\section{Factor Analysis}

As the CSMS based on the four-factor model has been verified in Hong Kong, can the CSMS based on the four-factor model be used as a valid indicator to measure the first-year students' perceptions of peer mentoring in a Chinese FYE program? To answer Research Question 1, I carried out a factor analysis.

Factor analysis is a statistical method employed to discover a small group of unobserved variables, known as factors, that can explain the covariance between a larger set of observed variables known as dominant variables (Leavy, 2017). A factor is an unobservable variable that is imagined to impact the observed variable; factor analysis is also chosen to evaluate the reliability and validity of measurement scales (Albright \& Park, 2009; Carmines \& Zeller, 1979). With factor analysis, measurable and observable variables are reduced to a smaller number of 
potential variables that shared a common variance, called dimensionality reduction (Bartholomew et al., 2011).

Factor analysis has three main goals. The first function is to help researchers investigate the users of potential variables related to a group of items; therefore, factor analysis assists researchers in deciding whether a broader or more specific set of constructs is needed to depict a set of items (DeVellis, 2016). Factor analysis also reveals a path to explain changes between relatively more original variables, using relatively fewer newly created variables; the information is condensed while fewer variables explain changes in variables (DeVellis, 2016). The demarcation of defining the substance or significance (i.e., potential variables) is to show the differences between a greater set of items. The next function of the factor analysis is to identify which items contribute to the best performance (DeVellis, 2016).

Variables in the data should be normalized to perform factor analysis (Child, 2006). Outliers should be minimized in the relevant variables (Field et al., 2009). In addition, an important factor is the assumption of a linear relationship between factor and variable (Gorsuch, 1983). A minimum sample size of 300 people is recommended, with at least $5-10$ observations for each factor analysis variable (Comrey \& Lee, 1992). Second, the correlation coefficient $(r)$ must be greater than or equal to .30 , as any value lower indicates a very weak relationship between variables (Tabachnick et al., 2007).

PCA is one of the factor analyses commonly used by researchers. I used principal component analysis to validate the translation version of CSMS in Mainland China. Self-report research in psychological fields, such as attitude and perception surveys, focus on the coefficient alpha, construct validity (i.e., factor analysis), concurrent validity, and the criterion group method (Birchwood et al., 1994; Winters et al., 1990). Therefore, factor analysis is often an 
indispensable part of the research of self-reported measurement methods because it can effectively improve the validity of research methods.

The final sample size for this study was more than 1,100 , well over the 300 recommended for the analysis. The coefficient of items for the strength of intercorrelations was greater than .3 in this study. There are two factors with a Kaiser's criterion with an eigenvalue of 1.0, which are likely to be further investigated. I chose the oblique rotation method for the correlated factor solutions. Then, my study identified the principal axis factor for the CSMS as direct oblimin rotation with Kaiser normalization. Finally, standardized factor loading for the final scale, including the reliability of the new scale, was formed.

\section{Research Question 2}

How are first-year students' perceptions of peer mentoring on CSMS (and subscales PES, NAKS) scores correlated to integration scores as measured by CSPS scores in a Chinese FYE program?

Research Question 2a-2d: Are first-year students' perceptions of peer mentoring on CSMS (and subscales PES, NAKS) scores correlated to integration scores as measured by CSPS for (a) the whole group, (b) female students, (c) first-generation students, and (d) four major groups in a Chinese FYE program?

Hypotheses. The null hypotheses are there are no relationships between first-year students' perceptions of peer mentoring on CSMS (and subscales PES, NAKS) scores and integration scores as measured by CSPS scores for (a) the whole group, (b) female students, (c) first-generation students, and (d) four major groups in a Chinese FYE program. The alternative hypotheses are there are correlations between first-year students' perceptions of peer mentoring on CSMS (and subscales PES, NAKS) scores and integration scores as measured by CSPS 
scores for (a) the whole group, (b) female students, (c) first-generation students, and (d) four major groups in a Chinese FYE program.

Main Analysis. To answer Research Question 2, I implemented data analyses by calculating the coefficient of determination $\left(r^{2}\right)$ in a correlation between the scores of CSMS, PES, NAKS, and CSPS scores for (a) the whole group, (b) female students, (c) first-generation students, and (d) four major groups in a Chinese FYE program.

Correlation. I analyzed the correlation between the first-year students' perceptions of peer mentoring on CSMS (and subscales PES, NAKS) scores and integration scores as measured by CSPS and examined how much of the variance in student integration can be explained by CSMS for the whole group in a Chinese FYE program. Pearson correlations were used in the questions. The correlation coefficient $(r)$ measures the correlation between CSMS (and subscales PES, NAKS) scores and integration scores, as measured by CSPS for the whole group. The coefficient of determination showed as $r$-squared $\left(r^{2}\right)$ is the measurement of effect size (Cohen, 1988). The $r^{2}$ stands for the percentage of variance in CSPS explain by CSMS (Pallant, 2016). Moreover, it indicates whether there is a statistically significant correlation and the strength and direction of the relationship between the two variables. In terms of the strength of the Pearson correlation, variance between .10-0.29 is considered small; variance between $0.30-0.49$ is considered medium; and variance between 0.50-1.00 is considered large (Urdan, 2017). The Pearson correlation analysis can also be used to explain Questions 2b-2d.

\section{Research Question 3}

How are the first-year students' perceptions of peer mentoring on CSMS (and subscales PES, NAKS) scores correlated to the cumulative GPA scores in a Chinese FYE program? 
Research Question 3a-3d: Are first-year students' perceptions of peer mentoring on CSMS (and subscales PES, NAKS) scores correlated to the cumulative GPA scores for (a) the whole group, (b) female students, (c) first-generation students, and (d) different major groups in a Chinese FYE program?

Hypotheses. The null hypotheses are there are no relationships between first-year students' perceptions of peer mentoring on CSMS (and subscales PES, NAKS) scores and the cumulative GPA scores for (a) the whole group, (b) female students, (c) first-generation students, and (d) different major groups in a Chinese FYE program. The alternative hypotheses are there are correlations between first-year students' perceptions of peer mentoring on CSMS (and subscales PES, NAKS) scores and the cumulative GPA scores for (a) the whole group, (b) female students, (c) first-generation students, and (d) different major groups in a Chinese FYE program.

Main Analysis. To answer Research Question 3, I implemented data analyses by calculating the coefficient of determination $\left(r_{s}{ }^{2}\right)$ in a correlation between the scores of CSMS, PES, NAKS and the cumulative GPA scores for (a) the whole group, (b) female students, (c) first-generation students, and (d) different major groups in a Chinese FYE program.

Correlation. I analyzed the correlation between the first-year students' perceptions of peer mentoring on CSMS (and subscales PES, NAKS) scores and the cumulative GPA scores and examined how much of the variance in student integration could be explained by CSMS for the whole group in a Chinese FYE program. Spearman correlations were used in these questions. The correlation coefficient $r_{s}$ measures the correlation between CSMS (and subscales PES, NAKS) scores and GPA scores for the whole group. The coefficient of determination showed as rho-squared $\left(r_{s}^{2}\right)$ is the measurement of effect size (Cohen, 1988). The $r_{s}^{2}$ stands for the 
percentage of variance in GPA explain by CSMS (Pallant, 2016). Moreover, it indicates whether there is a statistically significant correlation and the strength and direction of the relationship between the two variables. In terms of the strength of the correlation, the variance of .10-0.30 is explained as small; the variance of $0.40-0.60$ is explained as medium; the variance of $0.70-0.90$ is explained as large (Urdan, 2017). The correlation analysis can also be used to explain Questions 3b-3d.

\section{Assumptions}

There are two basic assumptions in this study. First, the data filled in the self-reported scales by participants in this study were their personal, authentic perceptions and authentic status. Second, I believed the survey study results from T College are instructive to other private colleges and universities in China.

In addition, an important factor is the assumption of a linear relationship between the factor and the variable (Gorsuch, 1983). The assumptions of a correlation test are normality, linearity, and homoscedasticity (Pallant, 2016). Assumption checks mainly focused on normality, linearity, and homoscedasticity. Bivariate correlational analysis was conducted to assess the strength and direction of the correlation.

\section{Ethical Considerations}

I conducted postprogram research to measure students' perceptions of mentoring support at $\mathrm{T}$ College. I was the director of student affairs for more than 10 years at a Chinese private college, and I researched students from a private college. Given the relationship between college administrators and students, if any students who participated in the questionnaire felt uncomfortable, they could have withdrawn from the questionnaire at any time. Before the implementation of the questionnaire, the implementation plan was approved by Chapman 
University and T College. Second, all the questionnaire participants were 18 years old and signed the informed consent in Chinese. The content of this questionnaire was only used for the research of this dissertation and potential future research. The research of this project was beneficial for future FYE program improvement at T College and to better promote the university transition of first-year students. During the sampling process of this study, the researcher fully respected the independent choice of participating students. Students could terminate or withdraw from the questionnaire at any time, and all the participating students were equally respected. The implementation of this program paid full attention to the legal, ethical, and academic norms of the United States and China, and approved by the Institutional Review Board (IRB).

I took some measures to ensure risks were minimized in data analysis. First, I protected the data security from the beginning when students filled in the questionnaire. Wenjuanxing, which distributed electronic questionnaires, had strict password protection, and only the researcher had access to data. I bought a more secure enterprise version of the Wenjuanxing account, and the data filled in by students were well protected from the beginning. Second, all electronic data has been stored on a designated and password-protected computer. The computer that stores the data is a stationary desktop that could not be carried out of the room. All entrances to the rooms where the computers are stored are strictly secured. All participants' data were collected anonymously without any personal identifiers. I will keep my data with no identifying information for 7 years. Then, I will delete all the information.

\section{Summary}

In this study, quantitative research was carried out via survey. The self-reported survey was appropriate and applicable for measuring first-year students' perceptions of their peer mentoring. Crisp's (2009) CSMS from the United States and was translated to Mainland China 
contexts for the study. In this process, I used scale translation and principal factor analysis to reexamine its reliability and validity. In the translation process, I used a 5-step translation method of cross-cultural adaptation based on the review of the expert committee. Correlation research methods were used to analyze the relationship between perceived peer mentoring support and first-year student success. Participants are from the class of 2022 at T College. With the help of counselors, an online questionnaire was used. Data collection was completed within a month. The validated CSMS in Mainland China has only two dimensions (PES, NAKS). In the data analysis, Pearson correlation and Spearman correlation methods were used. The coefficient of determination showed the measure of effect size. The strength and direction of the correlation between peer mentoring and student success were also discussed. Two research questions were discussed in each of the four groups: all first-year students, female students, first-generation students, four different major groups. Finally, assumptions and ethical considerations were discussed. 


\section{CHAPTER 4: RESULTS}

Chapter 4 presents results from the data analysis of three main research questions in this study. The data analysis procedures included preliminary analyses, factor analysis, and correlation analyses. Preliminary analyses consisted of demographic variables, College Student Mentoring Scale (CSMS) items, and outcome variables. Principal component analysis (PCA) was used to validate CSMS in a Chinese first-year experience (FYE) program. Factor extraction and factor rotation were interpreted to validate CSMS. Correlation analyses were used to examine (a) the relationship between students' perceptions of mentoring support and student integration, and (b) the relationship between students' perceptions of mentoring support and their cumulative grade point average (GPA).

\section{Research Purpose and Research Questions}

The purpose of this study was to validate Crisp's (2009) CSMS in Mainland China and to examine the relationship among mentoring support, student integration, and cumulative GPA for all participants in a Chinese FYE program at T College, including by gender, first generation status, and major. Table 6 shows the three research questions and their corresponding analysis methods. 


\section{Table 6}

Research Questions and Analysis Methods

\begin{tabular}{lc}
\hline \multicolumn{1}{c}{ Research questions (RQ) } & Analysis method \\
\hline RQ1: Can the CSMS based on the four-factor model be used as a & PCA \\
valid indicator to measure first-year students' perceptions of peer & \\
mentoring in a Chinese FYE program? & \\
RQ2: How are first-year students' perceptions of peer mentoring on & Pearson product-moment \\
CSMS correlated to integration as measured by CSPS in a Chinese & \\
FYE program for total, gender, first generation status, majors' & Correlation coefficient \\
groups? & Effect size $(r$-square) \\
RQ3: How are first-year students' perceptions of peer mentoring on & Spearman \\
CSMS related to cumulative GPA in a Chinese FYE program for & \\
total, gender, first generation status, majors'groups? & Correlation coefficient \\
& Effect size $\left(r_{s}\right.$-square) \\
\hline
\end{tabular}

\section{Preliminary Analyses}

Three kinds of variables have been presented in this section: demographic variables, predictor variables (items from CSMS), and outcome variables. First, I described basic characteristics of demographic variables. For these categorical variables, frequency and percentage were calculated. Second, I preliminarily analyzed 25 CSMS items from the predictor variables, including assumption checking for factor analysis. For the continuous variables, I calculated mean, standard deviation, maximum, minimum, skewness, and kurtosis. Third, the College Student Perception Scale (CSPS) included six items as one outcome variable and cumulative GPA as another outcome variable. The mean and standard deviation of variables were described, and reliability of CSPS was checked. In this section, I present the results of all descriptive statistics.

\section{Demographic Variables}

The demographic variables in this study focused on participants' personal characteristics (i.e., gender, age, Hukou, one-child family status, and first-generation status) and academic 
background (i.e., major and GPA). All demographic variables were categorical. I calculated and presented the frequency and percentage of each variable.

\section{Gender}

The study included 879 (76.2\%) female respondents and 274 (23.8\%) male respondents. The percentage showed more female respondents compared to male respondents. The gender ratio aligns with the study body of the private college sampled in this study, with the overall ratio of female students to male students at about 7:3 (T College Profile, 2021). The demographic profile of the respondents includes a detailed description of respondents' genders (see Table 7).

\section{Table 7}

Demographic Characteristics of Participants

\begin{tabular}{lcc}
\hline \multicolumn{1}{c}{ Characteristic } & $n$ & $\%$ \\
\hline Gender & & \\
Male & 274 & 23.8 \\
Female & 879 & 76.2 \\
Age & & \\
18 & 102 & 8.8 \\
19 & 113 & 9.8 \\
20 & 571 & 49.5 \\
21 & 282 & 24.5 \\
22 & 65 & 5.6 \\
23 & 14 & 1.2 \\
24 & 6 & .5 \\
Hukou & & \\
Others & 20 & 1.7 \\
Shanghai & 602 & 52.0 \\
Jiangsu & 60 & 5.2 \\
Zhejiang & 57 & 4.9 \\
Anhui & 85 & 7.4 \\
Inner Mongolia & 8 & .7 \\
Sichuan & 32 & 2.8 \\
Chongqing & 7 & .6 \\
Shandong & 4 & .3 \\
Hunan & 3 & .3 \\
Guangdong & 8 & .7 \\
& &
\end{tabular}




\begin{tabular}{lcc}
\hline \multicolumn{1}{c}{ Characteristic } & $n$ & $\%$ \\
\hline Guangxi & 16 & 1.4 \\
Yunnan & 11 & 1.0 \\
Xinjiang & 31 & 2.7 \\
Jiangxi & 10 & .9 \\
Shanxi & 39 & 3.4 \\
Guizhou & 49 & 4.2 \\
Fujian & 3 & .3 \\
Xizang & 3 & .3 \\
Ningxia & 1 & .1 \\
Gansu & 22 & 1.9 \\
Hainan & 19 & 1.6 \\
Henan & 51 & 4.4 \\
Liaoning & 4 & .3 \\
Heilongjiang & 10 & .9 \\
One-child status & & \\
One-child family (OCF) students & 797 & 69.1 \\
Non-OCF students & 356 & 30.9 \\
First generation status & & \\
First generation (FG) students & 640 & 55.5 \\
Non-FG students & 513 & 44.5 \\
\hline
\end{tabular}

Note. $N=1,153$.

Age

Of the included 1,153 respondents, all (100\%) were 18-24 years old; most participants (571) were 20-years-old (49.5\%), and 282 participants were 21-years-old (24.5\%). During the data-cleaning stage, ages of three participants were not within the normal range and were removed from the study dataset. All participants' ages were in line with my expectations at $\mathrm{T}$ College (see Table 2 for a detailed description of respondents' ages).

\section{Hukou}

The Hukou system has the power to restrict migration and provide state-funded benefits to most of China's rural population. It also created uneven access to education for students in different Hukou regions (Chan \& Buckingham, 2008). In this study, 1,153 participants came from more than 24 provinces, as measured by Hukou in Mainland China. First, $71 \%$ of 
participants' data indicated their Hukou were from Eastern China: 600 from Shanghai (52.0\%), 85 from Anhui (7.4\%), 60 from Jiangsu (5.2\%), 57 from Zhejiang (4.9\%), 10 from Jiangxi (.9\%), four from Shandong (.3\%), and three from Fujian (.3\%). Second, 5.3\% of participants were from North and Northeast China: 39 from Shanxi (3.4\%), eight from Inner Mongolia (.7), 10 from Heilongjiang (.9\%), and four from Liaoning (.3\%). Of participants, $8.9 \%$ were from Southwest China: 32 from Sichuan (2.8\%), 11 from Yunnan (1\%), 49 from Guizhou (4.2\%), eight from Chongqing (.7\%), and three from Xizang (.3\%). Of participants, 9.6\% were from Central and Northwest China: three from Hunan (.3\%), 52 from Henan (4.5\%); one from Ningxia (.1\%), 31 from Xinjiang (2.7\%), and 22 from Gansu (1.9\%). Furthermore, 3.7\% were from South China: eight from Guangdong (.7\%), 16 from Guangxi (1.4\%), and 19 from Hainan (1.6\%). Finally, 20 participants (1.7\%) did not specify their Hukou location. The data distribution of this sample was in line with the actual composition of the school and my expectation. Students with Shanghai Hukou accounted for about 50\% of the total sampled private universities. Anhui, Guizhou, Jiangsu, Zhejiang, Henan, Xinjiang, and Shanxi were the provinces with the highest number of participating students outside Shanghai. The demographic profile of respondents includes a detailed description of respondents' Hukou of provinces (see Table 2).

\section{One-Child Family}

The one-child policy was a national policy implemented for more than 30 years in the latter half of the 20th century in Mainland China; students from families with only one child encounter certain difficulties when learning and living together in schools (Cameron et al., 2013). Students from one-child families face more obstacles in college than students from nonone-child families (Chen et al., 2012). In the study, 801 participants $(69.2 \%)$ were from one- 
child families, and 356 participants (30.8\%) were from non-one-child families. Table 2 has a detailed description of respondents' family status.

\section{First Generation}

In the study, 640 participants $(55.5 \%)$ were first-generation students and 513 participants $(44.5 \%)$ were non-first-generation students. The demographic profile of respondents in Table 2 includes a detailed description of respondents' generational status.

\section{Academic Background}

The academic background of participants included two aspects: student major groups' distribution and cumulative GPA (see Table 3).

\section{Majors}

In this study, 1,153 participants came from 25 majors, divided into four types: (a) education; (b) humanities; (c) business; and (d) science, technology, engineering, and math (STEM) majors. First, education majors included early childhood education, art education, primary education, and English education. Students majoring in education had high degrees of participation, with 440 participants $(38.2 \%)$ from education majors, including two international, cooperative education majors. Second, humanities majors included Japanese, international education of Chinese language, Chinese language and literature, digital media art, visual art communication, and environmental design. There were 203 participants $(17.6 \%)$ in the humanities. Third, business majors included international business, tourism management, financial management, logistics management, financial mathematics, and online finance. There were 320 participants $(27.8 \%)$ in business majors. Finally, STEM majors consisted of 11 specific majors, divided into two main areas, engineering and health. There were 190 participants $(16.5 \%)$ in STEM majors. The number of participants majoring in education was higher than that 
of students majoring in the other three categories, which met my general expectation (see Table 3 for a detailed description of respondents' majors).

\section{GPA}

The self-reported, cumulative GPA of 887 participants (76.9\%) was mainly distributed between 2.00 and 3.49. There were 83 participants (7.2\%) with a cumulative GPA between 3.50 and $4.00 ; 183$ participants $(16.0 \%)$ had a cumulative GPA between 0 and 1.99 . The GPA distribution of students who participated in the questionnaire was reasonable, which met my general expectations (see Table 8 for a detailed description of respondents' cumulative GPAs).

\section{Table 8}

Academic Characteristics of Participants

\begin{tabular}{lcc}
\hline \multicolumn{1}{c}{ Characteristic } & $n$ & $\%$ \\
\hline Major groups & & \\
Education & 440 & 38.2 \\
Humanities & 203 & 17.6 \\
Business & 320 & 27.8 \\
STEM & 190 & 16.5 \\
Cumulative GPA & & \\
3.50-3.99 & 83 & 7.2 \\
3.00-3.49 & 239 & 20.7 \\
$2.50-2.99$ & 379 & 32.9 \\
2.00-2.49 & 269 & 23.3 \\
$1.50-1.99$ & 87 & 7.5 \\
1.50-below & 96 & 8.3 \\
\hline
\end{tabular}

Note. $N=1,153$.

\section{Description of CSMS 25 Items}

The CSMS involved in this study had a total of 25 items. As a continuous variable, I conducted correlation analysis to calculate the mean, minimum, maximum, standard deviation, skewness, and kurtosis of CSMS scores (see Table A1). The frequency of 25 CSMS items was 
1,153. Mean values of 25 CSMS items were between 3.84 and 4.03. Standard deviation values of 25 CSMS items were between .692 and .806 . Skewness values of 25 CSMS items were between -.628 and -.294. The kurtosis values of 25 CSMS items were between .010 and 1.242. The values were within the normal range.

\section{Outcome Variables}

In this study, I analyzed two outcome variables whose means, and standard deviations were within the normal range. Characteristics of the two variables are shown in Table 9.

\section{Table 9}

Outcome Variables

\begin{tabular}{lccc}
\hline \multicolumn{1}{c}{ Variables } & $M$ & $S D$ & Range \\
\hline CSPS & 28.77 & 3.85 & $36-19=17$ \\
GPA & 3.72 & 1.30 & $6-1=5$ \\
\hline
\end{tabular}

\section{CSPS}

The CSPS has six items for examining student integration (see Table 10). The frequency of all its six items was 1,153 , and its mean value and standard deviation were within the normal range. Next, I performed a reliability analysis to examine the internal consistency of the CSPS, including six items. This reliability analysis revealed CSPS items formed a reliable scale ( $\alpha$ $=.822$ ), and the alpha would be improved following removal of CSPS 06 (i.e., Item 6: I hope to graduate from college in four years). This means that reliability of CSPS is high for colleges and 
universities in Mainland China, especially if Item 6 were deleted, improving Cronbach's alpha to .836 .

\section{Table 10}

Descriptive Statistics of CSPS

\begin{tabular}{lccc}
\hline \multicolumn{1}{c}{ Items of CSPS } & Frequency & $M$ & $S D$ \\
\hline $\begin{array}{l}\text { 1. I feel like I've been integrated into the campus. } \\
\text { 2. I have a strong and positive emotional connection to }\end{array}$ & 1,153 & 4.79 & .806 \\
$\quad$ this university. & & 4.39 & .925 \\
$\begin{array}{l}\text { 3. I consider myself an active participant on campus. } \\
\text { 4. I have at least one person in the university to whom I }\end{array}$ & 1,153 & 4.54 & .916 \\
$\quad$ can turn for academic support and help. & & 4.82 & .980 \\
$\begin{array}{l}\text { 5. I have at least one person in the university to whom I } \\
\quad \text { can turn for academic support and help. }\end{array}$ & 1,153 & 4.88 & .865 \\
6. I hope to graduate from college in four years. & 1,153 & 5.34 & .778 \\
\hline
\end{tabular}

\section{GPA}

In this study, the self-reported, cumulative GPA of 889 participants (76.8\%) was mainly distributed between 2.00 and 3.49. There were 84 participants (7.2\%) with a cumulative GPA between 3.50 and 4.00, and 185 participants (16.0\%) with a cumulative GPA between 0 and 1.99. The GPA distribution of students who participated in the questionnaire was reasonable, which met my expectation (see Table 3 for a detailed description of respondents' cumulative GPA).

The demographics of gender, age, Hukou, one-child family, and first-generation status from students sampled in this study generally met my research expectations and reflected the overall characteristics of students at the private college. The academic backgrounds of major groups and cumulative GPA from sampled students as predictor variables were in the normal range. 


\section{Descriptive Statistics and Factor Analysis}

To answer Research Question 1, I inspected the distribution of 25 items in the CSMS. Suitability assessment of analyzed items is the prerequisite for carrying out factor analysis. The descriptive statistics analysis checks the assumptions for the factor analysis. Basic assumptions have been examined in four main ways: (a) sample size, (b) factorability of the correlation matrix, (c) linearity, and (d) outliers among cases (Pallant, 2016).

Research Question 1: Can the CSMS based on the four-factor model be used as a valid indicator to measure first-year students' perceptions of peer mentoring in a Chinese FYE program?

\section{Sample Size}

The first assumption check involved evaluating whether data were suitable for factor analysis. The standard requirement is the size of sample data, which should have at least 300 cases. With more than 1,100 cases in this study, the sample size was sufficient to meet the factor analysis requirement.

\section{Assessing Suitability}

The second assumption checked was to consider the factorability of the correlation matrix and the strength of the intercorrelation of each factor. The correlation coefficients of the matrix were at least above .3 to prepare for factor analysis (Pallant, 2016). The coefficients of the correlation matrix were all larger than .3 , so this aspect was suitable for the procedures (see Table A2).

\section{Correlation Matrix Factorability}

Factor extraction and factor rotation are conducted to determine the smallest number of factors, and PCA is most used for factor extraction (Pallant, 2016). Kaiser's criterion can be used 
to decide the number of factors, but only factors with an eigenvalue of 1.0 or more should be retained (Pallant, 2016). Two factors had an eigenvalue of 1.0 in this study.

When the number of factors was determined, it was time to consider how to interpret them. Orthogonal factor solution is used for uncorrelated situations, with oblimin factor solution used for correlated situations. In this study, the overall correlation of 25 items was greater than or equal to .599 (see Table A2). Large correlations between the items were identified, which meant that I chose direct oblimin rotation method.

\section{Linearity and Outliers}

Next, I conducted the linearity check. Based on sample data of more than 1,100 cases and a spot check (see Table A1), this study could be regarded as linear. Finally, I checked outliers among cases, and deleted 48 cases of outliers.

\section{Factor Analysis}

PCA is a statistical way to find a smaller number of linear combinations of original variables, with all variances in original variables being used (Pallant, 2016). Crisp's (2009) CSMS included four dimensions: psychological and emotional support, degree and career support, academic subject knowledge support, and role modeling, and its reliability and validity were widely tested in the field of higher education in the United States. As described in detail in the previous chapter, I translated CSMS into a Chinese scale, meaning that its validity and reliability in the context of Mainland China had yet to be validated. I used PCA to confirm the construct of CSMS in the Mainland China context.

The 25 items of the CSMS were subjected to PCA using SPSS version 25. Prior to performing PCA, I assessed the suitability of data for factor analysis. Inspection of the correlation matrix in Table A2 revealed the Kaiser-Meyer-Olkin (KMO) value was .983, 
exceeding the recommended value of .6 (Kaiser, 1974), and Bartlett's test of sphericity (Bartlett, 1954) reached statistical significance, supporting the factorability of a correlation matrix. Variables with communalities lower than .40 do not contribute much to measuring the underlying factors and should be removed (Pallant, 2016); in the case of this study, all 25 items of CSMS with communalities were greater than .4 threshold. In addition, each component had a quality score eigenvalue; only components with high eigenvalues were likely to represent a real underlying factor (Pallant, 2016). The first two components had eigenvalues over 1. I considered these strong factors. Eigenvalues dropped dramatically after Component 3 and onward.

Corner (2009) advocated that if variables analyzed are highly correlated when conducting PCA, direct oblimin factor rotation is the best choice. The initial factor analysis - using principal components of extraction and direct oblimin factor rotation - produced two factors with eigenvalues greater than 1.0, which meant only two-dimensional, new constructs were generated (Pallant, 2016). Compared with original CSMS in Western countries, there were validated constructs in the Mainland China context. The first factor was distinguished by strong factor loadings for all eight of the psychological and emotional support items and none of the other items. This factor explained $69 \%$ of total variance of the items. The second factor had strong factor loadings for all five subject knowledge support items, six degree and career support items, and six existence of role model items, which explained an additional $4 \%$ of the variance.

I found two expected concepts via this PCA. The two-component solution explained a total of $73 \%$ of the variance, with Psychological and Emotional Support contributing 69\% and Subject Knowledge Support contributing 3\%. Table 11 is the specific component matrix rotated, which showed the discussion results. 
Table 11

Principal Axis Factor for CSMS

\begin{tabular}{lcc}
\hline \multicolumn{1}{c}{ Rotated factor matrix } & \multicolumn{2}{c}{ Factor } \\
\cline { 2 - 3 } & PES & AKS \\
\hline CSMS03. encourage me to use him or her as my advisor in exploring college & .939 & -.060 \\
life & & \\
CSMS02. discuss with him or her various social issues related to the university & .929 & -.048 \\
CSMS04. ask at least one person for emotional support and help & .882 & .004 \\
CSMS01. acknowledge my academic achievements & .862 & -.012 \\
CSMS05. talk openly about personal problems related to college life & .834 & .053 \\
CSMS06. make me feel that I have a sense of belonging in the university & .759 & .139 \\
CSMS08. encourage me to talk about social problems at university & .727 & .168 \\
CSMS07. fully Confident that I can complete my study & .634 & .261 \\
CSMS12. help me check the requirements for degree and certificate & -.100 & .933 \\
CSMS15. provide continuous support for my study in class & -.093 & .931 \\
CSMS20. share story of overcoming difficulties to achieve academic goals & -.062 & .897 \\
CSMS17. help me to achieve my academic success & -.004 & .882 \\
CSMS18. provide practical suggestions for improving my academic & -.014 & .877 \\
performance & & \\
CSMS21. be an example of how to succeed in college & -.033 & .874 \\
CSMS19. encourage me to discuss problems in the course assignments & -.006 & .862 \\
CSMS14. help me consider the cost of my choice to a college degree & -.013 & .860 \\
CSMS13. discuss the importance of degree choices in different majors & .005 & .844 \\
CSMS16. help me to exert my best potential in class performance & .046 & .829 \\
CSMS11. guide me to rationally evaluate my skills, to question my & .092 & .773 \\
assumptions & & .115 \\
CSMS10. examine the possibility of obtaining my degree and certificate & .738 \\
CSMS22. set a good example of how to get along with others & .185 & .653 \\
CSMS24. have great respect for his (her) views on issues related to the & & .674 \\
university & .286 & .627 \\
CSMS23. want to emulate his (her) behavior in college & .364 & .496 \\
CSMS25. I admire them & & \\
CSMS09. encourage me to consider opportunities beyond the current plans. & & \\
\hline
\end{tabular}

Note. KMO \& Bartlett's Test $=.983$, chi-square $=31688.463, d f=300$, sig $<.001$.

\section{Reliability Analysis}

Next, I performed a reliability analysis to examine the internal consistency of the two factors produced by the PCA. Two concepts of CSMS, Psychological and Emotional Support 
construct (PES) and New Academic Subject Knowledge Support (NAKS) were validated from 25 items; the internal consistency of PES $(\alpha=.957)$ and NAKS $(\alpha=.974)$ were high. All of these items had item-total correlations greater than .496 , and Cronbach's alpha would not be improved with the removal of any single item. Finally, degree and career support items and the existence of a role model items failed to load on the final CSMS. The six degree and career support items and six existence of a role model items were integrated into the Subject Knowledge Support factor.

In summary, Table 11 includes the validation on reliability and validity of CSMS used in this study. CSMS, based on the four-factor model, failed to be a valid indicator for measuring first-year students' perceptions of peer mentoring in a Chinese FYE program at T College. Therefore, hypothesis 1a was not fully supported in Mainland China. Only two constructs of CSMS, Psychological and Emotional Support construct (PES) and New Academic Subject Knowledge Support (NAKS), were validated in the Mainland China context. Factor loading for the final scale was formed in Table 12. The reliability of CSMS was also very high, which was successfully validated at a private college in Mainland China. 
Table 12

Standardized Factor Loading for Final Scale

\begin{tabular}{ccc}
\hline Factor & Factor loading & Cronbach's alpha \\
\hline Factor 1: Psychological & & .957 \\
and Emotional Support & & \\
X3 & .939 \\
X2 & .929 \\
X4 & .882 \\
X1 & .862 \\
X5 & .834 \\
X6 & .759 \\
X8 & .727 \\
X7 & .634 \\
Factor 2: New Academic & & \\
Knowledge Support & \\
X12 & .933 \\
X15 & .931 \\
X20 & .897 \\
X17 & .882 \\
X18 & .877 \\
X21 & .874 \\
X19 & .862 \\
X14 & .860 \\
X13 & .844 \\
X16 & .829 \\
X11 & .773 \\
X10 & .738 \\
X22 & .674 \\
X24 & .653 \\
X23 & .627 \\
X25 & .564 \\
X09 & .496 \\
\hline
\end{tabular}

\section{Descriptive Statistics and Correlation Analysis}

Checking assumptions of correlation were conducted for the predictor variables and outcome variables in this study. Based on three assumptions of normality, linearity, and homoscedasticity, two correlations among the variables have been presented via the major research questions and subtests. All scores of predictor and outcome variables involved in this study were standardized with $z$ scores. 


\section{Description of Variables}

In this study, the predictor variables are the Chinese version of CSMS and the two constructs of CSMS validated at T College in Mainland China: PES and NAKS (Crisp, 2009). The outcome variables are defined as CSPS and cumulative GPA. All predictor variables in this study are continuous. The variable of CSPS is continuous and the variable of GPA is categorical.

Next, I used correlation tests to examine the relationship between peer mentoring (CSMS) and student success (CSPS and GPA). First, because the two variables (CSMS and CSPS) covered in Research Question 2 have a linear relationship, a Pearson product-moment correlation was used (Urdan, 2017). Second, because the two variables (CSMS and GPA) covered in Research Question 3 have a nonparametric relationship, Spearman's rank order correlation was used. Meanwhile, I investigated three demographic characteristics (i.e., gender, first-generation, and majors' groups) in the study in the subquestions. Descriptive statistics of the primary final variables are shown in Table 13. The total score and two subscales of CSMS, CSPS, and GPA were all checked by mean and standard deviation. All variables examined were within the normal range (see Table 13). 


\section{Table 13}

Descriptive Statistics of the Primary Final Variables

\begin{tabular}{lllllll}
\hline Participants & M/SD & CSMS & PES & NAKS & CSPS & GPA \\
\hline All & & & & & & \\
& $M$ & .0944 & .0899 & .0033 & .5958 & .0025 \\
Female & $S D$ & .8523 & .8716 & .9930 & .9417 & .9965 \\
& & & & & & \\
& $M$ & .0545 & .0468 & -.0383 & .0877 & .1447 \\
First & $S D$ & .8664 & .8852 & 1.0101 & .9229 & .9477 \\
generation & & & & & & \\
& $M$ & .1155 & .1115 & .0268 & .0755 & -.0249 \\
Majors & $S D$ & .8530 & .8775 & .9879 & .9496 & .9901 \\
Education & $M$ & .2098 & .2129 & .1291 & .2084 & .1943 \\
& $S D$ & .8616 & .8814 & 1.0015 & .9183 & .9659 \\
Humanities & $M$ & .1491 & .1406 & .0675 & .0389 & -.0374 \\
& $S D$ & .8503 & .8482 & .9924 & .9521 & 1.1241 \\
Business & $M$ & -.0256 & -.0456 & -.1232 & -.0239 & .0562 \\
& $S D$ & .8789 & .9166 & 1.0232 & .9508 & .8356 \\
\multicolumn{1}{c}{ STEM } & $M$ & -.0289 & -.0207 & -.1438 & -.1223 & -.4892 \\
& $S D$ & .7442 & .7465 & .8778 & .9251 & 1.0111 \\
\hline
\end{tabular}

Note. For all students group $N=1,053$; for female students group $n=879$; For first-generation students group $n=797$; for education major groups $n=440$; for humanity major groups $n=272$; for business major groups $n=251$; for STEM major groups $n=190$.

\section{Assumption Checking}

Checking the assumption is an important premise before the correlation analysis (Urdan, 2017). After checking normality, linearity, and homoscedasticity, two parts of analyses and eight subsets answered Research Question 2 and Research Question 3, respectively. Assumptions of normality, linearity, and homoscedasticity for correlations are tested by observing scatterplots and simple histograms, and the three assumptions should not be violated (Pallant, 2016).

Generating a scatterplot for preliminary analysis is also helpful; if the data clearly showed the shape of a long, narrow cigar, researchers could preliminarily assume the two variables were 
linear; if the simple histogram showed a bell-shaped normal distribution, researchers could assume the variable is normally distributed (Pallant, 2016).

Based on preliminary test results, the scores in CSMS and the scores in CSPS have a statistically significant linear relationship $(p<.001)$; the scores in CSMS and the scores in GPA have a statistically significant, nonparametric relationship in some student groups $(p<.005)$. As a result, I used Pearson's correlation coefficient ( $r$ ) to answer Research Question 2 and to determine the direction and strength of the relationship between CSMS and CSPS. I used Spearman correlation $\left(r_{\mathrm{s}}\right)$ to answer Research Question 3 and determine the direction and strength of the relationship between CSMS and GPA.

By looking at the scatterplot and simple histogram graphs, the variables CSPS, GPA, CSMS, PES, and NAKS were normally distributed. The assumptions of normality, linearity, and homoscedasticity were not violated for Research Question 2 (see Appendix B, Figures B1-B45). The variable of GPA was categorical, so the nonparametric technique was used for Research Question 3. I performed preliminary analyses to ensure no violation of the assumption of normality, linearity, and homoscedasticity (see Figures B46-B73).

The following sections explain the results of data analysis in this dissertation. The key point to be interpreted was the correlation analysis of output from SPSS. The following parts of the analysis mainly answer Research Questions 2 and 3. In using Pearson's correlation and Spearman's correlation methods, the coefficient of determination showed the measure of effect size. I also discuss the strength and direction of the correlation between peer mentoring and student success.

Each main research question was followed by four subquestions on first-year students, female students, first-generation students, and four major groups of students. In addition, the 
correlations of the two constructs (i.e., PES and NAKS) to the dependent variables were analyzed under each subquestion. There was a strong correlation between CSMS and CSPS for four demographic mentored participants.

\section{Correlation Analysis}

First, to examine the construct validity of the Chinese version CSMS for all first-year students, gender, generational, majors' groups in this study, I examined the correlation between all variables in this study. As shown in Table 14, the correlation coefficients between all variables were higher than .8 in this study. Correlation coefficients between variables were all above .3, which proved that the Chinese version CSMS has a good structure (Pallant, 2016).

Second, to answer the research questions raised in the first chapter, I adopted the research methods of Pearson's correlation and Spearman's correlation to examine the correlation between variables. The strength of the correlation between the two variables is represented by Pearson's correlation $(r)$ or Spearman's correlation $\left(r_{s}\right)$. Developed for psychological research, Cohen (1988) used $r$ to explain correlation strength. There are two basic directions in correlation; when the $r$ value is positive, it means two variables are positively correlated; when $r$ is negative, two variables are negatively correlated. Moreover, if $r$ is 1 , the two variables are a perfectly positive correlation, and if the $r$ value is 0 , the two variables are not related. The correlation includes absolute value (e.g., positive and negative values); a Pearson correlation coefficient ( $r$ ) between \pm .10 to \pm .29 is considered a weak or small correlation (Cohen, 1988); a correlation coefficient of \pm .30 to \pm .49 is considered moderately correlated; a correlation coefficient of \pm 0.50 to \pm 1.00 is considered a strong or large correlation (Cohen, 1988).

A Spearman correlation coefficient $\left(r_{s}\right)$ between \pm .10 to \pm .30 is considered a weak or small correlation (Cohen, 1988); a correlation coefficient of \pm .40 to \pm .60 is considered 
moderately correlated; a correlation coefficient of \pm .70 to \pm .90 is considered a strong or large correlation (Akoglu, 2018). The coefficients of determination $\left(r^{2}\right.$ and $\left.r_{s}^{2}\right)$ were calculated to explain the percentage of variation between the two variables (Pallant, 2016). Then effect size was explained.

\section{Table 14}

Correlations Among CSMS Variables for Different Groups

\begin{tabular}{lcccc}
\hline \multicolumn{1}{c}{ Groups } & Variables & CSMS & PES & NAKS \\
\hline All first-year students & CSMS & 1 & & \\
& PES & $.948^{* *}$ & 1 & \\
& NAKS & $.986^{* *}$ & $.882^{* *}$ & 1 \\
Female & CSMS & 1 & & \\
& PES & $.948^{* *}$ & 1 & \\
First-generation & NAKS & $.986^{* *}$ & $.882^{* *}$ & 1 \\
& CSMS & 1 & & \\
& PES & $.952^{* *}$ & 1 & \\
MG-Education & NAKS & $.987^{* *}$ & $.981^{* *}$ & 1 \\
& CSMS & 1 & & \\
& PES & $.951^{* *}$ & 1 & \\
MG-Humanity & NAKS & $.987^{* *}$ & $.888^{* *}$ & 1 \\
& CSMS & 1 & & \\
& PES & $.951^{* *}$ & 1 & \\
MG-Business & NAKS & $.987^{* *}$ & $.888^{* *}$ & 1 \\
& CSMS & 1 & & \\
& PES & $.937^{* *}$ & 1 & \\
MG-STEM & NAKS & $.983^{* *}$ & $.857^{* *}$ & 1 \\
& CSMS & 1 & & \\
& PES & $.943^{* *}$ & 1 & \\
& NAKS & $.986^{* *}$ & $.874^{* *}$ & 1 \\
\hline
\end{tabular}

Note. $* *$ Correlation is significant at the 0.01 level (2-tailed). MG is abbreviation for Major Groups.

To further explore the potential relationship, the correlations between the CSMS total score of 1,053 participants and the scores of each part of the four subscales of CSMS were 
tested. Supporting tables for each subtest were provided (see Table A3) and supporting figures were provided in Appendix B (Figures B1-B73).

\section{Research Question 2}

How are the first-year students' perceptions of peer mentoring on CSMS (and subscales PES, NAKS) scores correlated to integration scores as measured by CSPS scores in a Chinese FYE program?

Based on the validity test of the Chinese version of CSMS showed in Table 14, CSMS had high construct validity for the participants in this study.

\section{Correlation Between CSMS and CSPS Scores for All First-Year Students}

Research Question 2a: Are all first-year students' perceptions of peer mentoring on CSMS (and subscales PES, NAKS) scores correlated to integration scores as measured by CSPS in a Chinese FYE program?

The relationship between all first-year students' perceptions of peer mentoring, as measured by the CSMS, and integration scores, as measured by CSPS, was investigated using the Pearson product-moment correlation coefficient. There was a strong, positive correlation between the two variables $(r=.589, n=1,153, p<.001)$, with high levels of perceptions from the CSMS associated with high levels of student integration (see Table A3). In this correlation relationship of CSMS and CSPS scores for all first-year students, the coefficient of determination $\left(r^{2}\right)$ was .35. The correlation relationship for all first-year students was significant at the 0.01 level (2-tailed). Therefore, hypothesis 2a was supported for all first-year students (see Table A3 for detailed data of this correlation study). 


\section{Correlation Between PES and CSPS Scores for All First-Year Students}

Research Question 2a: Are all first-year students' perceptions of peer mentoring on PES scores correlated to integration as measured by CSPS in a Chinese FYE program?

The relationship between all first-year students' perceptions of peer mentoring, as measured by the PES, and integration scores, as measured by CSPS, was investigated using Pearson's product-moment correlation coefficient. There was a strong, positive correlation between the two variables $(r=.587, n=1,153, p<.001)$, with high levels of perceptions of PES associated with high levels of institutional integration (see Table A3). In this correlation relationship of PES and CSPS scores for all first-year students, the coefficient of determination $\left(r^{2}\right)$ was .34 . The correlation relationship for all first-year students was significant at the 0.01 level (2-tailed). Therefore, hypothesis 2a was supported for all first-year students (see Table A3 for detailed data of this correlation study).

\section{Correlation Between NAKS and CSPS Scores for All First-Year Students}

Research Question 2a: Are all first-year students' perceptions of peer mentoring on NAKS scores correlated to integration as measured by CSPS in a Chinese FYE program?

The relationship between all first-year students' perceptions of peer mentoring, as measured by NAKS subscales, and integration scores, as measured by CSPS, was investigated using the Pearson product-moment correlation coefficient. There was a strong, positive correlation between the two variables $(r=.566, n=1,153, p<.001)$, with high levels of perceptions from the NAKS associated with high levels of student integration (see Table A3). In this correlation relationship of NAKS and CSPS scores for all first-year students, the coefficient of determination $\left(r^{2}\right)$ was .32 . The correlation relationship for all first-year students was 
significant at the 0.01 level (2-tailed). Therefore, hypothesis $2 \mathrm{a}$ was supported for all first-year students (see Table A3 for detailed data of this correlation study).

\section{Correlation Between CSMS and CSPS Scores for Female First-Year Students}

Research Question 2b: Are female first-year students' perceptions of peer mentoring on CSMS (and subscales PES, NAKS) scores correlated to integration scores as measured by CSPS in a Chinese FYE program?

The relationship between female first-year students' perceptions of peer mentoring, as measured by the CSMS subscales, and integration scores, as measured by CSPS, was investigated using Pearson's product-moment correlation coefficient. There was a strong, positive correlation between the two variables $(r=.586, n=879, p<.001)$, with high levels of perceptions from the CSMS associated with high levels of institutional integration (see Table A3). In this correlation relationship of CSMS and CSPS scores for female first-year students, the coefficient of determination $\left(r^{2}\right)$ was .34 . The correlation relationship for female first-year students was significant at the 0.01 level (2-tailed). Therefore, hypothesis $2 \mathrm{~b}$ was supported for female first-year students (see Table A3 for detailed data of this correlation study).

\section{Correlation Between PES and CSPS Scores Female First-Year Students}

Research Question 2b: Are female first-year students' perceptions of peer mentoring on PES scores correlated to integration scores as measured by CSPS in a Chinese FYE program?

The relationship between female first-year students' perceptions of peer mentoring, as measured by the PES subscales, and integration scores, as measured by CSPS, was investigated using Pearson's product-moment correlation coefficient. There was a strong, positive correlation between the two variables $(r=.595, n=879, p<.001)$, with high levels of perceptions from the PES associated with high levels of institutional integration (see Table A3). In this correlation 
relationship of PES and CSPS scores for female first-year students, the coefficient of determination $\left(r^{2}\right)$ was .35 . This correlation relationship for female first-year students was significant at the 0.01 level (2-tailed). Therefore, hypothesis $2 \mathrm{~b}$ was supported for female firstyear students (see Table A3 for detailed data of this correlation study).

\section{Correlation Between NAKS and CSPS Scores for Female First-Year Students}

Research Question 2b: Are female first-year students' perceptions of peer mentoring on NAKS scores correlated to integration scores as measured by CSPS in a Chinese FYE program? The relationship between female first-year students' perceptions of peer mentoring, as measured by the NAKS subscales, and integration scores, as measured by CSPS, was investigated using the Pearson product-moment correlation coefficient. There was a strong, positive correlation between the two variables $(r=.557, n=879, p<.001)$, with high levels of perceptions from the NAKS associated with high levels of student integration (see Table A3). In this correlation relationship of NAKS and CSPS scores for female first-year students, the coefficient of determination $\left(r^{2}\right)$ was .31 . The correlation relationship for female first-year students was significant at the 0.01 level (2-tailed). Thus, hypothesis $2 \mathrm{~b}$ was supported for female first-year students (see Table A3 for detailed data of this correlation study).

\section{Correlation Between CSMS and CSPS Scores for First-Generation First-Year Students}

Research Question 2c: Are first-generation first-year students' perceptions of peer mentoring on CSMS (and subscales PES, NAKS) scores correlated to integration scores as measured by CSPS in a Chinese FYE program?

The relationship between first-generation first-year students' perceptions of peer mentoring, as measured by the CSMS, and integration scores, as measured by CSPS, was investigated using the Pearson product-moment correlation coefficient. There was a strong, 
positive correlation between the two variables $(r=.605, n=640, p<.001)$, with high levels of perceptions from the CSMS associated with high levels of institutional integration (see Table A3). In this correlation relationship of CSMS scores and CSPS scores for first-generation firstyear students, the coefficient of determination $\left(r^{2}\right)$ was .37 . The correlation relationship of firstgeneration, first-year students was significant at the 0.01 level (2-tailed). The results mean that hypothesis 2c was supported for first-generation, first-year students (see Table A3 for detailed data of this correlation study).

\section{Correlation Between PES and CSPS Scores for First-Generation First-Year Students}

Research Question 2c: Are first-generation first-year students’ perceptions of peer mentoring on PES scores correlated to integration scores as measured by CSPS in a Chinese FYE program?

The relationship between first-generation, first-year students' perceptions of peer mentoring, as measured by the PES subscales, and integration scores, as measured by CSPS, was investigated using Pearson's product-moment correlation coefficient There was a strong, positive correlation between the two variables $(r=.591, n=640, p<.001)$, with high levels of perceptions from the PES associated with high levels of institutional integration (see Table A3). In this correlation relationship of PES scores and CSPS scores for first-generation, first-year students, the coefficient of determination $\left(r^{2}\right)$ was .34 . The correlation relationship between PES and CSPS scores for first-generation students was significant at the 0.01 level (2-tailed). For this research question, hypothesis $2 \mathrm{c}$ was supported for first-generation, first-year students (see Table A3 for detailed data of this correlation study). 


\section{Correlation Between NAKS and CSPS Scores for First-Generation First-Year Students}

Research Question 2c: Are first-generation first-year students' perceptions of peer mentoring on NAKS scores correlated to integration scores as measured by CSPS in a Chinese FYE program?

The relationship between first-generation, first-year students' perceptions of peer mentoring, as measured by the NAKS subscales, and integration scores, as measured by CSPS, was investigated using Pearson's product-moment correlation coefficient. There was a strong, positive correlation between the two variables $(r=.589, n=640, p<.001)$, with high levels of perceptions from the NAKS associated with high levels of institutional integration (see Table A3). The Pearson correlation coefficient (.589) was strong, showing a positive correlation between NAKS scores and CSPS scores for first-generation participants. In this correlation relationship of NAKS scores and CSPS scores for first-generation, first-year students, the coefficient of determination $\left(r^{2}\right)$ was .35. The correlation relationship of NAKS and CSPS scores was significant at the 0.01 level (2-tailed) for first-generation, first-year students. Therefore, hypothesis 2c was supported for first-generation, first-year students (see Table A3 for detailed data of this correlation study).

\section{Correlation Between CSMS and CSPS Scores for Four Different Major Groups}

Research Question 2d: Are first-year students' perceptions of peer mentoring on CSMS scores correlated with integration as measured by CSPS in a Chinese FYE program, and do these potential correlations vary by major groups?

The relationship between first-year students in four major groups' perceptions of peer mentoring, as measured by the CSMS, and integration scores, as measured by CSPS, was investigated using Pearson's product-moment correlation coefficient. There was a strong, 
positive correlation between the two variables, with high levels of perceptions from the CSMS associated with high levels of student integration for major groups (see Table A3). The Pearson correlation coefficient (.627) was strong $(r=.627, n=440, p<.001)$, showing a positive correlation between CSMS scores and CSPS scores for education major groups participants. In this correlation relationship of CSMS and CSPS scores for first-year education majors, the coefficient of determination $\left(r^{2}\right)$ was .39 for education majors. The Pearson correlation coefficient (.629) was again strong, showing a positive correlation between CSMS scores and CSPS scores for humanities major groups participants.

In this correlation relationship of CSMS scores and CSPS scores for first-year humanities majors, the coefficient of determination $\left(r^{2}\right)$ was .40 for humanities majors. The Pearson correlation coefficient (.531) was strong, showing a positive correlation between CSMS scores and CSPS scores for business major groups participants. Furthermore, in this correlation relationship of CSMS scores and CSPS scores for first-year education majors, the coefficient of determination $\left(r^{2}\right)$ was .28 for business majors. The Pearson correlation coefficient (.523) was similarly strong, showing a positive correlation between CSMS scores and CSPS scores for STEM major groups participants. Likewise, in this correlation relationship of CSMS scores and CSPS scores for first-year education majors, the coefficient of determination $\left(r^{2}\right)$ was .27 for STEM majors.

The correlation between CSMS scores and CSPS scores was significant at the 0.01 level (2-tailed) for first-year students within the four majors. After the analysis, it was determined that hypothesis $2 \mathrm{~d}$ was supported in terms of first-year students within the four major groups (see Table A3 for detailed data of this correlation study). 


\section{Correlation Between PES and CSPS Scores for Four Different Major Groups}

Research Question 2d: Are first-year students' perceptions of peer mentoring on PES scores correlated with integration as measured by CSPS in a Chinese FYE program, and do these potential correlations vary by major groups?

For this analysis, the relationship between first-year students in four major groups' perceptions of peer mentoring, as measured by the PES, and integration scores, as measured by CSPS, was investigated using Pearson's product-moment correlation coefficient. There was a strong, positive correlation between the two variables $(r=.610, n=440, p<.001)$, with high levels of perceptions from the PES associated with high levels of student integration (see Table A3). The Pearson correlation coefficient (.610) was strong, showing a positive correlation between PES scores and CSPS scores for education majors. In this correlation relationship of PES scores and CSPS scores for first-year education majors, the coefficient of determination $\left(r^{2}\right)$ was .37 for education majors. Like before, the Pearson correlation coefficient (.619) was strong, showing a positive correlation between PES scores and CSPS scores for humanities majors. In this correlation relationship of PES scores and CSPS scores for first-year education majors, the coefficient of determination $\left(r^{2}\right)$ was .38 for humanities majors. Again, the Pearson correlation coefficient (.560) was strong, showing a positive correlation between PES scores and CSPS scores for business major participants. In this correlation relationship of PES scores and CSPS scores for first-year education major students, the coefficient of determination $\left(r^{2}\right)$ was .31 for business majors. The Pearson correlation coefficient (.506) was strong, showing a positive correlation between PES scores and CSPS scores for STEM major groups participants. In this correlation relationship of PES scores and CSPS scores for first-year education students, the coefficient of determination $\left(\mathrm{r}^{2}\right)$ was .26 for STEM majors. 
The correlation relationship of PES and CSPS scores was significant at the 0.01 level (2tailed) for first-year students within the four majors, meaning that hypothesis $2 \mathrm{~d}$ was supported for four major groups of first-year students (see Table A3 for detailed data of this correlation study).

\section{Correlation Between NAKS and CSPS Scores for Four Different Major Groups}

Research Question 2d: Are first-year students' perceptions of peer mentoring on NAKS scores correlated with integration as measured by CSPS in a Chinese FYE program, and do these potential correlations vary by major groups?

The relationship between first-year students in four major groups' perceptions of peer mentoring, as measured by the NAKS, and integration scores, as measured by CSPS, was investigated using Pearson's product-moment correlation coefficient. There was a strong, positive correlation between the two variables $(r=.611, n=440, p<.001)$, with high levels of perceptions from the NAKS associated with high levels of institutional integration (see Table A3). The Pearson correlation coefficient (.611) was strong, showing a positive correlation between NAKS scores and CSPS scores for education major groups participants. In this correlation relationship of NAKS and CSPS scores for first-year education major students, the coefficient of determination $\left(r^{2}\right)$ was .37 for education majors. The Pearson correlation coefficient (.615) was strong, showing a positive correlation between NAKS scores and CSPS scores for humanities major participants. In this correlation relationship of NAKS scores and CSPS scores for first-year education majors, the coefficient of determination $\left(r^{2}\right)$ was .38 for humanities majors. The Pearson correlation coefficient (.488) was strong, showing a positive correlation between NAKS scores and CSPS scores for business major groups participants. In this correlation relationship of NAKS scores and CSPS scores for first-year education majors, the 
coefficient of determination $\left(r^{2}\right)$ was .24 for business majors. The Pearson correlation coefficient (.510) was also strong, showing a positive correlation between NAKS scores and CSPS scores for STEM major participants. In this correlation relationship of NAKS and CSPS scores for firstyear education majors, the coefficient of determination $\left(r^{2}\right)$ was .26 for STEM majors.

The correlation relationship of NAKS scores and CSPS scores was significant at the 0.01 level (2-tailed) for first-year students within the four majors. Therefore, hypothesis $2 \mathrm{~d}$ was supported for first-year students in the four major groups (see Table A3 for detailed data of this correlation study).

\section{Research Question 3}

How are the first-year students' perceptions of peer mentoring on CSMS (and subscales PES, NAKS) scores correlated to the cumulative GPA scores in a Chinese FYE program?

\section{Correlation Between CSMS Scores and Cumulative GPA for All First-Year Students}

Research Question 3a: Are all first-year students' perceptions of peer mentoring on CSMS (and subscales PES, NAKS) scores correlated to the cumulative GPA scores in a Chinese FYE program?

The relationship between all first-year students' perceptions of peer mentoring, as measured by the CSMS and cumulative GPA scores, was investigated using Spearman's rank correlation coefficient. Differing from much of the previous results, there was nearly no correlation between the two variables $\left(r_{\mathrm{s}}=.048, n=1,153\right)$, with very low levels of perceptions from the CSMS associated with high levels of institutional integration (see Table A3). In this correlation relationship of CSMS scores and GPA for all first-year students, the coefficient of

determination $\left(r_{\mathrm{s}}^{2}\right)$ was .002. Overall, there was no significant correlation between CSMS scores 
and cumulative GPA for all first-year students. Therefore, hypothesis 3a was not supported for all first-year students (see Table A3 for detailed data of this correlation study).

\section{Correlation Between PES Scores and Cumulative GPA for All First-Year Students}

Research Question 3a: Are all first-year students' perceptions of peer mentoring on PES scores correlated to the cumulative GPA scores in a Chinese FYE program?

The relationship between all first-year students' perceptions of peer mentoring, as measured by the PES and the cumulative GPA scores, was investigated using Spearman's rank correlation coefficient. Again, there was nearly no correlation between the two variables $\left(r_{s}\right.$ $=.051, n=1,153$ ), with very low levels of perceptions from the PES associated with low levels of cumulative GPA scores (see Table A3). In this correlation relationship of PES scores and GPA for all first-year students, the coefficient of determination $\left(r_{s}{ }^{2}\right)$ was .003 . Overall, there was no significant correlation between PES scores and cumulative GPA scores for all first-year students. Thus, hypothesis 3a was not supported for all first-year students (see Table A3 for detailed data of this correlation study).

\section{Correlation Between NAKS Scores and Cumulative GPA for All first-Year Students}

Research Question 3a: Are all first-year students' perceptions of peer mentoring on NAKS scores correlated to the cumulative GPA scores in a Chinese FYE program?

The relationship between all first-year students' perceptions of peer mentoring, as measured by the NAKS and cumulative GPA scores, was investigated using Spearman's rank correlation coefficient. However, once again, there was nearly no correlation between the two variables $\left(r_{\mathrm{s}}=.053, n=1,153\right)$, with very low levels of perceptions from the NAKS associated with low levels of cumulative GPA scores (see Table A3). In this correlation relationship of NAKS and GPA scores for all first-year students, the coefficient of determination $\left(r_{\mathrm{s}}^{2}\right)$ was .003. 
Overall, there was little correlation between NAKS scores and cumulative GPA scores for all first-year students, which means hypothesis 3a was not supported for all first-year students (see Table A3 for detailed data of this correlation study).

\section{Correlation Between CSMS Scores and Cumulative GPA for Female First-Year Students}

Research Question 3b: Are female first-year students' perceptions of peer mentoring on CSMS scores correlated to the cumulative GPA scores in a Chinese FYE program?

The relationship between female first-year students' perceptions of peer mentoring, as measured by the CSMS and cumulative GPA scores, was investigated using Spearman's rank correlation coefficient. There was a weak, positive correlation between the two variables $\left(r_{s}\right.$ $=.074, n=879, p<.005)$, with high levels of perceptions from the CSMS associated with high

levels of cumulative GPA scores (see Table A3). In this correlation relationship of CSMS scores and cumulative GPA for female first-year students, the coefficient of determination $\left(r_{s}^{2}\right)$ was .005 . The correlation relationship for female first-year students was significant at the 0.05 level (2-tailed). Therefore, hypothesis $3 b$ was supported for female first-year students (see Table A3 for detailed data of this correlation study).

\section{Correlation Between PES Scores and Cumulative GPA for Female First-Year Students}

Research Question 3b: Are female first-year students' perceptions of peer mentoring on PES scores correlated to the cumulative GPA scores in a Chinese FYE program?

The relationship between female first-year students' perceptions of peer mentoring, as measured by the PES subscales and cumulative GPA scores, was investigated using Spearman's rank correlation coefficient. There was a weak, positive correlation between the two variables $(r$ $=.078, n=879, p<.005)$, with high levels of perceptions from the PES associated with high levels of cumulative GPA scores for female first-year students (see Table A3). In this correlation 
relationship of PES scores and cumulative GPA for female first-year students, the coefficient of determination $\left(r_{s}^{2}\right)$ was .005 . The correlation relationship for female first-year students was significant at the 0.05 level (2-tailed). Therefore, hypothesis $3 \mathrm{~b}$ was supported for female firstyear students (see Table A3 for detailed data of this correlation study).

\section{Correlation Between NAKS Scores and Cumulative GPA for Female First-Year Students}

Research Question 3b: Are female first-year students' perceptions of peer mentoring on NAKS scores correlated to the cumulative GPA scores in a Chinese FYE program?

The relationship between female first-year students' perceptions of peer mentoring, as measured by the NAKS subscales and cumulative GPA scores, was investigated using Spearman's rank correlation coefficient. There was a weak, positive correlation between the two variables $(r=.078, n=879, p<.005)$, with high levels of perceptions from the NAKS associated with high levels of cumulative GPA scores for female first-year students (see Table A3). In this correlation relationship of NAKS scores and cumulative GPA for female first-year students, the coefficient of determination $\left(r_{\mathrm{s}}^{2}\right)$ was .006. The correlation relationship for female first-year students was significant at the 0.05 level (2-tailed). Therefore, hypothesis $3 \mathrm{~b}$ was supported for female first-year students (see Table A3 for detailed data of this correlation study).

\section{Correlation Between CSMS Scores and Cumulative GPA for First-Generation, First-Year}

\section{Students}

Research Question 3c: Are first-generation first-year students' perceptions of peer mentoring on CSMS (and subscales PES, NAKS) scores correlated with the cumulative GPA scores in a Chinese FYE program?

The relationship between first-generation, first-year students' perceptions of peer mentoring, as measured by the CSMS and cumulative GPA scores, was investigated using 
Spearman's rank correlation coefficient. There was nearly no correlation between the two variables $\left(r_{s}=.077, n=640\right)$, with very low levels of perceptions from the CSMS associated with low cumulative GPA scores (see Table A3). In this correlation relationship of CSMS scores and GPA for first-generation, first-year students, the coefficient of determination $\left(r_{\mathrm{s}}^{2}\right)$ was .006 . Overall, there was little correlation between CSMS scores and cumulative GPA scores for firstgeneration, first-year students. Therefore, hypothesis $3 \mathrm{c}$ was not supported for first-generation, first-year students (see Table A3 for detailed data of this correlation study).

Correlation Between PES Scores and Cumulative GPA Scores for First-Generation, first-Year Students

Research Question 3c: Are first-generation first-year students' perceptions of peer mentoring on PES scores correlated with cumulative GPA scores in a Chinese FYE program?

The relationship between first-generation, first-year students' perceptions of peer mentoring, as measured by the PES and cumulative GPA scores, was investigated using Spearman's rank correlation coefficient. There was nearly no correlation between the two variables $\left(r_{\mathrm{s}}=.073, n=640\right)$, with very low levels of perceptions from the PES associated with low cumulative GPA (see Table A3). In this correlation relationship of CSMS scores and GPA for first-generation, first-year students, the coefficient of determination $\left(r_{\mathrm{s}}^{2}\right)$ was .005. Overall, there was little correlation between PES scores and cumulative GPA for first-generation, firstyear students. Therefore, hypothesis $3 \mathrm{c}$ was not supported for first-generation, first-year students (see Table A3 for detailed data of this correlation study). 


\section{Correlation Between NAKS Scores and Cumulative GPA Scores for First-Generation, first-}

\section{Year Students}

Research Question 3c: Are first-generation first-year students' perceptions of peer mentoring on NAKS scores correlated with cumulative GPA scores in a Chinese FYE program?

The relationship between first-generation, first-year students' perceptions of peer mentoring, as measured by the NAKS and cumulative GPA scores, was investigated using Spearman's rank correlation coefficient. There was a weak correlation between the two variables $\left(r_{s}=.081, n=640\right)$, with very low levels of perceptions from the NAKS associated with low cumulative GPA (see Table A3). In this correlation relationship of CSMS scores and GPA for first-generation, first-year students, the coefficient of determination $\left(r_{s}^{2}\right)$ was .007. Overall, there was a weak correlation between NAKS scores and cumulative GPA for first-generation, firstyear students. The correlation relationship of NAKS and CSPS scores was significant at the 0.05 level (2-tailed) for first-year students in four major groups. Therefore, hypothesis $3 \mathrm{c}$ was supported for first-generation, first-year students only for NAKS Scores (see Table A3 for detailed data of this correlation study).

\section{Correlation Between CSMS Scores and Cumulative GPA for Four Different Major Groups}

Research Question 3d: Are different major groups of first-year students' perceptions of peer mentoring on CSMS (and subscales PES, NAKS) scores correlated with cumulative GPA scores, respectively, in a Chinese FYE program?

The relationship between four major groups' first-year students' perceptions of peer mentoring, as measured by the CSMS scores and cumulative GPA, was investigated using Spearman's rank correlation coefficient. There was a weak, positive correlation between the two variables $(r=.110, n=320, p<.05)$, with high levels of perceptions from the CSMS associated 
with high levels of cumulative GPA (see Table A3 for business majors). The Spearman's rank correlation coefficient (-.011) was very weak, showing a negative correlation between CSMS scores and cumulative GPA scores for education majors. In this correlation relationship of CSMS scores and cumulative GPA for first-year education major students, the coefficient of determination $\left(r^{2}\right)$ was .0001 for education majors. The Spearman's rank correlation coefficient (.053) was very weak, showing a positive correlation between CSMS scores and cumulative GPA scores for humanities majors.

In this correlation relationship of CSMS scores and GPA for first-year education majors, the coefficient of determination $\left(r^{2}\right)$ was .003 for humanities majors. The Spearman's rank correlation coefficient (.110) was weak, showing a positive correlation between CSMS scores and cumulative GPA scores for business majors. In this correlation relationship of CSMS scores and cumulative GPA for first-year education major students, the coefficient of determination $\left(r^{2}\right)$ was .0121 for business majors. The Spearman's rank correlation coefficient (-.055) was very weak, showing a negative correlation between CSMS scores and cumulative GPA scores for STEM majors. In this correlation relationship of CSMS scores and cumulative GPA for education major first-year students, the coefficient of determination $\left(r^{2}\right)$ was .0030 for STEM majors. The correlation relationship of CSMS scores and cumulative GPA was significant at the 0.05 level (2-tailed) only for first-year business majors. Therefore, hypothesis $3 \mathrm{~d}$ was only supported for first-year business majors (see Table A3 for detailed data of this correlation study). 


\section{Correlation Between PES Scores and Cumulative GPA for Four Major Groups' First-Year}

\section{Students}

Research Question 3d: Are different major groups' first-year students' perceptions of peer mentoring on PES scores correlated with cumulative GPA scores respectively in a Chinese FYE program?

The relationship between four major groups' first-year students' perceptions of peer mentoring, as measured by the PES and cumulative GPA scores, was investigated using Spearman's rank correlation coefficient. There was nearly no correlation between the two variables for four major groups. The Spearman's rank correlation coefficient (-.014) was very weak, showing a negative correlation between PES scores and cumulative GPA scores for education major groups participants. In this correlation relationship of PES scores and cumulative GPA scores for first-year education major students, the coefficient of determination $\left(r^{2}\right)$ was .0002 for education majors. The Spearman's rank correlation coefficient (.033) was very weak, showing a positive correlation between PES scores and cumulative GPA scores for humanities majors.

In this correlation relationship of PES scores and GPA scores for first-year education majors, the coefficient of determination $\left(r^{2}\right)$ was .001 for humanities majors. The Spearman's rank correlation coefficient (.107) was weak, showing a positive correlation between PES scores and cumulative GPA scores for business majors. In this correlation relationship of PES scores and cumulative GPA scores for first-year education majors, the coefficient of determination $\left(r^{2}\right)$ was .011 for business majors. The Spearman's rank correlation coefficient (-.020) was very weak, showing a negative correlation between PES scores and cumulative GPA scores for STEM majors. In this correlation relationship of PES scores and cumulative GPA scores for first-year 
education majors, the coefficient of determination $\left(r^{2}\right)$ was .0004 for STEM majors. Therefore, hypothesis $3 \mathrm{~d}$ was not supported for first-year students in all four major groups on PES Scores (see Table A3 for detailed data of this correlation study).

\section{Correlation Between NAKS Scores and Cumulative GPA for Four Major Groups First-Year}

\section{Students}

Research Question 3d: Are different major groups of first-year students' perceptions of peer mentoring on NAKS scores correlated with cumulative GPA scores respectively in a Chinese FYE program?

The relationship between four major groups' first-year students' perceptions of peer mentoring, as measured by the NAKS scores and cumulative GPA scores, was investigated using Spearman's rank correlation coefficient. There was a weak, positive correlation between the two variables $(r=.120, n=320, p<.05)$, with high levels of perceptions from the NAKS associated with high levels of cumulative GPA scores only for the business major group (see Table A3). The Spearman's rank correlation coefficient (-.003) was very weak, showing a negative correlation between NAKS scores and cumulative GPA scores for education major groups participants. In this correlation relationship of NAKS scores and cumulative GPA scores for first-year education major students, the coefficient of determination $\left(r^{2}\right)$ was almost nonexistent at just .00001. The Spearman's rank correlation coefficient (.077) was very weak, showing only a slight positive correlation between NAKS scores and cumulative GPA scores for humanities majors.

The Spearman's rank correlation coefficient (.120) was weak, showing a positive correlation between NAKS scores and cumulative GPA scores for business major groups participants. In this correlation relationship of NAKS scores and cumulative GPA scores for 
education major first-year students, the coefficient of determination $\left(r^{2}\right)$ was .0144 for business majors. The Spearman's rank correlation coefficient (-.082) was very weak, showing a negative correlation between NAKS scores and cumulative GPA scores for STEM majors. In this correlation relationship of NAKS scores and cumulative GPA scores for first-year education majors, the coefficient of determination $\left(r^{2}\right)$ was .0067 for STEM majors. The correlation relationship of NAKS scores and cumulative GPA scores was significant at the 0.05 level (2tailed) only for first-year business majors. Technically, hypothesis $3 \mathrm{~d}$ was only supported for first-year business majors (see Table A3 for detailed data of this correlation study), but the relationship in this specific analysis was very weak.

\section{Summary}

The data analysis was presented in this chapter. This chapter covered three parts of data analysis: descriptive analysis (continuous variables and categorical variables), PCA, and correlation analysis. This chapter began with a descriptive analysis of the preliminary stage. All continuous and categorical variables were within the normal range. I performed preliminary analyses to ensure no violation of the assumption of normality, linearity, and homoscedasticity. The validated CSMS in the United States had four dimensions. After PCA, the new CSMS, generated under the Chinese context, had only two dimensions: PES and NAKS. In the correlation test between mentoring support and student success, the relationship explored in Research Question 2 was linear, so Pearson's correlation was used. The variables in Research Question 2 were nonparametric, so Spearman's correlation was used.

Correlation analysis was used to test the hypotheses of Research Question 2 and Research Question 3. All hypotheses of Research Question 2 were accepted. There was a statistically significant correlation between all first-year students' (female and first-generation) perceptions 
of peer mentoring on CSMS (and subscales PES, NAKS) scores and integration scores, as measured by CSPS in a Chinese FYE program. However, in Research Question 3, there was no statistically significant correlation between all first-year students' perceptions of peer mentoring on CSMS (and subscales PES, NAKS) scores and the GPA scores in the study. Moreover, there was a statistically significant correlation between female first-year students' perceptions of peer mentoring on CSMS (and subscales PES, NAKS) scores and cumulative GPA scores. There was a statistically significant correlation between first-generation, first-year students' perceptions of peer mentoring on NAKS scores and GPA. There was also a significant positive correlation between CSMS and GPA for business students, but a very weak relationship. In Chapter 5, I discuss the significance of the results in conjunction with the literature review. 


\section{CHAPTER 5: DISCUSSION}

The main purpose of the study was to validate College Student Mentoring Scale (CSMS) at T College in Mainland China, and to examine the relationships among private college students' (a) perceptions of mentoring support, as measured by the CSMS; (b) student integration, as measured by the College Student Perception Scale (CSPS); and (c) grade point average (GPA). T College is a medium-sized private college located in Shanghai, China, and T College initiated peer mentoring in the FYE program in Fall 2009. This chapter offers the interpreted results related to the literature and discusses implications, study strengths, limitations, and future research. The chapter includes four sections: (a) a discussion of results; (b) implications for colleges and universities, first-year students, and peer mentors; (c) study strengths; and (d) limitations and recommendations for future research.

\section{Summary of the Study}

This study adopted quantitative survey research, focusing on the translation and validation of the CSMS from the United States into Chinese for use in Mainland China. Using the principal component analysis method, the CSMS, which originally had four dimensions in Western countries, was validated as a two-dimension scale in Mainland China. The literature review in Chapter 2 highlighted past work on the topic from mostly Western societies, which showed correlations among peer mentoring support, student integration, and academic success for all first-year students, gender, generational, majors' groups. However, few high-quality studies on peer mentoring were found in Mainland China. To fill in the gaps in peer mentoring for first-year student success, an empirical study was conducted at a private Chinese college to answer the following three major research questions: 
Research Question 1: Can the CSMS, based on the four-factor model, be used as a valid indicator to measure the first-year students' perceptions of peer mentoring in a Chinese FYE program?

Research Question 2: How are first-year students' perceptions of peer mentoring on CSMS correlated to integration as measured by the CSPS in a Chinese FYE program for total, gender, first-generation status, and major groups?

Research Question 3: How are first-year students' perceptions of peer mentoring on CSMS related to cumulative GPA in a Chinese FYE program for total, gender, first-generation status, and major groups?

\section{Discussion of Results}

Results of the study are discussed in this section. The first part addresses Research Question 1 and discusses results of a factor analysis related to literature. The second part addresses Research Question 2 and Research Question 3 and discusses results of correlation analyses related to literature.

\section{Factor Analysis Results Related to Literature}

Research Question 1 focused on whether the mentoring model from Western countries based on four factors could be validated in Mainland China. Based on Nora and Crisp's (2007) four dimensions of mentoring college students, Crisp (2009) validated CSMS in a community college in south-central United States and identified the four constructs of CSMS: Psychological and Emotional Support (PES), Degree and Career Support (DCS), Academic Subject Knowledge Support (AKS), and Existence of a Role Model (ERM). A review of literature, including Western countries and Hong Kong, indicated CSMS was based on a four-factor model and validated for college students (see Table 10; Crisp, 2009; Crisp \& Cruz, 2010; Kwan, 2014). In 
this study, results showed only two factors (i.e., PES, AKS) were valid in Mainland China;

meanwhile, two factors (i.e., DCS, ERM) failed to be validated.

Associated with qualitative studies, results of this study were consistent with Henry et al.'s (2011) findings; two dimensions (i.e., PES, AKS) were significant for first-year students. However, results of this study were inconsistent with findings in Gunn et al.'s (2017) study; the level of PES was 4.7; the level of DCS was 3.8; the level of AKS was 4.6; the level of ERM was 4.4 in level of occurrence (1-7) of mentoring (Gunn et al., 2017; see Table 15). The implications of the differing results within the Chinese higher education sector compared to Western counterparts is discussed next.

\section{Table 15}

Research Question 1 Results: Factor Analyses Associated With Literature

\begin{tabular}{|c|c|c|c|}
\hline Validation of CSMS & Result & Consistent & Inconsistent \\
\hline $\begin{array}{l}\text { Psychological and } \\
\text { Emotional Support (PES) }\end{array}$ & $\begin{array}{l}\text { PES factor was } \\
\text { validated in Mainland } \\
\text { China }\end{array}$ & $\begin{array}{l}\text { Crisp (2009); Crisp } \\
\text { \& Cruz (2010); } \\
\text { Kwan (2014); } \\
\text { Henry et al. } \\
\text { (2011) }\end{array}$ & \\
\hline $\begin{array}{l}\text { Degree and Career Support } \\
\text { (DCS) }\end{array}$ & $\begin{array}{l}\text { DCS factor was not } \\
\text { validated in Mainland } \\
\text { China }\end{array}$ & & $\begin{array}{l}\text { Crisp (2009); Crisp \& } \\
\text { Cruz (2010); Kwan } \\
\text { (2014) }\end{array}$ \\
\hline $\begin{array}{l}\text { Academic Subject } \\
\text { Knowledge Support } \\
(\mathrm{AKS})\end{array}$ & $\begin{array}{l}\text { AKS factor was } \\
\text { validated in Mainland } \\
\text { China }\end{array}$ & $\begin{array}{l}\text { Crisp (2009); Crisp } \\
\text { \& Cruz (2010); } \\
\text { Kwan (2014); } \\
\text { Henry et al. } \\
(2011)\end{array}$ & \\
\hline $\begin{array}{l}\text { Existence of a Role Model } \\
\text { (ERM) }\end{array}$ & $\begin{array}{l}\text { ERM factor was not } \\
\text { validated in Mainland } \\
\text { China }\end{array}$ & & $\begin{array}{l}\text { Crisp (2009); Crisp \& } \\
\text { Cruz (2010); Kwan } \\
\text { (2014); Gunn et al.'s } \\
\text { (2017) }\end{array}$ \\
\hline
\end{tabular}




\section{Results of Correlation Analyses Associated With Literature}

Research Question 2 examined the relationship between students' perceptions of mentoring support, as measured by CSMS, and student integration, as measured by CSPS. Results showed a large and significant positive correlation between the two variables for all participants, gender, generation, and major groups. A literature review including quantitative and qualitative studies showed peer mentoring for first-year students has helped with their integration in college (see Table 16).

\section{Table 16}

Results of Research Question (RQ) 2 and RQ 3: Correlation Results Associated With Literature

\begin{tabular}{|c|c|c|c|}
\hline Research questions & Results & Consistent & Inconsistent \\
\hline $\begin{array}{l}\text { RQ2a: the relationship } \\
\text { between CSMS (PES, } \\
\text { NAKS) and CSPS for } \\
\text { total students }\end{array}$ & $\begin{array}{l}\text { CSMS was significantly } \\
\text { positively correlated with } \\
\text { student integration }(r \\
\left.=.589, r^{2}=.35, p<.01\right)\end{array}$ & $\begin{array}{l}\text { Collings et al. (2014, } \\
\text { 2015); Yomtov et al. } \\
\text { (2017) }\end{array}$ & \\
\hline $\begin{array}{l}\text { RQ2b: the relationship } \\
\text { between CSMS (PES, } \\
\text { NAKS) and CSPS for } \\
\text { female students }\end{array}$ & $\begin{array}{l}\text { CSMS was significantly } \\
\text { positively correlated with } \\
\text { student integration }(r \\
\left.=.586, r^{2}=.34, p<.01\right)\end{array}$ & $\begin{array}{l}\text { Dennehy \& Dasgupta } \\
\text { (2017) }\end{array}$ & \\
\hline $\begin{array}{l}\text { RQ2c: the relationship } \\
\text { between CSMS and } \\
\text { CSPS for first- } \\
\text { generation students? }\end{array}$ & $\begin{array}{l}\text { CSMS was significantly } \\
\text { positively correlated with } \\
\text { student integration }(r \\
\left.=.605, r^{2}=.37, p<.01\right)\end{array}$ & $\begin{array}{l}\text { Moschetti et al. (2018); } \\
\text { Sparks (2017) }\end{array}$ & \\
\hline $\begin{array}{l}\text { RQ2d: the relationship } \\
\text { between CSMS and } \\
\text { CSPS for majors' } \\
\text { groups students? }\end{array}$ & $\begin{array}{l}\text { CSMS was significantly } \\
\text { positively correlated with } \\
\text { student integration for } \\
\text { education }\left(r=.627, r^{2}\right. \\
=.39, p<.01) \text {, for } \\
\text { humanities }\left(r=.629, r^{2}\right. \\
=.40, p<.01) \text {; for } \\
\text { business }\left(r=.531, r^{2}\right. \\
=.28, p<.01) \text {; STEM }(r \\
\left.=.523, r^{2}=.27, p<.01\right)\end{array}$ & $\begin{array}{l}\text { Chester et al. (2013); } \\
\text { Dennehy \& Dasgupta } \\
\text { (2017); Etzel et al. } \\
\text { (2018); Gunn et al. } \\
\text { (2017); Heirdsfield et } \\
\text { al. (2008); O'Brien et } \\
\text { al. (2012) }\end{array}$ & \\
\hline $\begin{array}{l}\text { RQ3a: the relationship } \\
\text { between CSMS and } \\
\text { GPA for total students }\end{array}$ & $\begin{array}{l}\text { There was no significant } \\
\text { correlation between } \\
\text { CSMS and GPA. }\end{array}$ & & $\begin{array}{l}\text { Colvin \& } \\
\text { Ashman } \\
(2010)\end{array}$ \\
\hline
\end{tabular}




\begin{tabular}{|c|c|c|c|}
\hline Research questions & Results & Consistent & Inconsistent \\
\hline $\begin{array}{l}\text { RQ3b: the relationship } \\
\text { between CSMS and } \\
\text { GPA for female } \\
\text { students }\end{array}$ & $\begin{array}{l}\text { CSMS was significantly } \\
\text { positively correlated with } \\
\text { GPA }\left(r=.074, r^{2}=.005,\right. \\
\text { p }<.05)\end{array}$ & $\begin{array}{l}\text { Dennehy \& Dasgupta } \\
\text { (2017) }\end{array}$ & \\
\hline $\begin{array}{l}\text { RQ3c: the relationship } \\
\text { between CSMS and } \\
\text { GPA for first- } \\
\text { generation students? }\end{array}$ & $\begin{array}{l}\text { Subscale (NAKS) was } \\
\text { significantly positively } \\
\text { correlated with GPA }(r \\
\left.=.081, r^{2}=.007, \mathrm{p}<.05\right)\end{array}$ & $\begin{array}{l}\text { Sparks (2017); Yomtov } \\
\text { et al. (2017) }\end{array}$ & \\
\hline $\begin{array}{l}\text { RQ3d: the relationship } \\
\text { between CSMS and } \\
\text { GPA for majors' groups } \\
\text { students? }\end{array}$ & $\begin{array}{l}\text { CSMS was significantly } \\
\text { positively correlated with } \\
\text { GPA }\left(r=.110, r^{2}=.01, p\right. \\
<.05) \text { for business } \\
\text { groups; NAKS }{ }^{\mathrm{E}} \text { was } \\
\text { negatively correlated with } \\
\text { GPA }(r=-.003) \text {; NAKS } \\
{ }^{S} \text { was negatively } \\
\text { correlated with GPA ( } r= \\
\text {-.082) }\end{array}$ & Dos Reis \& Yu (2018) & $\begin{array}{l}\text { Budny et al. } \\
\text { (2010); } \\
\text { Etzel et al. } \\
\text { (2018); } \\
\text { Heirdsfield } \\
\text { et al. (2008); } \\
\text { Lim et al. } \\
\text { (2017) }\end{array}$ \\
\hline
\end{tabular}

Note. NAKS ${ }^{\mathrm{E}}$ was NAKS for education major groups' students; NAKS ${ }^{\mathrm{S}}$ was NAKS for STEM major groups' students.

\section{Research Question 2}

How are first-year students' perceptions of peer mentoring on CSMS correlated to integration as measured by the CSPS in a Chinese FYE program for total, gender, first-generation status, and major groups?

\section{Research Question 2a: Relationship Between CSPS and CSMS for All first-Year Students}

Correlation analysis results confirmed a significant positive correlation between CSMS score and CSPS score for all first-year students $(r=.589)$. CSPS score could explain $35 \%\left(r^{2}\right.$ $=.35$ ) of the variance in CSMS. Results of this study were consistent with findings in prior literature (Collings et al., 2014, 2015; Yomtov et al., 2017). Yomtov et al. (2017) demonstrated the effectiveness of peer mentoring for academic and emotional integration using the CSPS. 
Collings et al. $(2014,2015)$ used a controlled comparative study and longitudinal study that revealed the positive effects of peer mentoring on student integration.

Regarding the correlations between CSPS score and CSMS subscales, student integration measured by CSPS was positively correlated with PES and New Academic Knowledge Support (NAKS). The correlation coefficients were large ( $r=.587$ for PES and $r=.566$ for NAKS). This result was similar to Collings et al.'s (2014) finding that social integration positively correlated with PES. Yomtov et al.'s (2017) finding that academic and social integration positively correlated with PES and AKS.

\section{Research Question 2b: Relationship Between CSMS and CSPS for Female First-Year}

\section{Students}

Correlation analysis results showed a significant positive correlation between CSMS score and CSPS score for female first-year students. The correlation coefficient was .586 and CSPS score could explain $34 \%\left(r^{2}=.34\right)$ of the variance in CSMS. Results of this study were consistent with findings in prior literature (Dennehy \& Dasgupta, 2017; Robinson, 2018). Dennehy and Dasgupta (2017) conducted a longitudinal experimental design to identify female peer mentors early in the first year, contributing to women's positive academic experiences and retention in engineering. Robinson (2018) used Crisp's CSMS as an indicator of student success, which was significant for female students in this study.

Regarding the correlations between CSPS score and CSMS subscales, CSPS was positively correlated with PES and NAKS. The correlation coefficients were large $(r=.587$ for PES and $r=.566$ for NAKS). This result was similar to Robinson's (2018) finding that PES and AKS were significant integration indicators of student success. 
Research Question 2c: Relationship Between CSMS and CSPS for First-Generation, firstYear Students

Correlation analysis results displayed a significant positive correlation between CSMS score and CSPS score for first-generation, first-year students $(r=.605)$. CSPS score could explain $37 \%\left(r^{2}=.37\right)$ of the variance in CSMS. The strength of correlation was large, with a positive correlation between the two variables. Results of this study were consistent with findings in prior literature (Moschetti et al., 2018; Sparks, 2017). Moschetti et al. (2018) used CSPS to examine the effectiveness of peer mentoring as social capital for Latinx students at a Hispanic-serving institution through a quasi-experimental method in an FYE course-embedded context for first-year students. Moschetti et al. also found CSPS an effective tool for measuring first-year integration for first-year students.

Regarding the correlations between CSPS score and CSMS subscales, CSPS was positively correlated with PES and NAKS. The correlation coefficients were large $(r=.591$ for PES and $r=.589$ for NAKS). This result was similar to Sparks's (2017) finding that student success positively correlated with peer mentoring support.

\section{Research Question 2d: Relationship Between CSMS and CSPS for Four Majors Groups}

The correlation analysis again results established a significant positive correlation between CSMS score and CSPS score for first-generation, first-year students $(r=.627)$. CSPS score could explain 39\% $\left(r^{2}=.39\right)$ of the variance in CSMS for education majors. For humanities majors $(r=.629)$, CSPS score could explain $40 \%\left(r^{2}=.40\right)$ of the variance in CSMS. For business majors $(r=.531)$, CSPS score could explain $28 \%\left(r^{2}=.28\right)$ of the variance in CSMS. For STEM students $(r=.523)$, CSPS score could explain $27 \%\left(r^{2}=.27\right)$ of the variance in CSMS. Results of this study were consistent with findings in prior literature (e.g., Budny et al., 
2010; Chester et al., 2013; Dennehy \& Dasgupta, 2017; Etzel et al., 2018; Gunn et al., 2017; Heirdsfield et al., 2008; Henry et al., 2011; Hogan et al., 2017; O’Brien et al., 2012).

Heirdsfield et al. (2008) used the qualitative data analysis of the longitudinal perspective and found reports of peer mentored students had significant social and academic outcomes for education majors. O’Brien et al. (2012) compared the expected and actual experiences of firstyear students through a pre- and post-test of the peer mentoring program for education majors and found items such as satisfying friends, satisfying academic experience, and sense of belonging were significant. Likewise, both Gunn et al. (2017) and Cornelius et al. (2016) illustrated how peer mentoring on integration for business majors, showing students had positive transition experiences.

In this study, students in psychology, pharmacy, and midwifery major groups were categorized into STEM majors groups students. Through quantitative and qualitative analysis on students from different professional groups, several researcher teams found that peer mentoring for first-year students can help students integrate into college and successfully achieve the transition of the first year of college (Chester et al., 2013; Etzel et al., 2018; Hogan et al., 2017; Lim et al., 2017).

Regarding the correlations between CSPS score and CSMS subscales, there was a significant positive correlation between CSPS score, PES score, and NAKS score. This result was similar to Gunn et al.’s (2017) and Henry et al.'s (2011) finding that student success positively correlated with PES and NAKS. 


\section{Research Question 3}

How are first-year students' perceptions of peer mentoring on CSMS related to cumulative GPA in a Chinese FYE program for total, gender, first-generation status, and major groups?

Research Question 3 examined the relationship between students' perceptions of mentoring support (i.e., CSMS) and academic success (i.e., GPA). Results showed a small but significant, positive correlation between the two variables for female students, for business majors, NAKS subscale, and GPA for first-generation students. A literature review including quantitative and qualitative studies showed peer mentoring for first-year students helped with academic success in college (see Table 2).

\section{Research Question 3a: Relationship Between CSMS and GPA for All First-Year Students}

For this question, the correlation analysis results showed no significant correlation between CSMS score and GPA score for all first-year students. The results of this study were inconsistent with findings in prior literature (e.g., Colvin \& Ashman, 2010). Through qualitative analysis, Colvin and Ashman (2010) concluded peer mentoring had a positive impact on academic success for all first-year students (see Table 2).

\section{Research Question 3b: Relationship Between CSMS and GPA for Female First-Year Students}

Correlation analysis results illustrated a significant positive correlation between CSMS score and GPA score for female, first-year students $\left(r_{\mathrm{s}}=.074\right)$. GPA score could explain $.5 \%\left(r_{\mathrm{s}}{ }^{2}\right.$ $=.005)$ of the variance in CSMS. Although the strength of the correlation was small, a positive correlation existed between the two variables. Results of this study were consistent with findings in prior literature (e.g., Dennehy \& Dasgupta, 2017). 
Regarding the correlations between GPA score and CSMS subscales, GPA score was positively correlated with PES and NAKS score. But the correlation coefficients were small $(r$ $=.078$ for PES and $r=.078$ for NAKS). This result was similar to Robinson's (2018) finding that PES and AKS were significant integration indicators of student success.

Research Question 3c: Relationship Between CSMS and GPA for First-Generation, first-Year Students

In this correlation analysis, there was no significant correlation between CSMS score and GPA score for female first-year students. Results of this study were inconsistent with findings in prior literature (e.g., Robinson, 2018; Sparks, 2017).

Regarding the relationship between GPA score and CSMS subscales, GPA was only weakly correlated with CSMS, but the correlation did reach statistical significance at the $p<.05$ level. The correlation coefficients were small $\left(r_{\mathrm{s}}=.081\right.$ for NAKS $)$. Although the strength of the correlation was small, a positive correlation existed between the two variables. This result was similar to Sparks' (2017) finding that academic success positively correlated with AKS (see Table 2).

Research Question 3d: Relationships Between CSMS and GPA for Four Majors Groups

Looking at these relationships, the results showed no significant correlation between CSMS score and GPA score for education, humanities, and STEM majors first-year students; but it did yield a significant positive correlation $(r=.110)$ between CSMS score and GPA score for business majors first-year students. GPA score could explain $1.21 \%\left(r^{2}=.0121\right)$ of the variance in CSMS. Although the correlation strength was small, a positive correlation existed between the two variables for business groups. However, there were negative correlations for education and STEM majors. NAKS scores for education majors were negatively correlated with GPA $(r=-.003)$; 
NAKS scores for education STEM majors were negatively correlated with GPA $(r=-.082)$. There was no significant correlation between the two variables for humanities majors. Results of this study were inconsistent with findings in prior literature (e.g., Budny et al., 2010; Chester et al., 2013; Dennehy \& Dasgupta, 2017; Dos Reis \& Yu, 2018; Heirdsfield et al., 2008; see Table 2). In terms of the correlations between GPA score and CSMS subscales, GPA score was positively correlated with PES and NAKS score. The correlation coefficients were small ( $r$ $=.011$ for PES and $r=.012$ for NAKS). This result was similar to Fox et al. (2010) and Dos Reis and Yu's (2018) findings that PES and AKS were significant integration indicators of student success. Fox et al. (2010) and Dos Reis and Yu (2018) found the effectiveness of peer mentoring on business students' academic success; Budny et al. (2010) described the effectiveness of peer guidance for academic success in STEM majors for 4 years and those who had implemented the peer mentoring program for 10 years and concluded peer mentoring had a positive effect on STEM students' GPA. Chester et al. (2013) confirmed the effectiveness of peer mentoring in promoting academic success for STEM group students (see Table 2).

In summary, there were significant correlations between CSMS scores and CSPS scores for total, gender, first-generation status, and major groups. At the same time, subscales (PES and NAKS) scores were positively correlated with CSPS scores for total, gender, first-generation status, and major groups, which meant that the relationships between predictor variable (mentoring support) and the outcome variable (student integration) showed a significant positive correlation.

There were significant correlations between PES scores and GPA scores only for female, and business major groups first-year students. Likewise, significant correlations were found between NAKS scores and GPA scores only for female, first-generation and business major 
groups first-year students. However, there were no significant correlations between CSMS scores and GPA scores for total first-year, female, first-generation, education major groups, humanity major groups, and STEM major groups students.

\section{Conclusion}

The CSMS, a four-dimension scale derived from the United States, has now been validated as a two-dimension scale in private colleges in Mainland China through this research. As Chinese private universities attach great importance to the academic success and retention of first-year students, PES and AKS dimensions are significant. The DCS and ERM dimensions were not significant in Mainland China, likely because first-year students basically did not have a choice of majors and were enrolled in the peer mentoring program mandatorily, which is considerably different from the US context of higher education. Among private colleges and universities in China, different colleges and universities have different policies for changing majors. As private colleges and universities in China have been lower on the national higher education hierarchy on public universities in terms of various educational resources (Allen, 2021), private colleges and universities as a whole can only provide very few resources for students who need to change majors. As the entrance scores of students in private colleges in China were generally lower than those in public universities, and the tuition fees at private colleges are 3-5 times higher than those at public colleges, private colleges took various measures to ensure that students could graduate in 4 years as soon as possible and were responsible for the high tuition fees paid by their parents (Davey et al., 2007). Private colleges should ensure that students could graduate as soon as possible in 4 years, given the high tuition costs to attend. 
Perceptions of mentoring support from 1,153 participants and the relationship between peer mentoring support, measured by CSMS, and student success measured by CSPS and GPA, were investigated in a Chinese FYE program. As for mentoring with the goal of student integration, results showed relationships between CSMS and CSPS were correlated significantly and positively. PES and NAKS subscales were also correlated significantly and positively. These results were consistent with findings in prior literature (e.g., Collings et al., 2014, 2015; Dennehy \& Dasgupta, 2017; Moschetti et al., 2018; Robinson, 2018; Sparks, 2017).

As for mentoring with the goal of academic success, results showed relationships between CSMS and cumulative GPA were correlated and positively significant at the $p<.05$ level only for female students. These results were consistent with findings in prior literature (Dennehy \& Dasgupta, 2017; Dos Reis \& Yu, 2018; Fox et al., 2010; Sparks, 2017). NAKS subscale was correlated significantly and positively at the $p<.05$ level for business majors only. There were no significant correlations between CSMS and cumulative GPA for all first-year students and the other three majors (i.e., education, humanities, and STEM). However, there were negative correlations between CSMS and cumulative GPA for education and STEM majors.

\section{Implications}

Results of this study provided data about the validated mentoring scale and the characteristics of relationships between Chinese private college students' mentoring support and student success across four groups of first-year students: all first-year students, female first-year students, first-generation first-year students, and four majors. Three aspects where the benefits of peer mentoring for promoting student success can be discussed include implications for (a) counselors and administrators in T College and similar educational context; (b) future first-year 
students and peer mentors; and (c) private and public universities in Mainland China. These impacts in three aspects are discussed in the following sections.

\section{Implications for Counselors and Administrators}

According to this study report, Chinese private college students' perceptions of peer mentoring are limited to PES and AKS dimensions. Because peer mentoring can promote students' holistic development, including DCS and ERM dimensions (Sparks, 2017) to develop students' holistic development further, administrators and counselors can foster and activate DCS and ERM functions in the setting and implementation of peer mentoring programs to promote student success. Counselors and administrators can help first-year students and peer mentors by offering workshops on career planning and leadership training.

At $\mathrm{T}$ College, peer mentoring is a program actively promoted by the school, mainly implemented by counselors and administrators. Peer mentoring programs in western countries have concluded that successful peer mentoring programs need to focus on key elements such as peer mentor matching process, training and contact frequency (Cornelius et al., 2016). The role of counselors and administrators is important in this process at $\mathrm{T}$ College. Correlations between CSMS and student integration showed significant positive correlations for all first-year, female, first-generation college student groups and four different majors. Therefore, student integration as the purpose of peer mentoring programs should be continued to support student success. The subscales of CSMS (i.e., PES and NAKS) were also positively correlated with student integration measured by CSPS. Findings showed emotional and academic support from peer mentors could promote students' integration into campus because the first-year peer mentoring in T College includes two parts: orientation and retention. The orientation part is relatively successful because of positive correlations between peer mentoring support and student 
integration, which helped first-year students integrate into the university academically and socially.

At T College, first-year students are required to watch English learning videos under the guidance of peer mentors during morning self-study. However, when seeking academic success, there was no significant correlation between perceived peer mentoring and long-term academic success measured by students' GPA. As far as T College is concerned, the impact of the unified English learning mentoring in morning class is challenging, as 16 majors were involved in the English-only curriculum for the class of 2022, and no significant correlations between peer mentoring and GPA for all students were found. Peer mentoring methods in English learning should be improved. With guidance from counselors and administrators, oral and reading content should be further added to consolidate the knowledge learned by students in peer mentoring.

The relationships between CSMS and GPA in education and STEM majors were negative, so results implied potential conflicts and challenges between first-year students and peer mentors in academic support areas. Because of the difficulty of STEM majors, students with less academic foundation need more external support, so they have a strong positive perception of peer mentoring. However, GPA is a long-term outcome that may not be revealed in the short term. Results showed that students with poor academic foundation had strong positive perception of mentoring support with lower GPA.

I suggest counselors and administrators reconsider the methods and strategies of peer mentoring for implementing academic support. Because peer mentors assist counselors and administrators in their work, it is easy to form a certain authority of peer mentors from the ideological and political education system over the first-year students in Mainland China (Qian, 2011). Colvin and Ashman (2010) and Gunn et al. (2017) argued students and peer mentors have 
a challenging role; counselors and administrators are needed to play a positive, coordinating role to manage relationships and reduce the risk of conflict between students and peer mentors.

\section{Implications for First-Year Students and Peer Mentors}

An important finding of this study was that most first-year students' perceptions of peer mentoring were positively correlated with student integration. According to the existing literature, colleges and universities carried out leadership training for peer mentors, which ultimately promoted the success of first-year students (Cornelius et al., 2016). This finding implies students can increase their interactions with peer mentors to improve their student integration. Schools can implement peer mentor leadership training and provide communication platforms for first-year students and peer mentors to improve first-year student integration. The relationships between CSMS and student integration, measured by CSPS, showed a significant positive correlation for most first-year, female, and first-generation students and first-year students in four majors. The first-year students can use peer mentors as important resources and social capital to help integrate into university (Moschetti et al., 2018). Female students' CSMS were positively correlated with academic success measured by GPA, and first-generation college students' NAKS were positively correlated with academic success. Thus, T College should give more mentoring support to female students, first-generation college students to help them succeed academically.

CSMS scores of business majors were positively correlated with academic success measured by GPA, and first-generation students' NAKS were also positively correlated with academic success; thus, I recommend business school should provide more academic supportive resources for first-year students during transition periods. There was no significant correlation between CSMS and academic success in education, humanities, and STEM majors. Perhaps, 
students in these three professional groups need more extensive help, such as academic advisors, faculty mentoring, but the results in this area are still inconclusive.

It can be deduced from the existing literature that peer mentors actively participate in training and take advantage of starting matching opportunities, which plays an important role in promoting the success of peer mentoring (Colvin \& Ashman, 2010; Cornelius et al., 2016; Etzel et al., 2018). Therefore, T College should actively carry out all kinds of peer mentor training to improve the leadership of peer mentors' group. At the same time, they should also use the matching opportunity between the original peer mentor and the class of first-year students to find the best match result. Moreover, leadership skills training should be strengthened for the three major groups of students' mentors according to the data on mentoring support for education, humanity, business, and STEM majors'students.

\section{Implications for Colleges and Universities}

Due to the massive expansion of higher education enrollment in China over the past 2 decades, there have been many peer mentoring programs started in public and private universities (Zhang, 2011). However, there is a lack of effective evaluation scale and quantitative analysis for such programs in practice. Therefore, this validated version of CSMS addresses this urgent need at T College. Meanwhile, this study has important implications for other private and public universities in China.

\section{Clarify the Role and Function of Peer Mentoring}

Crisp (2009) validated a four-dimensional scale in the context of the United States, while only two dimensions of CSMS were validated at a private college in Mainland China for this study. I posit this is because of the varying contexts of Chinese private education. Regarding missing degree and career support, does the university have more choices and flexibility in terms 
of policy for first-year students' major change? For example, with limited opportunities to apply for a major change after the first year, policy makers could consider setting up a minor to help first-year students have more major and career options. Given falling to validate the dimension of ERM at T College, I suggest that researchers in private universities in China can further optimize the CSMS scale to make it more conducive with China's national conditions.

The Chinese version of CSMS can continue to be validated in different educational settings, such as public colleges or vocational colleges, which can further examine the validity of CSMS in Chinese universities. For researchers and policy makers at Chinese universities, full consideration can be given to why the effective scale of four dimensions in Western countries can only be validated as two dimensions in a private college in Mainland China. Considering CSMS was validated in a Chinese private college, to validate the effectiveness of CSMS in Mainland China further, it is necessary to validate CSMS in other Chinese private colleges and public colleges. If CSMS is studied in other private and public universities in China, it will become a scale with reliability and validity that can help more students achieve college success.

\section{Improve FYE Program and Training Methods}

In China, students admitted to private universities generally have lower academic performance than their public counterparts, and important tasks of peer mentoring in FYE programs at private universities help students achieve academic integration and improve academic performance. Helping first-year students adjust to their new learning and living environment is also an important part of the peer mentoring program in China. Peer mentors provided a comprehensive range of psychological and emotional support for a year of students at T College. Peer mentors have been involved in the orientation program and FYE classroom for first-year students and should provide strong psychological and emotional support. 
In the FYE course, peer mentors participated in basic English-learning mentoring and some professional course mentoring. Therefore, the dimensions of DCS and ERM failed to be validated at $\mathrm{T}$ College. At present, in the peer mentoring program of T College, most peer mentors are 2nd-year students with limited experience on DCS. At the same time, the dimension of ERM was not significant in this study. Therefore, systematic leadership training for peer mentors is also necessary. According to Cornelius et al.'s (2016) study, the matching process, training, and contact frequency of peer mentors were indicators closely related to the success of first-year students. Therefore, it is important for counselors and administrators to match the peer mentors to first-year students and to train the student mentors.

\section{Integrate Extensive Resources}

The first year of college is a critical period for student success, during which peer mentoring is the most accessible support and help for first-year students. But peer mentoring alone is not enough, and schools should consider optimizing peer mentoring and using more resources to help students succeed in their first year. Colleges and universities should integrate all on-campus resources, including the academic advisor, service of the faculty, and support from peer mentors, which are student-centered and serve the success of students (Tinto, 1993). Therefore, private colleges and universities in China should recruit 3rd- and 4th-year students and alumni to participate in peer mentoring programs. Those students and alumni may have DCS and ERM, which have special advantages, such as understanding of the professional and degree to obtain experience and their leadership have prominent advantages. The significance of the DCS dimension might increase if the peer mentor group were more likely to involve 4th-year students or alumni. Senior peer mentors may have more mature experience and higher leadership, and the dimension of ERM may also be more significant. Second, universities and 
colleges should expand the sources of mentors and invite faculty to serve as academic advisors. Faculty and peer mentoring were implemented simultaneously to improve the effectiveness of academic support.

\section{Study Strengths}

This study has several strengths to mention in this section. One strength is that it provides a validated scale of a Chinese version of CSMS with reliability and validity for peer mentoring researchers in Mainland China with embedded cultural and contextual items. Next, appropriate constructs were found by factor analysis. Without prior studies on Chinese private college students' mentoring support and student success, this study represents a significant contribution to the extant quantitative research on private college students' peer mentoring, and the relationships between student success and mentoring support were tested in four student groups in Mainland China. Future research can now use the translated version of the instruments used in this study to propel the field of higher education in China, without the extra burden of translation and location that was carried out in this study.

Second, the sample size is large. I collected responses from 1,153 participants through an online survey. Participants' key demographics include gender, grade, generational status, and major. These findings are more representative in a larger context at $\mathrm{T}$ College. Third, prior quantitative data on Chinese private college students' peer mentoring were few; this study represents a significant contribution to the existing quantitative literature on peer mentoring for student success in private colleges and universities in Mainland China. Finally, in this study, some specific data related to Chinese cultures, such as one-child family status and Hukou, were collected and may also reflect the relationship between mentoring support and student success, deserving further study. 


\section{Study Limitations and Future Directions}

Some limitations of this study are worth mentioning, which can be addressed in future studies. These limitations relate to sampling, methods, and variables. Although this study was only a snapshot without an intervention, it initiates one of the first explorations into peer mentoring for first-year students and its impact on student success in Mainland China. Results of this study have guiding significance for future research in this field. The study limitations and recommendations for future research are discussed next.

This study mainly used self-reported data, including GPA, which has some limitations. Limitations of this study are related to weaknesses of self-reported measures. As with other assessment methods, self-reports have some shortcomings in the measurement. The first challenge is the credibility of self-reports; even when respondents were as forthright and insightful as they could be, their self-reports are subject to a variety of inaccuracies, such as selfdeception and vague memories (Paulhus \& Vazire, 2007). Some participants tended to answer questions in a systematic way that interfered with the validity of the answer (Paulhus, 1991). Future researchers should adopt a combination of qualitative and quantitative data, and authoritative official data, such as student GPA, should be used with permission.

Second, only the correlation relationships were tested in this study. There were no control variables or more advanced inferential statistics in the study. Therefore, I did not test the effectiveness of the interaction between variables. I recommend future researchers adopt quasiexperimental research designs to examine the effectiveness of peer mentoring in Mainland China. A longitudinal study should be conducted to examine long-term development of peer mentoring in Mainland China. 
Third, the generalizability of this study is limited. All data samples came from one private college in Mainland China; no data of other private universities were collected. The use of multigrade student data and multischool student data should be considered. The first-year programs of each school have their own characteristics to achieve retention. Some institutions do not necessarily use peers as mentors, using faculty or staff as mentors in the FYE programs. Regarding the sample population, the study only looked at a portion of students in one college in Mainland China. This means that a future study could consider a larger sampling frame, such as the entire school population or multiple sites. In addition, peer mentoring is often closely related to the specific educational context of each university. Researchers should consider comparative studies of these practices and policies at various types of Chinese universities to understand how the difference may impact disparate student populations.

Fourth, for other contexts of higher education in Mainland China, such as public universities, further research is needed to confirm whether Crisp's (2009) CSMS is applicable. Results of this study showed CSMS is applicable to higher education in Mainland China, meaning peer mentoring programs can be developed more systematically in Mainland China. The validated two-factor model provides guidance in implementing a plan suitable for private colleges and universities. The validation of CSMS in Mainland China is of great significance in theory and practice. According to the previous validation conclusions of CSMS at T College, the specific recommendations can be addressed from two aspects. China's private colleges and universities should continue to adhere to and improve the peer mentoring program based on FYE programs. Next, for other higher education contexts in Mainland China, such as other private and public universities, Crisp's (2009) CSMS needs validation in other educational contexts. 


\section{Conclusion}

This study validated the CSMS in a Chinese FYE program and examined the relationship between first-year students' perceptions of peer mentoring on CSMS and student success measured by CSPS and GPA. Participants were divided into four groups: all first-year students, female students, first-generation students, and students from four majors.

Results of this study validated the Chinese version of CSMS with two constructs (i.e., PES and NAKS) and confirmed the significant positive correlations between CSMS and CSPS for first-year, female, and first-generation student groups, and four major groups' students. Significant positive correlations between PES, NAKS, and CSPS subscales were reported for the four groups with large effect sizes. Significant positive correlations were found between CSMS and GPA only for female students, between PES and GPA only for female students, and between NAKS and GPA for female and first-generation student groups. Of the four majors, only the business major group showed a significant positive correlation between CSMS and GPA and a significant positive correlation between NAKS and GPA.

Although CSMS has only been validated in one private university, CSMS is the first scale with validity and reliability in Mainland China, which has very important theoretical value and practical significance. Using CSMS to measure the class of 2022 students at T College, students' perception of mentoring support is positively correlated with students' integration significantly. However, the correlation between students' academic success and perceived mentoring support was significant only for female and business students and partly for firstgeneration students. Results are limited, as described previously. I recommend future studies continue using and validating the Chinese version of CSMS in mentoring programs in other private and public universities in Mainland China. 


\section{REFERENCES}

Akinla, O., Hagan, P., \& Atiomo, W. (2018). A systematic review of the literature describing the outcomes of near-peer mentoring programs for first year medical students. BMC medical Education, 18(1), 1-10. https://doi.org/10.1186/s12909-018-1195-1

Akoglu, H. (2018). User's guide to correlation coefficients. Turkish Journal of Emergency Medicine, 18(3), 91-93. https://doi.org/10.1016/j.tjem.2018.08.001

Albright, J. J., \& Park, H. M. (2009). Confirmatory factor analysis using Amos, LISREL, Mplus, SAS/STAT CALIS. [Working paper.] The University Information Technology Services Center for Statistical and Mathematical Computing, Indiana University. http://hdl.handle.net/2022/19736

Allen, R. M. (2021). Adding an international lens to the university striving model: How both global and national indicators influence the Chinese higher education hierarchy. International Journal of Chinese Education, 10(1). https://doi.org/10.1177/22125868211006201

Astin, A. W. (1968). Undergraduate Achievement and Institutional "Excellence": Traditional indices of institutional quality do not appear to contribute to student achievement. Science, 161(3842), 661-668. https://doi.org/10.1126/science.161.3842.661

Astin, A. W. (1977). Four critical years: Effects of college on beliefs, attitudes, and knowledge. Jossey-Bass.

Astin, A. W. (1984). Student involvement: A developmental theory for higher education. Journal of College Student Personnel, 25(4), 297-308. https://psycnet.apa.org/record/198518630-001 
Astin, A. W. (1985). Involvement the cornerstone of excellence. Change: The Magazine of Higher Learning, 17(4), 35-39.

Astin, A. (1987). Retaining and satisfying students. Educational Record, 68(1), 36-42.

Astin, A. W. (1993). Diversity and multiculturalism on the campus: How are students affected? Change: The Magazine of Higher Learning, 25(2), 44-49. https://doi.org/10.1080/00091383.1993.9940617

Astin, A. W. (1997). How “good" is your institution's retention rate? Research in Higher Education, 38(6), 647-658. http://www.jstor.org/stable/40196281

Bartholomew, D., Knotts, M., \& Moustaki, I. (2011). Latent variable models and factor analysis: A unified approach (3rd ed.). John Wiley \& Sons.

Bartlett, M. S. (1954). Significance test for sphericity of a normal n-variate distribution. Journal of the Royal Statistical Society, 16, 296-298.

Bean, J. P. (1980). Dropouts and turnover: The synthesis and test of a causal model of student attrition. Research in Higher Education, 12(2), 155-187. https://doi.org/10.1007/BF00976194

Bean, J. P. (1983). The application of a model of turnover in work organizations to the student attrition process. The Review of Higher Education, 6(2), 129-148. https://doi.org/10.1353/rhe.1983.0026

Bean, J. P. (1985). Interaction effects based on class level in an explanatory model of college student dropout syndrome. American Educational Research Journal, 22(1), 35-64. https://doi.org/10.3102/00028312022001035 
Bean, J. P. (1990). Why students leave: Insights from research. In Hossler, D., Bean, J., Braxton J., Clark C., Abrahamson, T., Bers, T., Thomas, R., 7 Plascak-Craig, F., Vesper N., Noblitt, M., Abrams B., (Eds.), The strategic management of college enrollments (pp. 147-169). Jossey-Bass.

Bean, J. P. (2005). Nine themes of college student retention. In A. Seidman (Ed.), College student retention: Formula for student success (pp. 215-244). Praeger Publishers.

Beaton, D. E., Bombardier, C., Guillemin, F., \& Ferraz, M. B. (2000). Guidelines for the process of cross-cultural adaptation of self-report measures. Spine, 25(24), 3186-3191. https://doi.org/10.1097/00007632-200012150-00014

Birchwood, M., Smith, J., Drury, V., Healy, J., Macmillan, F., \& Slade, M. (1994). A self-report Insight Scale for psychosis: Reliability, validity and sensitivity to change. Acta Psychiatrica Scandinavica, 89(1), 62-67. https://doi.org/10.1111/j.16000447.1994.tb01487.x

Budge, S. (2006). Peer mentoring in postsecondary education: Implications for research and practice. Journal of College Reading and Learning, 37(1), 71-85. https://doi.org/10.1080/10790195.2006.10850194

Budny, D., Paul, C., \& Newborg, B. B. (2010). Impact of peer mentoring on freshmen engineering students. Journal of STEM Education: Innovations and Research, 11(5), 924.

Bullen, P., Farruggia, S. P., Gómez, C., Hebaishi, G., \& Mahmood, M. (2010). Meeting the graduating teacher standards: The added benefits for undergraduate university students who mentor youth. Educational Horizons, 89, 47-61. https://www.jstor.org/stable/42926943 
Cameron, L., Erkal, N., Gangadharan, L., \& Meng, X. (2013). Little emperors: Behavioral impacts of China's one-child policy. Science, 339(6122), 953-957. https://doi.org/10.1126/science.1230221

Campbell, T. A., \& Campbell, D. E. (1997). Faculty/Student mentor program: Effects on academic performance and retention. Research in Higher Education, 38, 727-742. https://doi.org/10.1023/A:1024911904627

Cao, X. L. (2014). 关于高校同辈辅导活动的国内研究现状综述 [Review of domestic research on peer mentoring activities in colleges and universities]. Journal of Beijing University of Chemical Technology: Social Sciences Edition, 28(14), 22-24.

Carmines, E. G., \& Zeller, R. A. (1979). Reliability and validity assessment (Vol. 17). SAGE Publications.

Chan, K. W., \& Buckingham, W. (2008). Is China abolishing the hukou system? The China Quarterly, 582-606. https://doi.org/10.1017/S0305741008000787

Chen, L. H., Wang, J., Li, H., Liu, M. T., \& Peng, J. X. (2012). 浅议独立学院独身子女自主学 习能力的培养 [On the cultivation of independent learning ability of one-child family students in private colleges]. Journal of Science and Technology Information, 35(1), 714715.

Chen, Y., Watson, R., \& Hilton, A. (2016). A review of mentorship measurement tools. Nurse Education Today, 40, 20-28. https://doi.org/10.1016/j.nedt.2016.01.020

Chester, A., Burton, L. J., Xenos, S., \& Elgar, K. (2013). Peer mentoring: Supporting successful transition for first-year undergraduate psychology students. Australian Journal of Psychology, 65(1), 30-37. https://doi.org/10.1111/ajpy.12006 
Chickering, A. W. (1969). Education and identity. Jossey-Bass.

Child, D. (2006). The essentials of factor analysis. A\&C Black.

Chomeya, R. (2010). Quality of psychology test between Likert scale 5 and 6 points. Journal of Social Sciences, 6(3), 399-403. https://doi.org/10.3844/jssp.2010.399.403

Clark, R., \& Andrews, J. (2009). Peer mentoring in higher education: A literature review. Aston Centre for Learning Innovation \& Professional Practice. http://publications.aston.ac.uk/id/eprint/17985/1/Peer_mentoring_in_higher_education.pd f

Cobb, S. (1976). Social support as a moderator of life stress. Psychosomatic Medicine, 38, 300314. https://doi.org/10.1097/00006842-197609000-00003

Cohen, J. V. (1988). Statistical power analysis for the behavioral sciences (2nd ed.). Lawrence Erlbaum Associates.

Cohen, N. H. (1995). The principles of adult mentoring scale. New Directions for Adult and Continuing, 66, 15-32. https://doi.org/10.1002/ace.36719956604

Collings, R., Swanson, V., \& Watkins, R. (2014). The impact of peer mentoring on levels of student wellbeing, integration and retention: A controlled comparative evaluation of residential students in UK higher education. Higher Education, 68(6), 927-942. https://doi.org/10.1007/s10734-014-9752-y

Collings, R., Swanson, V., \& Watkins, R. (2015). Peer mentoring during the transition to university: Assessing the usage of a formal scheme within the UK. Studies in Higher Education, 41, 1995-2010. https://doi.org/10.1080/03075079.2015.1007939 
Colvin, J. W., \& Ashman, M. (2010). Roles, risks, and benefits of peer mentoring relationships in higher education. Mentoring \& Tutoring: Partnership in Learning, 18(2), 121-134. https://doi.org/10.1080/13611261003678879

Comrey, A. L., \& Lee, H. B. (1992). Interpretation and application of factor analytic results. In A. L. Comrey \& H. B. Lee (Eds.), A first course in factor analysis (p. 2). Lawrence Erlbaum Associates.

Cornelius, V., Wood, L., \& Lai, J. (2016). Implementation and evaluation of a formal academicpeer-mentoring programme in higher education. Active Learning in Higher Education, 17(3), 193-205. https://doi.org/10.1177/1469787416654796

Corner, S. (2009). Choosing the right type of rotation in PCA and EFA. JALT Testing \& Evaluation SIG Newsletter, 13(3), 20-25.

Creswell, J. W., \& Creswell, D. J. (2018). Research design: Qualitative, quantitative, and mixed methods approaches. SAGE Publications.

Crisp, G. (n.d.). Mentoring undergraduate students. Gloria Crisp. http://www.gloriacrisp.com/mentoring-scale.html

Crisp, G. (2009). Conceptualization and initial validation of the College Student Mentoring Scale (CSMS). Journal of College Student Development, 50(2), 177-194. https://doi.org/10.1353/csd.0.0061

Crisp, G. (2010). The impact of mentoring on the success of community college students. The Review of Higher Education, 34(1), 39-60. https://doi.org/10.1353/rhe.2010.0003

Crisp, G., Baker, V. L., Griffin, K. A., Lunsford, L. G., \& Pifer, M. J. (2017). Mentoring undergraduate students. ASHE Higher Education Report, 43, 7-103. https://doi.org/10.1002/aehe.20117 
Crisp, G., \& Cruz, I. (2009). Mentoring college students: A critical review of the literature between 1990 and 2007. Research in Higher Education, 50, 525-545. https://doi.org/10.1007/s11162-009-9130-2

Crisp, G., \& Cruz, I. (2010). Confirmatory factor analysis of a measure of "mentoring" among undergraduate students attending a Hispanic serving institution. Journal of Hispanic Higher Education, 9, 232-244. https://doi.org/10.1177/1538192710371982

Cronbach, L. J., \& Meehl, P. E. (1955). Construct validity in psychological tests. Psychological Bulletin, 52(4), 281. https://doi.org/10.1037/h0040957

Cuseo, J. (2007). Defining student success: The critical first step in promoting it. eSource for College Transitions, 4, 2-3. National Resource Center for The First Year Experience and Students in Transition. http://sc.edu/fye/esource/archive.html

Davey, G., De Lian, C., \& Higgins, L. (2007). The university entrance examination system in China. Journal of further and Higher Education, 31(4), 385-396. https://doi.org/10.1080/03098770701625761

DeAngelo, L. (2014). Programs and practices that retain students from the first to second year: Results from a national study. New Directions for Institutional Research, 2013(160), 5375. https://doi.org/10.1002/ir.20061

Dennehy, T. C., \& Dasgupta, N. (2017). Female peer mentors early in college increase women's positive academic experiences and retention in engineering. Proceedings of the National Academy of Sciences, 114(23), 5964-5969. https://doi.org/10.1073/pnas.1613117114

DeVellis, R. F. (2016). Scale development: Theory and applications (Vol. 26). SAGE Publications. 
Dey, E. L., \& Astin, A. W. (1989). Predicting college student retention: Normative data from the 1985 freshman class. Higher Education Research Institute, UCLA.

Dillman, D. A., Smyth, J. D., \& Christian, L. M. (2014). Internet, phone, mail, and mixed-mode surveys: The tailored design method. John Wiley \& Sons.

Dipietro, J. A., Christensen, A. L., \& Costigan, K. A. (2008). The pregnancy experience scalebrief version. Journal of Psychosomatic Obstetrics, 29(4), 262-267. https://doi.org/10.1080/01674820802546220

Dos Reis, K. M., \& Yu, D. (2018). Peer mentoring: Enhancing economics first years' academic performance. South African Journal of Higher Education, 32(6), 234-250. https://doi.org/10.20853/32-6-2979

Drake, J. K. (2011). The role of academic advising in student retention and persistence. About Campus, 16(3), 8-12. https://doi.org/10.1002/abc.20062

Eby, L. T., \& Lockwood, A. (2005). Protégés' and mentors' reactions to participating in formal mentoring programs: A qualitative investigation. Journal of Vocational Behavior, 67(3), 441-458. https://doi.org/10.1016/j.jvb.2004.08.002

Erickson, L. D., McDonald, S., \& Elder, G. H. (2009). Informal mentors and education: Complementary or compensatory resources? Sociology of Education, 82(4), 344-67. https://doi.org/10.1177/003804070908200403

Etzel, A. M., Alqifari, S. F., Shields, K. M., Wang, Y., \& Bileck, N. B. (2018). Impact of student to student peer mentoring program in first year of pharmacy program. Currents in Pharmacy Teaching and Learning, 10(6), 762-770. https://doi.org/10.1016/j.cptl.2018.03.009 
Field, R., Hawkins, B. A., Cornell, H. V., Currie, D. J., Diniz-Filho, J. A. F., Guégan, J. F., Kaufman, D. M., Kerr, J. T., Mittelbach, G. G., Oberdorff, T., O’Brien, E. M., \& Turner, J. R. G. (2009). Spatial species-richness gradients across scales: a meta-analysis. Journal of Biogeography, 36(1), 132-147. https://doi.org/10.1111/j.1365-2699.2008.01963.x

Fox, A., Stevenson, L., Connelly, P., Duff, A., \& Dunlop, A. (2010). Peer-mentoring undergraduate accounting students: The influence on approaches to learning and academic performance. Active Learning in Higher Education, 11(2), 145-156. https://doi.org/10.1177/1469787410365650

Gardner, A. F. (2013). Predicting community college student success by participation in a firstyear experience course. Western Carolina University.

Gershenfeld, S. (2014). A review of undergraduate mentoring programs. Review of Educational Research, 84(3), 365-391. https://doi.org/10.3102/0034654313520512

Gorsuch, R. L. (1983). Factor analysis (2nd ed.). Erlbaum.

Gunn, F., Lee, S. H., \& Steed, M. (2017). Student perceptions of benefits and challenges of peer mentoring programs: Divergent perspectives from mentors and mentees. Marketing Education Review, 27(1), 15-26. https://doi.org/10.1080/10528008.2016.1255560

Harkness, J. A., Villar, A., \& Edwards, B. (2010). Translation, adaptation, and design. In J. A. Harkness, M. Braun, B. Edwards, T. P. Johnson, L. Lyberg, P. Mohler, B-E. Pennell, \& T. W. Smith (Eds.), Survey methods in multinational, multiregional, and multicultural contexts (pp. 115-140). John Hiley \& Sons. https://doi.org/10.1002/9780470609927.ch7 
Harper, S. R., \& Quaye, S. J. (2015). Making engagement equitable for students in U.S. higher education. In S. J. Quaye \& S. R. Harper (Eds.), Student engagement in higher education: Theoretical perspectives and practical approaches for diverse populations (2nd ed., pp. 29-44). Routledge.

Heirdsfield, A. M., Walker, S., Walsh, K., \& Wilss, L. (2008). Peer mentoring for first-year teacher education students: The mentors' experience. Mentoring \& Tutoring: Partnership in Learning, 16(2), 109-124. https://doi.org/10.1080/13611260801916135

Henry, J., Bruland, H. H., \& Sano-Franchini, J. (2011). Course-embedded mentoring for firstyear students: Melding academic subject support with role modeling, psycho-social support, and goal setting. International Journal for the Scholarship of Teaching and Learning, 5(2), n2. http://digitalcommons.georgiasouthern.edu/ij-sotl/

Hogan, R., Fox, D., \& Barratt-See, G. (2017). Peer to peer mentoring: Outcomes of third-year midwifery students mentoring first-year students. Women and Birth, 30(3), 206-213. https://doi.org/10.1016/j.wombi.2017.03.004

House, J. S. (1981). Work stress and social support. Addison-Wesley.

Hua, J. (2019). 同伴导师制促进大学生领导力提升的实践研究及启迪. [The practice research and enlightenment of peer mentoring system to promote the leadership enhancement of college students.] Journal of Lvliang Education Institute, 36(1), 19-36.

Huizing, R. L. (2012). Mentoring together: A literature review of group mentoring. Mentoring \& Tutoring: Partnership in Learning, 20(1), 27-55. https://doi.org/10.1080/13611267.2012.645599 
Hunt, D. M., \& Michael, C. (1983). Mentorship: A career training and development tool. Academy of Management Review, 8(3), 475-485. https://doi.org/10.5465/amr.1983.4284603

Hunter, M. S. (2006). Fostering student learning and success through first-year programs. Peer Review, 8(3), 4-7.

Hurtado, S., Eagan, M. K., Cabrera, N. L., Lin, M. H., Park, J., \& Lopez, M. (2008). Training future scientists: Predicting first-year minority student participation in health science research. Research in Higher Education, 49(2), 126-152. https://doi.org/10.1007/s11162007-9068-1

Jacobi, M. (1991). Mentoring and undergraduate academic success. A review of the literature. Review of Educational Research, 61(4), 505-532. https://doi.org/10.3102/00346543061004505

Jensen, M. P., \& Karoly, P. (1992). Self-report scales and procedures for assessing pain in adults. In D. C. Turk \& R. Melzack (Eds.), Handbook of pain assessment (pp. 19-44). The Guilford Press.

Kaiser, H. (1974). An index of factorial simplicity. Psychometrika, 39, 31-36.

Karcher, M. J., Kuperminc, G. P., Portwood, S. G., Sipe, C. L., \& Taylor, A. S. (2006). Mentoring programs: A framework to inform program development, research, and evaluation. Journal of Community Psychology, 34(6), 709-725. https://doi.org/10.1002/jcop.20125

Keeling, R. P. (2004). Learning reconsidered: A campus-wide focus on the student experience. National Association of Student Personnel Administrators and American College Personnel Association. 
Kimberlin, C. L., \& Winterstein, A. G. (2008). Validity and reliability of measurement instruments used in research. American Journal of Health-System Pharmacy, 65(23), 2276-2284. https://doi.org/10.2146/ajhp070364

Kram, K. E. (1983). Phases of the mentor relationship. Academy of Management Journal, 26(4), 608-625. https://doi.org/10.5465/255910

Kram, K. E. (1985). Mentoring at work: Developmental relationships on organization life. Scott Foresman. https://doi.org/10.2307/2392687

Kram, K. E. (1988). Mentoring at work: Developmental relationships in organizational life. University Press of America.

Kram, K. E., \& Isabella, L. A. (1985). Mentoring alternatives: The role of peer relationships in career development. Academy of Management Journal, 28, 110-132. https://doi.org/10.5465/256064

Kuh, G. D. (2001). Assessing what really matters to student learning: Inside the National Survey of Student Engagement. Change, 33(3), 10-17, 66. https://doi.org/10.1080/00091380109601795

Kuh, G. D. (2003). What we're learning about student engagement from NSSE: Benchmarks for effective educational practices. Change, 35(2), 24-32. https://doi.org/10.1080/00091380309604090

Kuh, G. D. (2007). What student engagement data tell us about college readiness. Peer Review, $9(1), 4-8$.

Kuh, G. D. (2009). What student affairs professionals need to know about student engagement. Journal of College Student Development, 50(6), 683-706. https://doi.org/10.1353/csd.0.0099 
Kuh, G. D., Kinzie, J. L., Buckley, J. A., Bridges, B. K., \& Hayek, J. C. (2006). What matters to student success: A review of the literature (Vol. 8). National Postsecondary Education Cooperative.

Kwan, J. C. L. (2014). Validating the College Student Mentoring Scale (CSMS) for a peer mentoring program in higher education-An exploratory study in Hong Kong [Doctoral dissertation, The University of Newcastle]. NOVA. http://hdl.handle.net/1959.13/1298973

Lang, M. (2001). Student retention in higher education: Some conceptual and programmatic perspectives. Journal of College Student Retention: Research, Theory \& Practice, 3(3), 217-229. https://doi.org/10.2190/L0RL-328M-4VVG-WKUB

Leavy, P. (2017). Research design: Quantitative, qualitative, mixed methods, arts-based, and community-based participatory research approaches. The Guilford Press.

Levinson, D. J., Carrow, C. N., Klein, E. B., Levinson, M. H., \& McKee, B. (1978). The seasons of a man's life. Ballentine.

Li, S. (2018). 朋辈导师计划 (PMS)工作室之大学生实现 自我教育管理服务的创新模式探究 [Study on the innovative mode of self-education management service for college students under the peer mentor program (PMS)]. Education Forum, 226(4), 266-267.

Lim, J. H., MacLeod, B. P., Tkacik, P. T., \& Dika, S. L. (2017). Peer mentoring in engineering: (un)shared experience of undergraduate peer mentors and mentees. Mentoring \& Tutoring: Partnership in Learning, 25(4), 395-416. https://doi.org/10.1080/13611267.2017.1403628 
Liu, B. B., Dai, Y. J., \& Gu, X. J. (2019). 四位一体-朋辈辅导模式在新生适应性教育的应用 探讨. [Discussion on the application of the four-in-one peer mentoring model in freshmen's adaptive education.] Education Teaching Forum, 28, 38-39.

Liu, C. (2013). 同辈导师制在新生适应中的效果优化. [The effect optimization of peer guidance system in freshmen adaptation. Educational Development]. Education Circle, 28(14), 22-24.

Lunsford, L. G., Crisp, G., Dolan, E. L., \& Wuetherick, B. (2017). Mentoring in higher education. In D. A. Clutterbuck, F. K. Kochan, L. Lunsford, N. Dominguez, \& J. Haddock-Millar (Eds.), The SAGE handbook of mentoring, (pp. 316-334). SAGE Publications. http://dx.doi.org/10.4135/9781526402011.n20

Ma, Y. S., \& Ma, C. (2016). 一年级书院制背景下的学长制朋辈教育实践与思考 [Practice and thinking of peer education in the context of first-year college system]. Journal of Weifang University, 16(4), 102-104.

Manyanga, F., Sithole, A., \& Hanson, S. M. (2017). Comparison of student retention models in undergraduate education from the past eight decades. Journal of Applied Learning in Higher Education, 7, 30-42.

McCroskey, J. C. (1984). Self-report measurement. In J. A. Daly \& J. A. McCroskey (Eds.), Avoiding communication: Shyness, reticence, and communication apprehension, (pp. 8194). SAGE Publications. 
McCroskey, J. C. (1997). Willingness to communicate, communication apprehension, and selfperceived communication competence: Conceptualizations and perspectives. In J. A. Daly, J. C. McCroskey, J. Ayres, T. Hopf, \& D. M. Sonadre (Eds.), Avoiding communication: shyness, reticence, and communication apprehension (2nd ed.; pp. 191216). Cresskill. https://doi.org/10.1080/08824099109359876

McInnis, C. (2001). Researching the first year experience: where to from here? Higher Education Research \& Development, 20(2), 105-114. https://doi.org/10.1080/07294360125188

McInnis, C., Hartley, R., Polesel, J., \& Teese, R. (2000). Non-completion in vocational education and training and higher education. Centre for the Study of Higher Education, The University of Melbourne \& The Department of Education Training and Youth Affairs. http://hdl.voced.edu.au/10707/145629

McNeely, J. H. (1937). College student mortality. U.S. Office of Education, Bulletin 1937, No. 11.

Miller, A. (2002). Mentoring students \& young people: A handbook of effective practice. Kogan Page.

Ministry of Education of the People's Republic of China. (2020, June). Education statistics on private students studying in China in 2019. http://www.moe.gov.cn/s78/A03/moe_560/jytjsj_2019/qg/202006/t20200611_464802.ht $\mathrm{ml}$

Moschetti, R. V., Plunkett, S. W., Efrat, R., \& Yomtov, D. (2018). Peer mentoring as social capital for Latina/o college students at a Hispanic-serving institution. Journal of Hispanic Higher Education, 17(4), 375-392. https://doi.org/10.1177/1538192717702949 
Nadelson, L. S., Semmelroth, C., Martinez, G., Featherstone, M., Fuhriman, C. A., \& Sell, A. (2013). Why did they come here? The influences and expectations of first-year students' college experience. Higher Education Studies, 3(1), 50-62.

National Collegiate Honors Council. (n.d.). Peer mentoring. http://nchc honors.org/facultydirectors/peer-mentoring-programs/

Nemoto, T., \& Beglar, D. (2014). Developing Likert-scale questionnaires. In JALT 2013 conference proceedings (pp. 1-8). https://jalt-publications.org/sites/default/files/pdfarticle/jalt2013_001.pdf

Nora, A., \& Crisp, G. (2007). Mentoring students: Conceptualizing and validating the multidimensions of a support system. Journal of College Student Retention: Research, Theory \& Practice, 9(3), 337-356. https://doi.org/10.2190/CS.9.3.e

O’Brien, M., Llamas, M., \& Stevens, E. (2012). Lessons learned from four years of peer mentoring in a tiered group program within Education. JANZSSA, 40, 7-15. https://search.informit.org/doi/10.3316/aeipt.195079

Pallant, J. (2016). SPSS survival manual: A step by step guide to data analysis using SPSS program (6th ed.). McGraw-Hill Education.

Pascarella, E. T. (1980). Student-faculty informal contact and college outcomes. Review of Educational Research, 50(4), 545-595. https://doi.org/10.3102/00346543050004545

Paulhus, D. L. (1991). Measurement and control of response bias. In J. P. Robinson, P. R. Shaver, \& L. S. Wrightsman (Eds.), Measures of personality and social psychological attitudes (pp. 17-59). Academic Press. https://doi.org/10.1016/B978-0-12-590241$0.50006-X$ 
Paulhus, D. L., \& Vazire, S. (2007). The self-report method. In R. W. Robins, R. C. Fraley, \& R. F. Krueger (Eds.), Handbook of research methods in personality psychology (pp. 224239). Guilford Press.

Perry, W. G. (1970). Forms of intellectual and ethical development in the college years. Holt, Rinehart \& Winston.

Phillips, R., Swanson, V., \& Morgan-Klein, B. (2004, November 5-7). Students helping students: The effectiveness of peer mentoring in UK higher education. [Paper presentation]. The Psychology of Education Section Annual Conference. Glasgow, Scotland, United Kingdom.

Qian, B. (2011). 地方高校本科生“三导师制”育人体系构建研究 [Research on the construction of "three tutorial system" education system for local undergraduates]. Data of Culture and Education, 32, 155-157.

Rieske, L. J., \& Benjamin, M. (2015). Utilizing peer mentor roles in learning communities. New Directions for Student Services, 2015(149), 67-77.

Roberts, A. (2000). Mentoring revisited: a phenomenological reading of the literature. Mentoring and Tutoring, 8(2), 145-170. https://doi.org/10.1080/713685524

Robinson, D. (2018). Perceptions of first-year college students: The impact of peer mentors on student success. Southern Connecticut State University.

Salehi, K., \& Golafshani, N. (2010). Commentary: Using mixed methods in research studies-an opportunity with its challenges. International Journal of Multiple Research Approaches, 4(3), 186-191. https://doi.org/10.5172/mra.2010.4.3.186

Santos, J. R. A. (1999). Cronbach's alpha: A tool for assessing the reliability of scales. Journal of Extension, 37(2), 1-5. 
Saunders, D. F., \& Romm, J. (2008). An historical perspective on first-year seminars. In B. F. Tobolowsky (Ed.), 2006 National Survey of First-Year Seminars: Continuing innovations in the collegiate curriculum, Monograph No. 51 (Vol. 51, pp. 1-4). National Resource Center for the First-Year Experience \& Students in Transition.

Schockett, M. R., \& Haring-Hidore, M. (1985). Factor analytic support for psychosocial and vocational mentoring functions. Psychological Reports, 57, 627-630. https://doi.org/10.2466/pr0.1985.57.2.627

Schrader, P. G., \& Brown, S. W. (2008, Winter). Evaluating the first year experience: Students' knowledge, attitudes, and behaviors. Journal of Advanced Academics, 19, 310-343. https://doi.org/10.4219/jaa-2008-775

Shi, X. (2008). 本科”朋辈导师制”探析. [Probe into Peer Tutorial System of Undergraduates]. Theory and Practice of Education, 28(12), 20-22.

Sparks, L. O. (2017). Mentoring as a predictor of student success among first-generation and continuing-generation students enrolled in a public four-year university (Publication No. 10287811) [Doctoral dissertation, Azusa Pacific University]. ProQuest Dissertations Publishing.

Stage, F. K., \& Hossler, G. (2000). Where is the student? Linking student behaviors, college choice and college persistence. In J. Braxton (Ed.), Rethinking the departure puzzle: New theory and research on college student retention (pp. 107-195). Vanderbilt University Press.

Tabachnick, B. G., Fidell, L. S., \& Ullman, J. B. (2007). Using multivariate statistics (Vol. 5). Pearson. 
Tao, H. (2011). 论朋辈教育模式在高校学生工作中的应用. [On the application of peer education model in college students affairs work]. Journal of Chifeng University, 32(5), 91-93.

Terrion, J. L., \& Leonard, D. (2007). A taxonomy of the characteristics of student peer mentors in higher education: Findings from a literature review. Mentoring \& Tutoring: Partnership in Learning, 15(2), 149-164. https://doi.org/10.1080/13611260601086311

Thornberry, T. P., \& Krohn, M. D. (2000). The self-report method for measuring delinquency and crime. Measurement and analysis of crime and justice: Criminal Justice, 4(4), 33-83. https://www.ncjrs.gov/criminal_justice2000/vol_4/04b

Tinto, V. (1975). Dropout from higher education: A theoretical synthesis of recent research. Review of Educational Research, 45(1), 89-125. https://doi.org/10.3102/00346543045001089

Tinto, V. (1987). Leaving college: Rethinking the causes and cures of student attrition. University of Chicago Press.

Tinto, V. (1993). Leaving College: Rethinking the causes and cures of student attrition (2nd ed.). University of Chicago.

Tinto, V. (1999). Taking retention seriously: Rethinking the first year of college. NACADA Journal, 19(2), 5-9.

Tinto, V. (2012). Completing college: Rethinking institutional action. University of Chicago Press.

Tinto, V., \& Wallace, D. L. (1986). Retention: An admission concern. College and University, 61(4), 290-293.

Urdan, T. C. (2017). Statistics in plain English. Routledge. 
Vaidya, J. G., Gray, E. K., Haig, J., \& Watson, D. (2002). On the temporal stability of personality: Evidence for differential stability and the role of life experiences. Journal of Personality and Social Psychology, 83(6), 1469-1484. https://doi.org/10.1037/00223514.83.6.1469

van der Zanden, P. J., Denessen, E., Cillessen, A. H., \& Meijer, P. C. (2019). Patterns of success: First-year student success in multiple domains. Studies in Higher Education, 44(11), 2081-2095. https://doi.org/10.1080/03075079.2018.1493097

Wang, G. P. (2010). 同伴导师: 美国高校新生计划的积极参与者与有效促进 [Peer mentors: active participants and effective facilitators of First-Year Experience programs in American colleges and universities] Education Exploration, 227(5), 150-151.

White, E., Goetz, J., Hunter, M., \& Barefoot, B. (1995). Creating successful transitions through academic advising. In M. L. Upcraft \& G. L. Kramer (Eds.), First-year academic advising: Patterns in the present, pathways to the future (Monograph No. 18). National Resource Center for the Freshman Year Experience and Students in Transition, University of South Carolina.

Williams, C. (2007). Research methods. Journal of Business Research, 5(3), 65-72. http://www.sciencedirect.com/science/journal/01482963

Winters, K. C., Stinchfield, R. D., Henly, G. A., \& Schwartz, R. H. (1990). Validity of adolescent self-report of alcohol and other drug involvement. International Journal of the Addictions, 25(sup11), 1379-1395. https://doi.org/10.3109/10826089009068469 
Wolf-Wendel, L., Ward, K., \& Kinzie, J. (2009). A tangled web of terms: The overlap and unique contribution of involvement, engagement, and integration to understanding college student success. Journal of College Student Development, 50(4), 407-428. https://doi.org/10.1353/csd.0.0077

World Values Survey. (2010). Homepage. www.worldvaluessurvey.org/WVSDocumentationWV6.jsp

Xie, J. F. (2018). 私人订制导师在班级管理中的实践与探索 [The practice and exploration of private mentor in class management]. Science \& Technology Information, 81(11), 146148.

Yomtov, D., Plunkett, S. W., Efrat, R., \& Marin, A. G. (2017). Can peer mentors improve first year experiences of university students? College Student Retention, 19(1), 25-24. https://doi.org/10.1177/1521025115611398

Young, D. G., \& Keup, J. R. (2016). Using hybridization and specialization to enhance the firstyear experience in community colleges: A national picture of high-impact practices in first-year seminars. New Directions for Community Colleges, 2016(175), 57-69. https://doi.org/10.1002/cc.20212

Yue, Z. L., \& Li, Q. P. (2016). 试论朋辈教育在民办高校学生管理中的应用 [On the application of peer education in the management of students in private universities]. Journal of Chifeng University (Natural Science Edition), 32(5), 218-220.

Zachary, L. J. (2002). The role of teacher as mentor. Contemporary Viewpoints on Teaching Adults Effectively, New Directions for Adult and Continuing Education, 93, 27-38. 
Zhang, X. M. (2011). 同伴导师制——大学新生教育的有效形式 [Peer mentoring systeman effective form of freshman education]. Education and Exploration, 27(4), 68-69.

Zhang, X. M., \& Duan, H. F. (2014). 主体间性视域下的大学生同伴教育探究 [Peer education of college students from the perspective of intersubjectivity]. Theory and Practice of Education, 34(24), 22-24. 


\section{APPENDICES}




\section{Appendix A}

\section{Table A1}

Descriptive Statistics of the Continuous Variables Included in the Study

\begin{tabular}{|c|c|c|c|c|c|}
\hline Items of CSMS & Frequency & Mean & $\begin{array}{c}\text { Std. } \\
\text { Deviation }\end{array}$ & Skewness & Kurtosis \\
\hline $\begin{array}{l}\text { Q1 When peer mentors come into my life in the first year of college, they } \\
\text { acknowledge my academic achievements. }\end{array}$ & 1153 & 3.98 & .721 & -.502 & .653 \\
\hline $\begin{array}{l}\text { Q2 When peer mentors come into my life in the first year of college, I can openly } \\
\text { discuss with him or her various social issues related to the university. }\end{array}$ & 1153 & 3.92 & .739 & -.485 & .583 \\
\hline $\begin{array}{l}\text { Q3 When peer mentors come into my life in the first year of college, they } \\
\text { encourage me to use him or her as my advisor in exploring college life. }\end{array}$ & 1153 & 3.95 & .752 & -.573 & .670 \\
\hline $\begin{array}{l}\text { Q4 When peer mentors come into my life in the first year of college, they give me } \\
\text { emotional support. }\end{array}$ & 1153 & 3.86 & .770 & -.507 & .493 \\
\hline $\begin{array}{l}\text { Q5 When peer mentors come into my life in the first year of college, I can talk } \\
\text { openly with him or her about personal problems related to college life. }\end{array}$ & 1153 & 3.85 & .788 & -.524 & .513 \\
\hline $\begin{array}{l}\text { Q6 When peer mentors come into my life in the first year of college, they make } \\
\text { me feel that I have a sense of belonging in the university. }\end{array}$ & 1153 & 3.85 & .806 & -.628 & .666 \\
\hline $\begin{array}{l}\text { Q7 When peer mentors come into my life in the first year of college, they are } \\
\text { fully Confident that I can complete my study. }\end{array}$ & 1153 & 3.96 & .717 & -.477 & .722 \\
\hline $\begin{array}{l}\text { Q8 When peer mentors come into my life in the first year of college, they } \\
\text { encourage me to talk about problems in my social life at university. }\end{array}$ & 1153 & 3.97 & .738 & -.606 & 1.000 \\
\hline $\begin{array}{l}\text { Q9 When peer mentors come into my life in the first year of college, they } \\
\text { encourage me to consider learning opportunities beyond my current plans. }\end{array}$ & 1153 & 3.93 & .708 & -.473 & .725 \\
\hline $\begin{array}{l}\text { Q10 When peer mentors come into my life in the first year of college, they help } \\
\text { me rationally examine the possibility of obtaining my undergraduate degree and } \\
\text { graduation certificate. }\end{array}$ & 1153 & 3.94 & .700 & -.386 & .311 \\
\hline $\begin{array}{l}\text { Q11 When peer mentors come into my life in the first year of college, they guide } \\
\text { me to rationally evaluate my skills, to question my assumptions. }\end{array}$ & 1153 & 3.84 & .729 & -.294 & .010 \\
\hline $\begin{array}{l}\text { Q12 When peer mentors come into my life in the first year of college, they help } \\
\text { me carefully check whether I meet the requirements for my undergraduate degree } \\
\text { and graduation certificate. }\end{array}$ & 1153 & 3.87 & .746 & -.454 & .351 \\
\hline Q13 When peer mentors come into my life in the first year of college, they & 1153 & 3.84 & .753 & -.491 & .578 \\
\hline
\end{tabular}


Q14 When peer mentors come into my life in the first year of college, they help me consider the cost associated with my choice to earn a college degree.

Q15 When peer mentors come into my life in the first year of college, they provide continuous support for my study in class.

Q16 When peer mentors come into my life in the first year of college, they help me to exert my best potential in class performance.

Q17 When peer mentors come into my life in the first year of college, they help me to achieve my academic success.

CSMS Q18 When peer mentors come into my life in the first year of college, they provide practical suggestions for improving my academic performance.

Q19 When peer mentors come into my life in the first year of college, they

encourage me to discuss problems in the course assignments.

Q20 When peer mentors come into my life in the first year of college, they share his/her story of overcoming difficulties to achieve his/her academic goals.

Q21 When peer mentors come into my life in the first year of college, they share his/her story of overcoming difficulties to achieve his/her academic goals

Q22 When peer mentors come into my life in the first year of college, they can be an example of how to succeed in college.

Q23 When peer mentors come into my life in the first year of college, they set a good example of how to get along with others.

Q24 When peer mentors come into my life in the first year of college, they I have great respect for his (her) views on issues re

\begin{tabular}{lllll}
1153 & 3.87 & .727 & -.466 & .576 \\
1153 & 3.96 & .692 & -.453 & .711 \\
1153 & 3.85 & .749 & -.405 & .246 \\
1153 & 3.85 & .734 & -.371 & .268 \\
1153 & 3.96 & .680 & -.379 & .435 \\
1153 & 3.95 & .695 & -.443 & .488 \\
1153 & 3.97 & .681 & -.297 & .084 \\
1153 & 3.94 & .682 & -.321 & .370 \\
1153 & 3.97 & .674 & -.445 & .856 \\
1153 & 3.85 & .775 & -.552 & .657 \\
1153 & 3.98 & .685 & -.427 & .774 \\
1153 & 4.03 & .676 & -.561 & 1.242 \\
\hline
\end{tabular}




\section{Table A2}

Correlation Matrix of CSMS 25 Items

\begin{tabular}{|c|c|c|c|c|c|c|c|c|c|c|}
\hline & Q1 & $\mathrm{Q} 2$ & Q3 & Q4 & Q5 & Q6 & Q7 & Q8 & Q9 & Q10 \\
\hline Q1 & 1.000 & .772 & .732 & .704 & .674 & .695 & .693 & .700 & .627 & .615 \\
\hline Q2 & .772 & 1.000 & .793 & .736 & .736 & .740 & .702 & .716 & .665 & .639 \\
\hline Q3 & .732 & .793 & 1.000 & .757 & .731 & .720 & .714 & .727 & .675 & .620 \\
\hline Q4 & .704 & .736 & .757 & 1.000 & .789 & .750 & .731 & .753 & .679 & .641 \\
\hline Q5 & .674 & .736 & .731 & .789 & 1.000 & .784 & .750 & .733 & .705 & .674 \\
\hline Q6 & .695 & .740 & .720 & .750 & .784 & 1.000 & .761 & .757 & .700 & .701 \\
\hline Q7 & .693 & .702 & .714 & .731 & .750 & .761 & 1.000 & .784 & .695 & .711 \\
\hline Q8 & .700 & .716 & .727 & .753 & .733 & .757 & .784 & 1.000 & .726 & .688 \\
\hline Q9 & .627 & .665 & .675 & .679 & .705 & .700 & .695 & .726 & 1.000 & .714 \\
\hline Q10 & .615 & .639 & .620 & .641 & .674 & .701 & .711 & .688 & .714 & 1.000 \\
\hline Q11 & .638 & .668 & .648 & .680 & .678 & .682 & .684 & .667 & .723 & .749 \\
\hline Q12 & .607 & .606 & .592 & .632 & .645 & .663 & .659 & .651 & .696 & .734 \\
\hline Q13 & .594 & .622 & .604 & .684 & .666 & .683 & .685 & .678 & .680 & .711 \\
\hline Q14 & .610 & .650 & .623 & .649 & .647 & .670 & .681 & .646 & .648 & .720 \\
\hline Q15 & .618 & .628 & .629 & .607 & .648 & .621 & .686 & .647 & .657 & .660 \\
\hline Q16 & .646 & .651 & .660 & .684 & .693 & .704 & .676 & .665 & .695 & .700 \\
\hline Q17 & .644 & .669 & .672 & .672 & .684 & .691 & .678 & .672 & .695 & .685 \\
\hline Q18 & .644 & .632 & .649 & .639 & .649 & .663 & .710 & .692 & .657 & .719 \\
\hline Q19 & .612 & .655 & .639 & .653 & .646 & .664 & .681 & .672 & .674 & .686 \\
\hline Q20 & .599 & .619 & .614 & .627 & .621 & .643 & .665 & .652 & .684 & .673 \\
\hline Q21 & .605 & .634 & .630 & .616 & .608 & .649 & .647 & .676 & .661 & .655 \\
\hline Q22 & .664 & .656 & .670 & .669 & .665 & .697 & .723 & .706 & .656 & .684 \\
\hline Q23 & .608 & .625 & .635 & .630 & .624 & .658 & .612 & .639 & .643 & .619 \\
\hline Q24 & .616 & .642 & .667 & .634 & .617 & .642 & .673 & .656 & .634 & .654 \\
\hline Q25 & .639 & .660 & .679 & .653 & .649 & .669 & .666 & .686 & .636 & .643 \\
\hline
\end{tabular}




\begin{tabular}{|c|c|c|c|c|c|c|c|c|c|c|c|c|c|c|c|c|}
\hline \multirow{2}{*}{\multicolumn{2}{|c|}{$\overline{\text { Correl O1 }}$}} & Q11 & Q12 & Q13 & Q14 & Q15 & Q16 & Q17 & Q18 & Q19 & Q20 & Q21 & Q22 & Q23 & Q24 & Q25 \\
\hline & & .638 & .607 & .594 & .610 & .618 & .646. & .644 & .644 & .612 & .599. & .605 & .664 & .608 & .616 & .639 \\
\hline \multirow[t]{24}{*}{ ation } & $\mathrm{Q} 2$ & .668 & .606 & .622 & .650 & .628 & .651 & .669 & .632 & .655 & .619 & .634 & .656 & .625 & .642 & .660 \\
\hline & Q3 & .648 & .592 & .604 & .623 & .629 & .660 & .672 & .649 & .639 & .614 & .630 & .670 & .635 & .667 & .679 \\
\hline & $\mathrm{Q} 4$ & .680 & .632 & .684 & .649 & .607 & .684 & .672 & .639 & .653 & .627 & .616 & .669 & .630 & .634 & .653 \\
\hline & Q5 & .678 & .645 & .666 & .647 & .648 & .693 & .684 & .649 & .646 & .621 & .608 & .665 & .624 & .617 & .649 \\
\hline & Q6 & .682 & .663 & .683 & .670 & .621 & .704 & .691 & .663 & .664 & .643 & .649 & .697 & .658 & .642 & .669 \\
\hline & Q7 & .684 & .659 & .685 & .681 & .686 & .676 & .678 & .710 & .681 & .665 & .647 & .723 & .612 & .673 & .666 \\
\hline & Q8 & .667 & .651 & .678 & .646 & .647 & .665 & .672 & .692 & .672 & .652 & .676 & .706 & .639 & .656 & .686 \\
\hline & Q9 & .723 & .696 & .680 & .648 & .657 & .695 & .695 & .657 & .674 & .684 & .661 & .656 & .643 & .634 & .636 \\
\hline & Q10 & .749 & .734 & .711 & .720 & .660 & .700 & .685 & .719 & .686 & .673 & .655 & .684 & .619 & .654 & .643 \\
\hline & Q11 & 1.000 & .777 & .777 & .719 & .684 & .739 & .731 & .668 & .691 & .705 & .665 & .654 & .638 & .645 & .630 \\
\hline & Q12 & .777 & 1.000 & .774 & .710 & .713 & .733 & .736 & .692 & .677 & .667 & .656 & .638 & .610 & .618 & .607 \\
\hline & Q13 & .777 & .774 & 1.000 & .758 & .687 & .752 & .741 & .666 & .685 & .658 & .634 & .648 & .654 & .640 & .644 \\
\hline & Q14 & .719 & .710 & .758 & 1.000 & .703 & .721 & .766 & .694 & .702 & .655 & .667 & .682 & .668 & .650 & .659 \\
\hline & Q15 & .684 & .713 & .687 & .703 & 1.000 & .770 & .775 & .759 & .711 & .669 & .686 & .677 & .609 & .652 & .682 \\
\hline & Q16 & .739 & .733 & .752 & .721 & .770 & 1.000 & .830 & .722 & .693 & .683 & .681 & .680 & .668 & .660 & .657 \\
\hline & Q17 & .731 & .736 & .741 & .766 & .775 & .830 & 1.000 & .747 & .741 & .694 & .706 & .697 & .649 & .667 & .660 \\
\hline & Q18 & .668 & .692 & .666 & .694 & .759 & .722 & .747 & 1.000 & .755 & .741 & .728 & .746 & .648 & 689 & .692 \\
\hline & Q19 & .691 & .677 & .685 & .702 & .711 & .693 & .741 & .755 & 1.000 & .750 & .725 & .732 & .650 & .682 & .695 \\
\hline & Q20 & .705 & .667 & .658 & .655 & .669 & .683 & .694 & .741 & .750 & 1.000 & .753 & .730 & .656 & .673 & .665 \\
\hline & Q21 & .665 & .656 & .634 & .667 & .686 & .681 & .706 & .728 & .725 & .753 & 1.000 & .797 & .705 & .706 & .714 \\
\hline & Q22 & .654 & .638 & .648 & .682 & .677 & .680 & .697 & .746 & .732 & .730 & .797 & 1.000 & .708 & .780 & .762 \\
\hline & Q23 & .638 & .610 & .654 & .668 & .609 & .668 & .649 & .648 & .650 & .656 & .705 & .708 & 1.000 & .685 & .687 \\
\hline & Q24 & .645 & .618 & .640 & .650 & .652 & .660 & .667 & .689 & .682 & .673 & .706 & .780 & .685 & 1.000 & .757 \\
\hline & Q25 & .630 & .607 & .644 & .659 & .682 & .657 & .660 & .692 & .695 & .665 & .714 & .762 & .687 & .757 & 1.000 \\
\hline
\end{tabular}


Table A3

Intercorrelations of Study's Primary Variables

\begin{tabular}{|c|c|c|c|c|c|c|c|}
\hline Variable & $n$ & 1 & 2 & 3 & 4 & 5 & 6 \\
\hline 1.CSMS ${ }^{\mathrm{A}}$ & 1153 & - & - & - & - & - & - \\
\hline 2.CSMS FE & 879 & - & - & - & - & - & - \\
\hline 3.CSMS ${ }^{\mathrm{FG}}$ & 640 & - & - & - & - & - & - \\
\hline 4. CSMS E & 440 & - & - & - & - & - & - \\
\hline 5. CSMS ${ }^{\mathrm{H}}$ & 203 & - & - & - & - & - & - \\
\hline 6. CSMS ${ }^{\text {B }}$ & 320 & - & - & - & - & - & - \\
\hline 7. CSMS ${ }^{\mathrm{S}}$ & 190 & - & - & - & - & - & - \\
\hline 8. PES A & 1153 & - & - & - & - & - & - \\
\hline 9. PES FE & 879 & - & - & - & - & - & - \\
\hline 10. PES FG & 640 & - & - & - & - & - & - \\
\hline 11. PES ${ }^{\mathrm{E}}$ & 440 & - & - & - & - & - & - \\
\hline 12. $\mathrm{PES}^{\mathrm{H}}$ & 203 & - & - & - & - & - & - \\
\hline 13. PES ${ }^{B}$ & 320 & - & - & - & - & - & - \\
\hline 14. $\mathrm{PES}^{\mathrm{S}}$ & 190 & - & - & - & - & - & - \\
\hline 15. NAKS ${ }^{A}$ & 1153 & - & - & - & - & - & - \\
\hline 16.NAKS ${ }^{\mathrm{FE}}$ & 879 & - & - & - & - & - & - \\
\hline 17.NAKS ${ }^{\mathrm{FG}}$ & 640 & - & - & - & - & - & - \\
\hline 18.NAKS E & 440 & - & - & - & - & - & - \\
\hline 19.NAKS ${ }^{H}$ & 203 & - & - & - & - & - & - \\
\hline 20.NAKS B & 320 & - & - & - & - & - & - \\
\hline 21.NAKS $\mathrm{s}$ & 190 & - & - & - & - & - & - \\
\hline 22. CSPS & - & $.589 * *$ & $.586 * *$ & $.605 * *$ & $.627 * *$ & $.629 * *$ & $.531^{* *}$ \\
\hline 23. GPA & - & .048 & $.074 *$ & .077 & -.011 & .053 & $.110^{*}$ \\
\hline
\end{tabular}

Intercorrelations of Study's Primary Variables

(Cont.)

\begin{tabular}{|c|c|c|c|c|c|c|c|}
\hline Variable & $n$ & 7 & 8 & 9 & 10 & 11 & 12 \\
\hline $1 . \mathrm{CSMS}^{\mathrm{A}}$ & 1153 & - & - & - & - & - & - \\
\hline 2.CSMS FE & 879 & - & - & - & - & - & - \\
\hline 3.CSMS FG & 640 & - & - & - & - & - & - \\
\hline 4. CSMS ${ }^{\mathrm{E}}$ & 440 & - & - & - & - & - & - \\
\hline 5. $\mathrm{CSMS}^{\mathrm{H}}$ & 203 & - & - & - & - & - & - \\
\hline 6. $\mathrm{CSMS}^{\mathrm{B}}$ & 320 & - & - & - & - & - & - \\
\hline 7. $\mathrm{CSMS}^{\mathrm{s}}$ & 190 & - & - & - & - & - & - \\
\hline 8. PES ${ }^{\mathrm{A}}$ & 1153 & - & - & - & - & - & - \\
\hline 9. PES FE & 879 & - & - & - & - & - & - \\
\hline 10. PES FG & 640 & - & - & - & - & - & - \\
\hline 11. PES ${ }^{\mathrm{E}}$ & 440 & - & - & - & - & - & - \\
\hline 12. $\mathrm{PES}^{\mathrm{H}}$ & 203 & - & - & - & - & - & - \\
\hline 13. PES ${ }^{B}$ & 320 & - & - & - & - & - & - \\
\hline 14. PES $^{\mathrm{S}}$ & 190 & - & - & - & - & - & - \\
\hline
\end{tabular}




\begin{tabular}{|c|c|c|c|c|c|c|c|}
\hline Variable & $n$ & 7 & 8 & 9 & 10 & 11 & 12 \\
\hline 15. NAKS ${ }^{A}$ & 1153 & - & - & - & - & - & - \\
\hline 16.NAKS FE & 879 & - & - & - & - & - & - \\
\hline 17.NAKS ${ }^{\text {FG }}$ & 640 & - & - & - & - & - & - \\
\hline 18.NAKS E & 440 & - & - & - & - & - & - \\
\hline 19.NAKS ${ }^{H}$ & 203 & - & - & - & - & - & - \\
\hline 20.NAKS B & 320 & - & - & - & - & - & - \\
\hline 21.NAKS S & 190 & - & - & - & - & - & - \\
\hline 22. CSPS & - & $.523 * *$ & $.587 * *$ & $.595 * *$ & $.591 * *$ & $.610 * *$ & $.619 * *$ \\
\hline 23. GPA & - & .055 & .051 & $.078^{*}$ & .073 & -.011 & .053 \\
\hline
\end{tabular}

Intercorrelations of the Primary Variables (Cont.)

\begin{tabular}{|c|c|c|c|c|c|c|c|}
\hline Variable & $n$ & 13 & 14 & 15 & 16 & 17 & 18 \\
\hline 1.CSMS A & 1153 & - & - & - & - & - & - \\
\hline 2.CSMS FE & 879 & - & - & - & - & - & - \\
\hline 3.CSMS FG & 640 & - & - & - & - & - & - \\
\hline 4. CSMS $^{\mathrm{E}}$ & 440 & - & - & - & - & - & - \\
\hline 5. CSMS ${ }^{\mathrm{H}}$ & 203 & - & - & - & - & - & - \\
\hline 6. CSMS ${ }^{\text {B }}$ & 320 & - & - & - & - & - & - \\
\hline 7. CSMS ${ }^{S}$ & 190 & - & - & - & - & - & - \\
\hline 8. PES A & 1153 & - & - & - & - & - & - \\
\hline 9. PES FE & 879 & - & - & - & - & - & - \\
\hline 10. PES ${ }^{\mathrm{FG}}$ & 640 & - & - & - & - & - & - \\
\hline 11. $\mathrm{PES}^{\mathrm{E}}$ & 440 & - & - & - & - & - & - \\
\hline 12. PES ${ }^{\mathrm{H}}$ & 203 & - & - & - & - & - & - \\
\hline 13. PES B & 320 & - & - & - & - & - & - \\
\hline 14. PES $\mathrm{S}$ & 190 & - & - & - & - & - & - \\
\hline 15. NAKS ${ }^{A}$ & 1153 & - & - & - & - & - & - \\
\hline 16.NAKS ${ }^{\mathrm{FE}}$ & 879 & - & - & - & - & - & - \\
\hline 17.NAKS FG & 640 & - & - & - & - & - & - \\
\hline 18.NAKS ${ }^{\text {E }}$ & 440 & - & - & - & - & - & - \\
\hline 19.NAKS ${ }^{H}$ & 203 & - & - & - & - & - & - \\
\hline 20.NAKS B & 320 & - & - & - & - & - & - \\
\hline 21.NAKS ${ }^{S}$ & 190 & - & - & - & - & - & - \\
\hline 22. CSPS & - & $.560 * *$ & $.506^{* *}$ & $.566^{* *}$ & $.557 * *$ & $.589 * *$ & $.611 * *$ \\
\hline 23. GPA & - & $.110 *$ & -.055 & .053 & $.078 *$ & $.081 *$ & -.003 \\
\hline
\end{tabular}

Intercorrelations of the Primary Variables (Cont.)

\begin{tabular}{|c|c|c|c|c|}
\hline Variable & $n$ & 19 & 20 & 21 \\
\hline 1.CSMS ${ }^{\mathrm{A}}$ & 1153 & - & - & - \\
\hline 2.CSMS FE & 879 & - & - & - \\
\hline 3.CSMS ${ }^{\mathrm{FG}}$ & 640 & - & - & - \\
\hline 4. $\mathrm{CSMS}^{\mathrm{E}}$ & 440 & - & - & - \\
\hline
\end{tabular}




\begin{tabular}{|c|c|c|c|c|}
\hline Variable & $n$ & 19 & 20 & 21 \\
\hline 5. CSMS ${ }^{\mathrm{H}}$ & 203 & - & - & - \\
\hline 6. CSMS $^{\text {в }}$ & 320 & - & - & - \\
\hline 7. CSMS $\mathrm{s}$ & 190 & - & - & - \\
\hline 8. PES A & 1153 & - & - & - \\
\hline 9. PES FE & 879 & - & - & - \\
\hline 10. PES FG & 640 & - & - & - \\
\hline 11. PES ${ }^{\mathrm{E}}$ & 440 & - & - & - \\
\hline 12. $\mathrm{PES}^{\mathrm{H}}$ & 203 & - & - & - \\
\hline 13. PES ${ }^{B}$ & 320 & - & - & - \\
\hline 14. PES $\mathrm{S}$ & 190 & - & - & - \\
\hline 15. NAKS ${ }^{A}$ & 1153 & - & - & - \\
\hline 16.NAKS FE & 879 & - & - & - \\
\hline 17.NAKS ${ }^{\text {FG }}$ & 640 & - & - & - \\
\hline 18.NAKS ${ }^{\mathrm{E}}$ & 440 & - & - & - \\
\hline 19.NAKS ${ }^{\mathrm{H}}$ & 203 & - & - & - \\
\hline 20.NAKS B & 320 & - & - & - \\
\hline 21.NAKS ${ }^{S}$ & 190 & - & - & - \\
\hline 22. CSPS & - & $.615^{* *}$ & $.488 * *$ & $.510 * *$ \\
\hline 23. GPA & - & .077 & $.012 *$ & -.082 \\
\hline
\end{tabular}

Note. CSMS ${ }^{\mathrm{A}}$ was CSMS for all first-year students. CSMS ${ }^{\mathrm{FE}}$ was CSMS for female first-year students. CSMS ${ }^{\mathrm{FG}}$ was CSMS for first-generation first-year students. CSMS ${ }^{\mathrm{E}}$ was CSMS for education major groups first-year students. CSMS ${ }^{\mathrm{H}}$ was CSMS for humanity major groups first-year students. CSMS ${ }^{\text {B }}$ was CSMS for business major groups first-year students. CSMS ${ }^{\text {B }}$ was CSMS for business major groups first-year students. CSMS ${ }^{\mathrm{S}}$ was CSMS for STEM major groups first-year students.

PES A ${ }^{A}$ was PES for all first-year students. PES ${ }^{\text {FE }}$ was PES for female first-year students. PES FG was PES for first-generation first-year students. PES ${ }^{\mathrm{E}}$ was PES for education major groups first-year students. PES ${ }^{\mathrm{H}}$ was PES for humanity major groups first-year students. PES ${ }^{\mathrm{B}}$ was PES for business major groups first-year students. PES ${ }^{\mathrm{B}}$ was PES for business major groups first-year students. PES ${ }^{S}$ was PES for STEM mAajor groups first-year students.

NAKS ${ }^{A}$ was PES for all first-year students. NAKS ${ }^{\mathrm{FE}}$ was NAKS for female first-year students. NAKS ${ }^{\text {FG }}$ was NAKS for first-generation first-year students. NAKS ${ }^{\mathrm{E}}$ was NAKS for education major groups first-year students. NAKS ${ }^{\mathrm{H}}$ was NAKS for humanity major groups first-year students. NAKS ${ }^{B}$ was NAKS for business major groups first-year students. NAKS ${ }^{B}$ was NAKS for business major groups first-year students. NAKS ${ }^{\mathrm{S}}$ was NAKS for STEM major groups first-year students.

**. Correlation was significant at the 0.01 level (2-tailed).

*. Correlation was significant at the 0.05 level (2-tailed). 


\section{Appendix B}

\section{Figure B1}

Scatterplot Showing Correlation Between CSMS Scores and CSPS Scores With 1,153

Participants

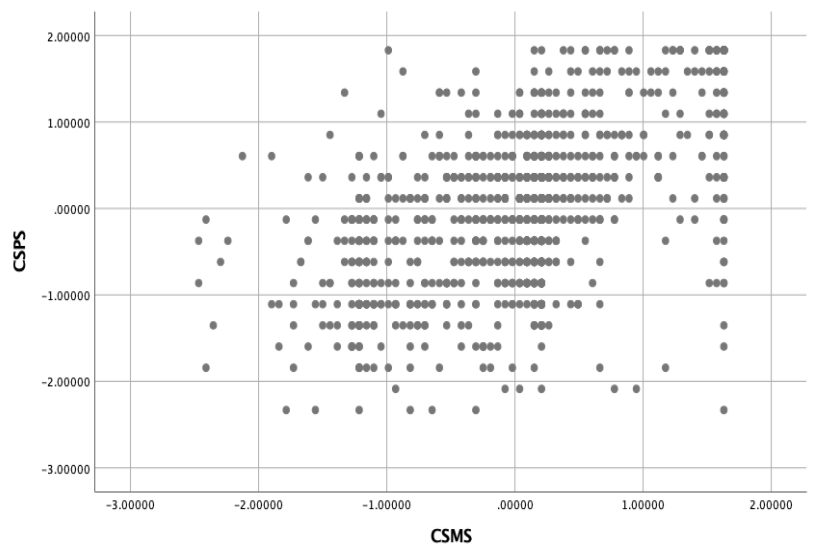

Note. $N=1,153$.

\section{Figure B2}

Simple Histogram of Total CSMS Scores

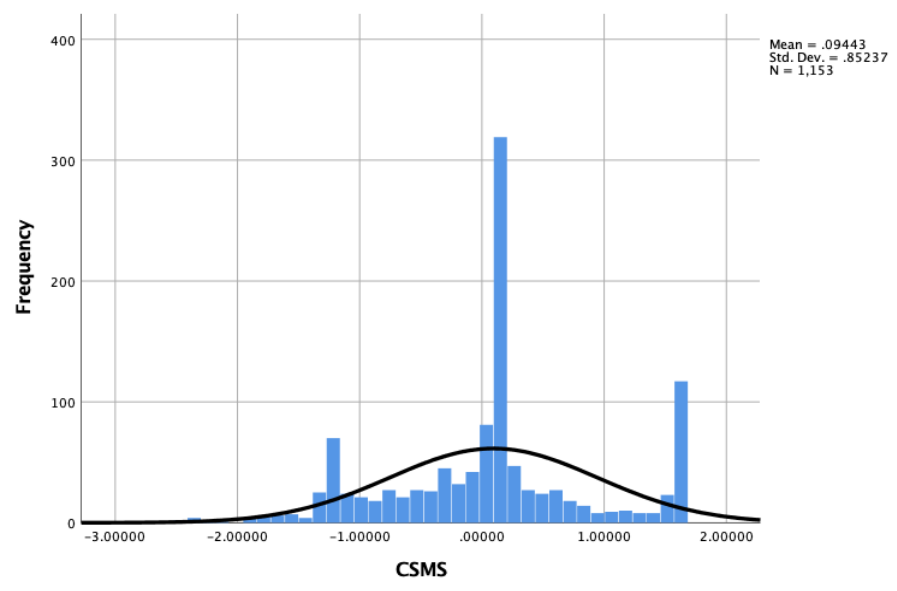

Note. $N=1,153$. 


\section{Figure B3}

Simple Histogram of CSPS Scores

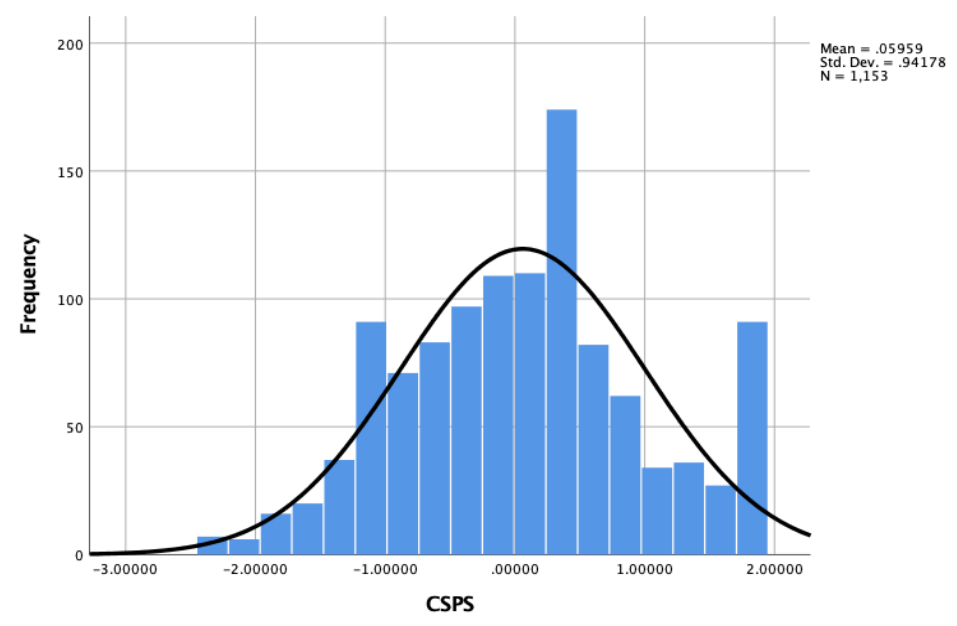

Note. $N=1,153$.

\section{Figure B4}

Correlation Between Scores of PES and Scores of CSPS

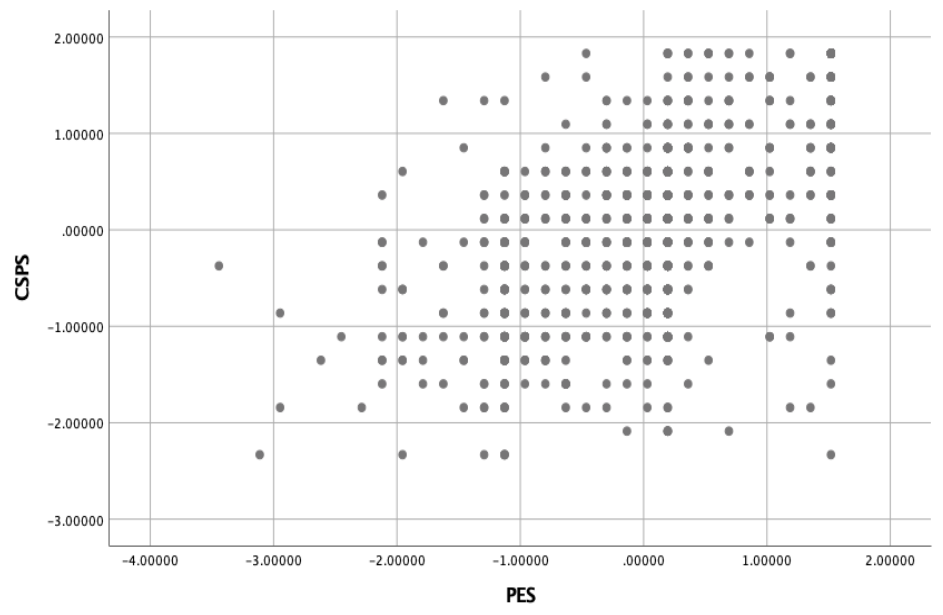

Note. $N=1,153$. 


\section{Figure B5}

Simple Histogram of PES Scores

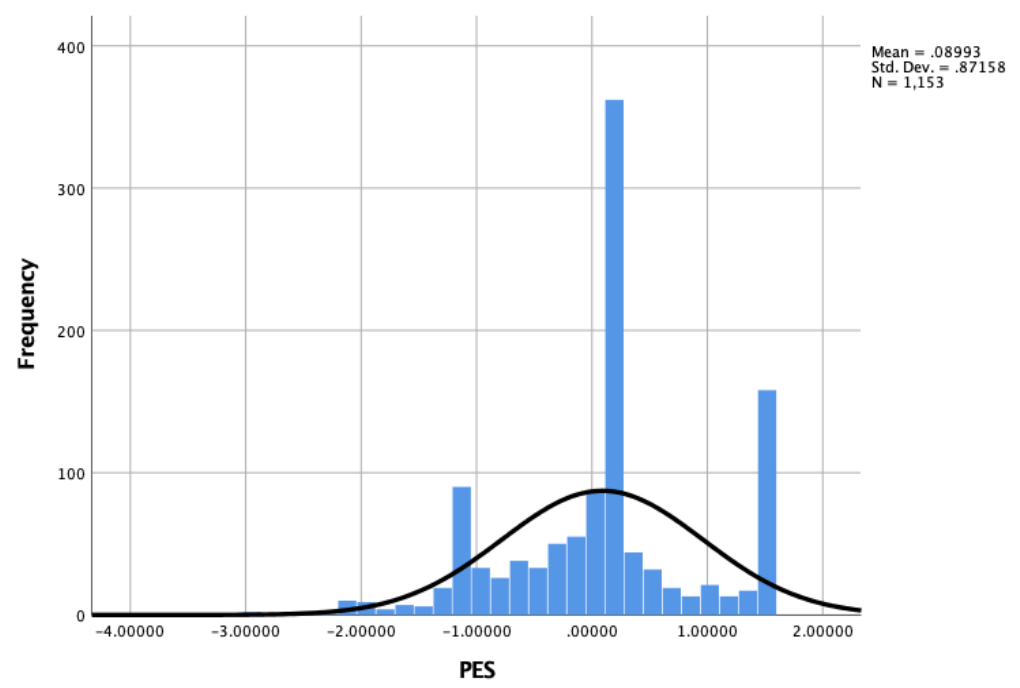

Note. $N=1,153$.

\section{Figure B6}

Simple Histogram of NAKS Scores With 1,153 Participants

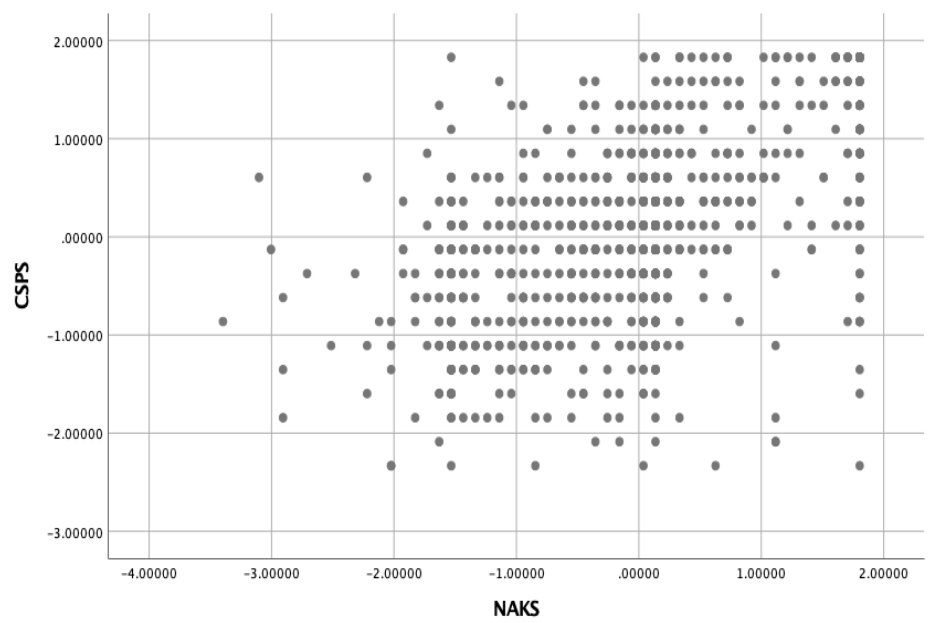

Note. $N=1,153$. 


\section{Figure B7}

Simple Histogram of NAKS Scores

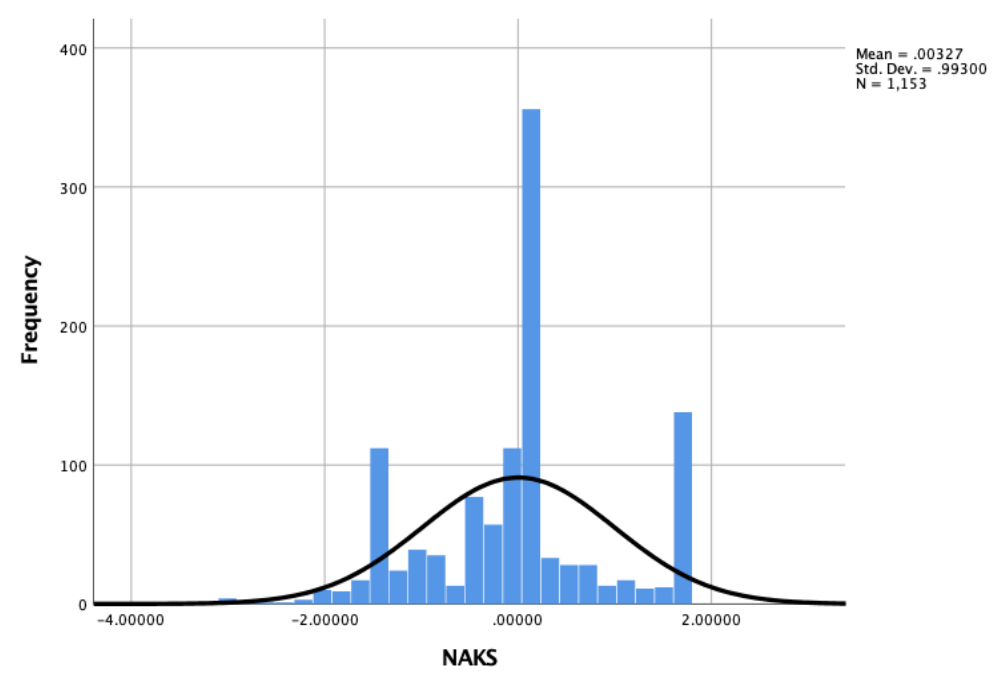

Note. $N=1,153$.

\section{Figure B8}

Scatterplot Showing Correlation Between CSMS Scores and CSPS Scores With 879 Participants

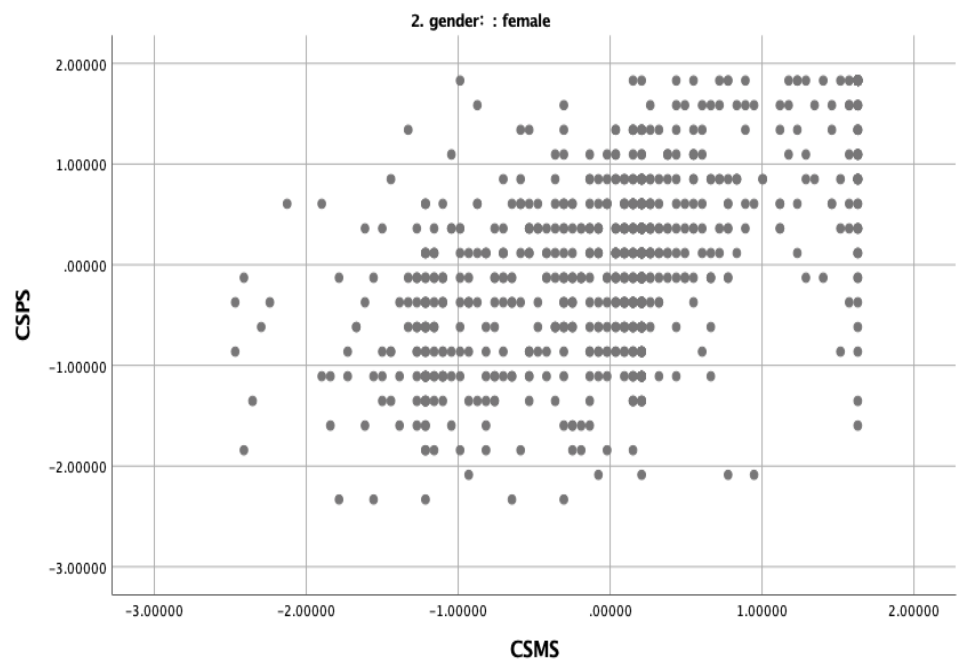

Note. $n=879$. 


\section{Figure B9}

Simple Histogram of CSMS Scores

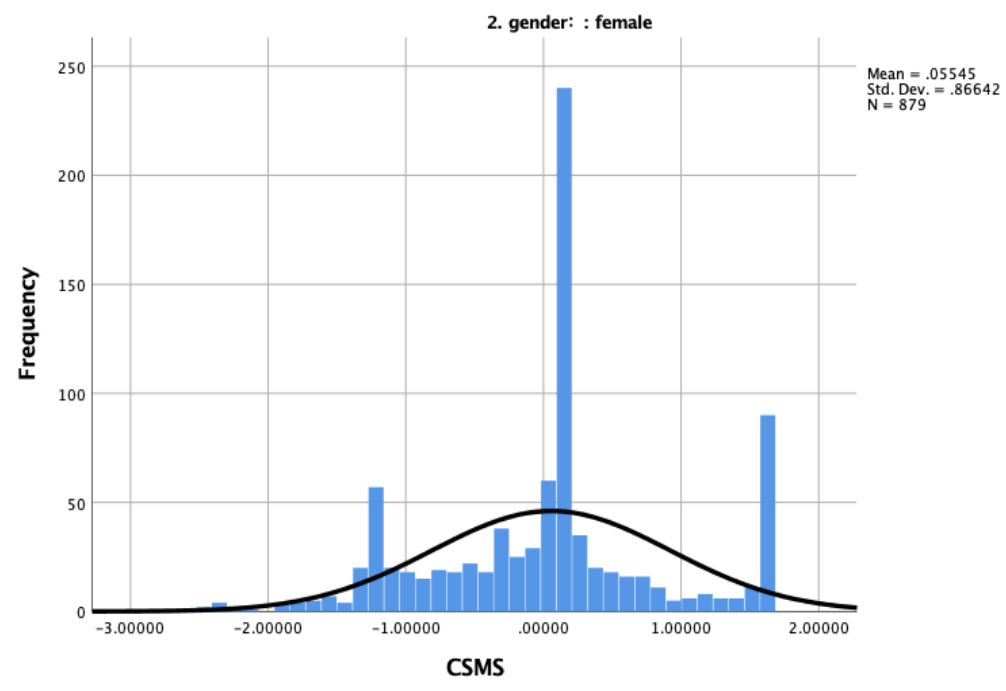

Note. $n=879$.

\section{Figure B10}

Simple Histogram of CSPS Scores

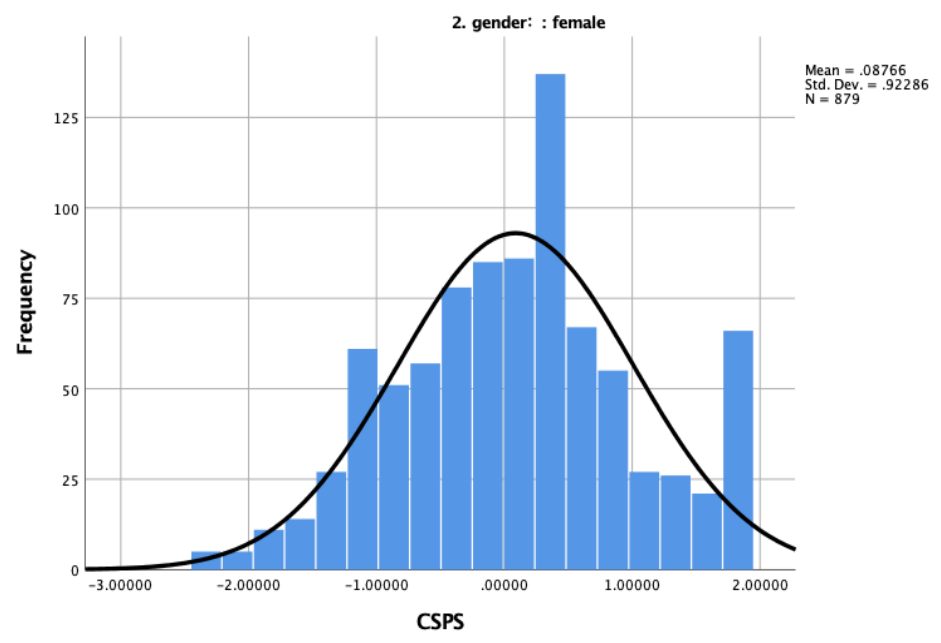

Note. $n=879$. 


\section{Figure B11}

Correlation Between Scores of PES and Scores of CSPS With 879 Participants

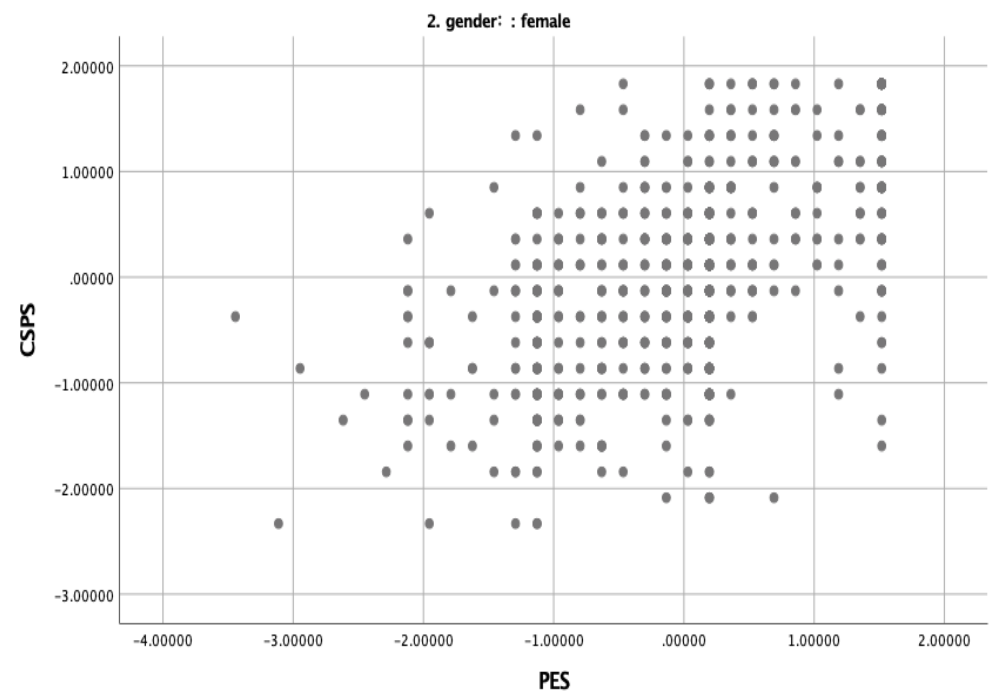

Note. $n=879$.

\section{Figure B12}

Simple Histogram of PES Scores

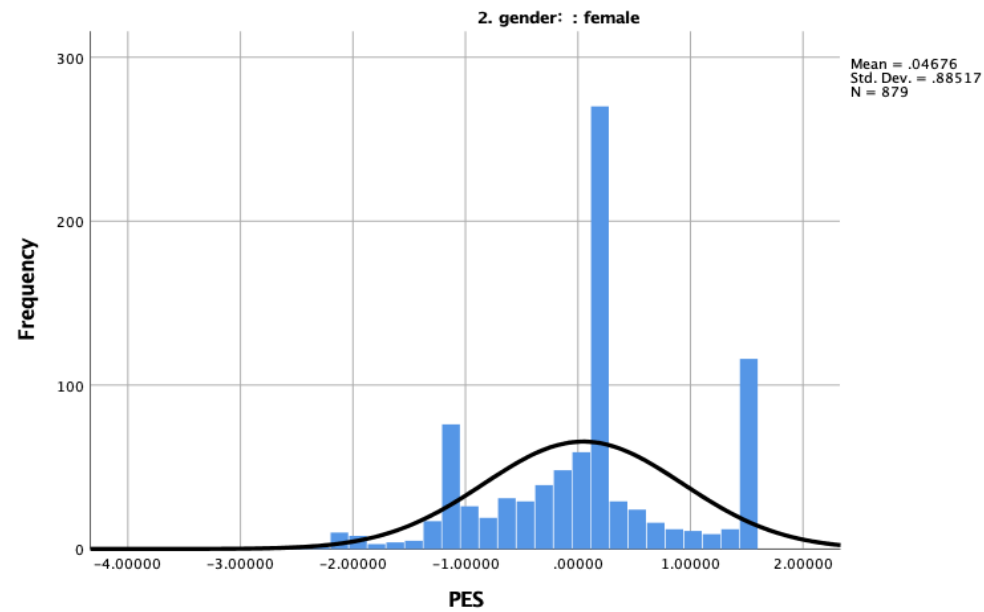

Note. $n=879$. 


\section{Figure B13}

Correlation Between Scores of NAKS and Scores of CSPS With 879 Participants

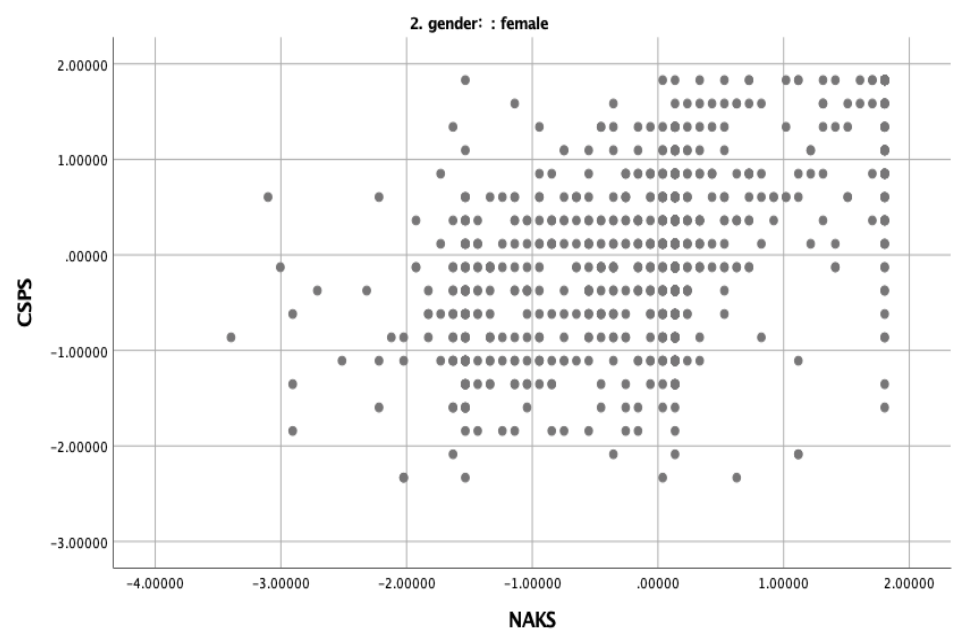

Note. $n=879$.

\section{Figure B14}

Simple Histogram of NAKS Scores

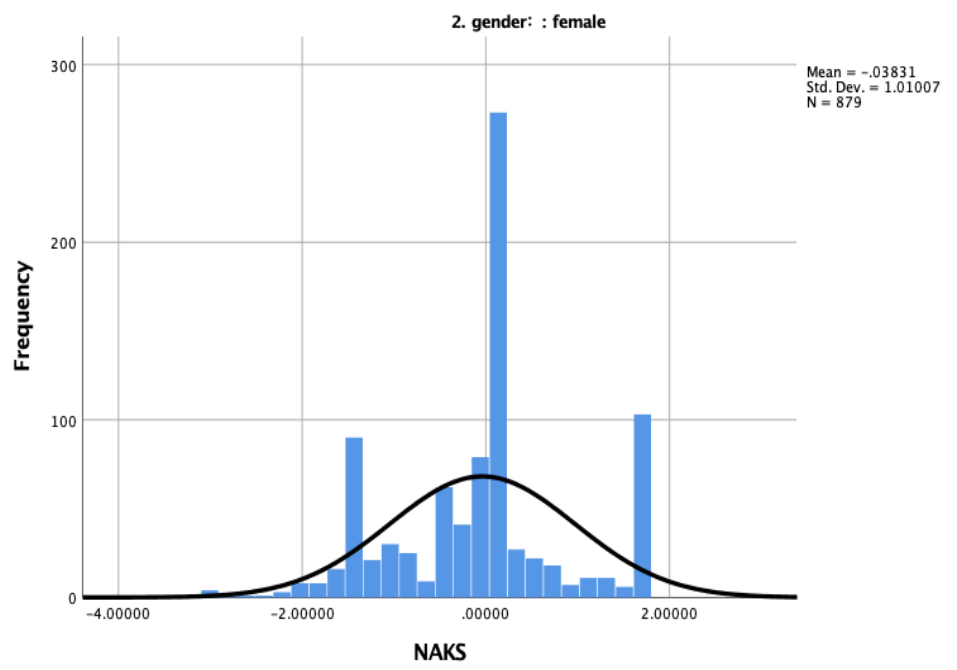

Note. $n=879$. 


\section{Figure B15}

\section{Correlation Between Scores of CSMS and Scores of CSPS With 640 Participants}

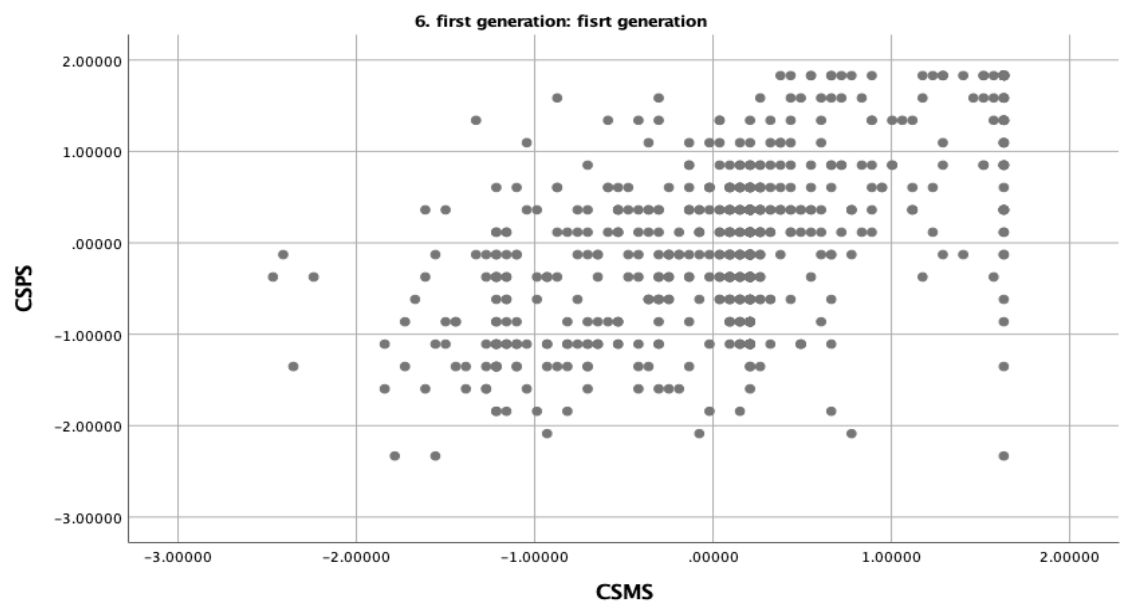

Note. $n=640$.

\section{Figure B16}

Simple Histogram of CSMS Scores

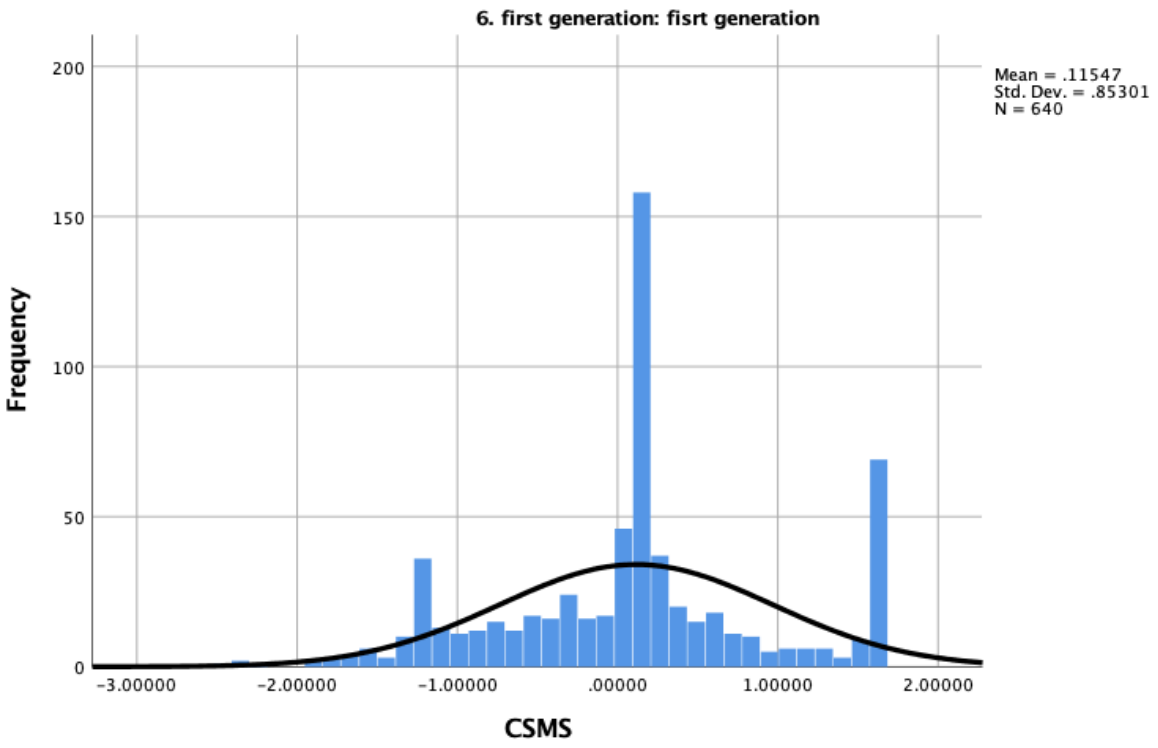

Note. $n=640$. 


\section{Figure B17}

Simple Histogram of CSMS Scores

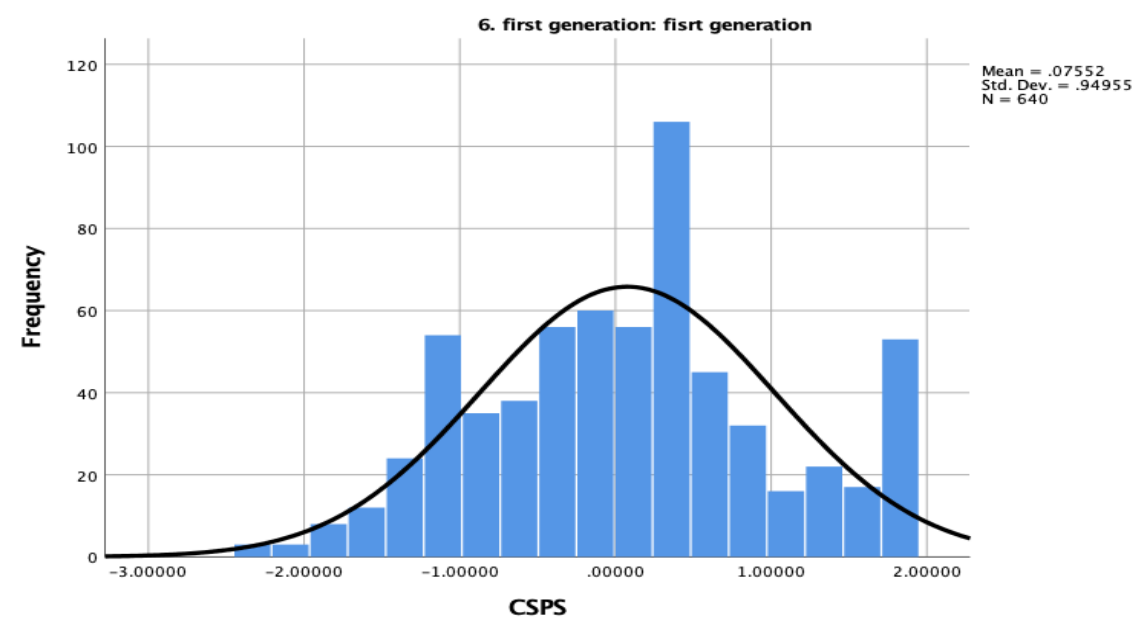

Note. $n=640$.

\section{Figure B18}

Correlation Between Scores of PES and Scores of CSPS With 640 Participants

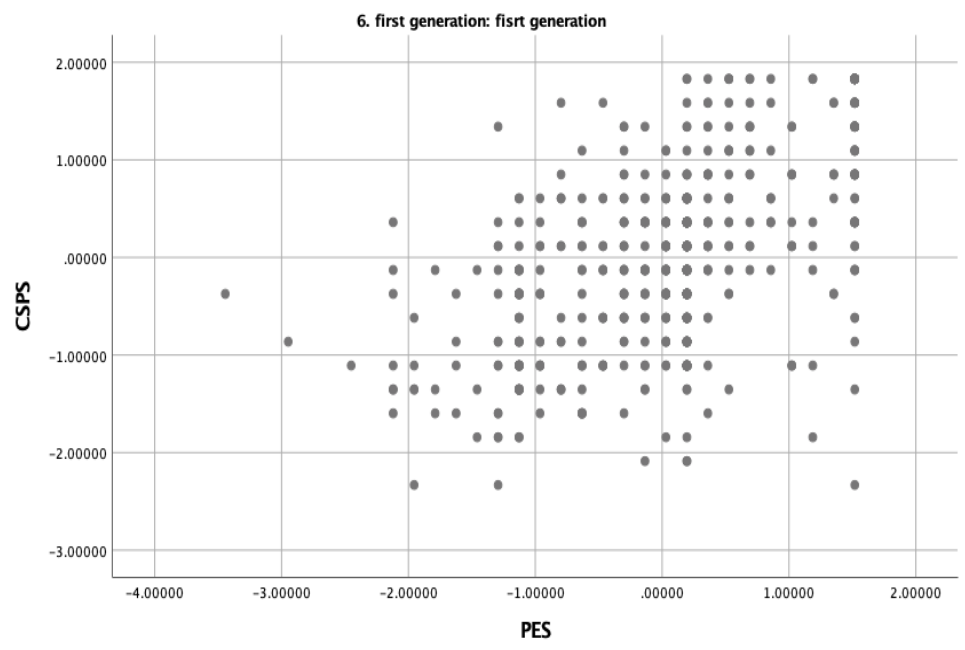

Note. $n=640$. 


\section{Figure B19}

Simple Histogram of PES Scores

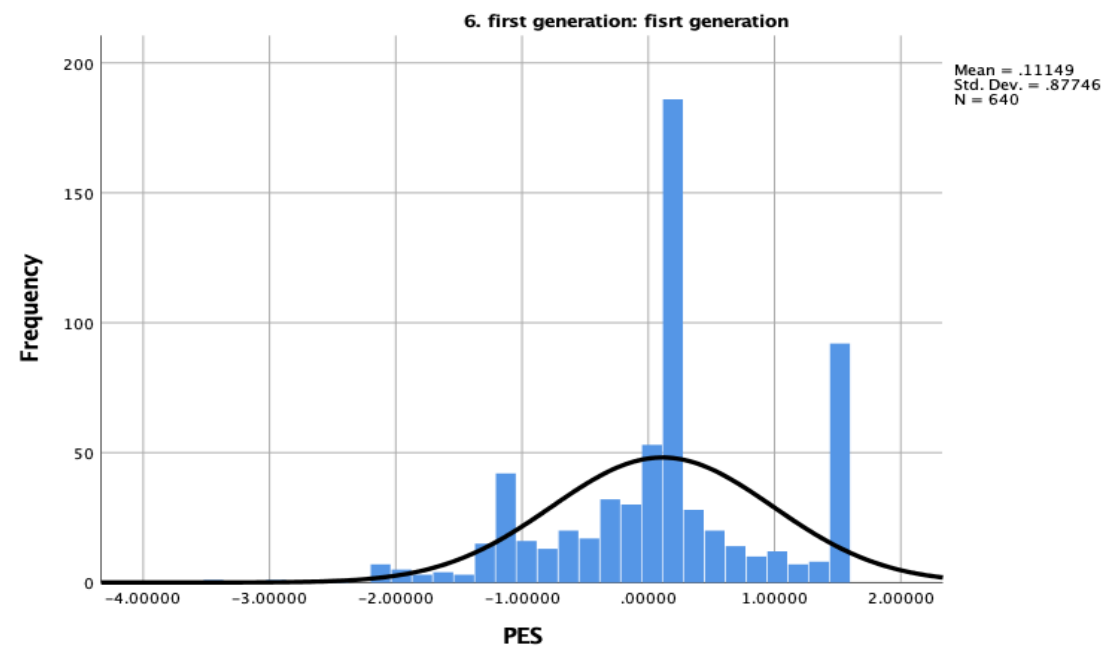

Note. $n=640$.

\section{Figure B20}

Correlation Between Scores of NAKS and Scores of CSPS With 640 Participants

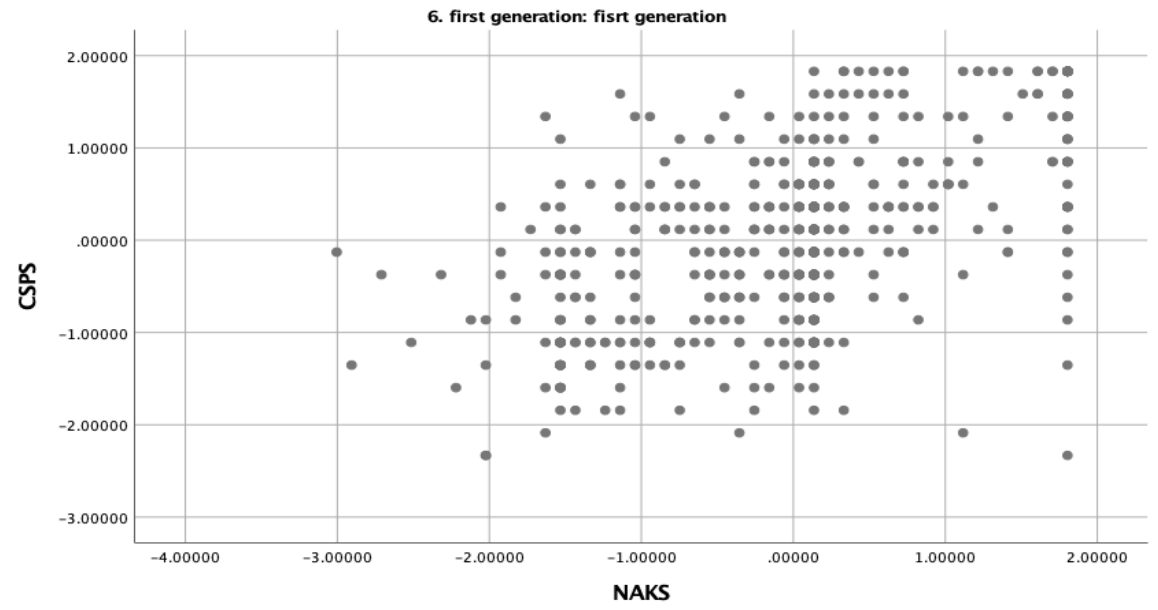

Note. $n=640$. 
Figure B21

Simple Histogram of NAKS Scores

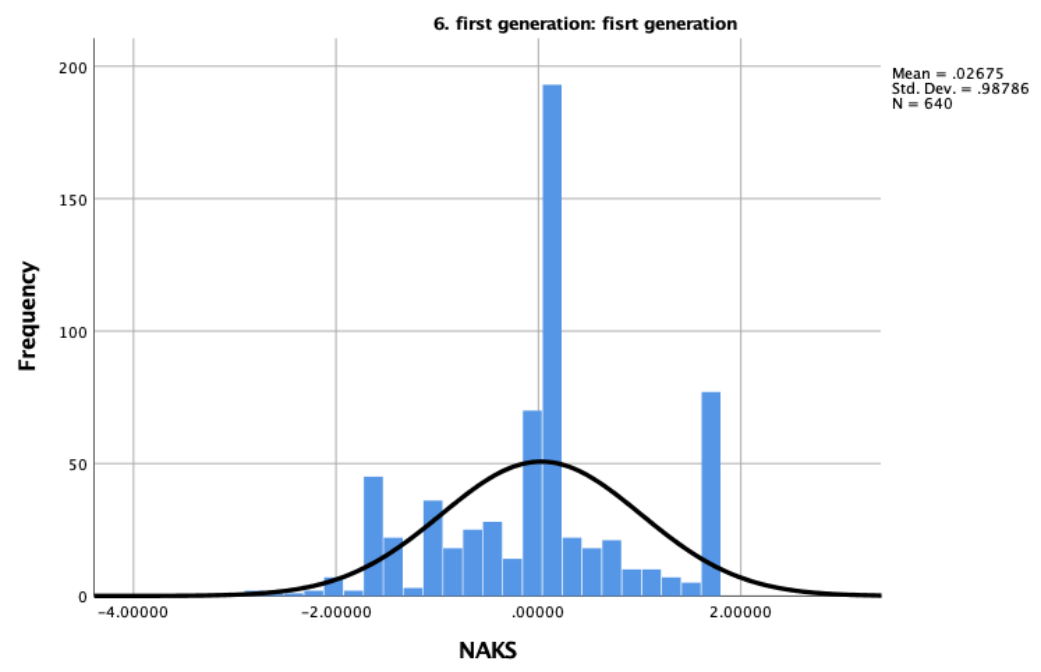

Note. $n=640$.

\section{Figure B22}

Correlation Between Scores of CSMS and Scores of CSPS With 440 Participants

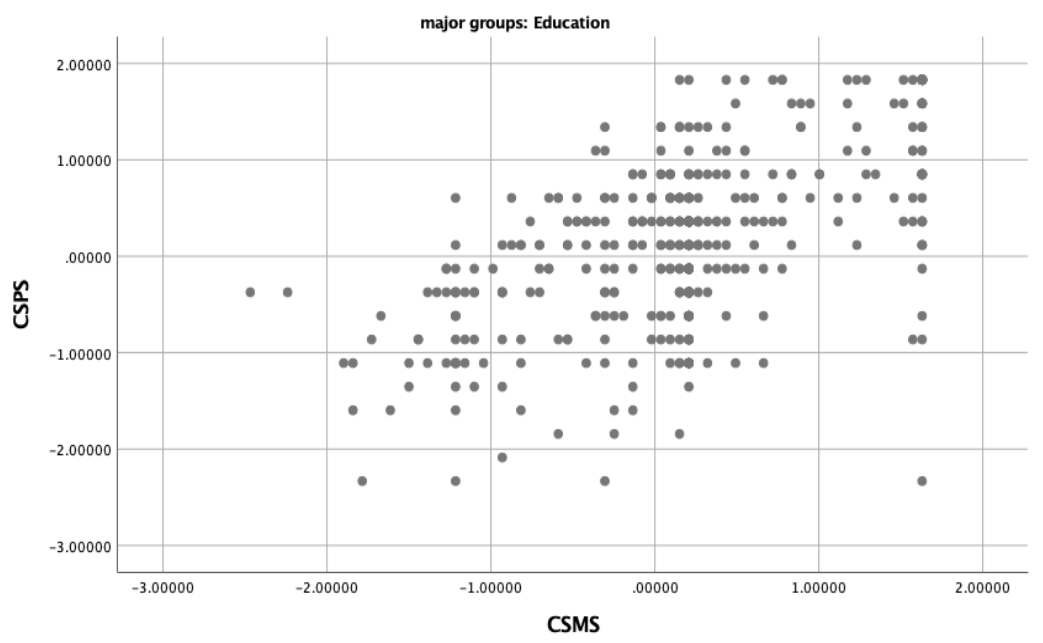

Note. $n=440$. 


\section{Figure B23}

Simple Histogram of CSMS Scores

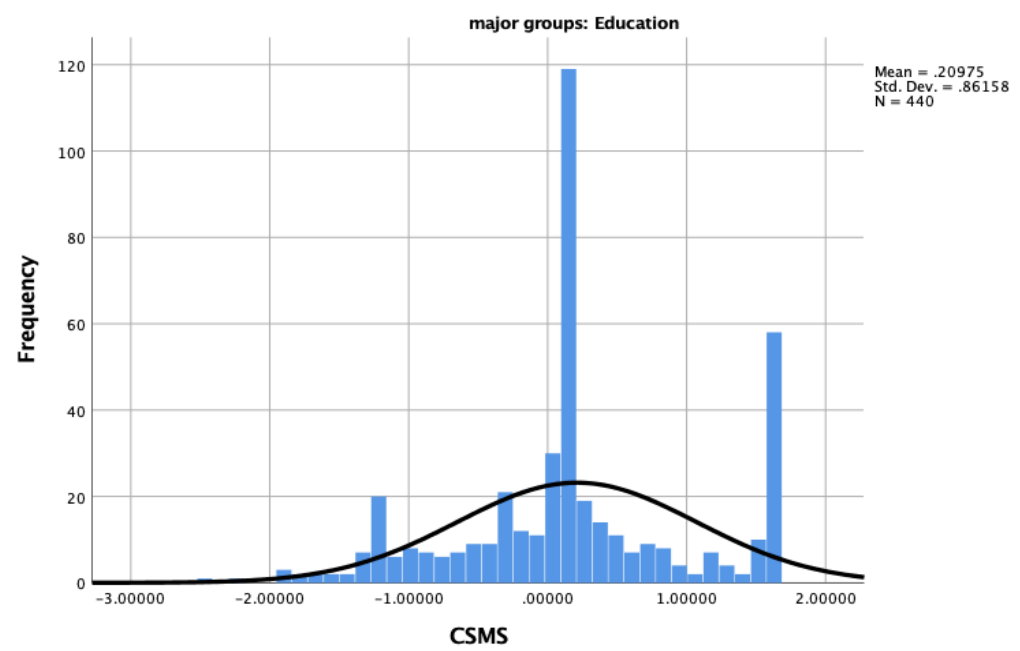

Note. $n=440$.

\section{Figure B24}

Simple Histogram of CSPS Scores

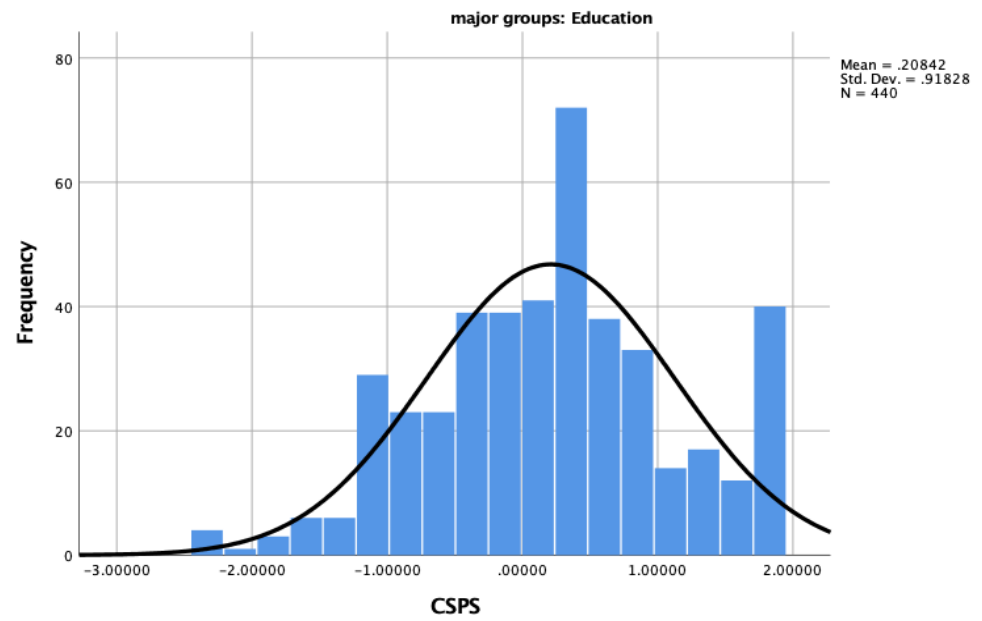

Note. $n=440$. 


\section{Figure B25}

\section{Correlation Between Scores of PES and Scores of CSPS With 440 Participants}

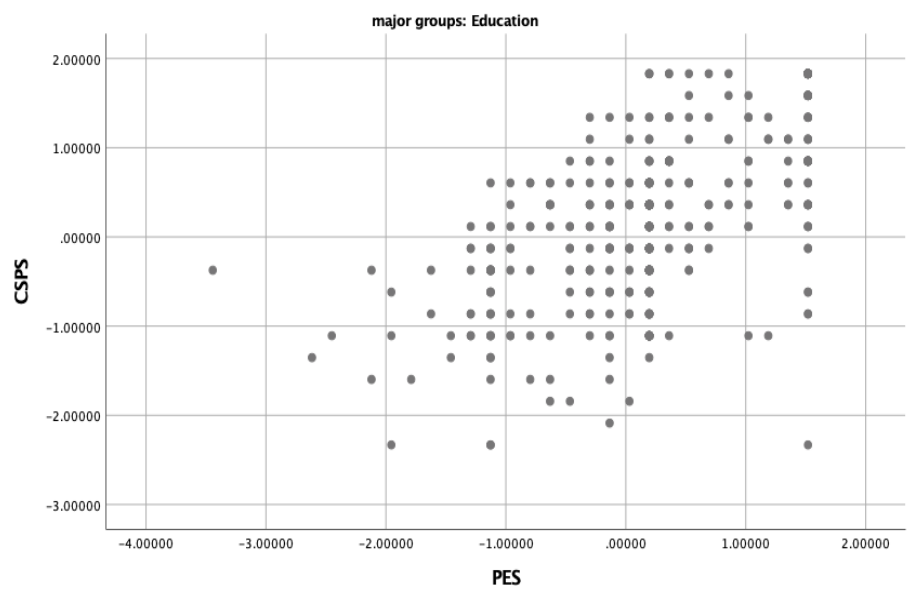

Note. $n=440$.

\section{Figure B26}

Simple Histogram of PES Scores

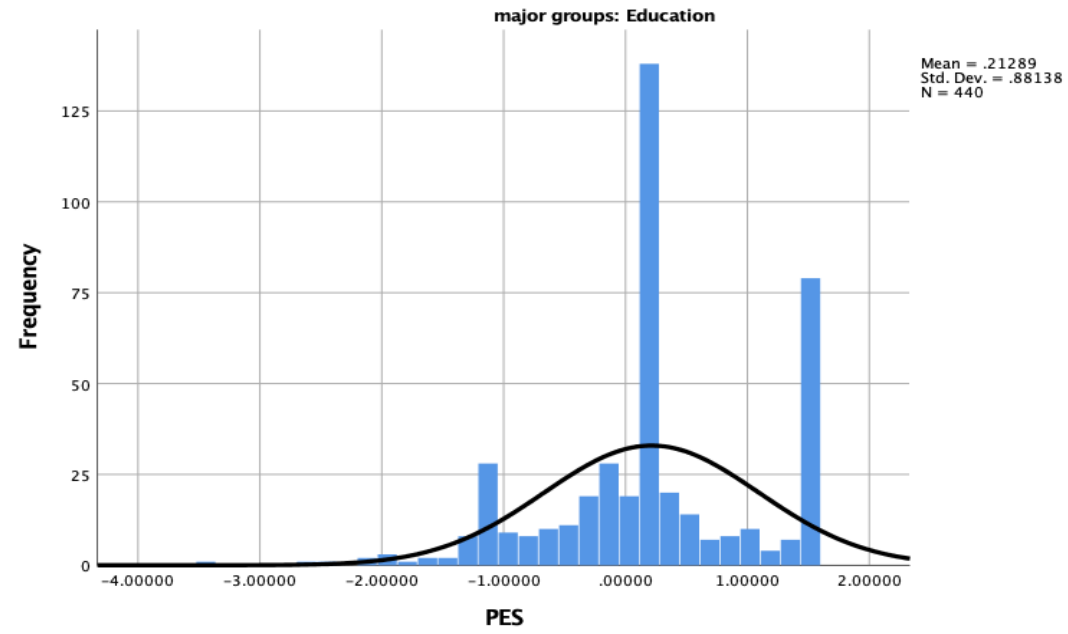

Note. $n=440$. 


\section{Figure B27}

\section{Correlation Between Scores of NAKS and Scores of CSPS With 440 Participants}

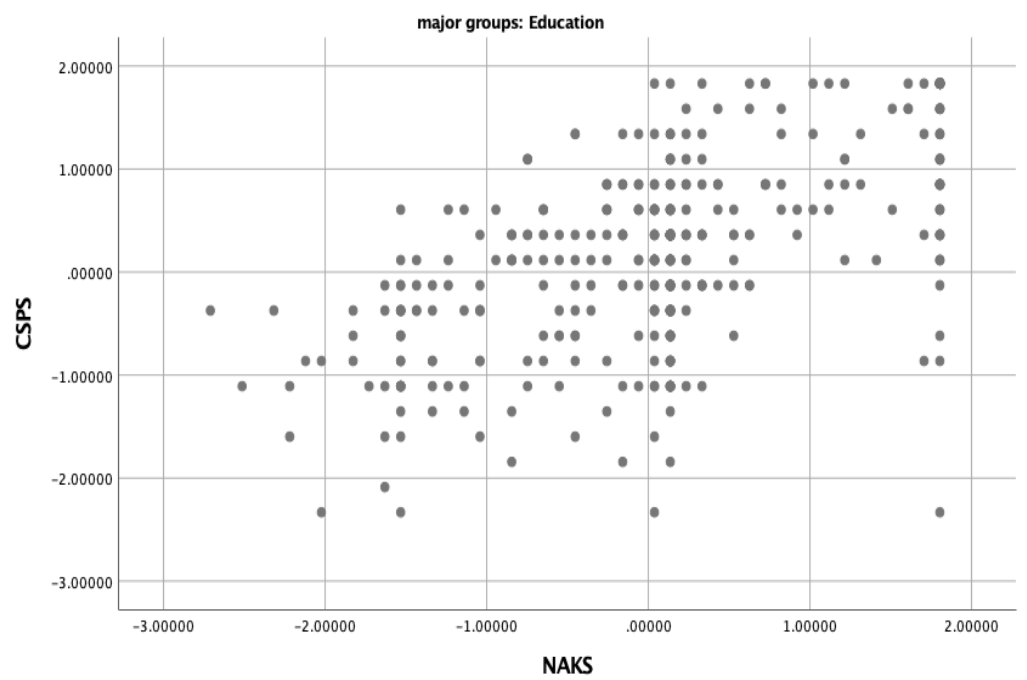

Note. $n=440$.

\section{Figure B28}

Simple Histogram of NAKS Scores

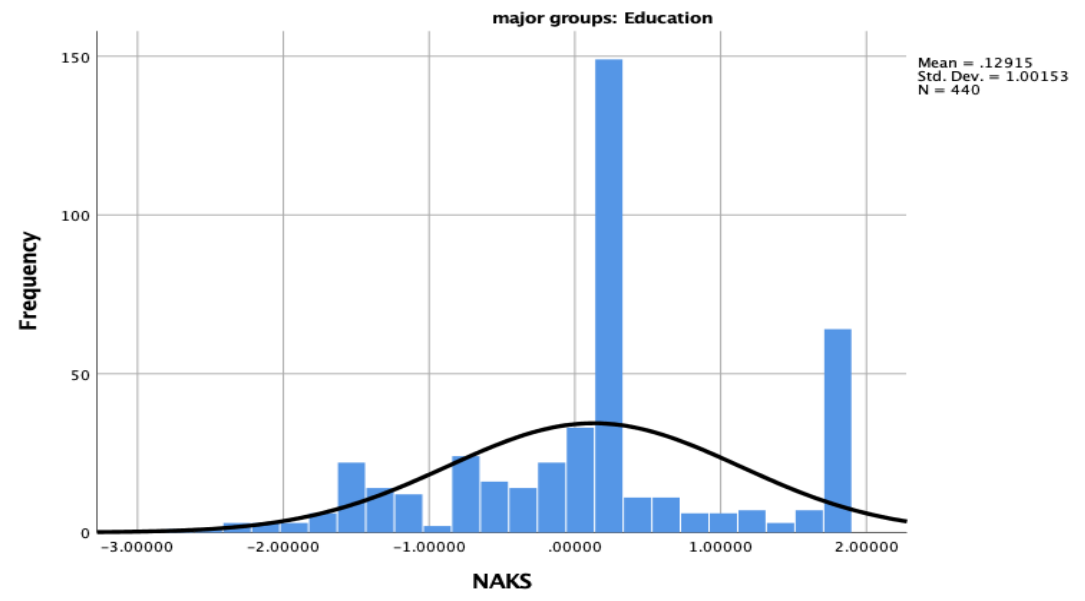

Note. $n=440$. 


\section{Figure B29}

Correlation Between Scores of CSMS and Scores of CSPS With 203 Participants

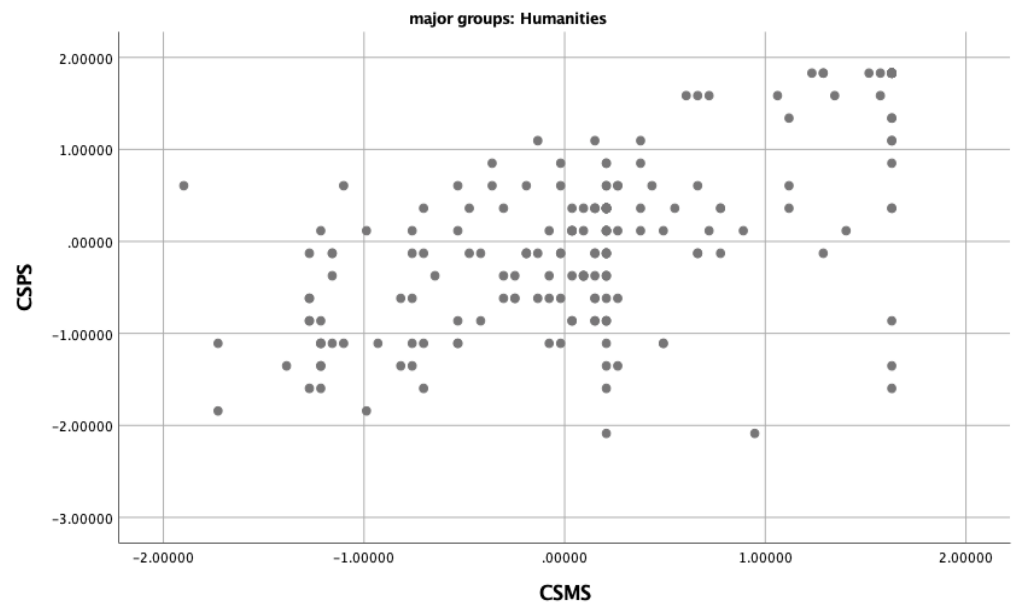

Note. $n=203$.

\section{Figure B30}

Simple Histogram of CSMS Scores

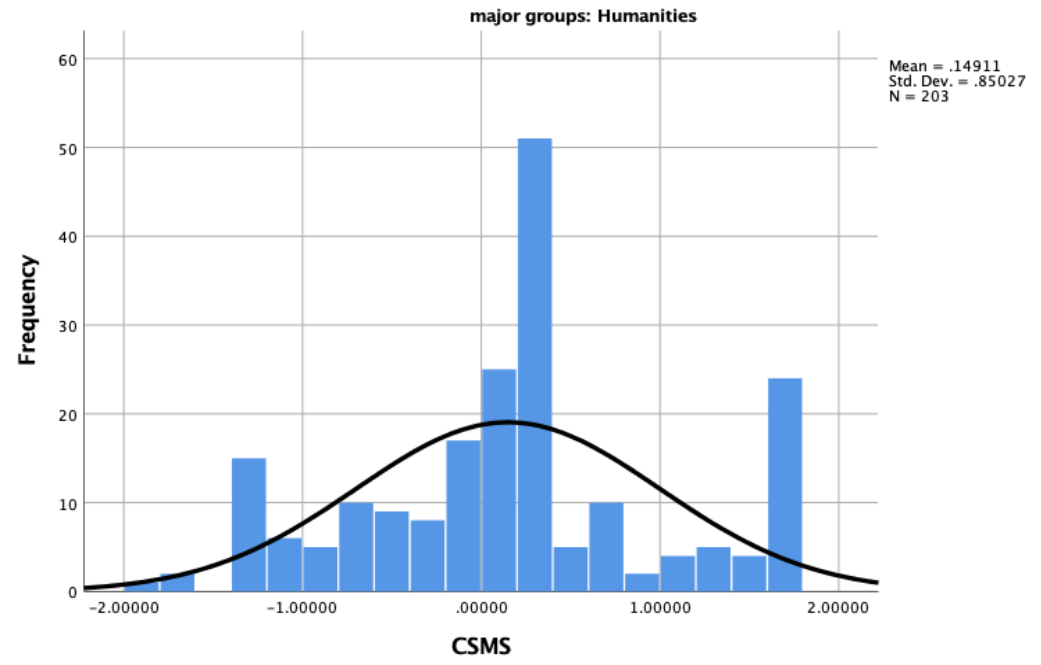

Note. $n=203$. 


\section{Figure B31}

Simple Histogram of CSPS Scores

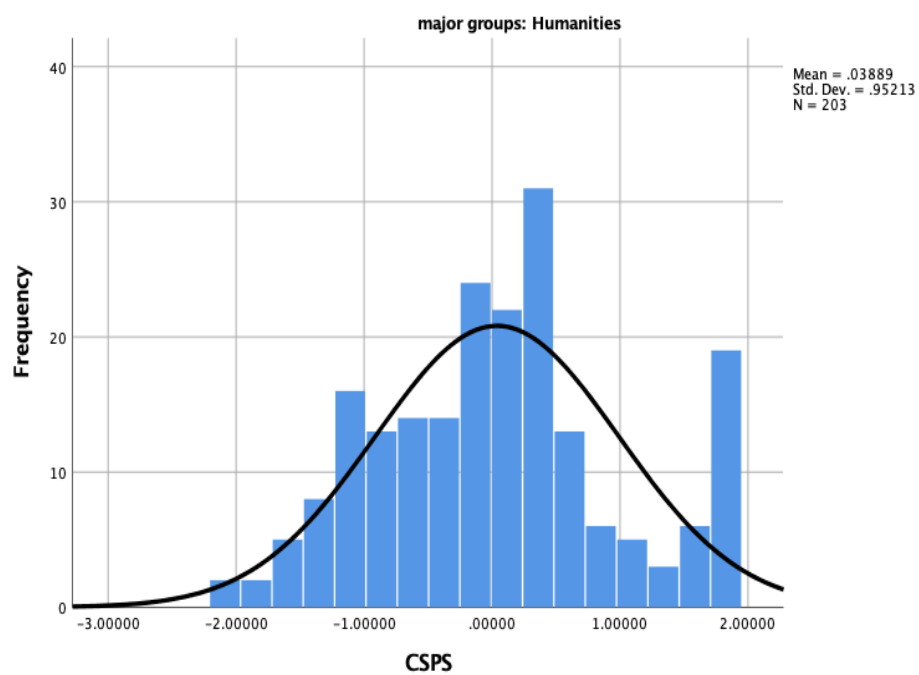

Note. $n=203$.

\section{Figure B32}

Correlation Between Scores of PES and Scores of CSPS With 203 Participants

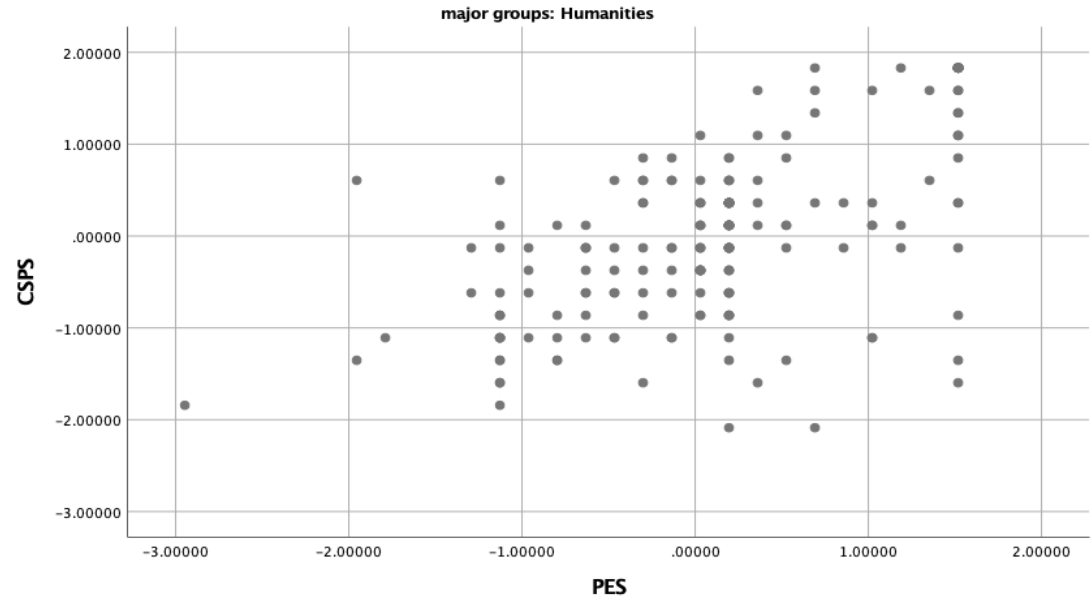

Note. $n=203$. 


\section{Figure B33}

Correlation Between Scores of NAKS and Scores of CSPS With 203 Participants

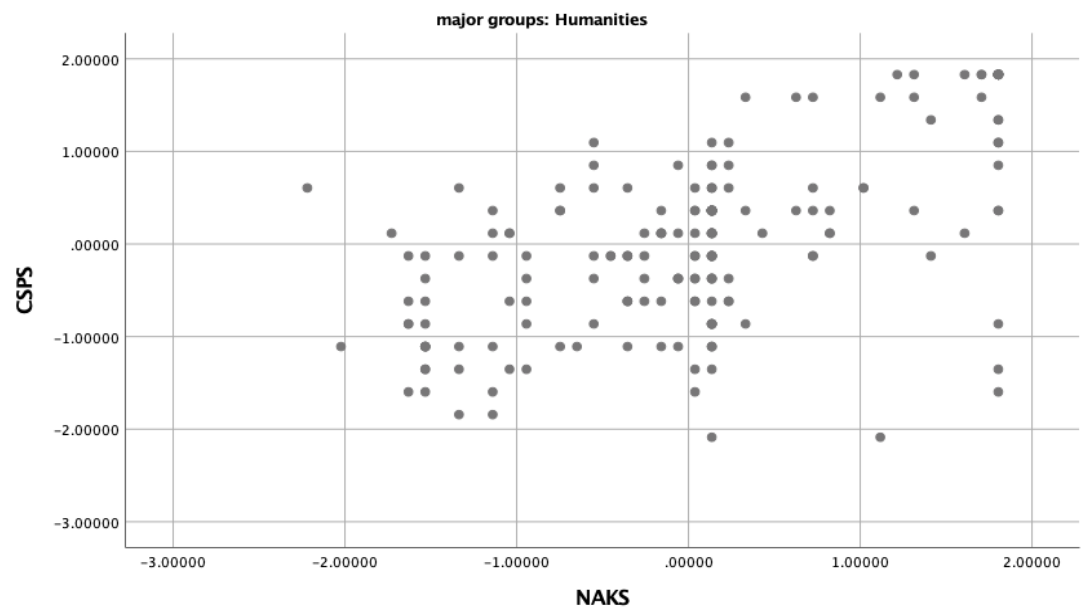

Note. $n=203$.

\section{Figure B32}

Correlation Between Scores of CSMS and Scores of CSPS With 320 Participants

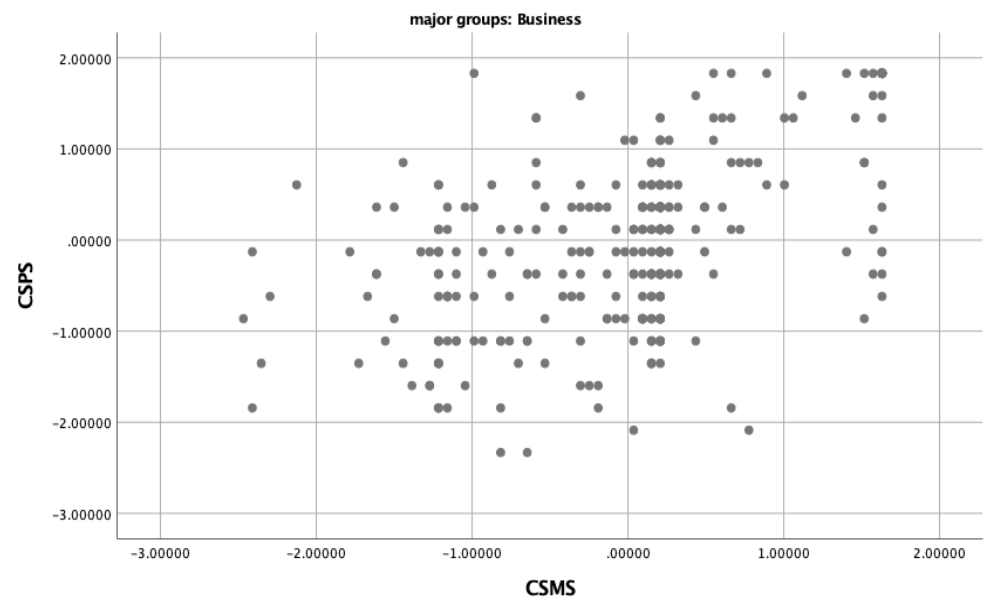

Note. $n=320$. 


\section{Figure B33}

Simple Histogram of CSMS Scores

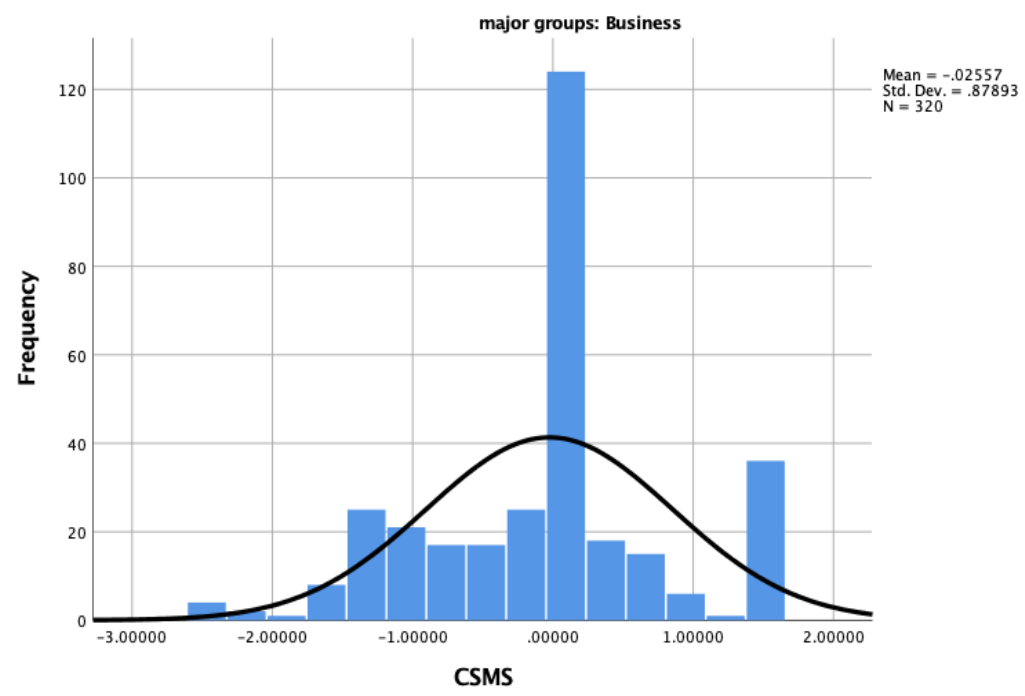

Note. $n=320$.

\section{Figure B34}

Simple Histogram of CSPS Scores

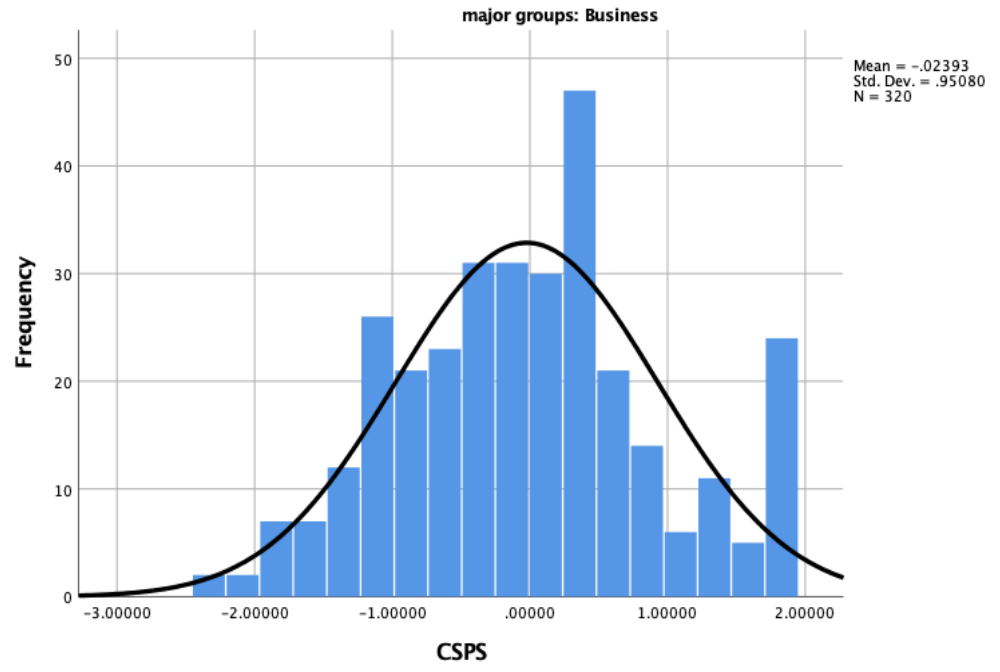

Note. $n=320$. 


\section{Figure B35}

\section{Correlation Between Scores of PES and Scores of CSPS With 320 Participants}

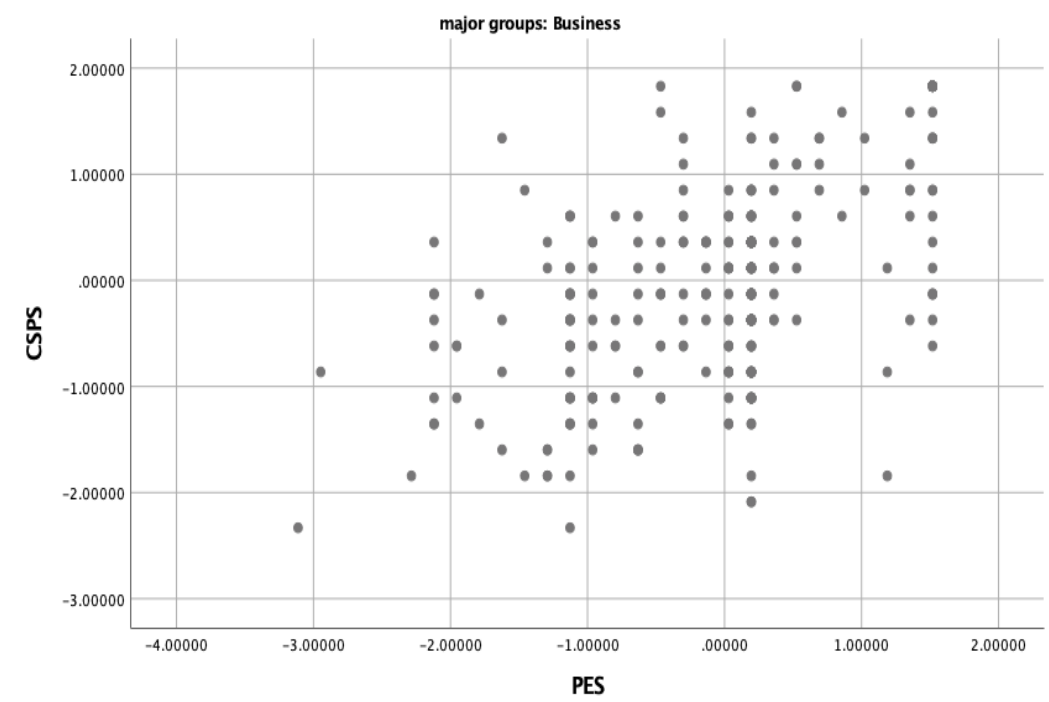

Note. $n=320$.

\section{Figure B36}

Simple Histogram of PES Scores

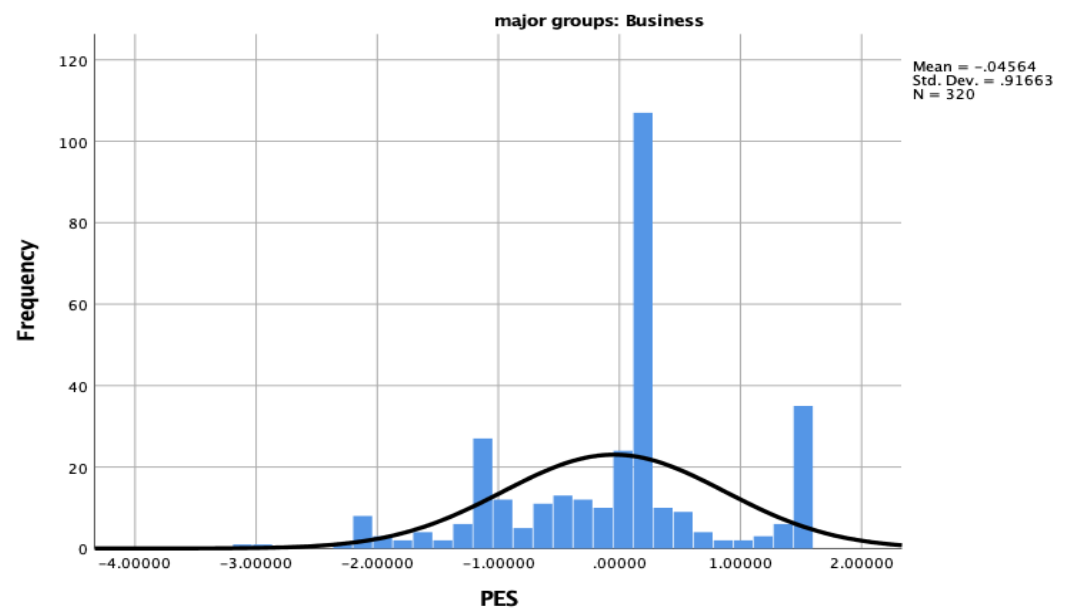

Note. $n=320$. 


\section{Figure B37}

Correlation Between Scores of NAKS and Scores of CSPS With 320 Participants

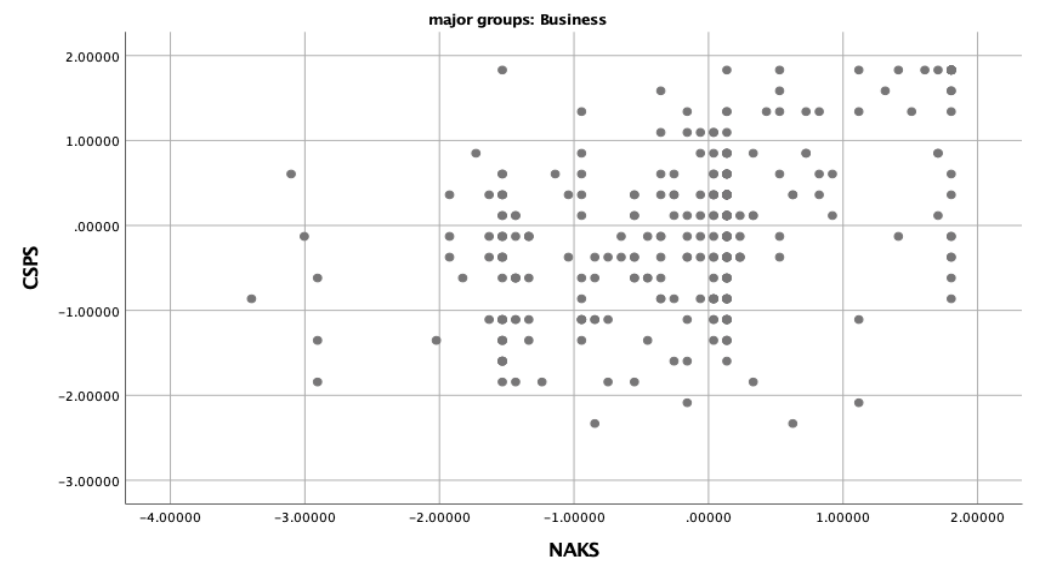

Note. $n=320$.

\section{Figure B38}

Simple Histogram of NAKS Scores

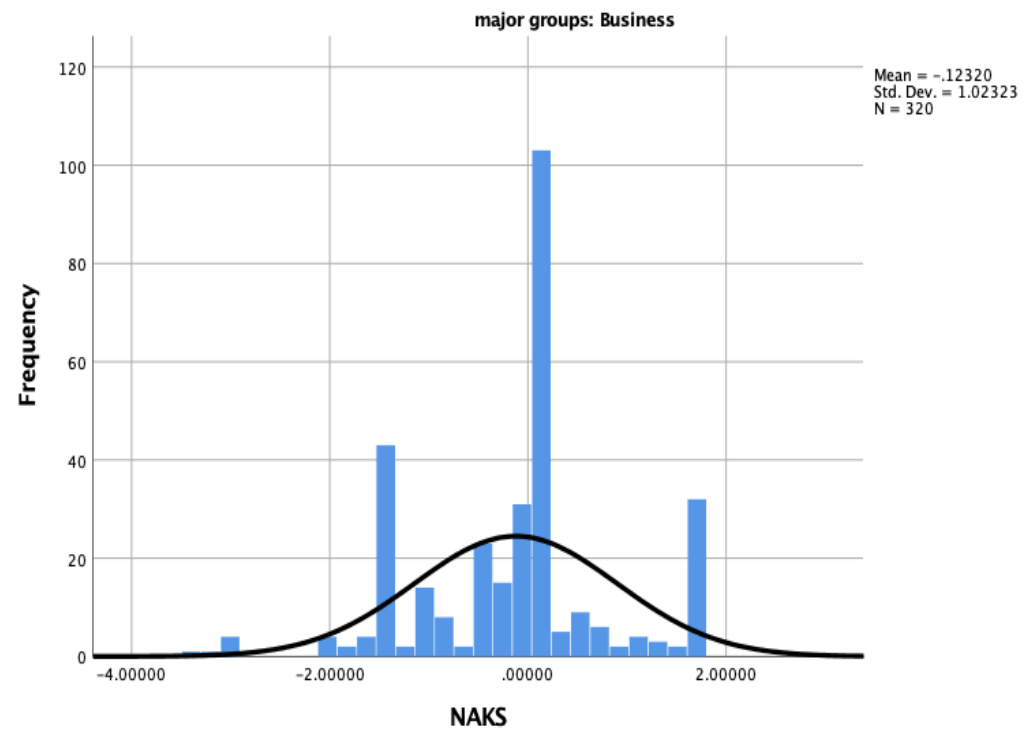

Note. $n=320$. 


\section{Figure B39}

\section{Correlation Between Scores of CSMS and Scores of CSPS With 190 Participants}

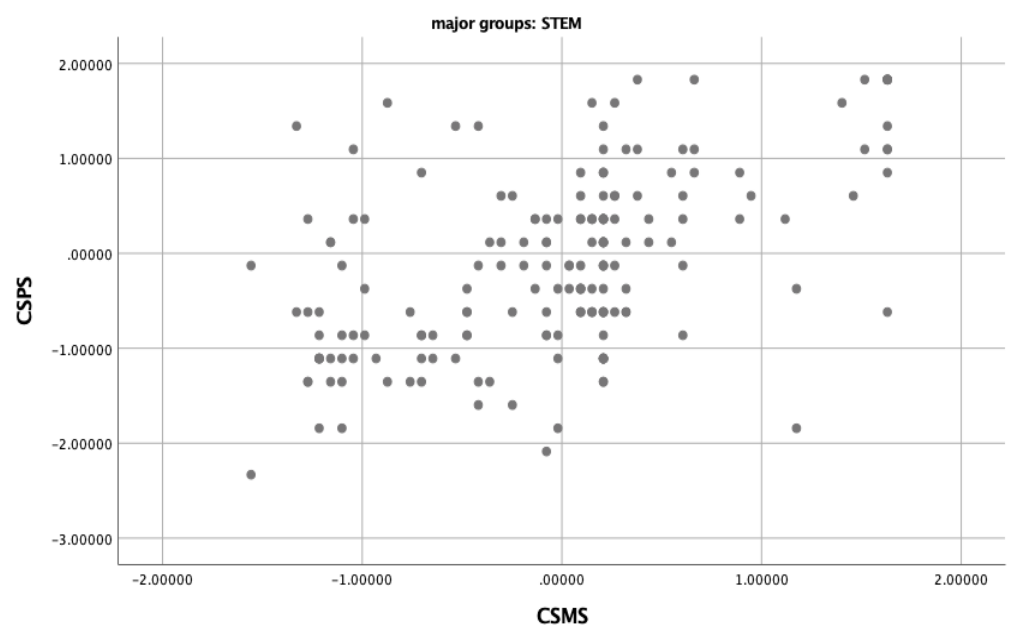

Note. $n=190$.

\section{Figure B40}

Simple Histogram of CSMS Scores

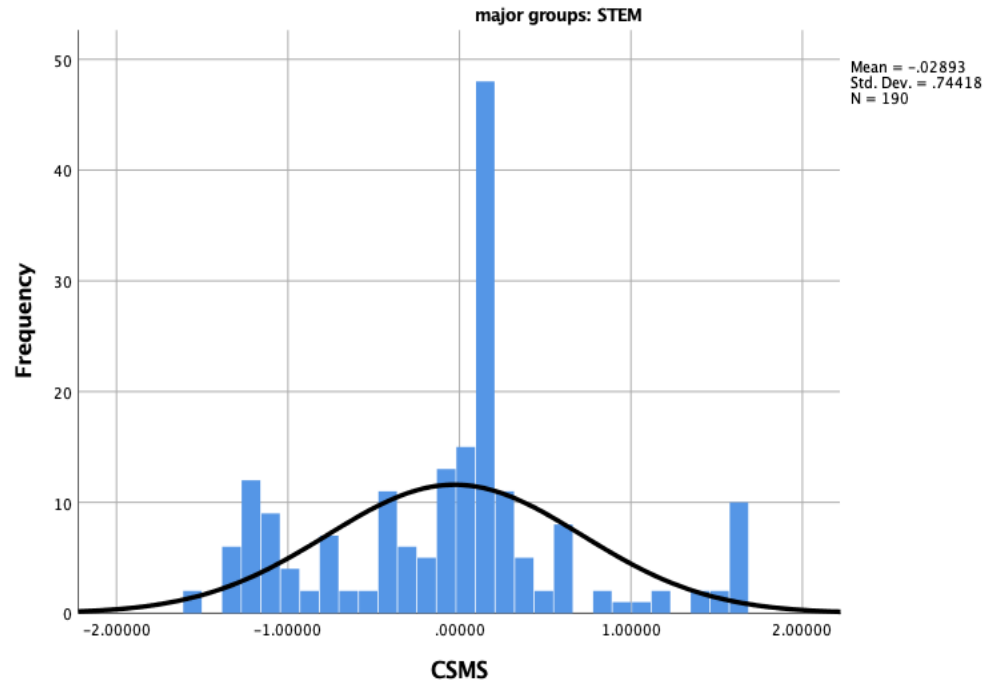

Note. $n=190$. 


\section{Figure B41}

Simple Histogram of CSPS Scores

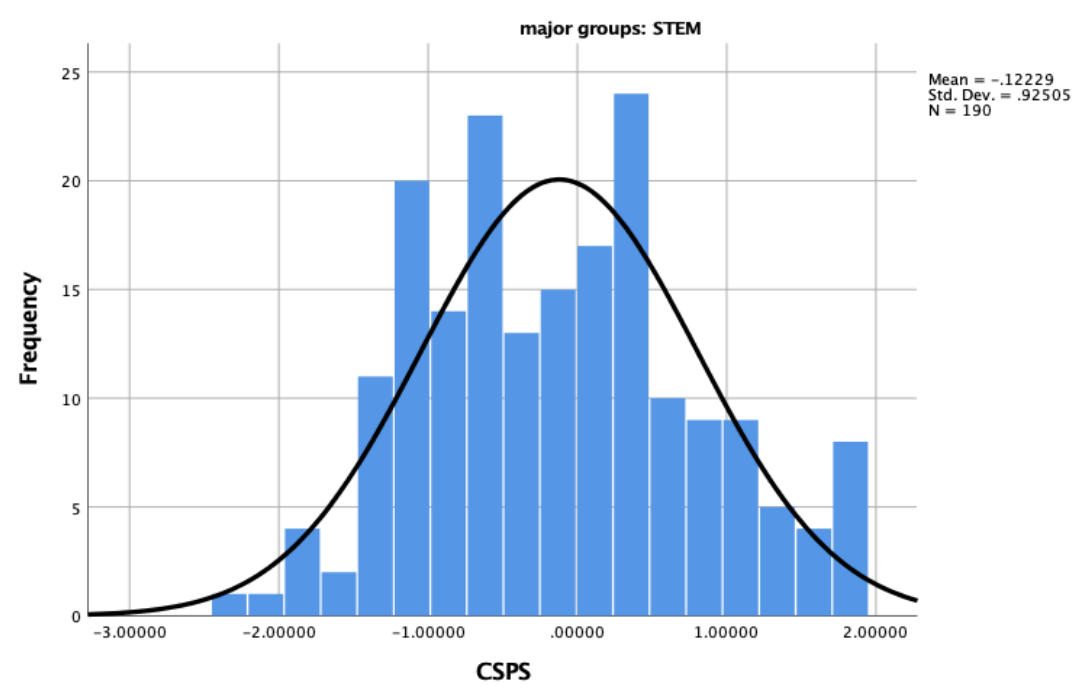

Note. $n=190$.

\section{Figure B42}

Correlation Between Scores of PES and Scores of CSPS With 190 Participants

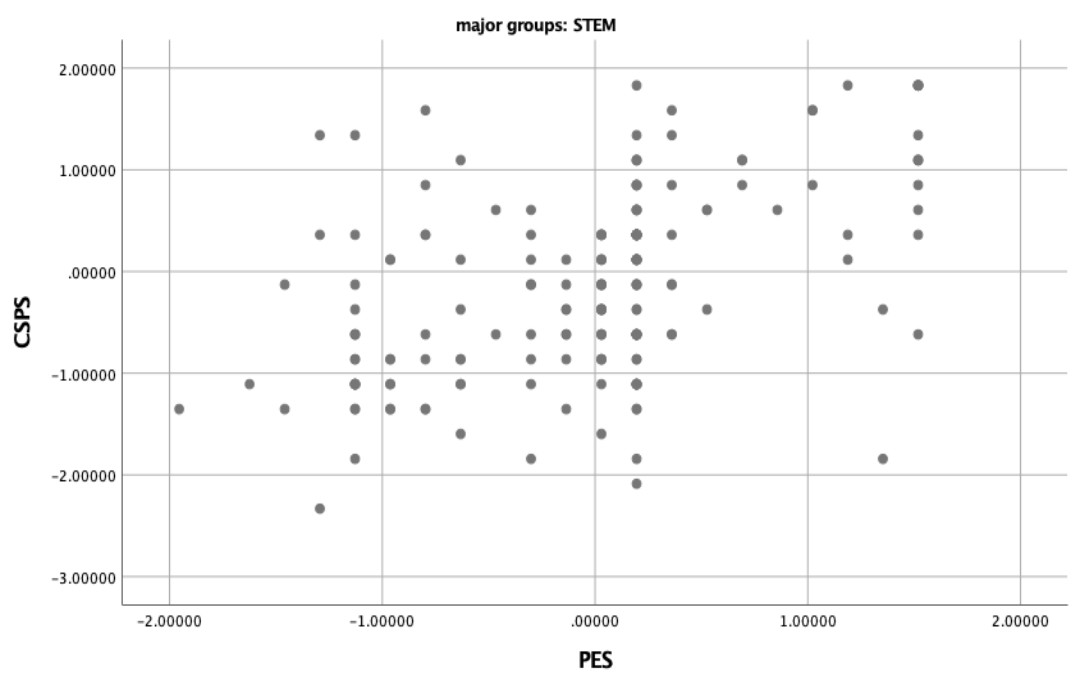

Note. $n=190$. 


\section{Figure B43}

Simple Histogram of PES Scores

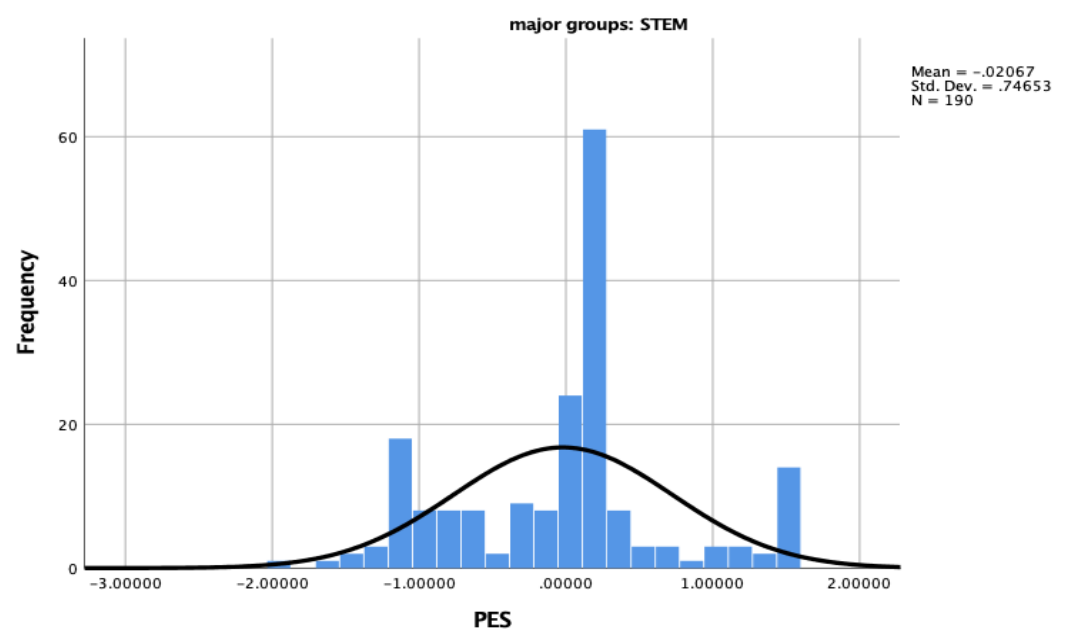

Note. $n=190$.

\section{Figure B44}

Correlation Between Scores of NAKS and Scores of CSPS With 190 Participants

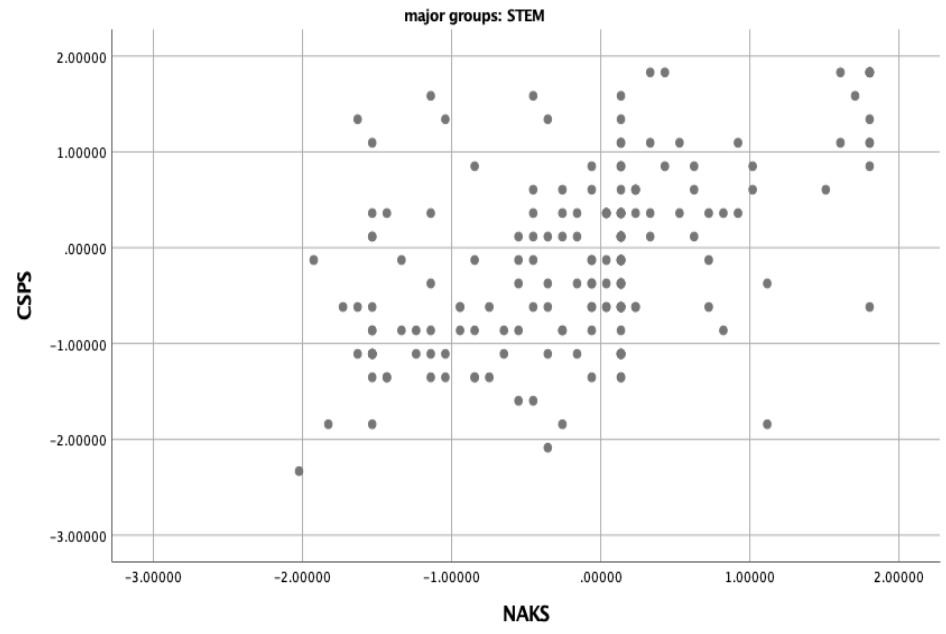

Note. $n=190$. 


\section{Figure B45}

Simple Histogram of NAKS Scores

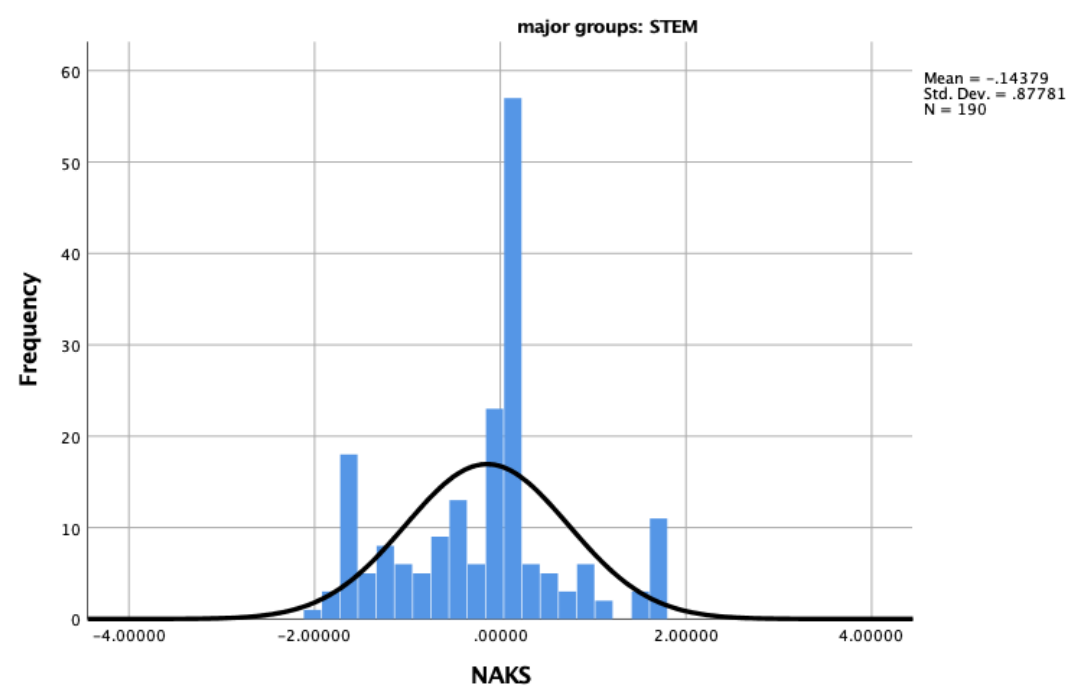

Note. $n=190$.

\section{Figure B46}

Relationship Between CSMS Scores and GPA Scores With 1153 Participants

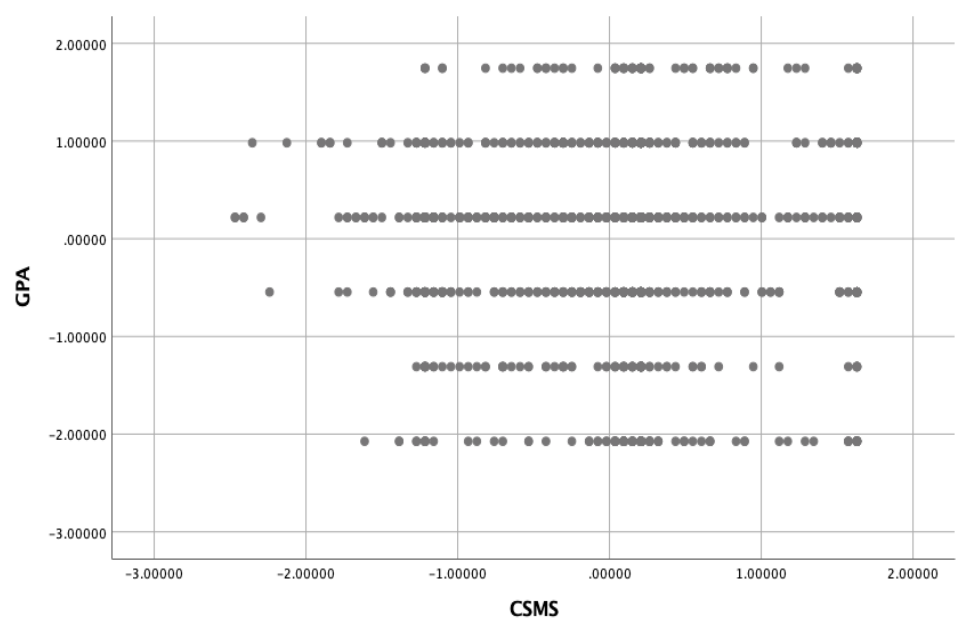

Note. $N=1,153$. 


\section{Figure B47}

Simple Histogram of GPA Scores

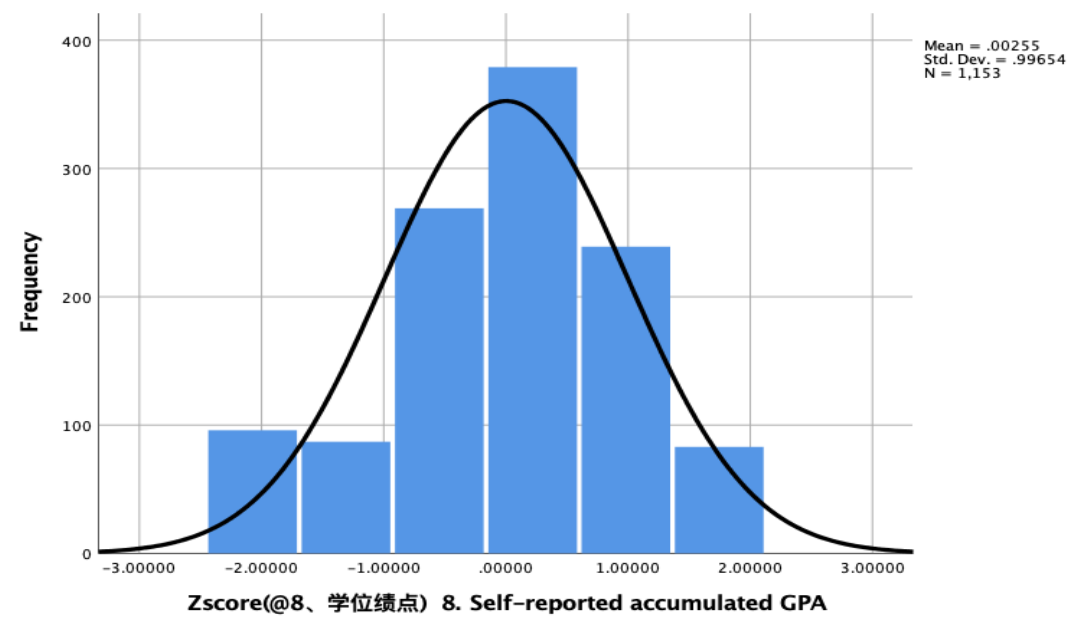

Note. $N=1,153$.

\section{Figure B48}

Relationship Between Scores of PES and Scores of GPA With 1,153 Participants

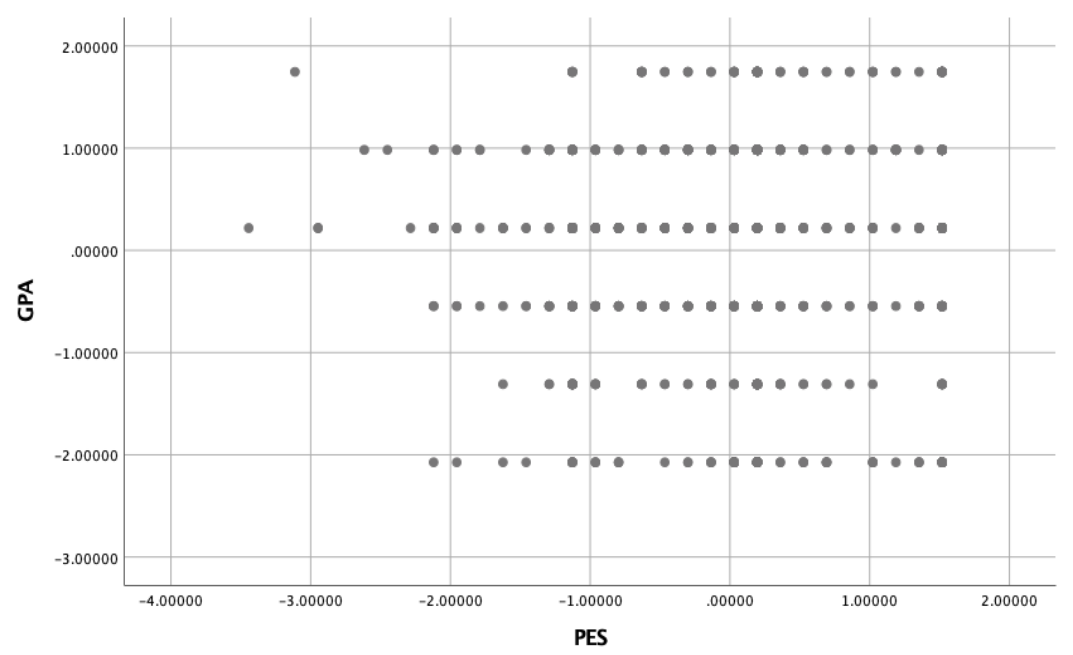

Note. $N=1,153$. 


\section{Figure B49}

Relationship Between Scores of NAKS and Scores of GPA With 1,153 Participants

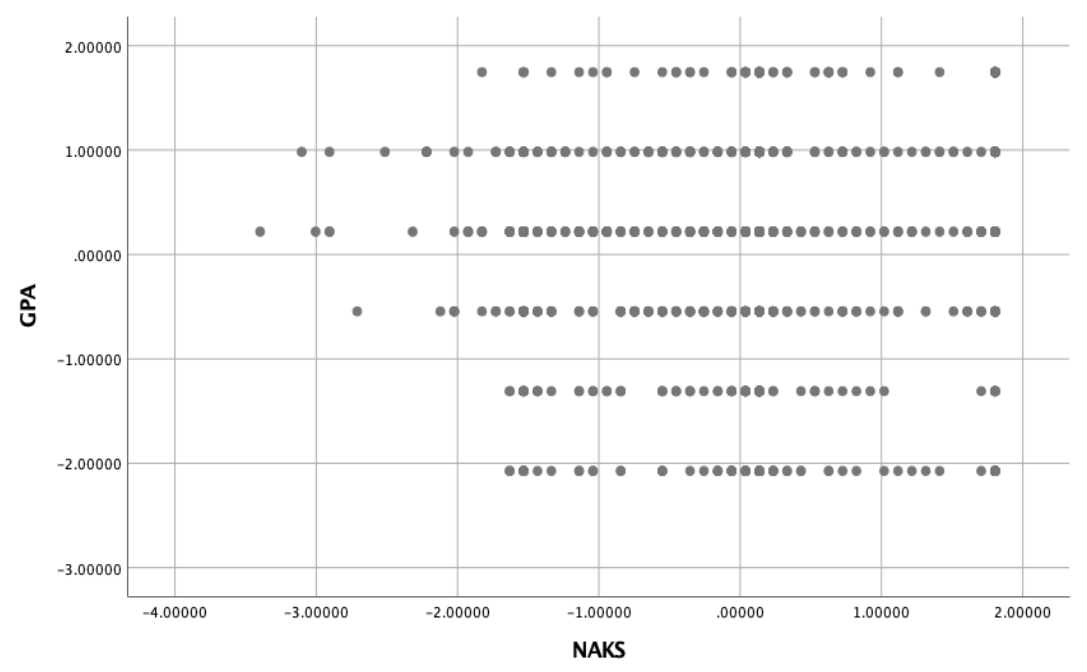

Note. $N=1,153$.

\section{Figure B50}

Relationship Between CSMS Scores and GPA Scores With 879 Participants

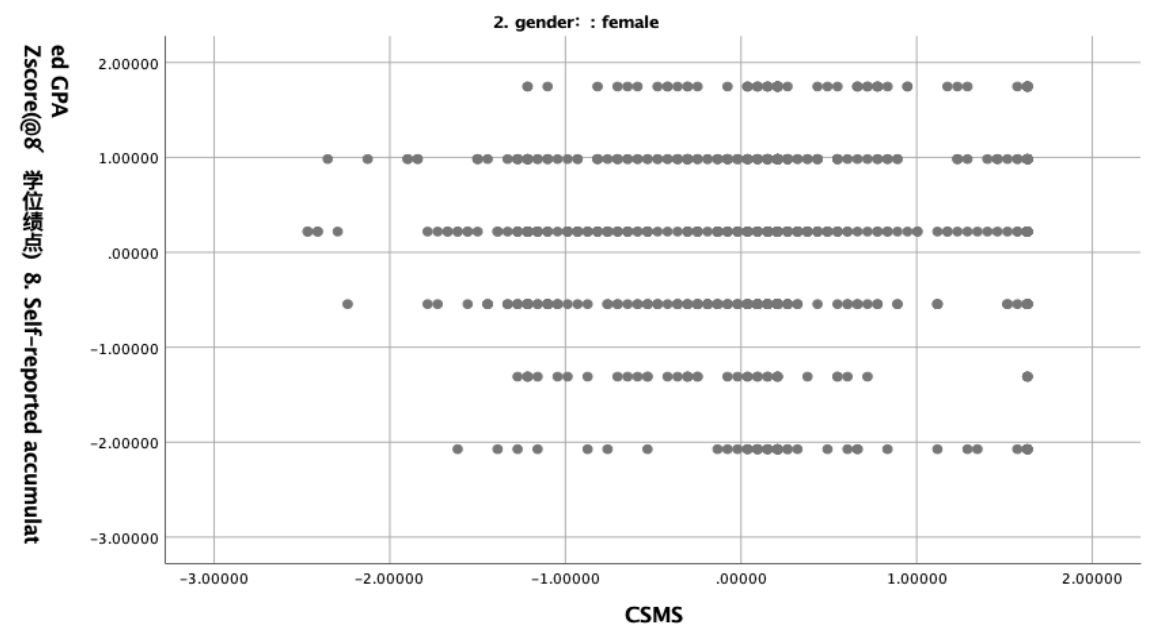

Note. $n=879$. 


\section{Figure B51}

Simple Histogram of GPA Scores

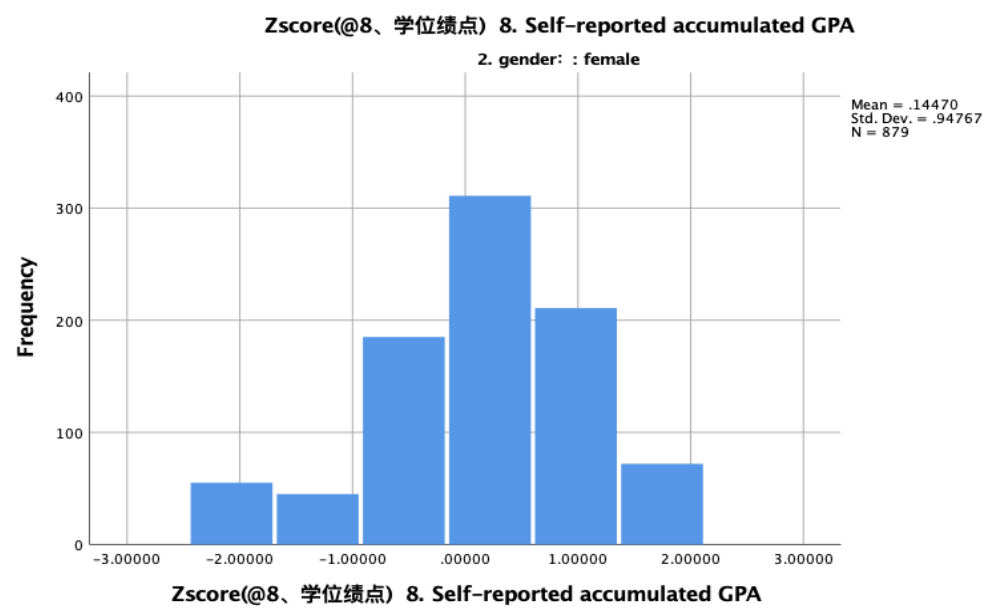

Note. $n=879$.

\section{Figure B52}

Relationship Between PES Scores and GPA Scores With 879 Participants

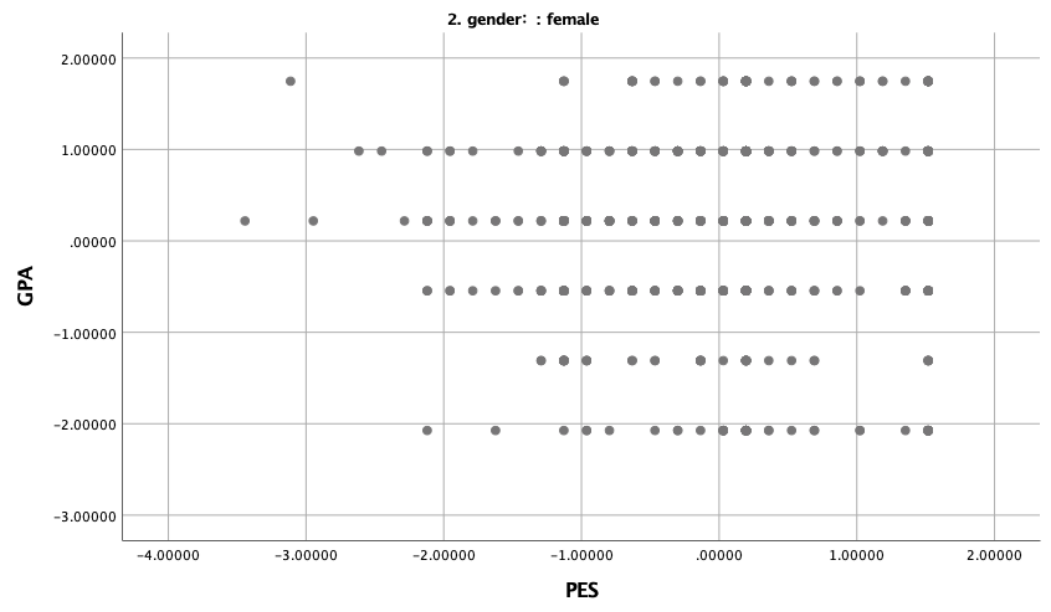

Note. $n=879$. 


\section{Figure B53}

Relationship Between NAKS Scores and GPA Scores With 879 Participants

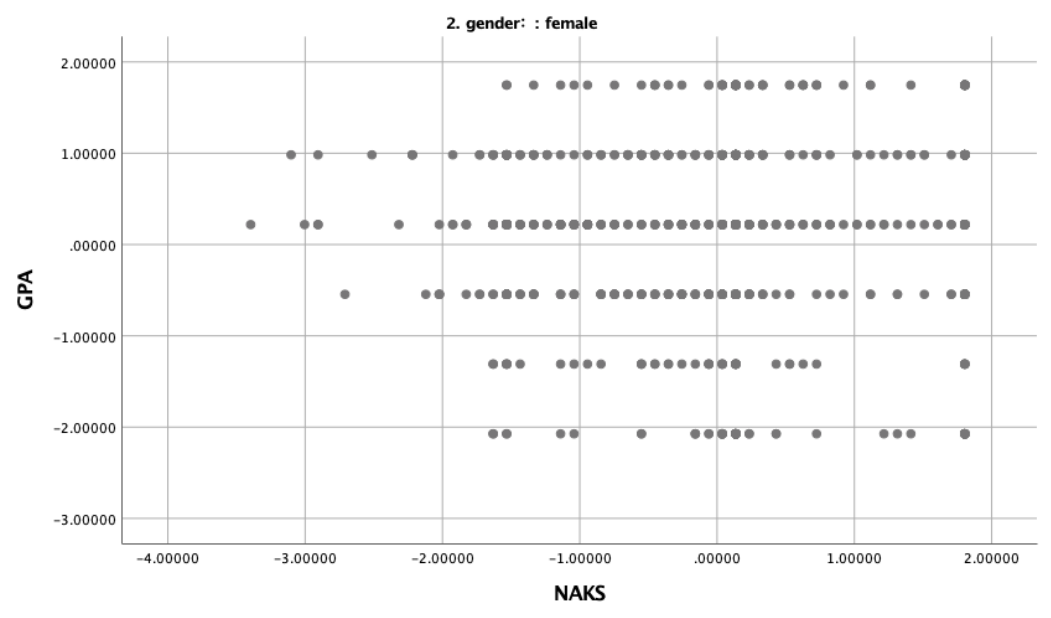

Note. $n=879$.

\section{Figure B54}

Scatterplot Showing Relationship Between CSMS Scores and GPA Scores With 640 Participants

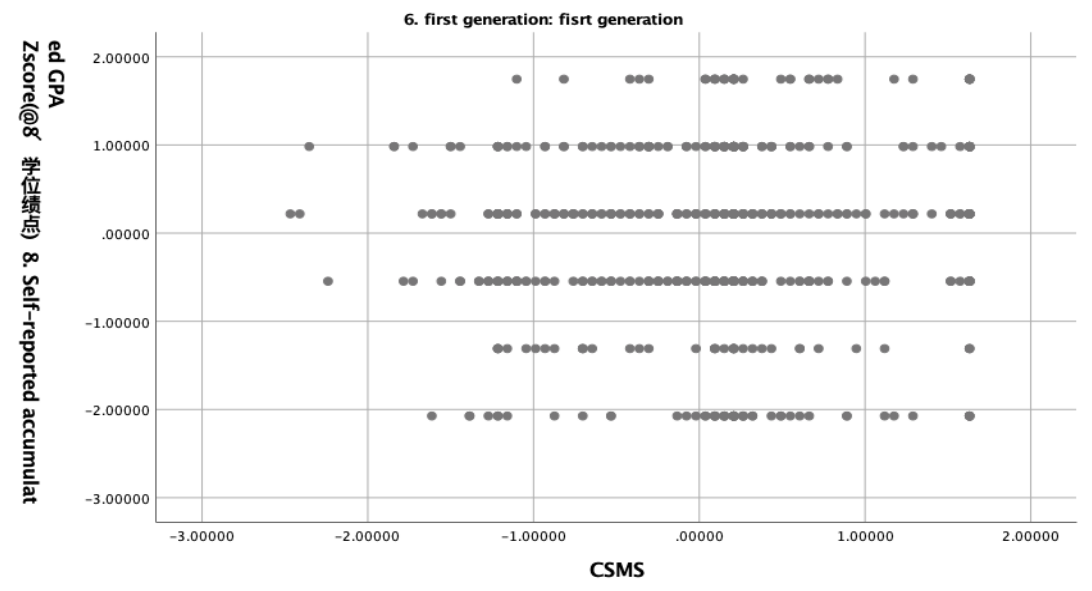

Note. $n=640$. 


\section{Figure B55}

Simple Histogram of GPA Scores

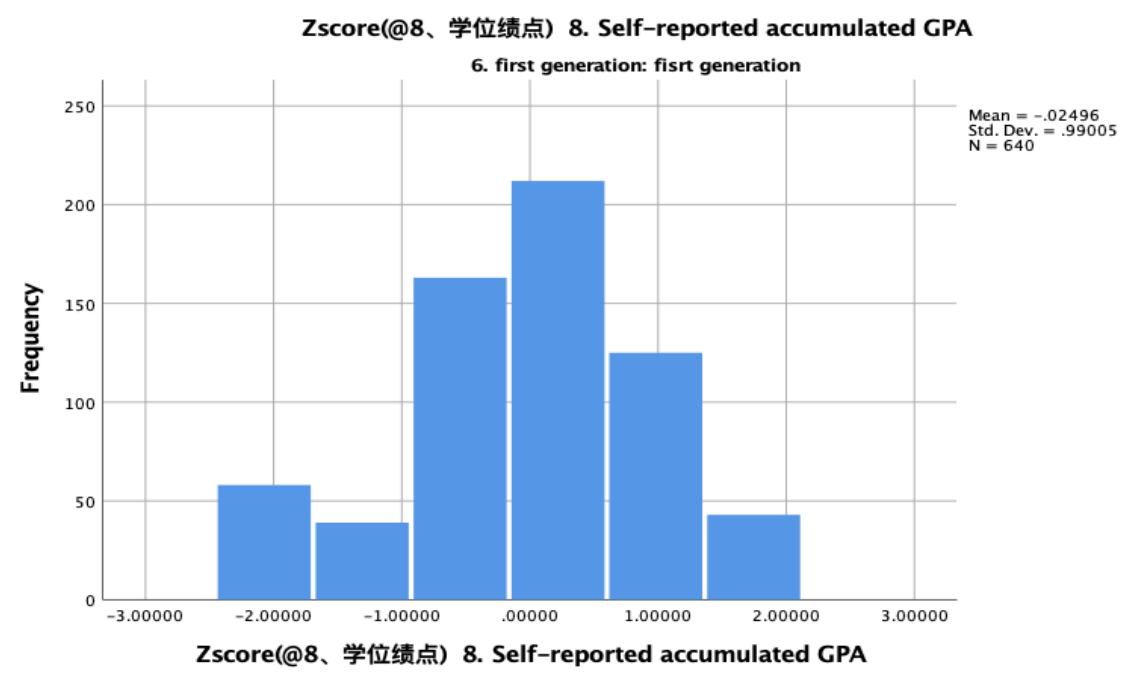

Note. $n=640$.

\section{Figure B56}

Scatterplot Showing Relationship Between PES Scores and GPA Scores With 640 Participants

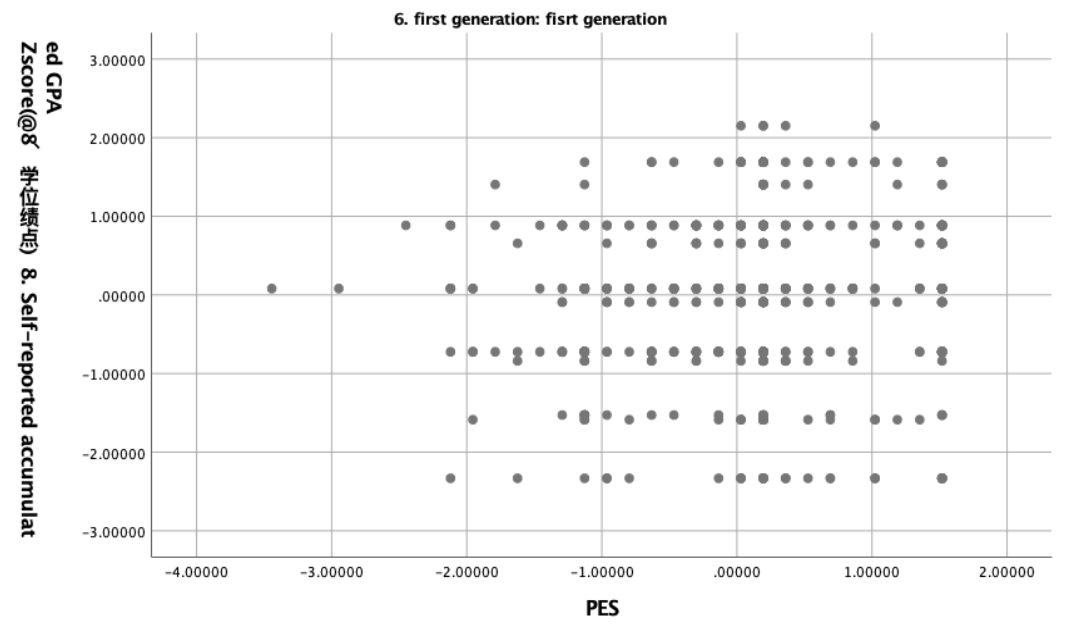

Note. $n=640$. 


\section{Figure B57}

Scatterplot Showing Relationship Between NAKS Scores and GPA Scores With 640 Participants

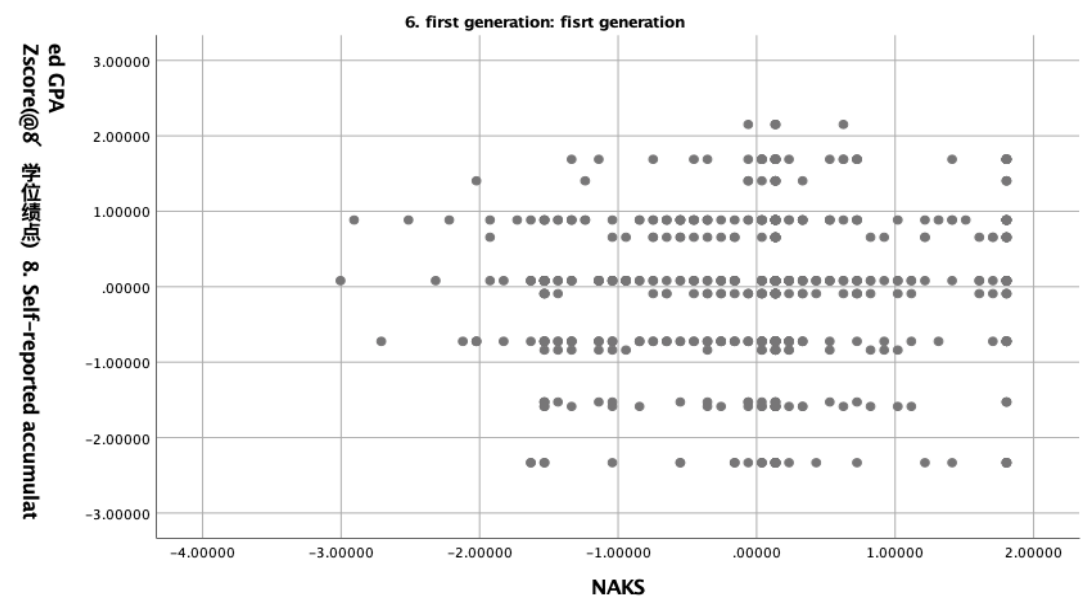

Note. $n=640$.

\section{Figure B58}

Scatterplot Showing Relationship Between CSMS Scores and GPA Scores With 440 Participants

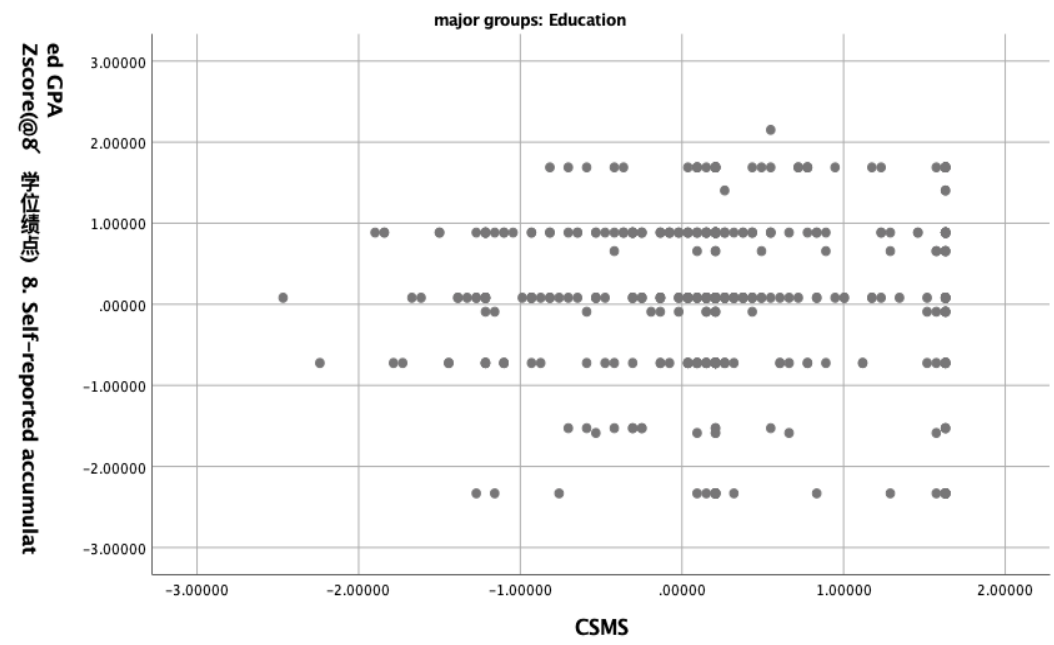

Note. $n=640$. 


\section{Figure B59}

Simple Histogram of GPA Scores

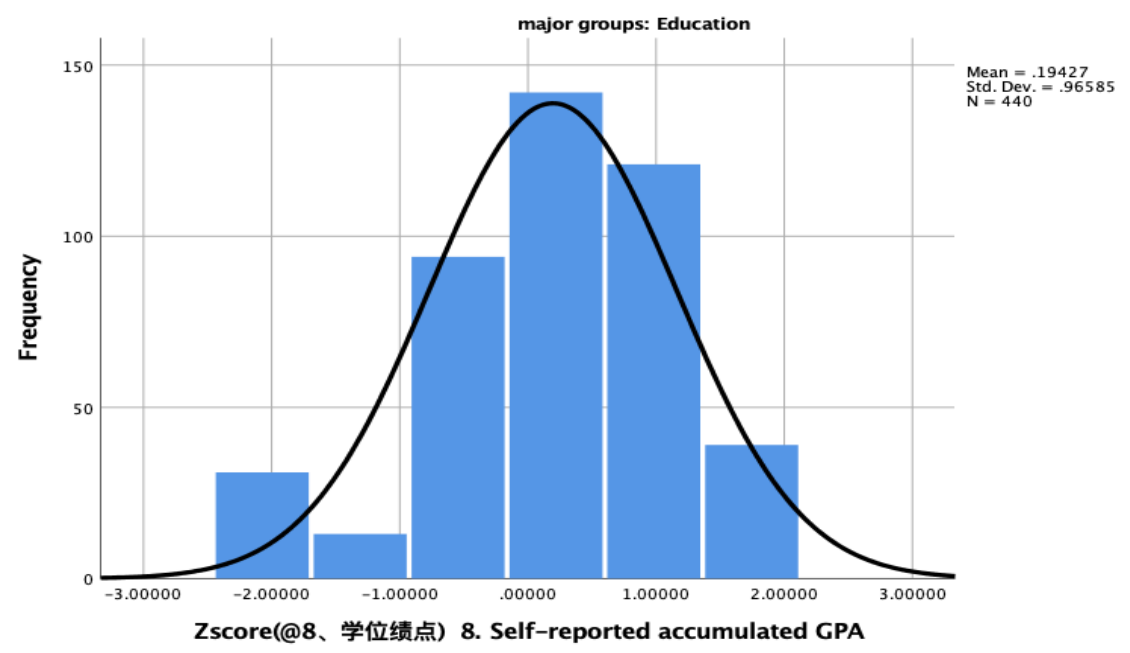

Note. $n=440$.

\section{Figure B60}

Scatterplot Showing Relationship Between PES Scores and GPA Scores With 440 Participants

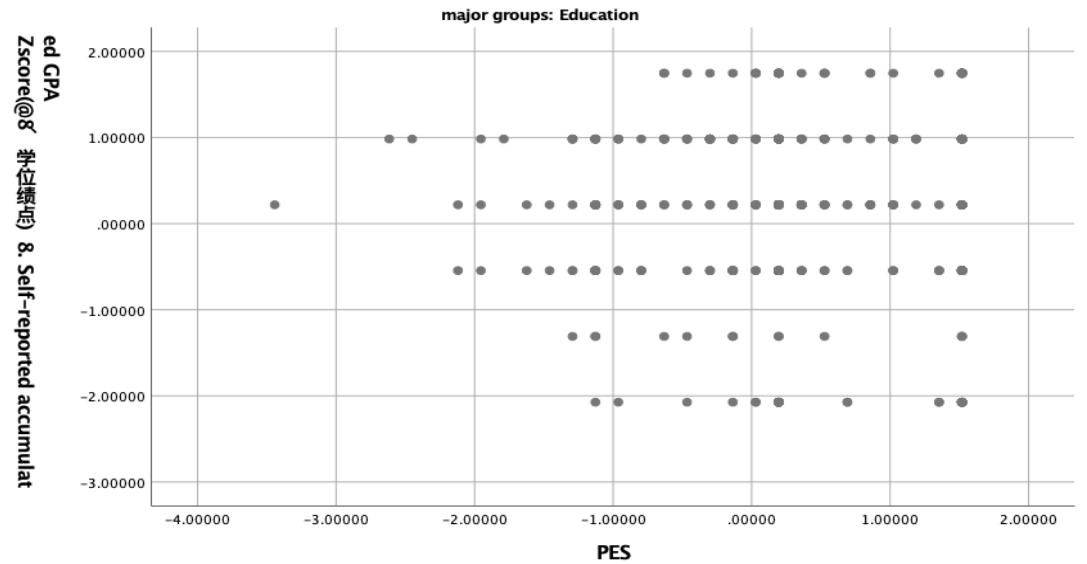

Note. $n=440$. 


\section{Figure B61}

Scatterplot Showing Relationship Between NAKS Scores and GPA Scores With 440 Participants

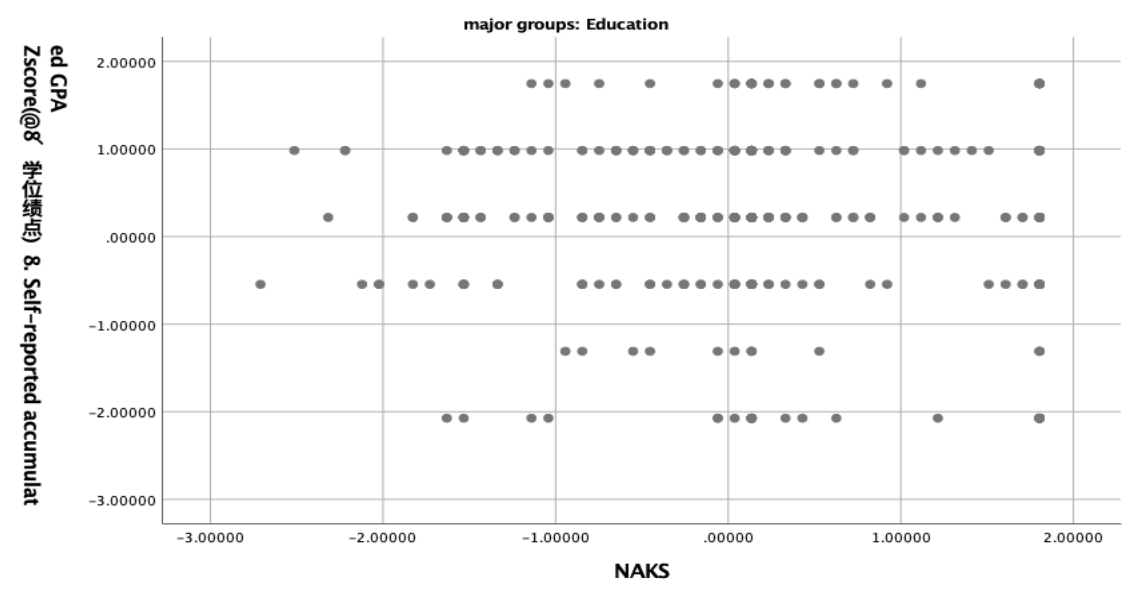

Note. $n=440$.

\section{Figure B62}

Scatterplot Showing Relationship Between CSMS Scores and GPA Scores With 203 Participants

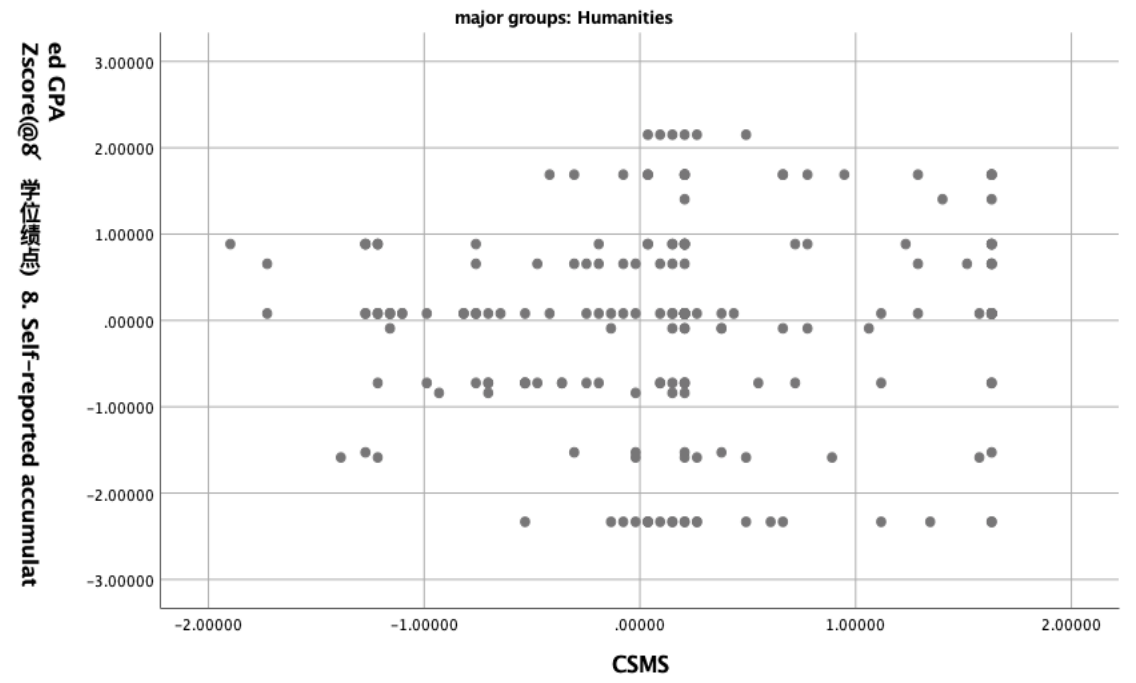

Note. $n=203$. 


\section{Figure B63}

Simple Histogram of GPA Scores

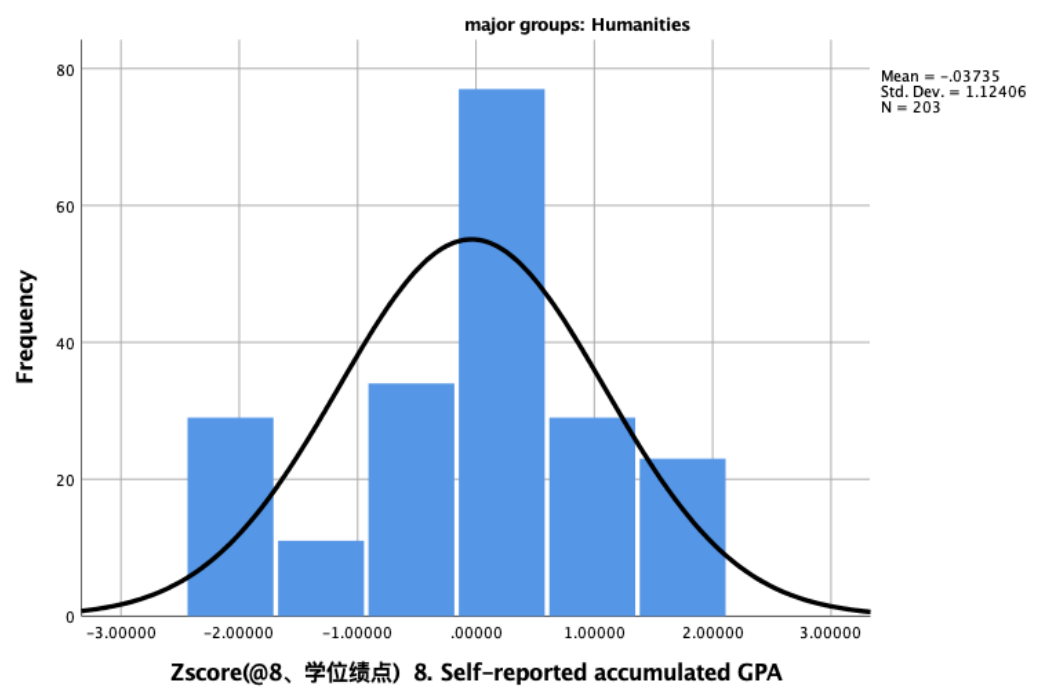

Note. $n=203$.

\section{Figure B64}

Scatterplot Showing Relationship Between PES Scores and GPA Scores With 203 Participants

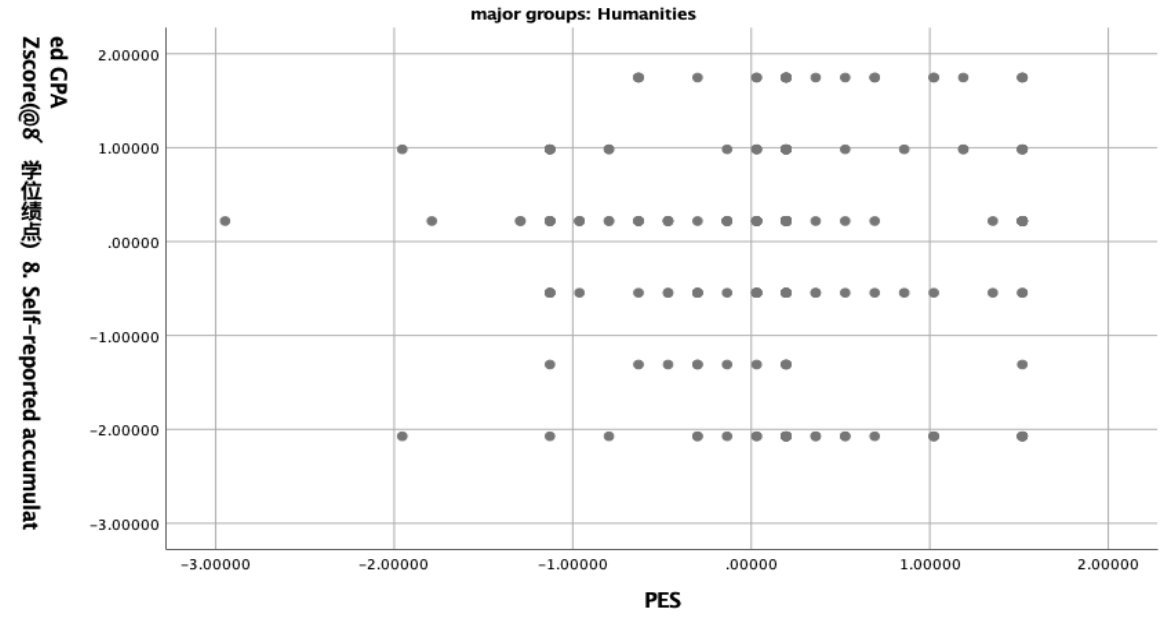

Note. $n=203$. 


\section{Figure B65}

Scatterplot Showing Relationship Between NAKS Scores and GPA Scores With 203 Participants

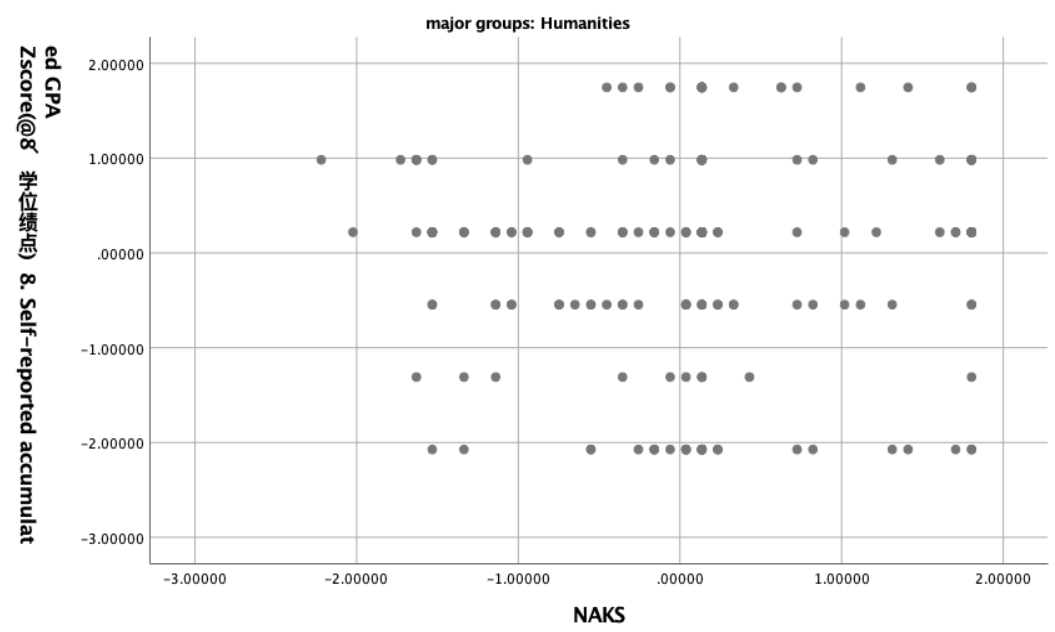

Note. $n=203$.

\section{Figure B66}

Scatterplot Showing Relationship Between CSMS Scores and GPA Scores With 320 Participants

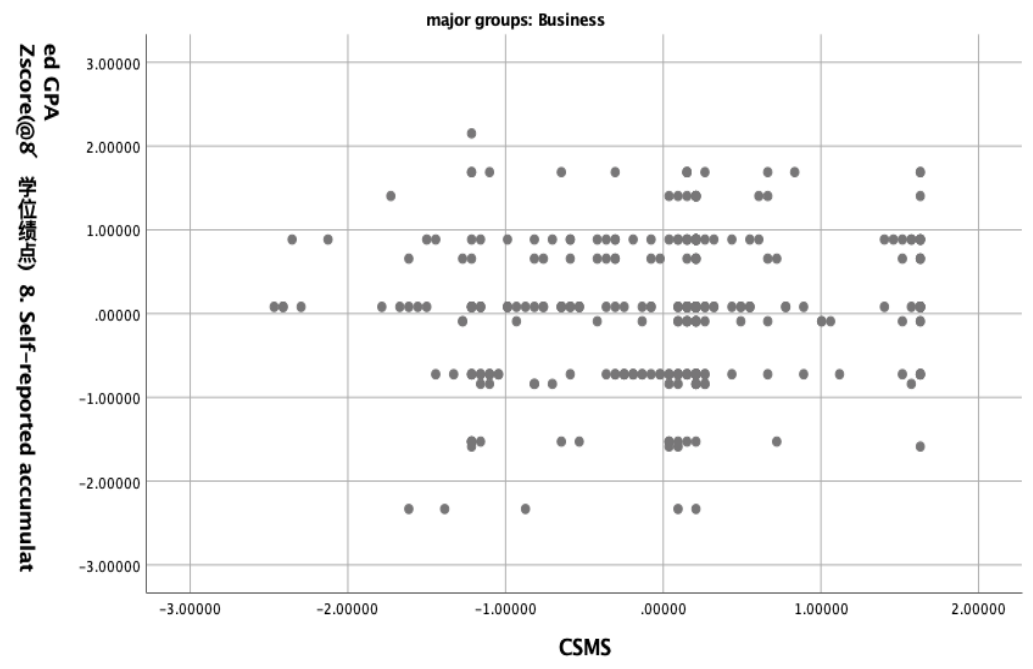

Note. $n=320$. 


\section{Figure B67}

Simple Histogram of GPA Scores

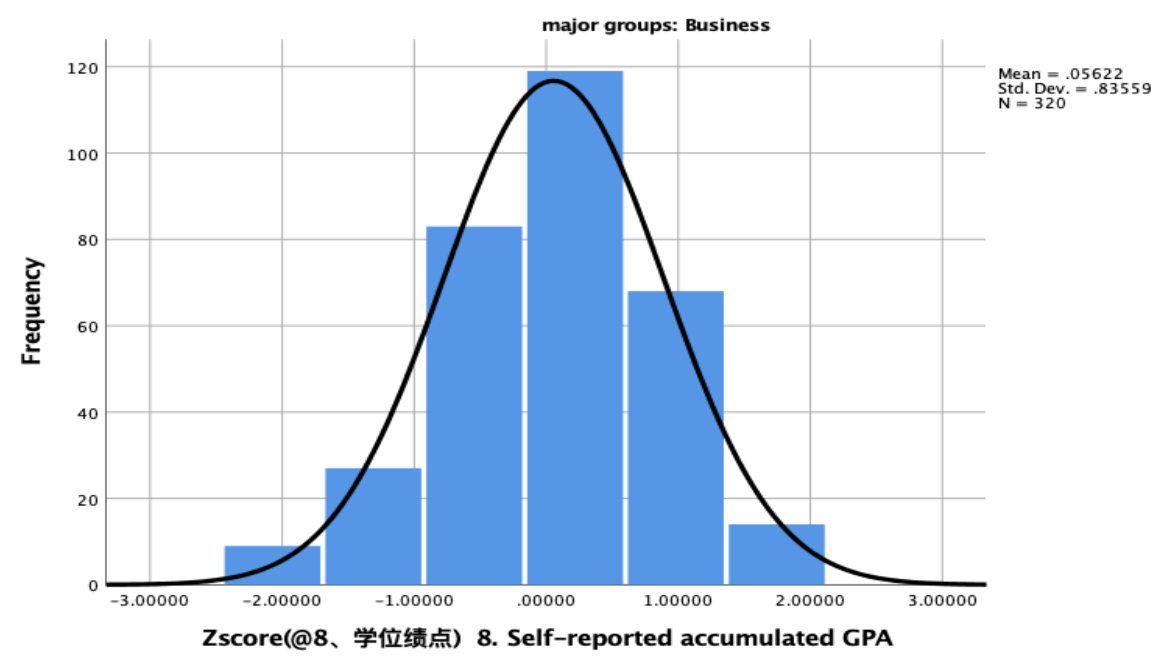

Note. $n=320$.

\section{Figure B68}

Scatterplot Showing Relationship Between PES Scores and GPA Scores With 320 Participants

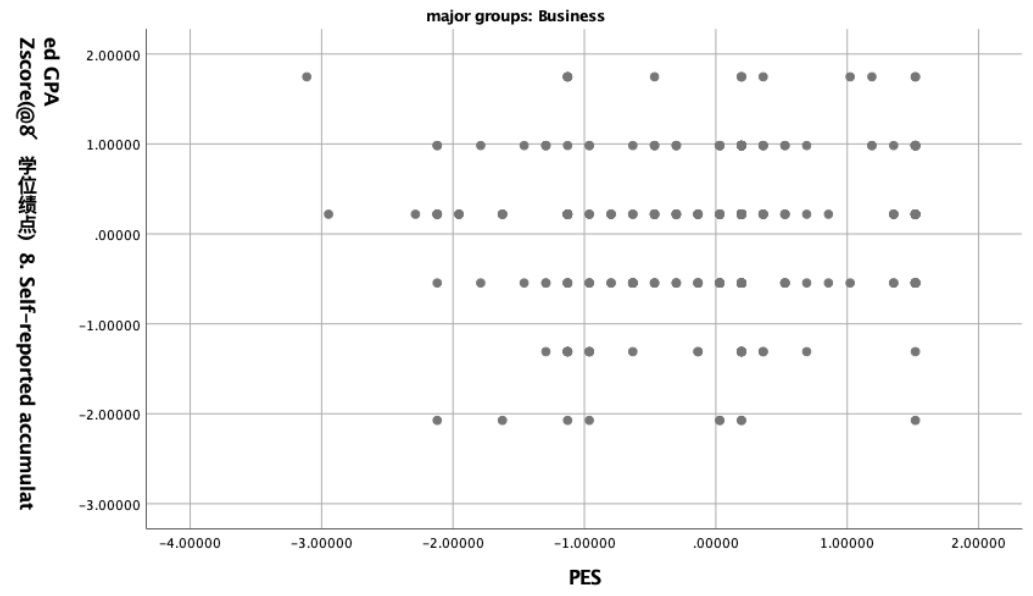

Note. $n=320$. 


\section{Figure B69}

Scatterplot Showing Relationship Between NAKS Scores and GPA Scores With 320 Participants

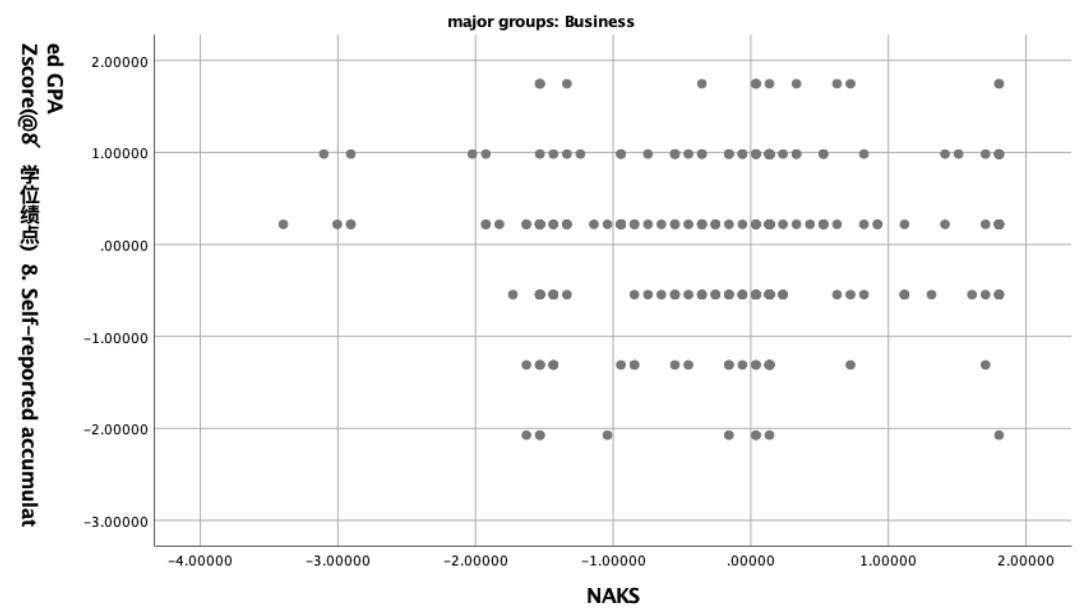

Note. $n=320$.

\section{Figure B70}

Scatterplot Showing Correlation Between CSMS Scores and GPA Scores With 190 Participants

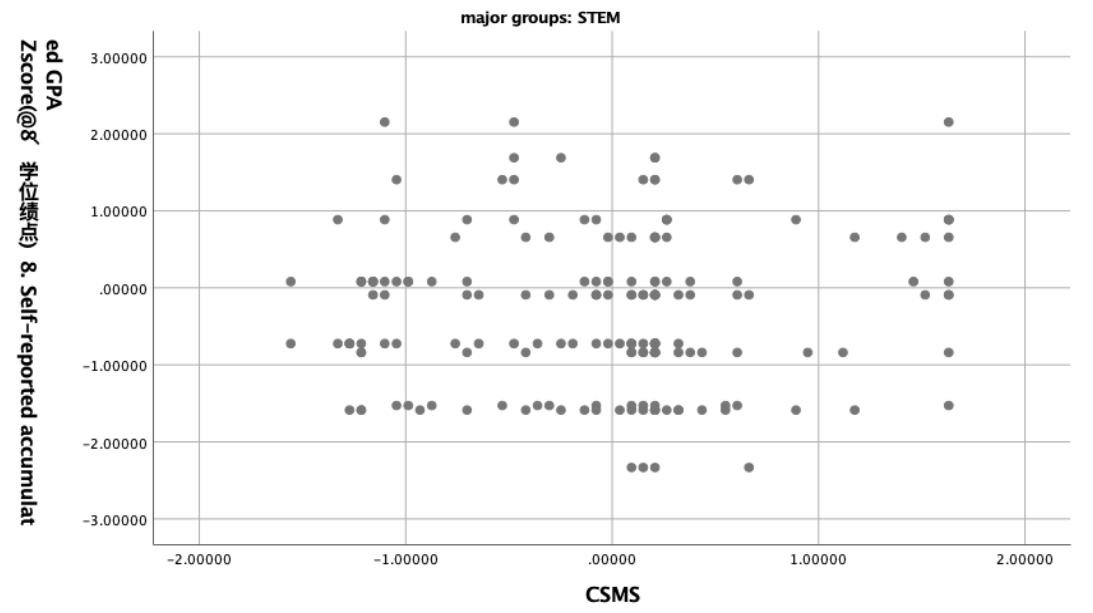

Note. $n=190$. 


\section{Figure B71}

Simple Histogram of GPA Scores

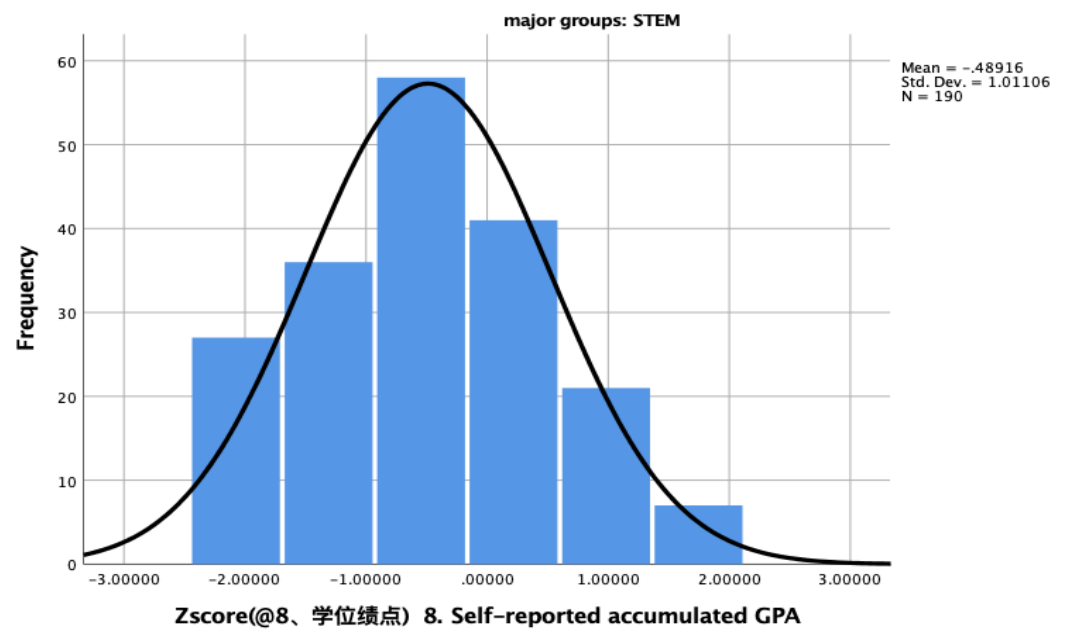

Note. $n=190$.

\section{Figure B72}

Scatterplot Showing Correlation Between PES Scores and GPA Scores With 190 Participants

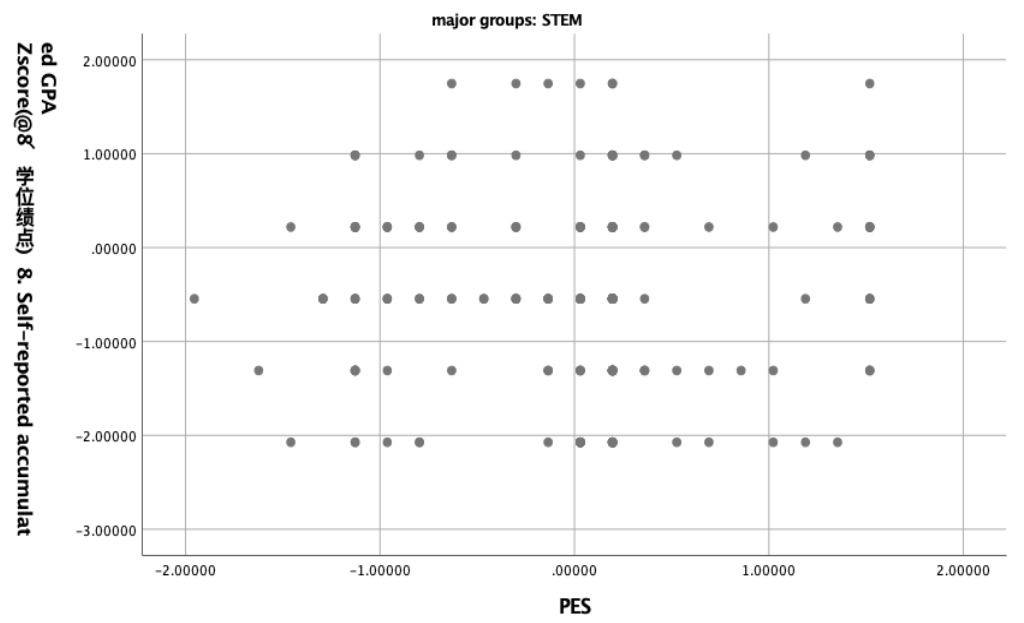

Note. $n=190$. 


\section{Figure B73}

Scatterplot Showing Correlation Between NAKS Scores and GPA Scores With 190 Participants

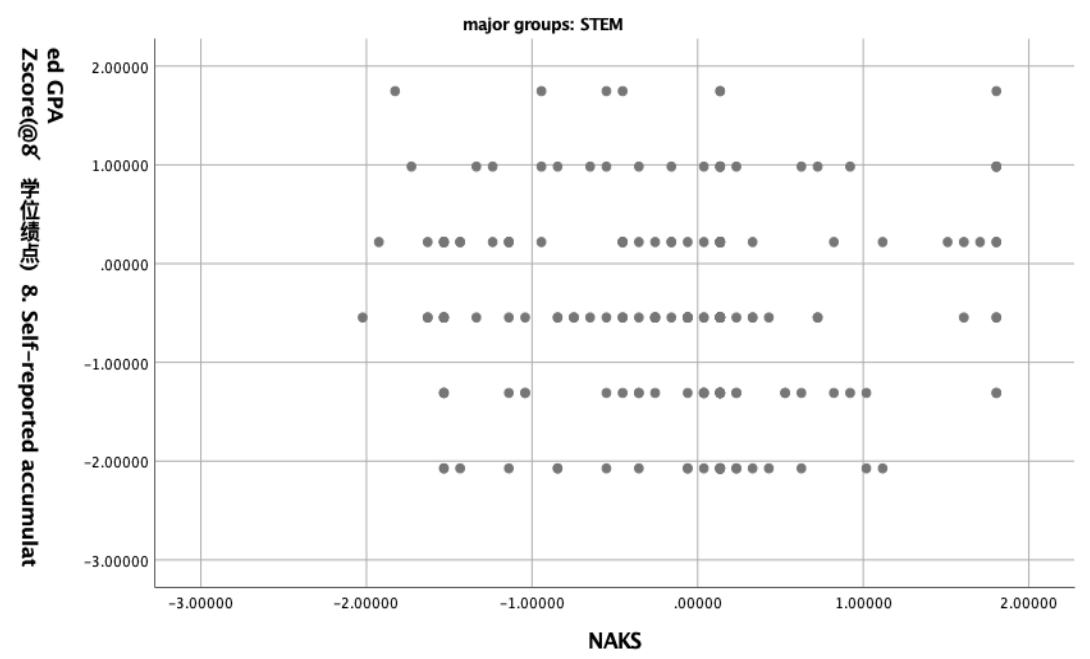

Note. $n=190$. 